\author{
UNIVERSIDADE DE SÃO PAULO \\ INSTITUTO DE ENERGIA E AMBIENTE \\ PROGRAMA DE PÓS-GRADUAÇÃO EM ENERGIA
}

ALEXANDRE DE BARROS GALLO

AVALIAÇÃO DA INSERÇÃO DO GÁS NATURAL NO SETOR INDUSTRIAL BRASILEIRO - UMA ANÁLISE DE INDICADORES DE IMPACTOS ENERGÉTICO, AMBIENTAL E ECONÔMICO 


\title{
AVALIAÇÃO DA INSERÇÃO DO GÁS NATURAL NO SETOR INDUSTRIAL BRASILEIRO - UMA ANÁLISE DE INDICADORES DE IMPACTOS ENERGÉTICO, AMBIENTAL E ECONÔMICO
}

Dissertação apresentada ao Programa de PósGraduação em Energia do Instituto de Energia e Ambiente da Universidade de São Paulo para a obtenção do título de Mestre em Ciências.

Orientador: Prof. Dr. Edmilson Moutinho dos Santos

Versão corrigida

(versão original disponível na Biblioteca do Instituto de Energia e Ambiente e na Biblioteca Digital de Teses e Dissertações da USP)

\author{
SÃO PAULO \\ 2018
}


AUTORIZO A REPRODUÇÃO E DIVULGAÇÃO TOTAL OU PARCIAL DESTE
TRABALHO, POR QUALQUER MEIO CONVENCIONAL OU ELETRÔNICO, PARA

FINS DE ESTUDO E PESQUISA, DESDE QUE CITADA A FONTE.

FICHA CATALOGRÁFICA

Gallo, Alexandre de Barros.

Avaliação da inserção do gás natural no setor industrial brasileiro: uma análise de indicadores de impactos energético, ambiental e econômico. I Alexandre de Barros Gallo; orientador: Edmilson Moutinho dos Santos. São Paulo, 2018.

148f.: il; $30 \mathrm{~cm}$.

Dissertação (Mestrado em Ciências) - Programa de PósGraduação em Energia - Instituto de Energia e Ambiente da Universidade de São Paulo.

1. Gás natural - aspectos ambientais - aspectos econômicos. 2. Eficiência energética. I. Título.

Elaborado por Maria Penha da Silva Oliveira CRB-8/6961 


\section{FOLHA DE APROVAÇÃO}

Nome: GALLO, Alexandre de Barros

Título: Avaliação da Inserção do Gás Natural no Setor Industrial Brasileiro - Uma Análise de Indicadores de Impactos Energético, Ambiental e Econômico.

Dissertação apresentada ao Programa de PósGraduação em Energia do Instituto de Energia e Ambiente da Universidade de São Paulo para a obtenção do título de Mestre em Ciências.

Aprovado em:

Banca examinadora:

Dr.

Julgamento.

Prof. Dr.

Julgamento.

Prof. ${ }^{\mathrm{a}}$ Dr. ${ }^{\mathrm{a}}$

Julgamento.

Prof. Dr.

Presidente
Instituição:

Assinatura:

Instituição:

Assinatura:

Instituição:

Assinatura:

Instituição:

Assinatura: 


\section{AGRADECIMENTOS}

Ao meu caro orientador Prof. Dr. Edmilson Moutinho dos Santos, pela orientação na condução da minha pesquisa, pela objetividade dos conselhos dados e por ter reconhecido em mim as capacidades para desenvolver a temática da pesquisa da presente dissertação.

Ao querido Prof. Dr. Murilo Tadeu Werneck Fagá, sempre presente e disponível para discussões sobre diversos temas e propondo reflexões que ajudaram muito na estruturação do desenvolvimento da minha pesquisa de mestrado.

Ao Dr. Alberto José Fossa, pelas oportunidades oferecidas para verificação em campo da realidade na qual se insere minha pesquisa e também para apresentação do desenvolvimento da pesquisa para distintas audiências em eventos.

Às caríssimas Dr. ${ }^{\text {as }}$ Hirdan Katarina de Medeiros Costa e Marilin Mariano dos Santos, que, ainda quando eu era aluno especial do Instituto de Energia e Ambiente da Universidade de São Paulo em 2015, reconheceram meu potencial, deram-me apoio e me incentivaram a iniciar o mestrado.

Ao Prof. Dr. Célio Bermann, Coordenador do Programa de Pós-Graduação em Energia do Instituto de Energia e Ambiente da Universidade de São Paulo, que nesta posição sempre atuou para permitir um bom encaminhamento do desenvolvimento das minhas atividades no mestrado.

À Juliana Oliveira da Silva, Chefe Administrativa do Serviço de Pós-Graduação do Instituto de Energia e Ambiente da Universidade de São Paulo, em nome de quem agradeço por todos os esclarecimentos e auxílios prestados na Secretaria de Pós-Graduação durante o período do mestrado.

Ao Instituto de Energia e Ambiente da Universidade de São Paulo, em nome do qual estendo os agradecimentos a todos os professores e funcionários com os quais tive o prazer de conviver durante esse tempo de muito aprendizado.

Finalmente, agradeço ao meu pai, minha mãe e minhas irmãs, minha família que sempre me deu o suporte necessário e me apoiou em todas minhas decisões, sem a qual eu nada seria. 


\section{RESUMO}

GALLO, Alexandre de Barros. Avaliação da Inserção do Gás Natural no Setor Industrial Brasileiro - Uma Análise de Indicadores de Impactos Energético, Ambiental e Econômico. 2018. 148 f. Dissertação (Mestrado) - Programa de Pós-Graduação em Energia, Universidade de São Paulo. São Paulo. 2018.

O paradigma atual do uso da energia no setor industrial brasileiro é fruto da conjuntura histórica do setor energético no país e permite explicar algumas de suas características particulares, a utilização intensiva de eletricidade em processos térmicos, a eletrotermia, algo que perdura até hoje. O cenário nacional de produção de gás natural é promissor, no contexto do Pré-Sal, o que sinaliza uma oportunidade para aplicar esse recurso natural para usos energéticos com maior valor agregado, como por exemplo como energia final para a indústria. É neste contexto que se insere esta dissertação onde foi desenvolvida e aplicada uma técnica de análise de dados com objetivo de avaliar a inserção do gás natural no setor industrial brasileiro e seus impactos. A técnica de análise de dados desenvolvida constitui-se na avaliação de quatro indicadores: Demanda Adicional (DA); Impacto em Energia Primária (IEP); Impacto em Emissões de Carbono (IEC) e Impacto em Custo Energético (ICE). Nos resultados obtidos, o Setor de Metais Não-Ferrosos teve maior destaque ao apresentar a maior demanda adicional por gás natural e as maiores reduções em demanda de energia primária, emissões de $\mathrm{CO}_{2}$ e custo energético. Outros setores que se destacaram foram o Setor de Ferro e Aço e Setor de Alimentos e Bebidas. Tomando 2013 como ano-base, a demanda adicional por gás natural resultante da substituição de óleo combustível e eletricidade em processos térmicos representaria um aumento entre $37 \%$ a $42 \%$ na demanda de gás natural no setor industrial brasileiro, equivalente a $12 \%$ a $14 \%$ da oferta interna de gás natural no Brasil, ou ainda 35\% a $40 \%$ da capacidade máxima do Gasbol. O impacto em energia primária representaria uma redução de $1 \%$ a $2 \%$ da demanda de energia primária do setor industrial brasileiro. $\mathrm{O}$ impacto em emissões de $\mathrm{CO}_{2}$ representaria uma redução de $4 \%$ a $5 \%$ das emissões de $\mathrm{CO}_{2}$ associadas ao uso de energia do setor industrial brasileiro. O impacto em custo energético representaria uma redução de $2 \%$ a $4 \%$ dos custos energéticos associados a eletricidade e óleo combustível do setor industrial brasileiro. Assim, considera-se que existe uma oportunidade de inserção do gás natural no setor industrial brasileiro resultante da substituição de óleo combustível e eletricidade por gás natural em processos térmicos. De forma geral, seus impactos reduzem a demanda de energia primária, as emissões de $\mathrm{CO}_{2}$ e o custo energético. Entretanto, trata-se de uma iniciativa de economia de energia via substituição energética, desse modo, ressalta-se necessidade de se fomentar a eficiência energética, para todos os usos finais e tipos de energia final em uso, de modo a se obter um maior impacto em termos de redução no consumo de energia e mitigação de emissões, dois elementos importantes no debate atual sobre combate a mudanças climáticas.

Palavras-chave: Gás natural, indústria, indicadores, eficiência energética, energia primária, emissões de $\mathrm{CO}_{2}$ 


\begin{abstract}
GALLO, Alexandre de Barros. Evaluation of the Natural Gas Insertion in the Brazilian Industrial Sector - An Assessment of Energy, Environmental and Economic Impact Indicators. 2018. 148 f. Master's Dissertation - Graduate Program on Energy, University of São Paulo. São Paulo. 2018.
\end{abstract}

The present energy use structure in the Brazilian industrial sector is a consequence of its historical context within the Brazilian energy sector. This historical background helps to explain some characteristics, like the intensive use of electricity in heating processes, the electrothermia, that lasts until today. The current natural gas production scenario in Brazil is promising, considering the Pre-Salt production, which signals an opportunity to apply this natural resource to final energy uses with higher value, such as final energy for industry. In this context was structured this dissertation, comprising a data analysis technique development and its application to evaluate the insertion of natural gas in the Brazilian industrial sector and its impacts. The developed data analysis technique is constituted by the assessment of four indicators: Additional Demand (DA); Impact on Primary Energy (IEP); Impact on Carbon Emissions (IEC) and Impact on Energy Cost (ICE). In the results obtained, the Non-Ferrous Metals Sector was more prominent as it presented the greater additional demand for natural gas and the largest reductions in primary energy demand, $\mathrm{CO}_{2}$ emissions and energy costs. Other sectors that stood out were the Iron and Steel Sector and the Food and Beverages Sector. Considering 2013 as the base year, the additional demand for natural gas resulting from the substitution of fuel oil and electricity in heating processes would represent a $37 \%$ to $42 \%$ increase in the demand for natural gas in the Brazilian industrial sector, equivalent to $12 \%$ to $14 \%$ of Brazil's domestic natural gas supply, or 35\% to $40 \%$ of Gasbol's maximum capacity. The impact on primary energy would represent a reduction of $1 \%$ to $2 \%$ of the primary energy demand of the Brazilian industrial sector. The impact on $\mathrm{CO}_{2}$ emissions would represent a reduction of $4 \%$ to $5 \%$ of the $\mathrm{CO}_{2}$ emissions associated to energy use of the Brazilian industrial sector. The impact on energy cost would represent a reduction of $2 \%$ to $4 \%$ of the energy costs associated with electricity and fuel oil of the Brazilian industrial sector. Thus, it is considered that there is an opportunity for the insertion of natural gas in the Brazilian industrial sector resulting from the substitution of fuel oil and electricity by natural gas in thermal processes. Overall, the substitution impacts reduce primary energy demand, $\mathrm{CO}_{2}$ emissions and energy costs. However, this is an energy-saving initiative through energy substitution, being necessary to further promote energy efficiency, for all end uses and types of final energy in use, to multiply the impacts in terms of reducing energy consumption and mitigating emissions, two important elements in the current debate on combating climate change.

Keywords: Natural gas, industry, indicators, energy efficiency, primary energy, $\mathrm{CO}_{2}$ emissions 


\section{LISTA DE FIGURAS}

Figura 1.1 - Mapa do Gasoduto Bolívia-Brasil (Gasbol)

Figura 1.2 - Evolução da produção de petróleo (à esquerda) e de gás natural (à direita) por ambiente exploratório 28

Figura 1.3 - Portifólio de medidas para redução das emissões de GEE no setor de energia.... 30

Figura 3.1 - Diagrama esquemático dos níveis de transformação de energia. 47

Figura 3.2 - Distribuição das emissões globais de gases de efeito estufa por setor (ano base 2014)

Figura 3.3 - Diagrama geral dos aspectos, conceitos e indicadores da técnica de análise de dados

Figura 3.4 - Visão esquemática do processo produtivo da produção de papel 59

Figura 3.5 - Diagrama esquemático para o processo de determinação do potencial de substituição através de benchmarking usando balanços de energia final por uso final

Figura 3.6 - Diagrama esquemático para o processo de determinação do potencial de substituição através de benchmarking usando balanços de energia final 61

Figura 4.1 - Distribuição da demanda da energia do setor industrial brasileiro por uso final (ano-base 2013)

Figura 4.2 - Distribuição da demanda de energia final do setor industrial brasileiro (ano-base 2013)

Figura 4.3 - Distribuição da demanda de energia final (com a biomassa detalhada por tipo) do setor industrial brasileiro (ano-base 2013) 74

Figura 4.4 - Distribuição dos tipos de derivados de petróleo demandados pelo setor industrial brasileiro (ano-base 2013) 75

Figura 4.5 - Espectro da radiação eletromagnética e os diferentes tipos de radiação 76 
Figura 4.6 - Exemplos de tipos de queimadores com tubo radiante (um tubo reto e um tubo em $\mathrm{U})$, à esquerda, e um exemplo de aplicação (forno contínuo), à direita

Figura 4.7 - Estrutura dos queimadores com superfície radiante, à esquerda, e exemplo de aplicação (queimador usado na secagem de papel), à direita.

Figura 4.8 - Comparação da distribuição do percentual do consumo energético por energia final e por uso final entre o Setor de Alimentos e Bebidas Exceto Açúcar e do Setor de Açúcar ...84

Figura 4.9 - Indicador de Demanda Adicional (DA) para substituição de eletricidade e óleo combustível por gás natural em processos térmicos - resultados expressos em $\mathrm{Mm}^{3} / \mathrm{ano}$......96

Figura 4.10 - Indicador de Demanda Adicional (DA) para substituição de eletricidade e óleo combustível por gás natural em processos térmicos - resultados expressos em porcentagem da oferta interna de gás natural (ano-base 2013) 96

Figura 4.11 - Indicador de Impacto em Energia Primária (IEP) para substituição de eletricidade e óleo combustível por gás natural em processos térmicos - resultados expressos em TJ/ano 98

Figura 4.12 - Indicador de Impacto em Energia Primária (IEP) para substituição de eletricidade e óleo combustível por gás natural em processos térmicos - resultados expressos em porcentagem da demanda de energia primária de cada setor industrial

Figura 4.13 - Indicador de Impacto em Emissões de Carbono (IEC) para substituição de eletricidade e óleo combustível por gás natural em processos térmicos - resultados expressos em $\mathrm{ktCO}_{2} / \mathrm{ano}$ 101

Figura 4.14 - Indicador de Impacto em Emissões de Carbono (IEC) para substituição de eletricidade e óleo combustível por gás natural em processos térmicos - resultados expressos em porcentagem da emissão de $\mathrm{CO}_{2}$ associada ao uso de energia de cada setor industrial ... 101

Figura 4.15 - Indicador de Impacto em Custo Energético (ICE) para substituição de eletricidade e óleo combustível por gás natural em processos térmicos - resultados expressos em M R \$/ano 103

Figura 4.16 - Indicador de Impacto em Custo Energético (ICE) para substituição de eletricidade e óleo combustível por gás natural em processos térmicos - resultados expressos em porcentagem do custo energético de eletricidade e óleo combustível de cada setor industrial 
Figura 4.17 - Indicador de Demanda Adicional (DA) para substituição de eletricidade e óleo combustível por gás natural em processos térmicos - resultados consolidados expressos em $\mathrm{Mm}^{3} / \mathrm{ano}$

Figura 4.18 - Indicador de Demanda Adicional (DA) para substituição de eletricidade e óleo combustível por gás natural em processos térmicos - resultados consolidados expressos em porcentagem da oferta interna de gás natural (ano-base 2013) 106

Figura 4.19 - Indicador de Impacto em Energia Primária (IEP) para substituição de eletricidade e óleo combustível por gás natural em processos térmicos - resultados consolidados expressos em TJ/ano 108

Figura 4.20 - Indicador de Impacto em Energia Primária (IEP) para substituição de eletricidade e óleo combustível por gás natural em processos térmicos - resultados consolidados expressos em porcentagem da demanda de energia primária de cada setor industrial 108

Figura 4.21 - Indicador de Impacto em Emissões de Carbono (IEC) para substituição de eletricidade e óleo combustível por gás natural em processos térmicos - resultados consolidados expressos em $\mathrm{ktCO}_{2} / \mathrm{ano}$

Figura 4.22 - Indicador de Impacto em Emissões de Carbono (IEC) para substituição de eletricidade e óleo combustível por gás natural em processos térmicos - resultados consolidados expressos em porcentagem da emissão de $\mathrm{CO}_{2}$ associada ao uso de energia de cada setor industrial

Figura 4.23 - Indicador de Impacto em Custo Energético (ICE) para substituição de eletricidade e óleo combustível por gás natural em processos térmicos - resultados consolidados expressos em M R\$/ano 110

Figura 4.24 - Indicador de Impacto em Custo Energético (ICE) para substituição de eletricidade e óleo combustível por gás natural em processos térmicos - resultados consolidados expressos em porcentagem do custo energético de eletricidade e óleo combustível de cada setor industrial 


\section{LISTA DE TABELAS}

Tabela 4.1 - Balanço de energia final por uso final considerando a eletricidade e o óleo combustível em processos térmicos por setor industrial

Tabela 4.2 - Eficiência do equipamento de uso final de energia considerando a eletricidade, o óleo combustível e o gás natural em processos térmicos por setor industrial

Tabela 4.3 - Fator de conversão em energia primária, fator de emissão de $\mathrm{CO}_{2}$ e preço (ou tarifa) considerando a eletricidade, o óleo combustível e o gás natural em processos térmicos

Tabela 4.4 - Resultados sobre a participação da eletricidade na demanda de energia final em cada setor industrial

Tabela 4.5 - Equivalência dos setores industriais de diferentes referências bibliográficas e as siglas adotadas

Tabela 4.6 - Tabela 4.1 com setores industriais ajustados 93

Tabela 4.7 - Tabela 4.2 com setores industriais ajustados 93

Tabela 4.8 - Resultado do potencial de substituição de eletricidade por gás natural em processos térmicos por setor industrial

Tabela 4.9 - Resultados do indicador de Demanda Adicional (DA) para substituição de eletricidade e óleo combustível por gás natural em processos térmicos por setor industrial ...95

Tabela 4.10 - Resultados do indicador de Impacto em Energia Primária (IEP) para substituição de eletricidade e óleo combustível por gás natural em processos térmicos por setor industrial

Tabela 4.11 - Resultados do indicador de Impacto em Emissões de Carbono (IEC) para substituição de eletricidade e óleo combustível por gás natural em processos térmicos por setor industrial

Tabela 4.12 - Resultados do indicador de Impacto em Custo Energético (ICE) para substituição de eletricidade e óleo combustível por gás natural em processos térmicos por setor industrial 
Tabela 4.13 - Resultados consolidados do indicador de Demanda Adicional para substituição de eletricidade e óleo combustível por gás natural em processos térmicos por setor industrial Cenários moderado e agressivo

Tabela 4.14 - Resultados consolidados dos indicadores de impacto para substituição de eletricidade e óleo combustível por gás natural em processos térmicos por setor industrial Cenário moderado. 106

Tabela 4.15 - Resultados consolidados dos indicadores para substituição de eletricidade e óleo combustível por gás natural em processos térmicos por setor industrial - Cenário agressivo

Tabela A.1 - Lista de países da base de dados de balanços de energia final

Tabela A.2 - Balanço de energia final e parâmetros de triagem baseado em IEA (2015b)... 130

Tabela A.3 - Balanço de energia final e parâmetros de triagem baseado em IEA (2015a) ...138

Tabela A.4 - Lista de países membros da OCDE referência para os setores industriais e a participação da eletricidade na demanda de energia final em cada setor industrial

Tabela A.5 - Lista de países não-membros da OCDE referência para os setores industriais e a participação da eletricidade na demanda de energia final em cada setor industrial 146

Tabela A.6 - Balanço de energia final, parâmetros de triagem, demanda de energia primária e custo energético por setor industrial para o Brasil 


\section{LISTA DE SIGLAS E ABREVIATURAS}

A\&B setor de Alimentos e Bebidas Exceto Açúcar

A.D. aquecimento direto

ANP Agência Nacional do Petróleo, Gás Natural e Biocombustíveis

APGA American Public Gas Association

AS antes da substituição

BAT Best Available Technique

(Melhor Técnica Disponível)

BEN Balanço Energético Nacional

BEU Balanço de Energia Útil

BNDES Banco Nacional de Desenvolvimento Econômico e Social

BPT Best Practicable Technology

(Melhor Tecnologia Praticável)

BR Brasil

BREF Best available techniques Reference document

Documento de referência das melhores técnicas disponíveis

C.P. calor de processo

CEn custo energético

CNI Confederação Nacional da Indústria

CONPET Programa Nacional da Racionalização do Uso dos Derivados do Petróleo e do Gás Natural

COPPE Instituto Alberto Luiz Coimbra de Pós-Graduação e Pesquisa de Engenharia

DA Demanda Adicional

DECC Department of Energy \& Climate Change 


\begin{tabular}{|c|c|}
\hline DEP & demanda de energia primária \\
\hline DEU & demanda de energia útil \\
\hline DS & depois da substituição \\
\hline EECA & Energy Efficiency and Conservation Authority \\
\hline $\mathrm{EF}$ & energia final \\
\hline EGTD & Energia Garantida por Tempo Determinado \\
\hline EIA & Energy Information Administration \\
\hline Eletroq & eletroquímica \\
\hline EmC & emissão de $\mathrm{CO}_{2}$ \\
\hline EPE & Empresa de Pesquisa Energética \\
\hline ESNG & Energia Sazonal Não Garantida \\
\hline $\mathrm{F} \& \mathrm{~A}$ & setor de Ferro e Aço \\
\hline F. Sec. Pet. & fontes secundárias de petróleo \\
\hline F.M. & força-motriz \\
\hline FAO & $\begin{array}{l}\text { Food and Agriculture Organization of the United Nations } \\
\text { (Organização das Nações Unidas para Agricultura e Alimentação) }\end{array}$ \\
\hline FCEP & fator de conversão em energia primária \\
\hline FDTE & Fundação para o Desenvolvimento Tecnológico da Engenharia \\
\hline FEm & fator de emissão de $\mathrm{CO}_{2}$ \\
\hline FIEMG & Federação das Indústrias do Estado de Minas Gerais \\
\hline FIRJAN & Federação das Indústrias do Estado do Rio de Janeiro \\
\hline GEE & gases de efeito estufa \\
\hline GLP & gás liquefeito de petróleo \\
\hline GN & gás natural \\
\hline GR & geração renovável \\
\hline GT & geração termoelétrica \\
\hline
\end{tabular}




\begin{tabular}{|c|c|}
\hline GTf & geração termoelétrica com uso de combustíveis fósseis \\
\hline \multirow[t]{2}{*}{ GWP } & global warming potential \\
\hline & (potencial de aquecimento global) \\
\hline IBP & Instituto Brasileiro de Petróleo, Gás e Biocombustíveis \\
\hline IC & intervalo de confiança \\
\hline ICE & Impacto em Custo Energético \\
\hline \multirow[t]{2}{*}{ IEA } & International Energy Agency \\
\hline & (Agência Internacional de Energia) \\
\hline IEC & Impacto em Emissões de Carbono \\
\hline IEE & Instituto de Energia e Ambiente \\
\hline IEP & Impacto em Energia Primária \\
\hline Ilum. & iluminação \\
\hline \multirow[t]{2}{*}{ IPCC } & Intergovernmental Panel on Climate Change \\
\hline & (Painel Intergovernamental sobre Mudanças Climáticas) \\
\hline JRC & Joint Research Centre - European Commission \\
\hline MCTIC & Ministério da Ciência, Tecnologia, Inovações e Comunicações \\
\hline MDL & Mecanismo de Desenvolvimento Limpo \\
\hline METI & Ministry of Economy, Trade and Industry \\
\hline MIC & Ministério de Indústria e Comércio \\
\hline MIN & setor de Mineração \\
\hline MME & Ministério de Minas e Energia \\
\hline MNF & setor de Metais Não-Ferrosos \\
\hline MNM & setor de Minerais Não-Metálicos \\
\hline OCDE & Organização para a Cooperação e Desenvolvimento Econômico \\
\hline OIGN & oferta interna de gás natural \\
\hline $\mathrm{P} \& \mathrm{C}$ & setor de Papel e Celulose \\
\hline
\end{tabular}


PBE

PPSA

PROCEL Programa de Conservação de Energia Elétrica

PROESCO linha de crédito do BNDES para ações de eficiência energética

QUI setor Químico

Refrig. refrigeração

RGO razão gás-óleo

RTA requisito de ar teórico

SBPE Sociedade Brasileira de Planejamento Energético

subs $\quad$ substituída

TAG Transportadora Associada de Gás S.A.

TEX setor Têxtil

UFABC Universidade Federal do ABC

UFRJ Universidade Federal do Rio de Janeiro

UNICAMP Universidade Estadual de Campinas

UNIDO United Nations Industrial Development Organization

(Organização das Nações Unidas para o Desenvolvimento Industrial)

USP Universidade de São Paulo

WRI World Resources Institute 


\section{LISTA DE SÍMBOLOS}

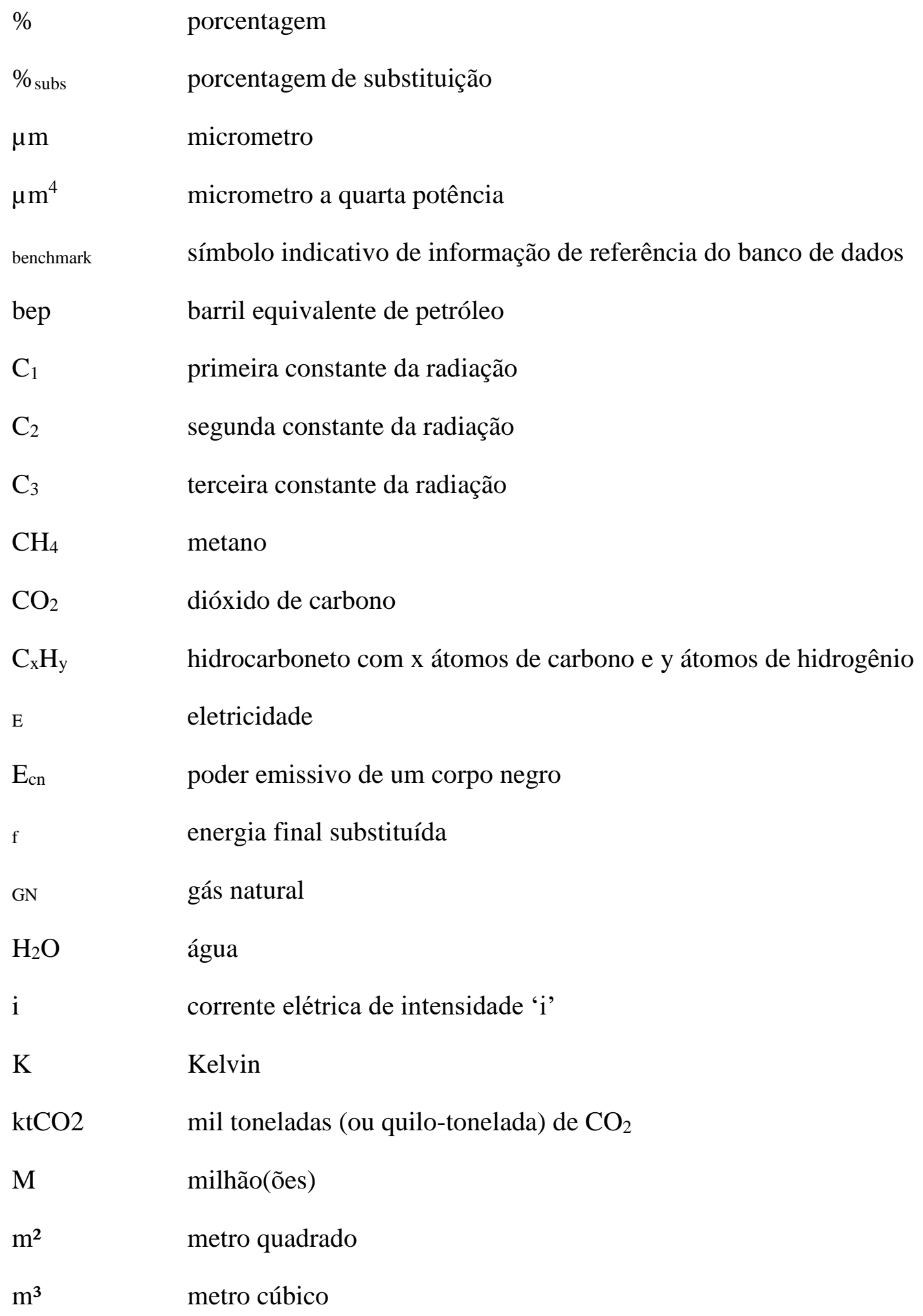




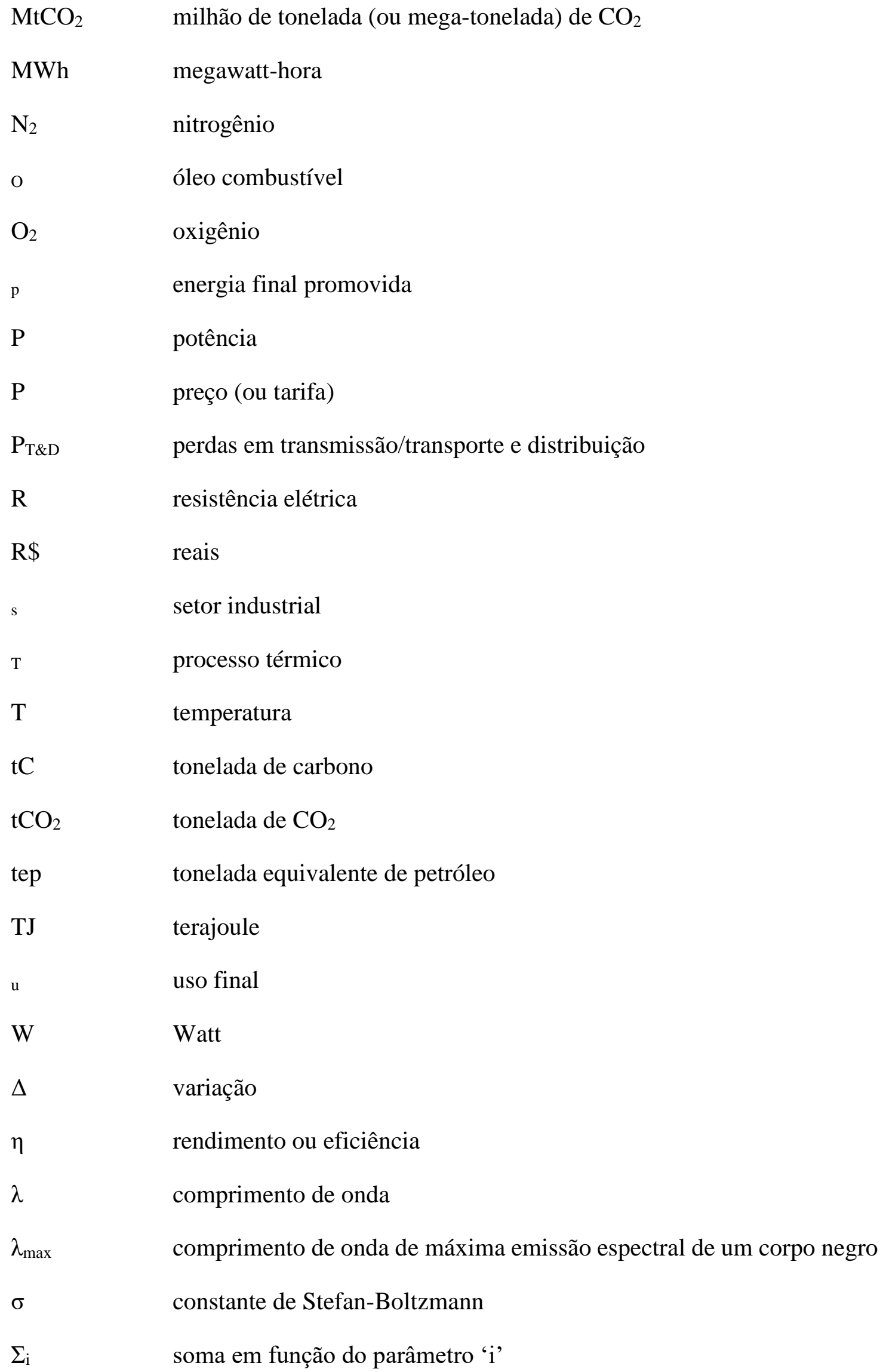




\section{SUMÁRIO}

1 INTRODUÇÃ

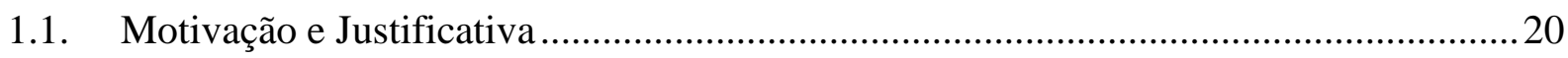

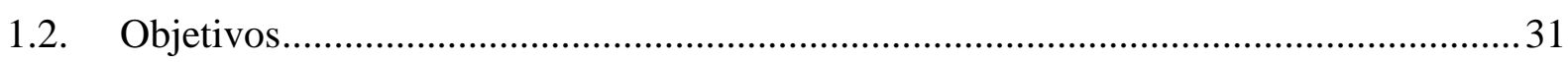

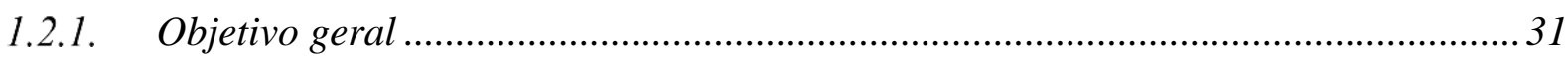

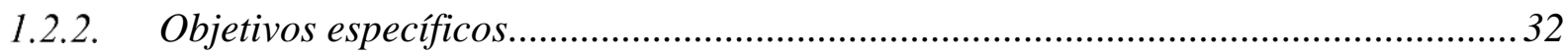

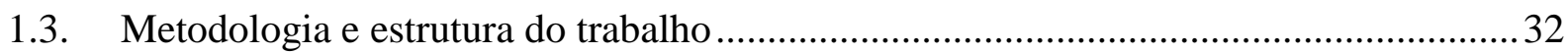

2 AVALIAÇÕES DO USO DA ENERGIA NO SETOR INDUSTRIAL BRASILEIRO - UMA PERSPECTIVA BIBLIOGRÁFICA ............................................35

2.1. Avaliação sob aspecto da eficiência energética.......................................................... 35

2.1.1. Oportunidades de Eficiência Energética para a Indústria - CNI / Eletrobras.......... 37

2.2. Avaliação sob aspecto da promoção dos gases combustíveis ....................................... 40

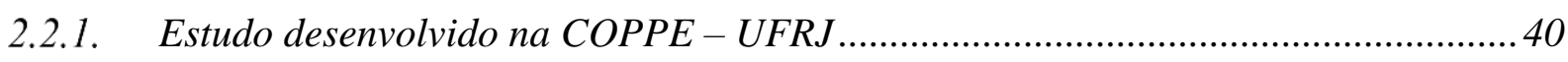

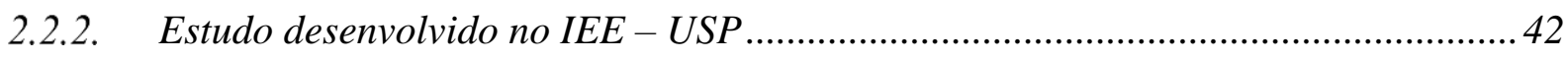

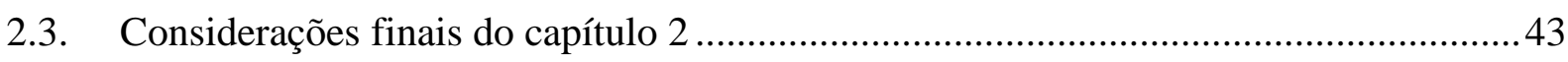

3 TÉCNICA DE ANÁlISE DE DADOS PARA AVALIAÇÃO DE SUBSTITUIÇÕES NO USO FINAL DE ENERGIA E SEUS IMPACTOS ENERGÉTICO, AMBIENTAL E ECONÔMICO............................................................45

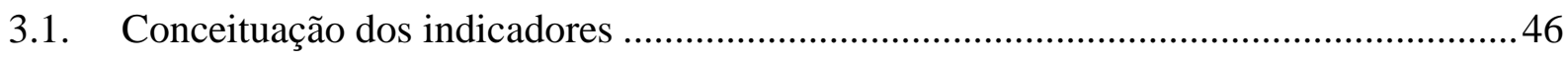

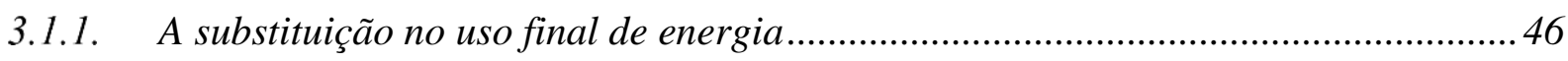

3.1.2. O aspecto energético através do consumo de energia primária ................................47

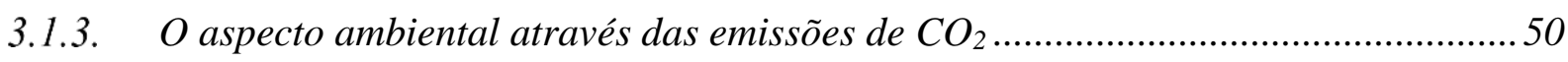

3.1.4. O aspecto econômico através do custo energético ...................................................52

3.1.5. Considerações finais da conceituação dos indicadores ........................................... 52

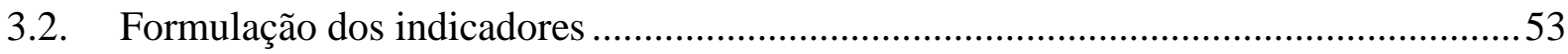

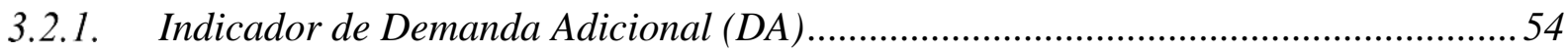

3.2.2. Mecanismo de estimação do potencial de substituição ........................................... 56

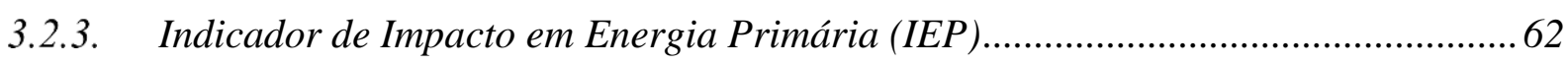

3.2.4. Indicador de Impacto em Emissões de Carbono (IEC) ........................................... 64

3.2.5. Indicador de Impacto no Custo Energético (ICE) ................................................... 66

3.2.6. Considerações finais da formulação dos indicadores .............................................67

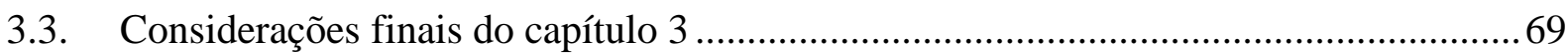




\section{APLICAÇÃO DA TÉCNICA DE ANÁLISE DE DADOS - AVALIAÇÃO DA}

INSERÇÃO DO GÁS NATURAL NO SETOR INDUSTRIAL BRASILEIRO ...............71

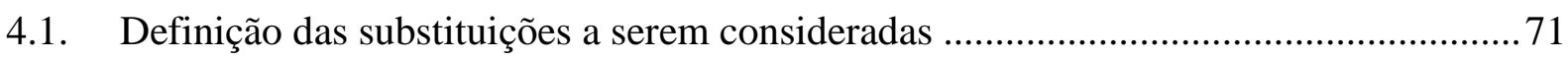

4.1.1. A definição dos usos finais a serem analisados.................................................... 72

4.1.2. A definição dos tipos de energia final a serem substituídos.................................... 73

4.1.3. As limitações técnicas das substituições consideradas ............................................. 75

4.2. Aplicação da técnica de análise de dados para as substituições consideradas .............. 81

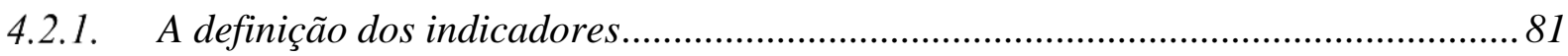

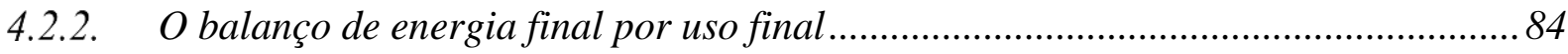

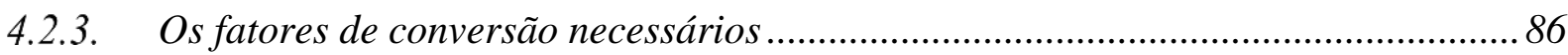

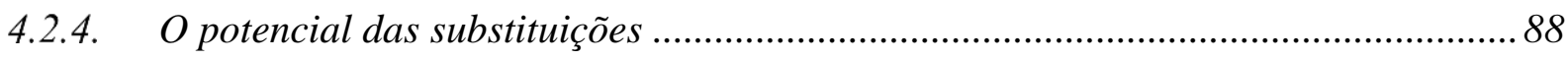

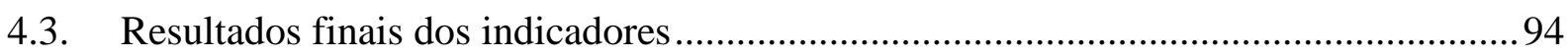

4.3.1. Resultados do indicador de Demanda Adicional (DA) ............................................ 95

4.3.2. Resultados do indicador de Impacto em Energia Primária (IEP) ........................... 97

4.3.3. Resultados do indicador de Impacto em Emissões de Carbono (IEC)...................... 99

4.3.4. Resultados do indicador de Impacto em Custo Energético (ICE)........................... 102

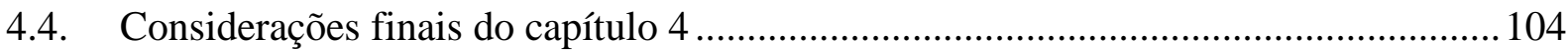

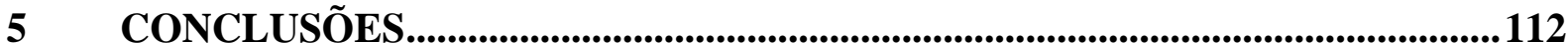

REFERÊNCIAS BIBLIOGRÁFICAS ..................................................................118

APÊNDICE A - Tabelas da Base de dados de balanços de energia final .......................128 


\section{INTRODUÇÃO}

Este capítulo introdutório busca apresentar a relevância do tema tratado, e seu contexto no setor energético nacional, em três seções. A primeira trata das motivações que levaram ao estudo da aplicação do gás natural no setor industrial brasileiro. Essa motivação é embasada e justificada com elementos da literatura que trata dos assuntos conexos ao assunto proposto. A segunda seção se dedica à apresentação dos objetivos deste trabalho que abordam a avaliação da inserção do gás natural no setor industrial brasileiro através do uso de indicadores que representam a relação entre essa inserção e seus impactos ${ }^{1}$. Por fim, a terceiraexpõe a sua estrutura que ordena os pontos que serão cobertos e que foram introduzidos neste capítulo.

\subsection{Motivação e Justificativa}

O trabalho desenvolvido nesta dissertação tem duas motivações principais. A primeira é a questão do uso da energia na atividade industrial brasileira e a segunda é o aproveitamento dos recursos naturais, em particular os recursos energéticos, disponíveis no Brasil, em especial o gás natural.

Tratando-se da primeira motivação, a compreensão de que o paradigma atual do uso da energia no setor industrial brasileiro é fruto da conjuntura histórica do setor energético no país permite explicar características particulares observadas no setor industrial brasileiro. Esse histórico se inicia no final do século XIX e início do século XX, época em que houve um primeiro movimento de industrialização que se caracterizou pela dependência da agricultura de exportação. O modelo econômico brasileiro primário-exportador era o motor que induzia o crescimento da produção industrial, pois gerava mercado interno, capacidade de importar e formação de capital. Os setores desenvolvidos eram restritos, centrados nas indústrias de bens

$1 \mathrm{O}$ termo impacto é utilizado nesta dissertação para denotar um elemento de análise da consequência da substituição de um determinado tipo de energia final por outro. 
de consumo mais básicos (têxtil e produtos alimentares) e nas indústrias de bens de capital que forneciam os insumos pesados da agricultura de exportação (máquinas e equipamentos agrícolas) (SUZIGAN, 2000; MARSON, 2015; DE MOURA CUNHA et al., 2017).

No início desse período, por volta de 1900, a indústria começava a se mecanizar, ou seja, realizar suas atividades com força motriz não humana ou animal. A principal tecnologia que se destacava era a máquina a vapor, mas outras tecnologias também eram aplicadas, como turbinas hidráulicas, sem conversão em eletricidade, e já se observava a introdução dos motores elétricos. Até a Primeira Guerra Mundial, a demanda de força motriz era basicamente atendida por energia final química, principalmente carvão-vapor (nas máquinas a vapor) e energia hidráulica (nas rodas d'água e turbinas hidráulicas) (DE LORENZO, 1994; LAMARÃO, 1997).

A Primeira Guerra Mundial provoca um choque no suprimento energético pela redução das importações e elevação dos preços do carvão-vapor, que era o insumo básico tanto das máquinas a vapor quanto da geração termoelétrica. Esse acontecimento histórico provoca dois movimentos, a difusão das novas técnicas para geração hidroelétrica e uma rápida eletrificação do uso final de força motriz na indústria. Entre 1914 e 1930 essa mudança no padrão de consumo de energia pela indústria, a eletrificação, que ocorre não apenas no setor industrial, promove uma radical transformação, tornando-se quase hegemônica no atendimento da demanda de força motriz (DE LORENZO, 1994; LAMARÃO, 1997).

A Crise de 1929 impossibilitou o país de continuar no modelo primário-exportador, iniciando-se uma segunda fase no movimento de industrialização do Brasil com uma diferente natureza de desenvolvimento, a substituição, por produção interna, de alguns produtos anteriormente importados, notadamente os bens de consumo não-duráveis. O crescimento da produção industrial adquiriu dinamismo próprio, impulsionado primeiro pela substituição de importações e depois, cada vez mais intensamente, pela expansão do mercado interno e, por fim, pelas exportações de produtos manufaturados sob forte esquema de promoção, inclusive com subsídios (VICECONTI, 1977; SUZIGAN, 2000).

O padrão de desenvolvimento industrial avançou substancialmente em termos estruturais, convergindo para o padrão estrutural e tecnológico das economias industrializadas, embora sem alcançá-lo inteiramente (SUZIGAN, 2000). Esse período de desenvolvimento atravessa diferentes momentos políticos do Brasil, abrangendo a Era Vargas (1930-1945), o 
governo de Juscelino Kubistchek (1956-1961) e o Regime Militar (1964-1985), sendo importante fazer aqui um recorte temporal no final do governo de Emilio Médici (1969-1974).

Nesse período, da década de 1930 a de 1970, o desenvolvimento industrial estava suportado no suprimento energético baseado em eletricidade e nos derivados de petróleo, em sua maior parte importados. A evolução da capacidade instalada do setor elétrico mostra que a hidroeletricidade sempre teve um papel destacado na geração de energia elétrica, partindo de $80 \%$ nas décadas de 1930 e 1940, descendo a $70 \%$ na década de 1960, retornando a $80 \%$ no início da década de 1970 e atingindo 86\% no final da década de 1970 (LANDI, 2006).

Esse aumento na participação da geração hidrelétrica da década de 1970 tem relação com o Primeiro Choque do Petróleo, em 1973, que também deu origem a outras iniciativas do lado da oferta de energia que visavam diminuir a dependência da importação de derivados de petróleo, como o Proálcool $^{2}$ (Programa Nacional do Álcool) e o reforço nas pesquisas de exploração na plataforma continental pela Petrobras na busca de reservas de petróleo offshore ${ }^{3}$. Embora essas iniciativas tenham dados frutos, os resultados a curto-prazo não foram suficientes para reduzir a dependência externa e em 1979 ocorre o Segundo Choque do Petróleo, levando o governo a tomar iniciativas para reduzir o consumo de derivados de petróleo, agindo então do lado da demanda (PICCININI, 1994).

\footnotetext{
${ }^{2}$ O Programa Nacional do Álcool (Proálcool) foi estabelecido em 1975 como uma medida de resposta ao impacto do Primeiro Choque do Petróleo, em 1973, tendo objetivo de promover a produção de etanol anidro para adição na gasolina e, por consequência, diminuição na dependência externa desse derivado. Contudo, com o agravamento da situação com o Segundo Choque do Petróleo, em 1979, o Proálcool passa a estimular o uso do etanol hidratado como combustível substituto da gasolina. O programa teve um bom desempenho, apoiado em forte marco regulatório, até a queda do preço do petróleo em meados dos anos 1980, seguido de uma crise de abastecimento que abalou a confiança dos consumidores no combustível que só se reverteu nos anos 2000 com o advento dos veículos flex que utilizam tanto gasolina quanto etanol como combustível. Essas informações e mais detalhes sobre o Proálcool estão disponíveis em NNOGUEIRA et al. (2008).

${ }^{3}$ A Petrobras detinha o monopólio da exploração, produção, refino, transporte e comercialização do petróleo e seus derivados desde a sua instalação em 1954. Desde então a exploração se concentrava mais em terra, ainda que houvesse pesquisas exploratórias marinhas com resultados modestos. O Primeiro Choque do Petróleo em 1973 aliado a uma descoberta offshore mais relevante levou o governo a aumentar os investimentos em pesquisa e exploração offshore, o que resultou no final de 1974 na primeira descoberta importante: o Campo de Garoupa na Bacia de Campos. Daí em diante as reservas offshore cresceram e em 1984 já eram equivalentes às reservas onshore, que apresentavam tímido crescimento. Uma grande quantidade de descobertas passa a acontecer, resultado desses investimentos, a partir de 1984 e então o crescimento das reservas é ainda mais brusco, as reservas onshore permanecem praticamente estáveis e em 1997 as reservas offshore já equivalem a cerca de seis vezes as reservas em terra. Essas informações e mais detalhes sobre as fases de exploração de petróleo no Brasil de 1858 a 1997 estão disponíveis em Lucchesi (1998).
} 
O setor industrial, consumidor de quase $80 \%$ do óleo combustível no Brasil à época, foi objeto de diversas dessas ações, como os protocolos assinados em 1979 com alguns dos setores dentre os maiores consumidores que visavam estimular a redução do derivado de petróleo através da substituição por fontes alternativas nacionais. Segue-se a esses protocolos o Programa de Conservação de Energia no Setor Industrial (Conserve), criado pelo Ministério de Indústria e Comércio (MIC) em 1981 que tinha como objetivos reduzir o consumo de energia, fomentar a substituição de fontes de energia importadas por alternativas nacionais, estimular o desenvolvimento de processos e de produtos que promovessem a eficiência energética ${ }^{4}$ e aportar recursos financeiros a programas, projetos e estudos de substituição de fontes de energia importadas e de redução do consumo de energia (PICCININI, 1994).

Essas ações provocaram uma queda na atividade econômica, devido ao aumento dos preços e na restrição ao acesso aos derivados de petróleo, que resultou em ociosidade da capacidade instalada do parque gerador de energia elétrica. Esse fator associado a um período de chuvas favorável e a perspectiva de entrada em operação da Usina Hidrelétrica de Itaipu, levou o governo a estabelecer tarifas subsidiadas - EGTD, Energia Garantida por Tempo Determinado e ESNG, Energia Sazonal Não Garantida — incentivando o uso de eletricidade

${ }^{4}$ Existem no Brasil uma série de mecanismos de promoção à eficiência energética e conservação de energia, alguns advindo de ações do Ministério de Minas e Energia, outros de leis e decretos que regulamentam a matéria, e também de programas. Alguns dos principais mecanismos são:

- a Lei n ${ }^{\circ}$ 9.478/1997, que define nos princípios e objetivos da "Política Energética Nacional" a competência do Estado brasileiro quanto à promoção da conservação de energia, dentre outros assuntos;

- a Lei ${ }^{\circ} 10.295$, de 17 de outubro de 2001 também conhecida como a "Lei de Eficiência Energética" (regulamentada pelo Decreto $n^{\circ} 4.059$, de 19 de dezembro de 2001), estabelece o procedimento para a adoção de "níveis máximos de consumo específico de energia, ou mínimos de eficiência energética, de máquinas e aparelhos consumidores de energia fabricados ou comercializados no País";

- o Programa Nacional de Conservação de Energia Elétrica - PROCEL (será abordado na Nota de Rodapé seguinte);

- o Programa Nacional da Racionalização do Uso dos Derivados do Petróleo e do Gás Natural - CONPET, cujo principal objetivo é incentivar o uso eficiente destas fontes de energia não renováveis no transporte, nas residências, no comércio, na indústria e na agropecuária;

- o Programa Brasileiro de Etiquetagem - PBE, que visa prover os consumidores de informações sobre o consumo de energia dos equipamentos eletrodomésticos, permitindo que ele possa selecionar produtos de maior eficiência em relação ao consumo, gerando uma economia nos custos de energia.

- o PROESCO, uma linha de financiamento do BNDES, que visa apoiar a implementação de projetos de eficiência energética.

Essas informações foram baseadas em Souza et al. (2009) onde mais informações sobre esses assuntos podem ser encontradas. 
na indústria como fonte de calor a fim de substituir os derivados de petróleo (DE SOUZA; GUERRA e KRUEGER, 2011).

O uso de energia elétrica na geração de calor em processos produtivos, seja como aquecimento direto ou calor de processo, é denominado de eletrotermia (FINOCCHIO, 2014). Segundo Lyra (1987), o consumo de eletricidade em eletrotermia estimulado pela EGTD chegou a 10 TWh em 1984, o que era equivalente a 6,7\% do consumo de eletricidade no Brasil naquele ano. Ainda segundo o mesmo autor, essa demanda adicional por energia elétrica fez com que a taxa de crescimento anual, que havia caído fortemente devido à recessão de 1981, retornasse a um nível próximo ao de 1980, de cerca de $10 \%$ a.a.

Embora o Conserve fosse o "Programa de Conservação de Energia no Setor Industrial" e, assim, seu objetivo central era estimular a conservação de energia, a redução de derivados de petróleo prevista para ser alcançada com o programa estava mais ligada à substituição de energia importada do que a medidas de eficiência energética. A substituição de derivados de petróleo por outras fontes energéticas correspondeu a $79 \%$ da economia prevista, enquanto a conservação de energia correspondeu apenas a 21 \% (PICCININI, 1994).

Esses resultados tímidos na área de conservação de energia se devem em parte ao fato que ela não foi considerada por muitas empresas como relacionada a ganhos de produtividade de longo prazo, isto é, como resultado de melhorias introduzidas na qualidade dos produtos e processos. Com isso, as empresas deram prioridade apenas temporária à conservação de energia, enquanto os preços do petróleo mantinham-se elevados. Essa visão de curto prazo fez com que muitas empresas retornassem ao consumo de óleo combustível após 1986, quando o preço do petróleo caiu e a tarifa de energia elétrica subsidiada foi suspensa (PICCININI, 1994).

Essa suspensão ocorreu porque os excedentes de eletricidade que permitiram o aumento no consumo por esse estímulo eram conjunturais devido ao acréscimo de capacidade instalada somado ao período de chuvas e à recessão econômica. Contudo, em meados dos anos 1980, combinou-se o efeito da retomada do crescimento da economia com um período de estiagem que se avizinhava. Nessa ocasião, o Ministério das Minas e Energia (MME) assumiu a liderança do processo de fomento à eficiência energética e implantou, em fins de 1985, o Programa de 
Conservação de Energia Elétrica (PROCEL ${ }^{5}$ ), que tinha iniciativas pioneiras como os projetos de diagnóstico do potencial de conservação de energia elétrica nos setores industrial e comercial (MARQUES, 2006).

Essa contextualização histórica do suprimento da demanda de energia do setor industrial brasileiro explica a origem da utilização intensiva de energia elétrica em processos térmicos, a eletrotermia, algo que perdura até hoje, ainda que tenha sido observada a disponibilização, a partir de meados dos anos 1980 e principalmente a partir dos anos 2000, de outra fonte de energia final ao setor industrial, que é o gás natural, o que leva à discussão da segunda motivação desta dissertação (MME, 2007).

Esse segundo motivador está vinculado à questão do aproveitamento dos recursos naturais, em particular os recursos energéticos, disponíveis no Brasil. O trabalho focaliza, em especial, o gás natural. Embora a inserção do gás natural tenha sido mencionada como ocorrida entre 1980 e 2000 no parágrafo anterior, o seu uso teve início nos anos 1940, com a exploração das reservas de petróleo na região do Recôncavo Baiano. Contudo, como o consumo era destinado às indústrias locais e em pequena quantidade, os primeiros marcos mais significativos para a indústria do gás natural ocorreram no outro período assinalado anteriormente (PERLOTTI; MOUTINHO DOS SANTOS E COSTA, 2016).

O primeiro marco se dá a partir de meados dos anos 1980 quando a produção de petróleo começa a crescer significativamente, em particular devido à exploração das descobertas da Bacia de Campos, cujas reservas de petróleo ao serem explotadas ${ }^{6}$ disponibilizaram significativos volumes de gás natural associado, que passou a ser então destinado ao mercado

\footnotetext{
${ }^{5}$ O PROCEL é constituído por diversos subprogramas, com ações nas áreas de iluminação pública, industrial, edificações, prédios públicos, gestão energética municipal, entre outras. As ações de Etiquetagem, o Selo e o Prêmio PROCEL são responsáveis pela maior parte dos resultados do Programa. Os recursos destinados ao eram limitados a recursos da Eletrobrás e da Reserva Global de Reversão (fundo federal constituído com recursos das concessionárias). Recentemente foi aprovada a Lei 13.280/2016, que reserva 20\% dos recursos das empresas de energia elétrica destinados à eficiência energética para aplicação no PROCEL, o que deu uma injeção de recursos e deve permitir mais ações de promoção de eficiência energética pelo programa. (SOUZA et al, 2009; SENADO FEDERAL, 2016).

${ }^{6}$ Explotar: extrair proveito econômico de (área, terra etc.), especialmente quanto aos recursos naturais (HOUAISS, 2018). Na área de Petróleo e Gás, a Fase de Explotação é a etapa de serviços que contempla as técnicas de desenvolvimento e produção da reserva comprovada de hidrocarbonetos de determinado campo petrolífero. Essa fase se inicia após a Fase de Pesquisa e Exploração, que é o conjunto de operações ou atividades destinadas a avaliar áreas, objetivando a descoberta e a identificação de jazidas de petróleo ou gás natural. (ANP, 2018).
} 
doméstico. O segundo marco é a entrada em operação do Gasoduto Bolívia-Brasil (Gasbol), o trecho em amarelo no mapa da Figura 1.1, que liga a região produtora de gás natural na Bolívia às regiões centro-oeste, sudeste e sul do Brasil (LUCCHESI, 1998).

Figura 1.1 - Mapa do Gasoduto Bolívia-Brasil (Gasbol)

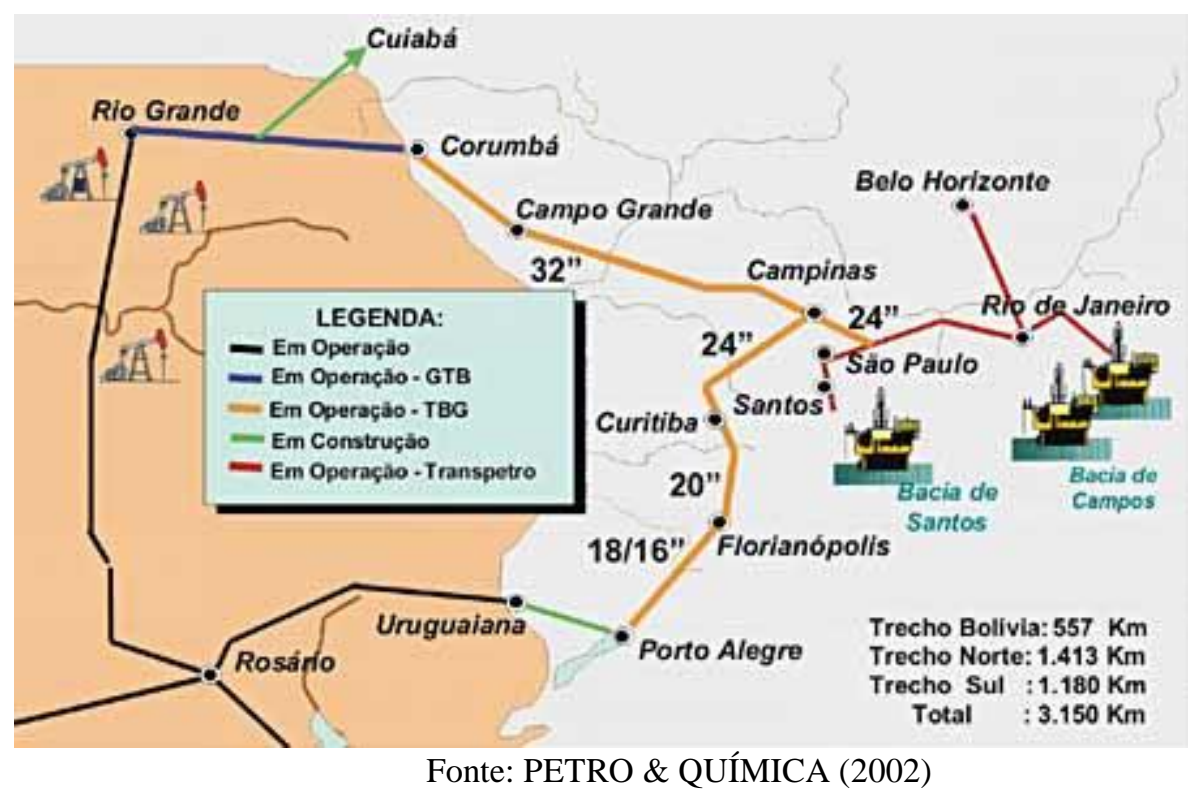

$\mathrm{O} \mathrm{Gasbol}^{7}$ liga a região produtora de gás natural na Bolívia ao maior centro consumidor de gás natural no Brasil, a região Sudeste, em particular o Estado de São Paulo, onde se conecta à rede de gasodutos da Transportadora Associada de Gás (TAG), uma subsidiária da Petrobras. Há também um trecho que parte em direção à região Sul, saindo do Estado de São Paulo, cruzando Paraná e Santa Catarina até chegar no Rio Grande do Sul. A entrada em operação desse gasoduto permitiu, já em 1999, adicionar 8 milhões de m³/dia de gás natural importados da Bolívia à oferta interna dessa fonte de energia no Brasil, um valor considerável comparado à produção nacional que, à essa época, estava na casa dos 10 milhões de m³/dia de gás natural. A capacidade máxima do Gasbol no trecho norte é de 30 milhões de $\mathrm{m}^{3} / \mathrm{dia}$ e no trecho sul é de 12,5 milhões de m³/dia (LUCCHESI, 1998).

\footnotetext{
${ }^{7}$ O Gasoduto Bolívia-Brasil (Gasbol) é concebido quando da assinatura do Tratado sobre Saída e Aproveitamento do Petróleo Boliviano, assinado pelo Brasil e Bolívia em 1938. Esse acordo sofre alterações em 1958, mas a ideia do Gasbol permanece. Apenas em 1992 é assinado um acordo sobre o assunto, em 1993 um contrato de fornecimento de gás, em 1997 as obras se iniciam e em 1999 o Gasbol começa a sua operação de transporte de gás natural (LOURENÇO, 2006).
} 
Além desses marcos, é importante também destacar o marco mais recente da indústria do gás natural, a descoberta e a exploração de petróleo e gás em águas ultraprofundas, na região denominada de Pré-Sal. A produção do Pré-Sal é um marco para a indústria do petróleo e gás como um todo, mas em particular para a do gás natural, devido a dois fatores: o conteúdo de gás natural associado no petróleo do Pré-Sal é maior e o crescimento da produção do Pré-Sal tem sido exponencial (ALMEIDA et al., 2017b).

O primeiro fator pode ser avaliado pela razão gás-óleo (RGO), que relaciona o volume de gás natural e o volume de óleo contidos em um reservatório, medidos nas condições de superfície (ALMEIDA et al., 2017b). O RGO do Pré-Sal é, em média, o dobro do verificado no Pós-Sal, mas essa diferença pode ser ainda maior. Iost (2015) calcula um RGO médio no PréSal de cerca de 200, com base nos dados de produção até 2014. Almeida et al. (2017b) já apontam que os campos atuais do Pré-Sal possuem RGO entre 250 e 300, sendo que o Campo de Libra ${ }^{8}$ apresenta um RGO que pode atingir 500, ou ser ainda maior. A título de comparação, o Campo de Marlim , no Pós-Sal, tem RGO entre 90 e 100 (REVISTA BRASIL ENERGIA, 2009).

Já o segundo fator, o crescimento rápido da produção no Pré-sal, como observado na Figura 1.2, é evidenciado pelos dados de produção média de gás natural que, no Pré-Sal, passou de 2 milhões de m³/dia em 2010 para quase 40 milhões de $\mathrm{m}^{3} /$ dia em 2016, fazendo com que a produção do Pré-Sal subisse de 3\% para 38\% da produção nacional. Considerando apenas a produção offshore, a produção de gás no Pré-Sal já tem praticamente a mesma ordem de magnitude da produção no Pós-Sal (MME, 2017). Observe-se também que nesse pequeno intervalo de tempo viabilizou-se a produção de uma quantidade de gás natural superior à capacidade do Gasbol, outra comparação que mostra a importância do Pré-Sal para a indústria do gás natural.

\footnotetext{
${ }^{8}$ O campo de Libra é considerado a maior reserva do Pré-Sal e a Petrobras estima sua entrada em operação para 2020 (G1, 2017). Os cinco principais campos do Pré-Sal são Lula, Iracema, Sapinhoá, Jubarte e Baleia Azul no mês de novembro de 2017 foi de 1,225 milhão de barris de óleo por dia e representa $92 \%$ do total produzido na camada de pré-sal (PPSA, 2017).

${ }^{9}$ O campo de Marlim foi o quinto maior produtor de petróleo em 2016, com média de 162 mil barris/dia. Se considerado junto ao campo de Marlim Sul, que teve média de $159 \mathrm{mil}$ barris/dia, eles passam a ser o segundo maior produtor de petróleo do país, atrás apenas de Lula (campo do Pré-sal), com 527 mil barris/dia (MME, 2017).
} 
Esse cenário de produção de gás natural, no contexto do Pré-Sal, sinaliza para uma grande oportunidade em se explorar esse recurso natural disponível para usos energéticos com maior valor agregado, por exemplo, como energia final para a indústria, do que realizar a reinjeção, que triplicou entre 2010 e 2016 (ALMEIDA et al., 2017b). Para tanto, duas questões são fundamentais para viabilizar essa oportunidade: como disponibilizar esse gás natural ao mercado doméstico e que mercado esse gás natural pode atender. A primeira questão envolve a separação do $\mathrm{CO}_{2}$, cuja concentração no gás natural do Pré-Sal é mais elevada em comparação ao do Pós-Sal, o escoamento e o tratamento do gás natural, assuntos que não serão tradados nessa dissertação ${ }^{10}$. Já a segunda questão está no escopo desta dissertação, e diz respeito à avaliação do setor industrial brasileiro como possível mercado a ser estimulado para uma melhor destinação do gás natural proveniente do Pré-Sal.

Figura 1.2 - Evolução da produção de petróleo (à esquerda) e de gás natural (à direita) por ambiente exploratório
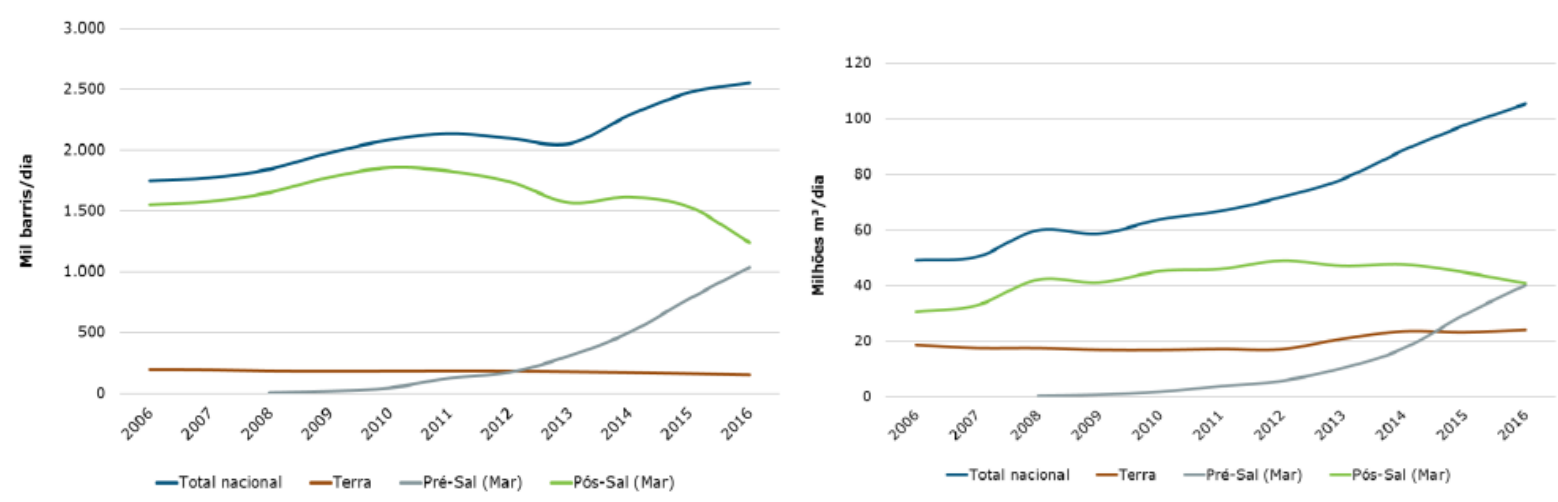

Fonte: Almeida et al. (2017a)

Essa possibilidade de maior inserção do gás natural, nesse contexto de maior disponibilidade, insere-se em um debate que hoje, no mundo, discute a sustentabilidade no uso da energia. Uma primeira vertente argumenta que a escolha da energia a ser usada deve considerar o uso no qual ela será empregada, buscando conciliar o nível da "qualidade" da energia usada à "qualidade" da energia útil. Essa "qualidade" é a qualidade exergética, ou seja, o potencial que uma determinada forma de energia possui para produzir energia útil na forma de trabalho (WALL, 1990). De Stercke (2014) desenvolveu um trabalho de construção de uma

\footnotetext{
${ }^{10}$ Informações sobre o assunto podem ser encontradas em: ALMEIDA et al. Gás do Pré-Sal: Oportunidades, Desafios e Perspectivas. Rio de Janeiro: IBP/UFRJ - Instituto Brasileiro de Petróleo, Gás e Biocombustíveis / Universidade Federal do Rio de Janeiro, 2017. Texto para Discussão. Ciclo de Debates sobre Petróleo e Economia.
} 
base de dados com tendências históricas de longo-prazo da demanda de energia primária em escala global, também expresso em energia final e energia útil e ele justifica a escolha dessa forma representação da seguinte maneira:

Neste estudo, observamos tendências de longo-prazo em energia primária, energia final e energia útil. Distinguir entre esses níveis permite quantificar a eficiência do setor a montante (extração e transformação), por um lado, e o setor de uso final, por outro lado. Desta forma, as mudanças tecnológicas no nível de uso final podem ser estudadas, quantificadas e seu papel nas melhorias de eficiência de sistemas agregados (crescimento de produtividade) isoladas. Por conseguinte, uma perspectiva de uso final proporciona uma representação muito melhor das mudanças tecnológicas que são ignoradas ao medir apenas entradas de energia primária (DE STERCKE, 2014, p.

2 , tradução nossa).

O autor também se preocupou em rebater sua base de dados em exergia, expressando a importância dos resultados dessa ação no seguinte trecho de seu trabalho:

A análise de exergia baseada nos usos finais estimados dos fluxos de energia revela, como muitos estudos já demonstraram anteriormente, a importância dos equipamentos de uso final na entrega de serviços de energia e a eficiência global geralmente baixa da provisão de serviços de energia. Muito da disponibilidade de realização de trabalho é destruída no processo de fornecimento de serviços de energia e, à luz das restrições externas colocadas no fornecimento de energia (economia, limitações de recursos e externalidades ambientais, incluindo mudanças climáticas), as políticas devem ser destinadas a combinar melhor a qualidade do fornecimento com a qualidade da demanda. (DE STERCKE, 2014, p. 42, tradução nossa).

Essa discussão permeia diversos estudos sobre sustentabilidade no uso da energia, como em Wall e Gong (2001), Ness et al. (2007) e Duflou et al. (2012) e de forma mais ampla, o debate que envolve discussões sobre economia de energia e eficiência energética.

O uso racional da energia, por exemplo, alcançado através de ações de gestão ou investimentos estruturais que promovam a eficiência energética, é, sem dúvida, um dos principais pilares sobre os quais estão as iniciativas destinadas a promover o consumo sustentável de recursos naturais e combater as mudanças climáticas. De acordo IEA (2012), cerca de $50 \%$ do potencial de redução das emissões de gases de efeito estufa (GEE) até 2030 está relacionado ao aumento da eficiência energética, tanto pela troca de combustível quanto pelo uso de tecnologias mais eficientes, como mostrado na Figura 1.3. 
As ações para melhorar a eficiência energética no setor da indústria continuam a ser uma das opções mais econômicas para alcançar reduções de emissões de gases de efeito estufa em toda a economia e melhorar a segurança energética e a produtividade. Outra vantagem de buscar a eficiência na indústria em relação a outros setores da economia é que relativamente menos atores estão envolvidos. O potencial de eficiência energética pode ser capturado através da melhoria das práticas de milhares de entidades, em oposição a milhões ou bilhões de entidades em todo o mundo quanto se trata do setor de edificações (residencial e comercial) (PRICE e MCKANE, 2009).

Figura 1.3 - Portifólio de medidas para redução das emissões de GEE no setor de energia

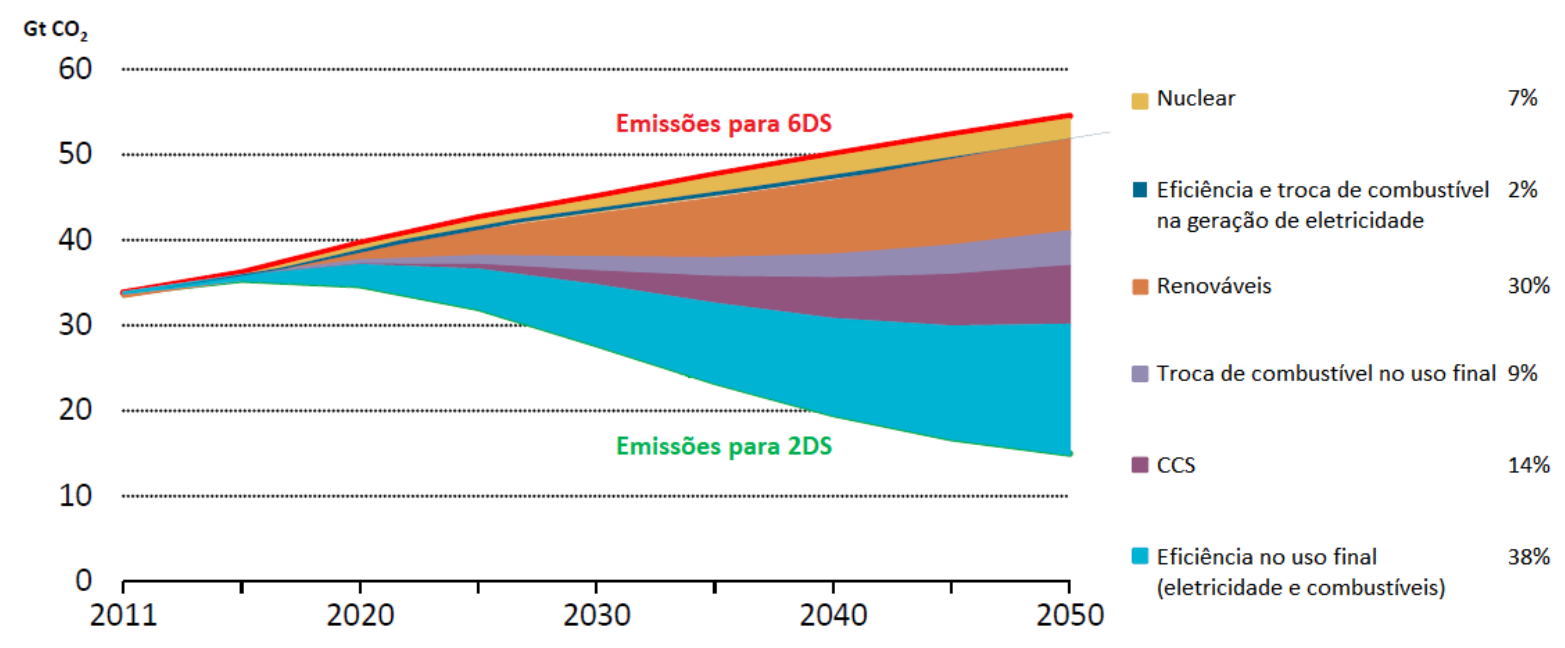

Fonte: IEA (2016a)

Contudo, a temática de eficiência energética na indústria não será objeto de estudo explícito nesta dissertação, mas guarda relação direta ao objeto principal, pois como apontado por De Stercke (2014), é preciso adequar a fonte de energia final em uso com sua destinação e, segundo Wall (1977), a eletricidade é a forma de energia com mais alto grau de qualidade ${ }^{11}$. Assim, destinar a eletricidade para outros fins e utilizar o gás natural em usos finais térmicos, de qualidade mais baixa em termos relativos (WALL, 1977), é uma forma de melhorar a alocação dos recursos energéticos e, de certa forma, promover o aumento de eficiência do sistema energético como um todo (STRAPASSON, 2004).

\footnotetext{
${ }^{11}$ Ao lado da energia potencial gravitacional e cinética (WALL, 1977)
} 
Por fim, considerando os dois temas motivadores deste trabalho, a questão do uso da energia na atividade industrial brasileira e o aproveitamento dos recursos naturais energéticos disponíveis no Brasil, o presente estudo é orientado no sentido de avaliar o gás natural como uma fonte de energia final para a indústria, considerando seus impactos em três diferentes aspectos: o energético, o ambiental e o econômico. Para tanto, o desenvolvimento desta dissertação se dividiu em duas etapas: a elaboração de uma técnica de análise de dados para a avaliação do uso final de energia que compreendesse os aspectos considerados e a aplicação dessa técnica com objetivo de avaliar uma maior inserção do gás natural como fonte de energia final para o setor industrial brasileiro. Optou-se por elaborar uma técnica de análise de dados com aplicabilidade maior que apenas ao estudo de caso concreto dessa dissertação de forma que essa contribuição seja uma referência que possa ser replicada em diferentes casos e que, assim, os casos possam ser comparados entre si, em diferentes cenários e hipóteses, ou ainda se comporem como uma avaliação de um quadro maior, como avaliação conjunta com outros setores como o residencial ${ }^{12}$ e o comercial.

\subsection{Objetivos}

Nesta seção serão apresentados os objetivos geral e específicos desta dissertação.

\subsubsection{Objetivo geral}

O objetivo geral da presente dissertação é realizar uma análise do potencial de inserção do gás natural no setor industrial brasileiro, em substituição a outros tipos de energia final, com

\footnotetext{
${ }^{12}$ Como o estudo de Cursino dos Santos (2011) em que é estudada maior utilização de gases combustíveis no setor residencial.
} 
uso de indicadores que considerem os impactos dessa substituição segundo aspectos energético, ambiental e econômico.

\subsubsection{Objetivos específicos}

Os objetivos específicos da desta dissertação incluem:

- desenvolver uma técnica de análise de dados para a avaliação dos impactos energético, ambiental e econômico de substituições no uso final de energia;

- aplicar a técnica desenvolvida para avaliar o potencial de inserção do gás natural e os impactos dessa maior inserção nas atividades do setor industrial brasileiro presentes no Balanço Energético Nacional ${ }^{13}$.

\subsection{Metodologia e estrutura do trabalho}

A metodologia científica desta dissertação, utilizando como referência o trabalho de Ponte et al. (2007), tem as seguintes características:

- é uma pesquisa descritiva, ou seja, busca descrever um fenômeno, a inserção do gás natural no setor industrial brasileiro, e estabelecer relações entre variáveis, como avaliar o potencial e o impacto dessa inserção;

- é delineada de forma documental e bibliográfica, visto que são levantados tanto estudos prévios e informações da literatura (fontes secundárias) como levantamentos de

${ }^{13} \mathrm{O}$ Balanço Energético Nacional (BEN) documenta a contabilidade relativas à oferta e consumo de energia no Brasil, incluindo informações sobre os recursos energéticos primários, sua conversão em formas secundárias, a importação e exportação, a distribuição e o uso final da energia (EPE, 2018). São tratados no BEN os seguintes setores industriais: Setor de Alimentos e Bebidas; Setor Cerâmico; Setor Cimenteiro; Setor de Ferro-Gusa e Aço; Setor de Ferro-Ligas; Setor de Mineração e Pelotização; Setor de Não-Ferrosos e Outros da Metalurgia; Setor de Papel e Celulose; Setor Químico e Setor Têxtil. (EPE, 2014) 
contabilidade oferta e demanda de energia final, os balanços de energia (fontes primárias);

- tem natureza quantitativa, pois um de seus objetivos é quantificar o potencial de inserção do gás natural no setor industrial brasileiro e também os impactos dessa inserção;

- a coleta de dados é realizada via documentação indireta, tanto documental quanto bibliográfica, uma decorrência da forma com que a pesquisa foi delineada;

- e a técnica de análise de dados é quantitativa e foi construída como parte integrante desta dissertação, com objetivo de permitir a análise do fenômeno de interesse.

A aplicação desta metodologia científica com as características acima levou à construção desta dissertação que está organizada em 5 capítulos. Neste primeiro capítulo (Capítulo 1) foi feita uma apresentação geral do contexto da temática abordada, com os elementos motivadores, suas justificativas, os objetivos, geral e específicos, e a metodologia e estrutura da dissertação.

O conteúdo do Capítulo 2 se concentra na discussão de diferentes abordagens sobre avaliações realizadas sobre o uso de energia no setor industrial brasileiro. Esse capítulo é uma revisão bibliográfica não exaustiva de estudos presentes na literatura sobre essa temática, cujo objetivo é evidenciar dois diferentes movimentos, um ligado à eficiência energética e outro à promoção de um determinado tipo de energia final como os gases combustíveis, no caso, o gás natural. Assim, é possível traçar nesse segundo capítulo algumas relações entre o histórico apresentado no Capítulo 1 e tais movimentos, assim como apontar como o presente trabalho contribui para as discussões nessa área.

O Capítulo 3 contém a proposta de uma técnica de análise de dados para a avaliação de substituições no uso final de energia e seus impactos energético, ambiental e econômico. Estão contemplados a discussão sobre a conceituação de indicadores para representar a substituição e seus impactos, a formulação desses indicadores e o mecanismo de estimação do potencial de substituição. Nesse primeiro momento, a técnica de análise de dados é construída de modo mais amplo para que ela possa ser replicada em diferentes casos e que, assim, os resultados possam ser comparados entre si, em diferentes cenários e hipóteses, ou ainda realizar uma composição para diagnóstico de um quadro energético maior, como avaliação conjunta com outros setores como o residencial e o comercial. 
Já o Capítulo 4 trata do objetivo principal dessa dissertação, a aplicação da técnica de análise de dados apresentada no capítulo anterior para avaliar a inserção do gás natural no setor industrial brasileiro. Inicialmente é realizada a delimitação do estudo, ou seja, são especificadas quais substituições no uso final de energia serão consideradas. Em seguida é aplicada a técnica de análise de dados desenvolvida nesta dissertação e os resultados são discutidos no final do capítulo.

As conclusões sobre o trabalho desenvolvido nesta dissertação são apresentadas no Capítulo 5, tanto do ponto de vista da técnica de análise de dados quanto dos resultados da avaliação sobre a inserção do gás natural no setor industrial brasileiro. Também são sugeridas linhas de estudo para trabalhos futuros.

Por fim, os Apêndices que estão incluídos no final desta dissertação contemplam as planilhas com informações mais detalhadas sobre o estudo de aplicação da técnica de análise de dados realizado, cuja apresentação não se deu ao longo do corpo da dissertação para manter melhor fluidez na leitura do trabalho. 


\section{AVALIAÇÕES DO USO DA ENERGIA NO SETOR INDUSTRIAL BRASILEIRO - UMA PERSPECTIVA BIBLIOGRÁFICA}

Neste capítulo será apresentada uma discussão de diferentes abordagens sobre avaliações realizadas sobre o uso de energia no setor industrial brasileiro. Para tanto foi feita uma revisão bibliográfica não exaustiva de estudos presentes na literatura sobre essa temática, tendo sido trazidos para discussão neste capítulo apenas algumas referências do ponto de vista acadêmico e institucional.

O objetivo deste capítulo apresentar duas diferentes abordagens identificadas nessas referências bibliográficas e que se relacionam com a temática desta dissertação, uma ligada à eficiência energética e outra à promoção de um determinado tipo de energia final como os gases combustíveis, no caso, o gás natural. Assim, será possível traçar algumas relações entre o histórico apresentado no Capítulo 1 e esses movimentos, assim como apontar como o presente trabalho contribui para as discussões nessa área.

A primeira seção deste capítulo vai abordar a avaliação do uso da energia no setor industrial sob o aspecto da eficiência energética, seguida de outra seção que trada das avaliações sob o aspecto da promoção dos gases combustíveis. Em ambas seções haverá subseções dedicadas a detalhamento de estudos específicos que foram considerados importantes. Finalmente, a última seção irá estabelecer a relação entre essas avaliações, o histórico do padrão de uso de energia do setor industrial e contextualizar a proposta desta dissertação.

\subsection{Avaliação sob aspecto da eficiência energética}

Uma abordagem de avaliação do uso da energia no setor industrial muito utilizada envolve o aspecto da eficiência energética. Do ponto de vista histórico, essas avaliações têm como origem, direta ou indiretamente, ações do poder público em função de diferentes situações do quadro energético nacional. No Capítulo 1, por exemplo, foram apresentados programas de promoção de ações de eficiência energética e conservação de energia. 
Uma estratégia adotada ao analisar a eficiência energética em setores industriais é avaliar um indicador de intensidade energética. De fato, esse indicador está incluído em um contexto mais geral de avaliação da eficiência energética. Patterson (1996) classifica os indicadores de eficiência energética em quatro grupos principais: indicadores termodinâmicos, um indicador teórico que compara o consumo de energia real e o consumo de energia ideal; indicadores físico-termodinâmicos, um indicador que relaciona o consumo de energia à produção física ou ao serviço fornecido; indicadores econômico-termodinâmicos, um indicador construído de forma semelhante ao anterior, mas neste caso a produção ou o serviço são dados em termos monetários; e, finalmente, indicadores econômicos, uma relação de valores econômicos em que a energia e a produção física ou o serviço são avaliados em termos monetários. A discussão envolvendo esses indicadores também é tratada por Proskuryakova e Kovalev (2015), onde os autores avaliam em que escala local, setorial ou global deveria corresponder melhor a cada tipo de grupo indicador conforme apresentado por Patterson (1996).

Para os setores industriais cujos produtos são similares (padronizados ou sem diferenciação significativa), é muito frequente o uso da intensidade energética no formato de um indicador de eficiência energética físico-termodinâmico, representando quantas unidades de energia são necessárias para produzir uma determinada quantidade de produto (tep/t, tonelada equivalente de petróleo por tonelada de produção, por exemplo). Trabalhos como da UNIDO (2010) utilizam esses indicadores de intensidade energética para construir índices de eficiência energética, comparando a intensidade energética de um determinado setor industrial de um país ou região em relação aos valores de intensidade energética de referência das melhores práticas ou técnicas disponíveis como no estudo publicado por Worrell et al. (2008), onde essas referências são conhecidas pelas siglas BPT (sigla em inglês para best practicable technology) ou BAT (sigla em inglês para best available technique).

No Brasil, dentre os estudos que seguem essa linha de avaliação do uso da energia no setor industrial, pode ser destacado um projeto desenvolvido em parceria pela CNI e Eletrobras, através do PROCEL Indústria, chamado de "Oportunidades de Eficiência Energética para a Indústria, que será apresentado a seguir, em função da sua abrangência em termos de setores cobertos, de dados coletados e resultados disponibilizados. 


\subsubsection{Oportunidades de Eficiência Energética para a Indústria - CNI / Eletrobras}

Publicado em 2010, este estudo foi desenvolvido pela CNI em parceria com a Eletrobras, através do PROCEL Indústria, com o intuito de identificar oportunidades de uso eficiente da energia na indústria que pudessem ser traduzidas em aumento de competitividade, assim como sugerir ações para um melhor e mais sustentável desenvolvimento do mercado de eficiência energética (CNI/Eletrobras, 2010).

Uma parte do estudo se dedicou aos aspectos de projetos de eficiência energética, incluindo levantamento sobre as principais ações e programas de fomento em âmbito nacional, além de uma análise de experiências internacionais. O resultado dessa primeira parte do estudo foi um grupo de relatórios (completos e em formato de sumários executivos) dividido nas seguintes temáticas:

- experiências internacionais em eficiência energética na indústria ${ }^{14}$;

- histórico dos principais programas e ações de eficiência energética propostos e adotados pela indústria brasileira ${ }^{15}$;

- novas tecnologias para processos industriais com vistas à promoção de eficiência energética ${ }^{16}$;

- oportunidades de negócios para a indústria em projetos de eficiência energética com MDL Programático ${ }^{17}$.

Uma segunda parte do estudo ficou concentrada na análise das oportunidades de conservação de energia em diversos setores industriais, cujo resultado foi uma série de

${ }^{14}$ BAJAY, S. V. e SANT'ANA, P. H. M. Experiências internacionais em eficiência energética para a indústria. In: CNI/Eletrobras. Oportunidades de eficiência energética para a indústria. Brasília: CNI/Eletrobras, 2010.

${ }^{15}$ GUARDIA, E. et al. Histórico de Programas. In: CNI/Eletrobras. Oportunidades de eficiência energética para a indústria. Brasília: CNI/Eletrobras, 2010.

${ }^{16}$ BAJAY, S. V. e SANT’ANA, P. H. M. Novas Tecnologias para Processos Industriais: Eficiência Energética na indústria. In: CNI/Eletrobras. Oportunidades de eficiência energética para a indústria. Brasília: CNI/Eletrobras, 2010.

${ }^{17}$ CNI. Confederação Nacional da Indústria. Oportunidades de negócios para a indústria em projetos de eficiência energética com MDL programático. In: CNI/Eletrobras. Oportunidades de eficiência energética para a indústria. Brasília: CNI/Eletrobras, 2010. 
relatórios setoriais cobrindo os seguintes setores: Setor de alimentos e bebidas ${ }^{18}$; Setor de cal e gesso $^{19}$; Setor cerâmico ${ }^{20}$; Setor cimenteiro $^{21}$; Setor extrativo mineral ${ }^{22}$; Setor de ferro-ligas ${ }^{23}$; Setor de fundição ${ }^{24}$; Setor de metais não-ferrosos ${ }^{25}$; Setores não energo-intensivos ${ }^{26}$; Setor químico $^{27}$; Setor papel e celulose ${ }^{28}$; Setor têxtil ${ }^{29}$; e Setor vidreiro ${ }^{30}$.

Esses relatórios setoriais têm cada um algumas particularidades em suas estruturas, mas, no geral, são compostos pelos seguintes blocos:

- caracterização técnica: descreve os produtos, matérias-primas e processos dos setores, fazendo também menção a dados históricos sobre esses elementos;

18 ROCHA, C. R., BAJAY, S. V. e GORLA, F. D. Relatório Setorial: Setor de alimentos e bebidas. In: CNI/Eletrobras. Oportunidades de eficiência energética para a indústria. Brasília: CNI/Eletrobras, 2010.

19 BAJAY, S. V. e SANT'ANA, P. H. M. Relatório Setorial: Setor de cal e gesso. In: CNI/Eletrobras. Oportunidades de eficiência energética para a indústria. Brasília: CNI/Eletrobras, 2010.

20 BERNI, M. D., BAJAY, S. V. e GORLA, F. D. Relatório Setorial: Setor cerâmico. In: CNI/Eletrobras. Oportunidades de eficiência energética para a indústria. Brasília: CNI/Eletrobras, 2010.

${ }^{21}$ DORILEO, I. L., BAJAY, S. V. e GORLA, F. D. Relatório Setorial: Setor cimenteiro. In: CNI/Eletrobras. Oportunidades de eficiência energética para a indústria. Brasília: CNI/Eletrobras, 2010.

${ }^{22}$ DORILEO, I. L., BAJAY, S. V. e GORLA, F. D. Relatório Setorial: Setor extrativo mineral. In: CNI/Eletrobras. Oportunidades de eficiência energética para a indústria. Brasília: CNI/Eletrobras, 2010.

${ }^{23}$ LEITE, A. A. F., BAJAY, S. V. e GORLA, F. D. Relatório Setorial: Setor de ferro-ligas. In: CNI/Eletrobras. Oportunidades de eficiência energética para a indústria. Brasília: CNI/Eletrobras, 2010.

${ }^{24}$ SIMÕES, A. F. e BAJAY, S. V. Relatório Setorial: Setor de fundição. In: CNI/Eletrobras. Oportunidades de eficiência energética para a indústria. Brasília: CNI/Eletrobras, 2010.

${ }^{25}$ SIMÕES, A. F. e BAJAY, S. V. Relatório Setorial: Setor de metais não-ferrosos. In: CNI/Eletrobras.

Oportunidades de eficiência energética para a indústria. Brasília: CNI/Eletrobras, 2010.

${ }^{26}$ LEITE, A. A. F., BAJAY, S. V. e GORLA, F. D. Relatório Setorial: Setores não energo-intensivos. In: CNI/Eletrobras. Oportunidades de eficiência energética para a indústria. Brasília: CNI/Eletrobras, 2010.

${ }^{27}$ BAJAY, S. V., BEISSMANN, A. e GORLA, F. D. Relatório Setorial: Setor químico. In: CNI/Eletrobras. Oportunidades de eficiência energética para a indústria. Brasília: CNI/Eletrobras, 2010.

${ }^{28}$ BERNI, M. D., BAJAY, S. V. e GORLA, F. D. Relatório Setorial: Setor papel e celulose. In: CNI/Eletrobras. Oportunidades de eficiência energética para a indústria. Brasília: CNI/Eletrobras, 2010.

${ }^{29}$ BAJAY, S. V. e SANT'ANA, P. H. M. Relatório Setorial: Setor têxtil. In: CNI/Eletrobras. Oportunidades de eficiência energética para a indústria. Brasília: CNI/Eletrobras, 2010.

30 LEITE, A. A. F., BAJAY, S. V. e GORLA, F. D. Relatório Setorial: Setor vidreiro. In: CNI/Eletrobras. Oportunidades de eficiência energética para a indústria. Brasília: CNI/Eletrobras, 2010. 
- caracterização econômica: descreve o mercado dos setores (através de dados exportações, importações e demanda aparente); lista o conjunto das principais empresas; e aponta os principais investimentos previstos nesses setores à época;

- caracterização ambiental: trata dos aspectos dos poluentes envolvidos nas atividades dos setores (incluindo não apenas da poluição do ar, mas também da água e do solo); e descreve algumas ações realizadas pelos setores para mitigar os impactos ambientais;

- caracterização energética: descreve o quadro de consumo de energia com dados históricos; faz uma análise da distribuição dos consumos de energia final e energia útil por usos finais; e por fim trata do aspecto do consumo energético específico;

- potencial de eficiência energética: inicialmente é definida a metodologia de cálculo, que é baseada na comparação do consumo energético específico com valores obtidos de referências da literatura técnica; depois os resultados são apresentados e, em alguns casos, comparados com valores obtidos do Balanço de Energia Útil;

- barreiras ao uso racional de energia: traz uma breve apresentação sobre as possíveis barreiras ao uso racional de energia segundo informações levantadas em análises da literatura técnica que depois foram validadas com os comentários dos técnicos e dirigentes das indústrias visitadas.

Dessa forma, esses relatórios se constituem uma significativa referência para estudos de potencial de economia de energia na indústria brasileira, devido à elevada quantidade de informações que foram coletadas e resultados disponibilizados, mas também porque esses resultados obtidos através da literatura técnica (dados secundários) foram debatidos e confrontados em discussão com pessoas que atuam nos respectivos setores (dados primários). Por fim, cabe mencionar que a produção desse estudo foi orientada por Sérgio Valdir Bajay, fundador e professor do Programa de Pós-Graduação em Planejamento de Sistemas Energéticos da Universidade Estadual de Campinas (UNICAMP), e Paulo Henrique de Mello Sant'Ana, professor do Programa de Pós-Graduação em Energia da Universidade Federal do ABC (UFABC). As atividades relacionadas ao desenvolvimento desse projeto, por esses pesquisadores, geraram outras publicações correlatas, tanto no formato de trabalhos acadêmicos, como o de Gorla (2009), como no de artigos publicados em periódicos científicos nacionais, como o de Bajay, Gorla e Bordoni (2009), e internacionais, como o de Santana e Bajay (2016). 


\subsection{Avaliação sob aspecto da promoção dos gases combustíveis}

Uma outra abordagem de avaliação do uso da energia no setor industrial utilizada envolve o aspecto da promoção dos gases combustíveis. Do ponto de vista histórico, essas avaliações são mais recentes, em comparação às de aspecto de eficiência energética, e, na sua maioria, têm como origem a orientação no sentido de suportar uma proposta de política energética em função da disponibilização de um recurso natural energético, em particular o gás natural. As evidências remontam aos anos 2000, na esteira da entrada em operação do Gasbol, como o "Plano de Massificação do Uso de Gás Natural" da Petrobras (SAUER, 2003), e vão até ações mais recentes, em função da crescente produção do Pré-Sal, como iniciativas como o “Gás para Crescer” do Governo Federal (MME, 2016).

A presente dissertação está, nessa perspectiva histórica, incluída como um estudo direcionado a suportar a promoção do gás natural dentro do contex to da crescente produção do Pré-Sal. Assim, foram levantados alguns estudos acadêmicos desenvolvidos ao longo dos anos 2000 que guardassem essa mesma motivação, mas com o contexto histórico da entrada em operação do Gasbol. Foram selecionados dois trabalhos acadêmicos, que serão apresentados a seguir, um desenvolvido na COPPE - UFRJ, e publicado em 2000, e um desenvolvido no IEE - USP, e publicado em 2004.

\subsubsection{Estudo desenvolvido na COPPE - UFRJ}

Esse trabalho acadêmico é a dissertação de mestrado de Paulo Marcelo de Figueiredo Montes, desenvolvida no âmbito do Programa de Pós-Graduação de Planejamento Energético do Instituto Alberto Luiz Coimbra de Pós-Graduação e Pesquisa de Engenharia (COPPE) da Universidade Federal do Rio de Janeiro (UFRJ) sob a orientação de Roberto Schaeffer e defendida em 2000. O título da dissertação é “O potencial do consumo de gás natural pelo setor industrial no Brasil" (MONTES, 2000). 
O objetivo da dissertação era avaliar o potencial de consumo de gás natural pelo Setor Industrial no Brasil no período 1998-2010, estimando também eventuais ganhos de eficiência energética e benefícios ambientais obtidos em decorrência da maior utilização do gás natural. Esse trabalho acadêmico também foi publicado como um artigo na Revista Brasileira de Energia (MONTES e SCHAEFFER, 2000), organizada pela Sociedade Brasileira de Planejamento Energético (SBPE).

O trabalho foi desenvolvido com uma metodologia direcionada por uma modelagem analítica para realizar a previsão do consumo em função de três indicadores: consumo específico de energia por uso final, produção física e nível de substituição entre combustíveis. Dessa forma, os setores industriais são estudados em um primeiro cenário em que o crescimento do consumo de todos os tipos de energia se dá somente pelo crescimento vegetativo da produção física, ou seja, não há substituição entre combustíveis. Depois desse cenário, são construídos dois outros onde o gás natural substitui outros tipos de energia final em dados usos finais (MONTES, 2000).

No segundo cenário ocorre a substituição gradual de outros energéticos por gás natural em processos térmicos, seja com uso final de calor de processo ou de aquecimento direto, de forma que a participação do gás natural em um dado setor industrial brasileiro em 2010 seja correspondente ao mesmo nível do mesmo setor industrial dos países europeus da OCDE em 1996. Já no terceiro cenário o processo de substituição é o mesmo, mas ao final do horizonte de tempo analisado o gás natural passa a suprir toda a demanda dos usos finais de processos térmicos. $\mathrm{O}$ autor trata o segundo cenário como moderado de penetração do gás natural, algo que pudesse ser observado para estudos de políticas energéticas para o fomento do uso do gás natural no setor industrial, ao passo que o terceiro cenário é caracterizado como uma "hipótese economicamente absurda" (MONTES, 2000), cujo objetivo é delimitar a fronteira possível de expansão do consumo de gás natural.

Dentre os resultados apresentados, destacam-se, além do aumento na participação do gás natural como energia final nos setores estudados, o aumento do nível de eficiência energética dos setores industriais e o impacto sobre as emissões de $\mathrm{CO}_{2}$. O primeiro resultado era o foco principal de estudo, dado que o objetivo do trabalho era avaliar o potencial de incremento do consumo de gás natural na indústria. $\mathrm{O}$ segundo resultando decorre do fato de que a queima do gás natural é mais eficiente que de outros combustíveis fósseis e que os 
equipamentos a gás natural também costumam apresentar maior eficiência. Finalmente, o último resultado é função do tipo de energia que está sendo substituída, havendo impacto positivo (redução de emissões) quando a substituição é de outros combustíveis fósseis e impacto negativo (aumento nas emissões) quando a substituição é de eletricidade ou renováveis como biomassa (MONTES, 2000).

\subsubsection{Estudo desenvolvido no IEE - USP}

O estudo considerado do IEE - USP é a dissertação de mestrado de Alexandre Betinardi Strapasson, desenvolvida no âmbito do Programa de Pós-Graduação em Energia do Instituto de Energia e Ambiente (IEE) da Universidade de São Paulo (USP) ${ }^{31}$ sob a orientação de Murilo Tadeu Werneck Fagá e defendida em 2004 (STRAPASSON, 2004). O título da dissertação é “A Energia Térmica e o Paradoxo da Eficiência Energética: Desafios para um Novo Modelo de Planejamento Energético". Durante o desenvolvimento do trabalho o autor produziu

publicações que apresentaram seus resultados em congresso (STRAPASSON e FAGÁ, 2004b), em periódico científico nacional (STRAPASSON e FAGÁ, 2004a) e também internacional (STRAPASSON e FAGÁ, 2007).

O objetivo da dissertação era identificar o que foi considerado como uma distorção no atual modelo energético nacional, que é o uso de eletricidade para fins térmicos, e avaliar o potencial de economia de energia primária que poderia ser obtido através da substituição da eletricidade nesses usos pela energia química contida nos combustíveis, particularmente os gases combustíveis. Também é feita uma avaliação do impacto ambiental dessa substituição, observando a emissão de $\mathrm{CO}_{2}$ e $\mathrm{NO}_{\mathrm{x}}$. Como metodologia para estimar os potenciais de economia de energia primária através da substituição da eletricidade por energia química em processos térmicos, o autor dividiu seu trabalho em duas partes, a primeira consiste numa

\footnotetext{
31 À época era denominado Programa Interunidades de Pós-Graduação em Energia - Escola Politécnica / Faculdade de Economia, Administração e Contabilidade / Instituto de Eletrotécnica e Energia / Instituto de Física (EP / FEA / IEE / IF) da Universidade de São Paulo (USP).
} 
metodologia de cálculo que relaciona a substituição com o impacto de economia de energia primária e a segunda que estima o percentual de substituição (STRAPASSON, 2004).

A primeira parte faz a relação entre a energia química e a eletricidade utilizadas no uso final considerado e traz as duas em bases de energia primária, contudo, sem considerar perdas de transmissão e distribuição, no caso da eletricidade, e produção, transporte e distribuição, no caso da energia química. Uma premissa básica nessa metodologia de cálculo é que a eletricidade substituída é convertida em energia primária com um rendimento médio de 40\%. Já a segunda parte da metodologia, com uma base de dados sobre o consumo de energia em âmbito internacional, foi estimado o percentual de substituição considerando que, após a substituição, o nível da participação da eletricidade em relação ao total de energia consumida nos setores industriais analisados se equipararia à uma média observada nessa base de dados, no caso chamado de moderado, e ao valor inferior observado nessa base de dados, no caso chamado de agressivo. Na seleção dos países, o autor utiliza filtros para determinar os países relevantes, como a necessidade de o setor avaliado ter um consumo superior a $10 \%$ do consumo total do respectivo setor brasileiro (STRAPASSON, 2004).

Os resultados obtidos pelo autor são apresentados de forma desagregada no aspecto do potencial de economia de energia primária, para os dois casos (moderado e agressivo). Já outras análises são apresentadas de forma agregada, como a comparação entre a demanda gerada por gás natural (uma forma de energia química considerada pelo autor) e a capacidade do Gasbol, assim como a análise do impacto ambiental na forma de emissões de $\mathrm{CO}_{2}$ e $\mathrm{NO}_{\mathrm{x}}$ (STRAPASSON, 2004).

\subsection{Considerações finais do capítulo 2}

Os estudos apresentados neste capítulo mostraram algumas formas de avaliação do uso da energia no setor industrial brasileiro, tendo sido apresentadas duas abordagens identificadas na literatura que guardam relação com a temática desta dissertação: a que estuda o assunto sob o aspecto da eficiência energética e a que o estuda sob o aspecto da promoção dos gases combustíveis. 
Dentro da primeira abordagem, a referência mais significativa é o estudo desenvolvido pela parceria CNI/Eletrobras. Esse estudo é uma significativa referência para pesquisas de potencial de economia de energia na indústria brasileira, contendo uma grande quantidade de informações de dados secundários validados com dados primários. Ainda que o aspecto da eficiência energética não seja o foco principal do estudo desta dissertação, esse trabalho é uma referência a ser observada para comparações na análise do quadro de uso da energia no setor industrial brasileiro.

Da abordagem vertente, dois são os estudos mais significativos. O primeiro, de Montes (2000), é significativo por ser um dos primeiros estudos a trabalhar com a possibilidade de aumento da penetração do gás natural no setor industrial brasileiro, no contexto da entrada em operação do Gasbol. O segundo, de Strapasson (2004), é um estudo de substituição no uso final de energia visando a economia de energia primária através da inserção de energia química, o gás natural é um exemplo. Este trabalho foi a principal referência e fonte de inspiração para o desenvolvimento dos estudos dessa dissertação. 


\section{TÉCNICA DE ANÁlISE DE DAdOS PARA AVALIAÇão DE SUBSTITUIÇÕES NO USO FINAL DE ENERGIA E SEUS IMPACTOS ENERGÉTICO, AMBIENTAL E ECONÔMICO}

Este capítulo apresenta a proposta de uma técnica de análise de dados para a avaliação de substituições no uso final de energia e seus impactos energético, ambiental e econômico. $\mathrm{O}$ princípio que norteia a construção dessa técnica é a replicabilidade, ou seja, sua elaboração é feita de modo amplo para que ela possa ser aplicada em diferentes casos e que, assim, os resultados possam ser comparados entre si, em diferentes cenários e hipóteses, ou ainda realizar uma composição para diagnóstico de um quadro energético maior, como avaliação conjunta com outros setores como o residencial.

O presente capítulo está dividido em três seções. Na primeira seção é feita uma a discussão conceitual sobre como representar a substituição e seus impactos com elementos no formato de indicadores. Após a definição do conceito que motiva o estabelecimento de cada indicador são apresentadas, na segunda seção, as formulações de cada um deles.

Na conceituação e na formulação dos indicadores, fica evidenciada a importância do diagnóstico do potencial de substituição para a aplicação da técnica de análise de dados aqui apresentada. Uma subseção é dedicada ao mecanismo de estimação do potencial de substituição, onde são apontadas duas soluções de análise de benchmark $^{32}$ para essa avalição.

Na terceira seção, ao final deste capítulo, são apresentadas considerações finais, particularmente no que diz respeito a uma sugestão de etapas a serem seguidas para a aplicação da técnica de análise de dados.

\footnotetext{
32 O termo benchmark é usado nesta dissertação para denotar um processo de comparação entre um elemento que se quer avaliar e este elemento em determinada referência, que pode ser de fonte primária ou secundária (dados coletados em campo ou pesquisa bibliográfica, respectivamente).
} 


\subsection{Conceituação dos indicadores}

O objetivo dos indicadores é representar os aspectos envolvidos na avaliação da substituição no uso final de energia e seus impactos. Dessa forma, optou-se por construir quatro indicadores: um indicador para representar a substituição em si e um indicador para cada um dos aspectos a serem considerados, o energético, o ambiental e o econômico. A conceituação dos quatro indicadores será apresentada nas subseções a seguir.

\subsubsection{A substituição no uso final de energia}

A substituição no uso final de um tipo de energia final por outro, ceteris paribus, irá levar à redução da demanda do primeiro e ao aumento da demanda do segundo. Assim, a substituição pode ser representada tanto pela redução da demanda do tipo de energia substituído como pela demanda adicional do tipo de energia que faz a substituição.

A opção escolhida para esta técnica de análise de dados foi representar a redução da demanda do tipo de energia substituído por um parâmetro denominado "potencial de substituição", que representará qual porcentagem de um dado tipo de energia final será substituída por outro tipo de energia final promovido no uso final considerado para o setor industrial tratado. Já a demanda adicional, que será criada para o tipo de energia final que é inserido de modo a promover a substituição do outro tipo de energia final, será representada por um indicador a ser formulado. Essa escolha tem objetivo de orientar a técnica de análise de dados no sentido da sua aplicação em estudos de promoção de determinado tipo de energia final.

Assim, o indicador a ser formulado para representar a promoção via substituição no uso final de energia será denominado "Demanda Adicional (DA)". Outros estudos fazem análise do potencial de consumo de gás natural no setor industrial brasileiro, tratando assim de assuntos correlacionados a este indicador, como Carmo e Santos (2014), além dos trabalhos já citados de Montes (2000) e Montes e Schaeffer (2000), e também em certa medida os de Fernandes 
(2004), Strapasson (2004), Strapasson e Fagá (2007), Fernandes (2008) e Costa (2013), esses últimos dedicados a gases combustíveis ou energia química mais genericamente.

\subsubsection{O aspecto energético através do consumo de energia primária}

O primeiro impacto da substituição no uso final de energia representará a aspecto energético. Quando observado o quadro energético de forma mais holística, o mais indicado é observar o impacto da substituição na demanda de energia primária. Assim, eliminam-se possíveis vantagens (ou desvantagens) comparativas de determinados tipos de energia final que passam por transformações intermediárias antes de serem disponibilizados para o uso final, como apresentado no diagrama da Figura 3.1. Outro motivador para avaliação na forma de energia primária é que essa é uma forma de se representar o recurso natural energético, o que guarda relação com as ideias de sustentabilidade do uso da energia. Essa análise holística do uso da energia reflete a questão da relação entre qualidade exergética da energia em função do uso final, ou seja, da energia útil requerida, como apresentado nos trabalhos de Strapasson (2004), Fernandes (2008), Cursino dos Santos (2011) e De Stercke (2014).

Figura 3.1 - Diagrama esquemático dos níveis de transformação de energia

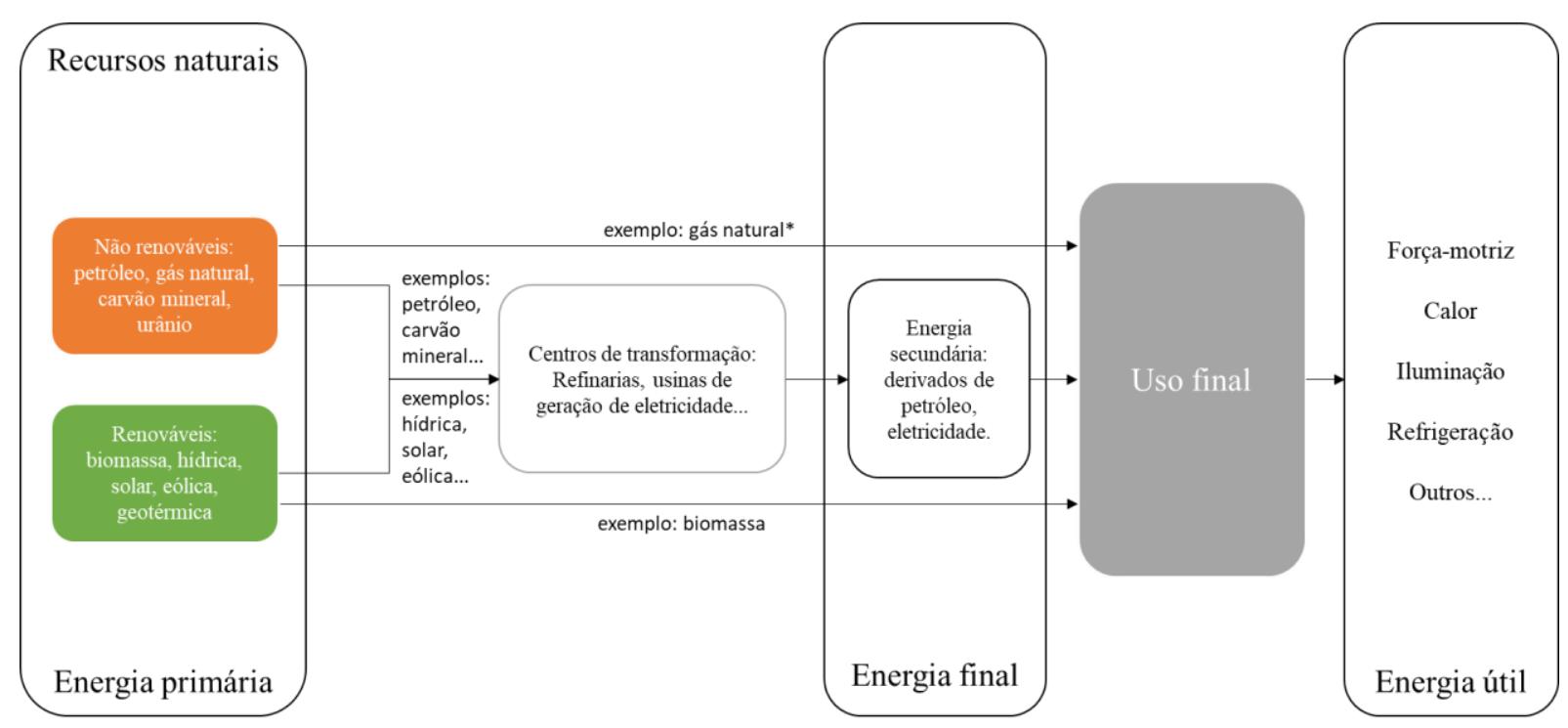

Fonte: Elaboração própria, baseado em Stanek et al. (2017).

Nota: O gás natural passa por processamento antes de ser usado como energia final, mas não se caracteriza como uma transformação, sendo assim uma fonte de energia primária que pode ser usada diretamente como energia final. 
Essa visão holística também é apresentada, por exemplo, no trecho abaixo, disponível em uma página intitulada "Primary Energy Efficiency (ou Eficiência em Energia Primária)" da American Public Gas Association (APGA):

[...] devemos começar a olhar para o ciclo de vida completo ao medir o uso de energia: considerando o uso de energia a partir do ponto de extração, [...], de modo contínuo até seu uso final. A linguagem acima menciona claramente a intenção de que a política de eficiência energética aborde os recursos energéticos de forma holística. (APGA, 2018, tradução nossa)

Assim, o indicador a ser formulado para representar o aspecto energético fará o rebatimento em energia primária do impacto na demanda de energia final devido à substituição, sendo denominado "Impacto em Energia Primária (IEP)". Estudos internacionais também adotam postura semelhante, como o de ADAPT Consulting (2013), Leslie (2014) e Esser e Sensfuss (2016) onde são discutidas questões de rebatimento para energia primária de tipos de energia final e formas para calcular os fatores de conversão para cada tipo de energia final em função de diferentes cenários, particularmente no caso de geração de eletricidade.

\subsubsection{Fator de Conversão em Energia Primária (FCEP)}

Fatores de conversão em energia primária podem ser estimados através de diferentes formas como nas referências apresentadas anteriormente. Como o objetivo desta técnica de análise de dados é ser mais simples para que possa ser replicada, uma forma de cálculo simplificado desses fatores será adotada. As fronteiras de análise do fator de conversão de energia primária (FCEP) serão o nível de consumo de energia final e o nível de oferta interna bruta de energia primária. Em outras palavras, apenas as perdas nos centros de transformação, no transporte/transmissão e na distribuição estarão cobertas, ficando fora de escopo as perdas na exploração e produção das fontes de energia primária.

Tomando em considerando essas delimitações, o fator de conversão de energia primária para um tipo de energia final analisado $\left(\mathrm{FCEP}_{\mathrm{i}}\right)$ pode ser calculado através da Equação 3.1: 
$\operatorname{FCEP}_{\mathrm{i}}=\left(1 / \eta_{\mathrm{CTi}}\right) /\left(1-\mathrm{P}_{\mathrm{T} \& \mathrm{D}, \mathrm{i}}\right)$

Onde:

FCEP $_{\mathrm{i}}$ é o fator de conversão em energia primária do tipo de energia final analisado;

$\eta_{\mathrm{CTi}}$ é a eficiência do centro de transformação do tipo de energia final analisado;

$\mathrm{P}_{\mathrm{T \& D}, \mathrm{i}}$ é a porcentagem de perdas na transmissão/transporte e distribuição do tipo de energia final analisado.

O caso específico da eletricidade merece uma análise mais detalhada, sendo possível duas abordagens. Numa primeira, o fator de conversão é baseado no mix de geração de eletricidade, sendo chamado de fator de conversão médio (FCEP $\left.\mathrm{E}_{\mathrm{E} \text { médio}}\right)$, dado pela Equação 3.2:

$\mathrm{FCEP}_{\mathrm{E}, \text { médio }}=\left(\% \mathrm{GR}+\% \mathrm{GT} / \eta_{\mathrm{GT} \text {,médio }}\right) /\left(1-\mathrm{P}_{\mathrm{T} \& \mathrm{D}, \mathrm{E}}\right)$

Onde:

$\mathrm{FCEP}_{\mathrm{E} \text {,médio }}$ é o fator de conversão em energia primária médio da eletricidade, \%GR é a participação no mix de geração das fontes renováveis não térmicas (como as fontes hidroelétricas, eólica, solar fotovoltaica, entre outras); \%GT é a participação no mix de geração da termoeletricidade (incluindo uso de combustíveis fósseis, nuclear e fontes renováveis como biomassa, solar térmica e geotérmica, por exemplo);

$\eta_{\mathrm{GT}, \text { médio }}$ é o rendimento médio da geração termoelétrica presente no mix de geração;

$\mathrm{P}_{\mathrm{T \& D}, \mathrm{E}}$ é a porcentagem de perdas na transmissão e distribuição de eletricidade.

Numa segunda abordagem, o fator de conversão é baseado apenas na geração termoelétrica com uso de combustíveis fósseis, sendo chamado de fator de conversão marginal (FCEP $\left.{ }_{\text {E,marginal }}\right)$, dado pela Equação 3.3:

$\operatorname{FCEP}_{\text {E,marginal }}=\left(1 / \eta_{\mathrm{GTf} \text {,médio }}\right) /\left(1-\mathrm{P}_{\mathrm{T \& D}, \mathrm{E}}\right)$

Onde:

$\mathrm{FCEP}_{\mathrm{E} \text {,marginal }}$ é o fator de conversão em energia primária marginal da eletricidade;

$\eta_{\mathrm{GTf} \text {,médio }}$ é o rendimento médio da geração termoelétrica com uso de combustíveis fósseis presente no mix de geração;

$\mathrm{P}_{\mathrm{T \& D}, \mathrm{E}}$ é a porcentagem de perdas na transmissão e distribuição de eletricidade.

A motivação que baseia essa segunda abordagem está no fato de que quando uma medida de substituição energética é implementada e reduz a demanda de eletricidade, esta última é deslocada em sua margem que, geralmente, é suprida por geração termoelétrica com uso de combustíveis fósseis. No limite, poder-se-ia fazer uma análise média das usinas termoelétricas que são acionadas na margem para uma avaliação mais precisa, entretanto optase por simplificar a análise considerando o rendimento médio da geração termoelétrica com uso de combustíveis fósseis presente no mix de geração. 


\subsubsection{O aspecto ambiental através das emissões de $\mathrm{CO}_{2}$}

O aspecto ambiental é representado pelo segundo impacto da substituição no uso final de energia. Contudo, o aspecto ambiental do uso da energia abrange desde questões de poluição local até os efeitos das mudanças climáticas. Assim, para tratar do quadro ambiental de forma global, será observado o impacto da substituição nas emissões de gases de efeito estufa (GEE), tendo em vista que o uso de energia é o maior responsável pelas emissões de GEE antropogênicas, como apresentado na Figura 3.2, e essas emissões são majoritariamente de $\mathrm{CO}_{2}$ (cerca de 90\%) e $\mathrm{CH}_{4}$ (cerca de 10\%), segundo IEA (2014).

Figura 3.2 - Distribuição das emissões globais de gases de efeito estufa por setor (ano base 2014)

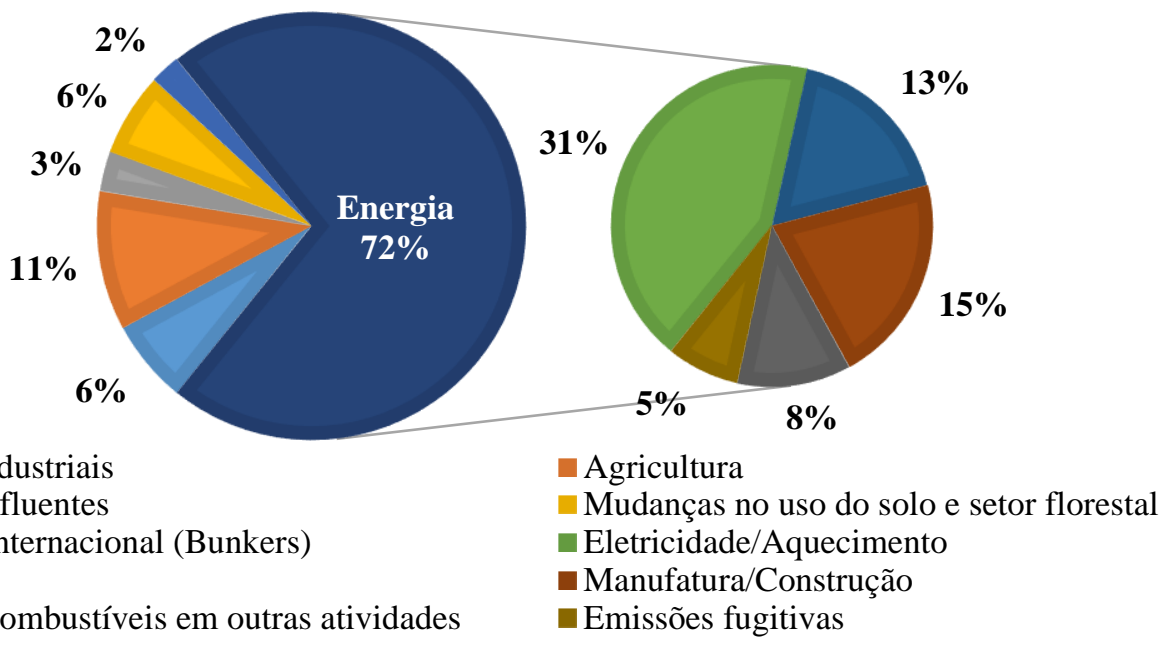

Fontes: WRI (2017) e FAO (2017b).

Da mesma forma que para o fator de conversão em energia primária, deve ser feita uma delimitação das fronteiras de análise. Neste caso, a fronteira de análise das emissões se restringe ao uso final para todos tipos de energia final, exceto para a eletricidade, para a qual será considerada a emissão no seu centro de transformação (ou seja, no parque gerador). Assim, além do $\mathrm{CO}_{2}$, um outro GEE que poderia ser considerado é o $\mathrm{NO}_{\mathrm{x}}$. Na realidade, o $\mathrm{NO}_{\mathrm{x}}$ potencializa o impacto dos outros GEE (HARVEY, 1993), mas alguns autores estimam seu potencial de aquecimento global (GWP, sigla em inglês para global warming potential) ${ }^{33}$, como

\footnotetext{
${ }^{33}$ Potencial de aquecimento global ou global warming potential (GWP) é uma medida relativa de como uma determinada quantidade de GEE contribui para o aquecimento global em relação a mesma quantidade de dióxido de carbono (cujo potencial é definido como 1). O GWP é calculado sobre um intervalo de tempo específico, que deve ser declarado para a comparação. (IPCC,)
} 
Lammel e Grabl (1995) que apontam o GWP do $\mathrm{NO}_{\mathrm{x}}$ como 7 a 10 vezes o do $\mathrm{CO}_{2}$, na escala de tempo de 100 anos, e, a título de comparação, nessa mesma escala o GWP do $\mathrm{CH}_{4}$ é de 21 (IPCC, 2018). Contudo, a taxa de emissão de $\mathrm{NO}_{\mathrm{x}}$ é baixa comparada à do $\mathrm{CO}_{2}$, conforme apresentado por Strapasson (2004). Assim, ainda que multiplicado pelo GWP do $\mathrm{NO}_{\mathrm{x}}$, a emissão de $\mathrm{NO}_{\mathrm{x}}$ representaria pouco mais de $2 \%$ da emissão $\mathrm{CO}_{2}$.

Dessa forma, o indicador levará em conta apenas as emissões de $\mathrm{CO}_{2}$ e o indicador a ser formulado para representar o aspecto ambiental será denominado "Impacto em Emissões de Carbono (IEC)". Estudos internacionais também adotam postura semelhante ao analisar somente as emissões de $\mathrm{CO}_{2}$, como o de ADAPT Consulting (2013).

\subsubsection{Fator de emissão de $\mathrm{CO}_{2}$ (FEm)}

$\mathrm{O}$ fator de emissão de $\mathrm{CO}_{2}$ para um tipo de energia final analisado é dado na forma de uma quantidade de emissões de $\mathrm{CO}_{2}$ por unidade desse tipo de energia considerada. Para os combustíveis fósseis podem ser adotados os valores apresentados pelo IPCC (1997), incluindo sua metodologia para cálculo dos fatores, quando aplicável. Já o caso da eletricidade apresenta uma diversidade maior de formulações possíveis, merecendo uma avaliação mais detalhada.

O fator de emissão de $\mathrm{CO}_{2}$ para a eletricidade é função da participação da geração termoelétrica com uso de combustíveis fósseis no mix de geração de eletricidade. Novamente, há possibilidade de se estabelecer um fator médio e um fator marginal, aos moldes do que foi apresentado na Subseção 3.1.2.1 para o fator de conversão em energia primária, expressos pelas Equações 3.4 e 3.5:

$\mathrm{FEm}_{\mathrm{E}, \text { médio }}=\% \mathrm{GTf} . \mathrm{FEm}_{\mathrm{GTf}}$

Onde:

$\mathrm{FEm}_{\mathrm{E} \text {,médio }}$ o fator de emissão de $\mathrm{CO}_{2}$ médio da eletricidade;

\%GTfé a participação no mix de geração de eletricidade da geração termoelétrica com uso de combustíveis fosseis; $\mathrm{FEm}_{\mathrm{GTf}}$ é fator de emissão de $\mathrm{CO}_{2}$ da geração termoelétrica com uso de combustíveis fósseis presente no mix de geração. 
$\mathrm{FEm}_{\mathrm{E}, \text { marginal }}=\mathrm{FEm}_{\mathrm{GTf}}$

Onde:

$\mathrm{FEm}_{\mathrm{E} \text {,marginal }}$ ó fator de emissão de $\mathrm{CO} 2$ marginal da eletricidade;

$\mathrm{FEm}_{\mathrm{GTf}}$ é fator de emissão de $\mathrm{CO} 2$ da geração termoelétrica com uso de combustíveis fósseis presente no mix de geração.

\subsubsection{O aspecto econômico através do custo energético}

Finalmente, o aspecto econômico é representado pelo terceiro impacto da substituição no uso final de energia a ser avaliado. A avaliação econômica de um investimento envolve alguns elementos como, por exemplo, o investimento inicial, o fluxo de receitas geradas, o fluxo de despesas realizadas (ASSAF NETO, 1992). No caso da substituição de um tipo de energia final por outro, o investimento inicial geralmente está associado à troca de equipamentos; o fluxo de receitas geradas advindo da redução no custo energético, ou seja, a diferença no custo de aquisição dos tipos de energia final envolvidos na substituição; e o fluxo de despesas realizadas relativas aos custos envolvidos em operação e manutenção. Esses elementos também aparecem em análises de custo de energia economizada, como em Shen (2017).

A avaliação do investimento depende fortemente do tipo tecnológico e de configurações das instalações físicas onde se dá o processo de uso final de energia. Os custos de manutenção e operação, a priori, são elementos mais ligados à questão de mão-de-obra, mas também dependem do processo de uso final de energia. Tendo em vista essas considerações, o indicador só levará em consideração o impacto no custo energético. Assim, o indicador a ser formulado para representar o aspecto econômico será denominado "Impacto em Custo Energético (ICE)".

\subsubsection{Considerações finais da conceituação dos indicadores}

De forma geral, a conceituação dos indicadores pode ser representada através do diagrama a seguir, apresentado na Figura 3.3: 
Figura 3.3 - Diagrama geral dos aspectos, conceitos e indicadores da técnica de análise de dados

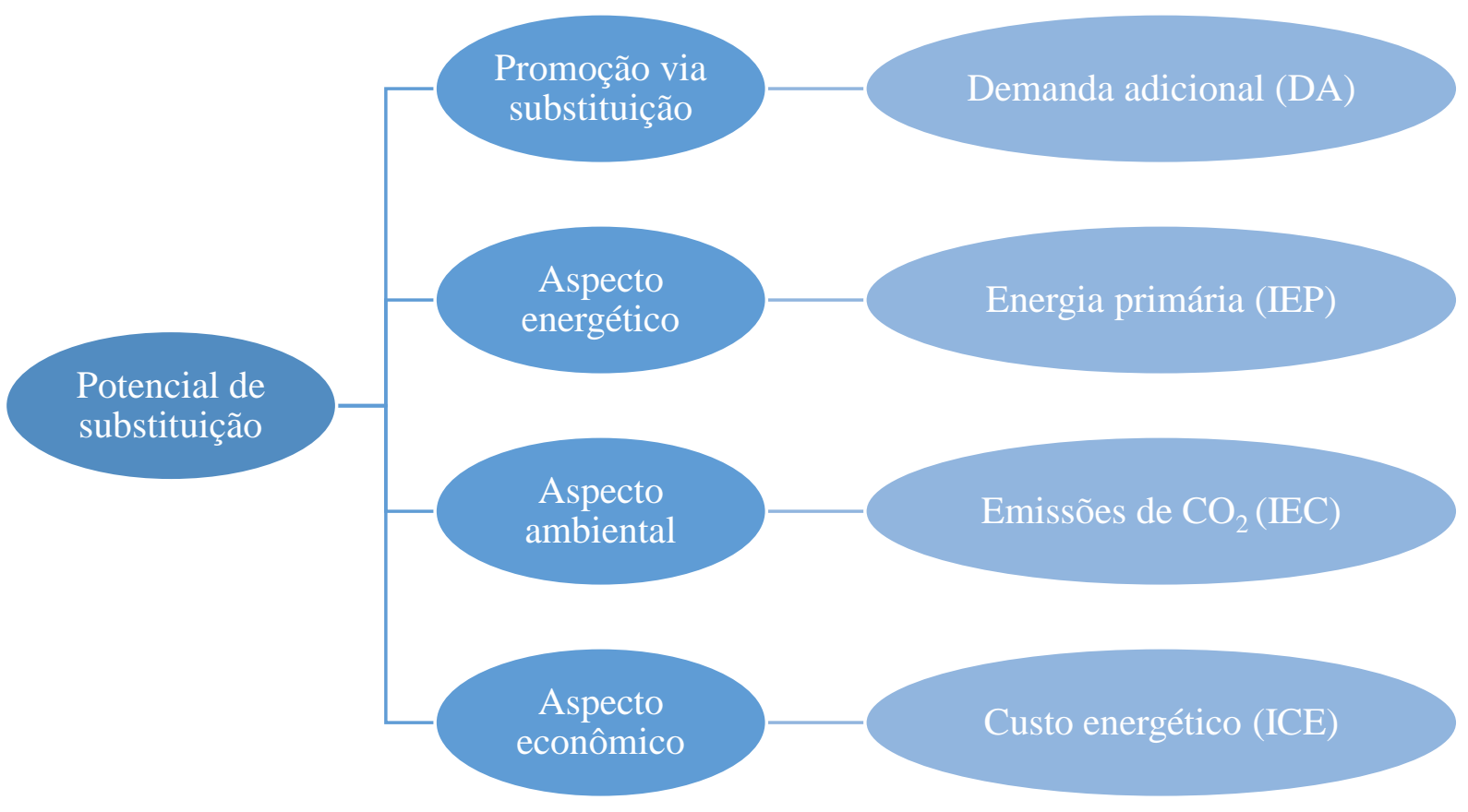

Fonte: Elaboração própria

A partir de um contexto de substituição, pode-se estimar então um potencial de substituição, através do qual são calculados os quatro indicadores represetando os elementos de interesse para a presente técnica de análise de dados. A formulação dos indicadores e do mecanismo de estimação de potencial de substituição será apresentada na seção a seguir.

\subsection{Formulação dos indicadores}

Nesta seção ${ }^{34}$ é apresentada a formulação dos indicadores, baseada para um uso final específico de um dado setor industrial, na substituição de um tipo de energia final por outro tipo de energia final que se deseja promover, como, por exemplo, o gás natural. Assim, se mais de

${ }^{34}$ Serão usados ao longo desta seção uma série de siglas e símbolos, as primeiras serão explicadas com o decorrer das formulações e os últimos, mais recorrentes, são usados para identificar genericamente os seguintes elementos: 's' para um setor industrial, 'u' para um uso final, 'f' para um tipo de energia final a ser substituída e 'p' para um tipo de energia final a ser promovida. 
um tipo de energia final for substituída e/ou se mais de um uso final for considerado, os indicadores devem ser avaliados separadamente e depois agregados apropriadamente, como será exposto nas subseções a seguir.

A formulação dos indicadores e do mecanismo de estimação do potencial de substituição está descrita nas cinco subseções a seguir em uma estrutura detalhada, seguida de uma subseção para considerações finais. Por uma questão didática, decidiu-se começar a apresentação da formulação pelo indicador DA, em seguida, o mecanismo de estimação do potencial de substituição, e depois a formulação dos outros indicadores.

\subsubsection{Indicador de Demanda Adicional (DA)}

Para a construção do indicador DA, deve-se primeiramente definir o contexto de substituição, composto pelos seguintes elementos:

- tipo de energia final promovida, aquela que irá substituir outros tipos de energia final e cuja demanda adicional será calculada por este indicador;

- tipo de energia final substituída;

- uso final de energia considerado na substituição;

- o setor industrial tratado na substituição.

Em seguida, deve-se elaborar um balanço de energia final por uso final ${ }^{35}$ que contemple os tipos de energia final substituídas, os usos finais considerados e os setores industriais tratados que foram definidos no passo anterior.

\footnotetext{
${ }^{35}$ Esse balanço pode ser elaborado diretamente a partir de balanços de energia final por uso final, como por exemplo MME/FDTE (2005) e EIA (2013). Uma alternativa caso não exista um balanço desse tipo para o país analisado, utiliza-se o balanço de energia final complementado com a estudos de tragam informações sobre a repartição da destinação da energia final em função dos usos finais, como por exemplo, Fleiter et al. (2016). Esse complemento também pode ser feito através de pesquisa de campo, quando possível. É fundamental que esse balanço seja construído com os dados de energia em uma unidade comum, de preferência um múltiplo de joules (J) a depender da escala do balanço, pois os diferentes tipos de energia serão comparados e transformados entre si, o que não seria possível utilizando unidades especificas em cada tipo de energia final (como $\mathrm{kWh}$ para eletricidade, $\mathrm{m}^{3}$ para gás natural e assim por diante).
} 
Especifica-se então a porcentagem do tipo de energia final substituída nesse uso final considerado que será efetivamente substituída no setor industrial tratado. Assim, pode ser calculada a energia final substituída em unidades de energia (ex. TJ) a partir da Equação 3.6:

EFsubs $_{\mathrm{s}, \mathrm{u}, \mathrm{f}}=\mathrm{EF}_{\mathrm{s}, \mathrm{u}, \mathrm{f}} \cdot \%_{\mathrm{subs}_{\mathrm{s}, \mathrm{u}, \mathrm{f}, \mathrm{p}}}$

Onde:

EFsubs $_{\mathrm{s}, \mathrm{u}, \mathrm{f}}$ é a energia final substituída no uso final considerado para o setor industrial tratado; $\mathrm{EF}_{\mathrm{s}, \mathrm{u}, \mathrm{f}}$ é a demanda de energia final do tipo substituído no uso final considerado para o setor industrial tratado;

$\%_{\text {subs }}^{\text {s,uff,p }}$ é a porcentagem do tipo de energia final substituída no uso final considerado para o setor industrial tratado.

A partir do valor calculado na Equação 3.6 é possível calcular a demanda de energia útil coberta pela energia final substituída através da Equação 3.7:

$\operatorname{DEUsubs}_{\mathrm{s}, \mathrm{u}, \mathrm{f}}=$ EFsubs $_{\mathrm{s}, \mathrm{u}, \mathrm{f}} \cdot \eta_{\mathrm{s}, \mathrm{u}, \mathrm{f}}$

Onde:

DEUsubs $_{\mathrm{s}, \mathrm{u}, \mathrm{f}}$ é a demanda de energia útil coberta pela energia final substituída no uso final considerado para o setor industrial tratado;

EFsubs $_{\mathrm{s}, \mathrm{u}, \mathrm{f}}$ é a energia final substituída no uso final considerado para o setor industrial tratado;

$\eta_{\mathrm{s}, \mathrm{u}, \mathrm{f}}$ é a eficiência do equipamento de uso final considerado do tipo de energia final substituída para o setor industrial tratado.

Finalmente é possível calcular o valor do indicador DA, ou seja, a demanda adicional pela energia final promovida que será necessária para suprir a mesma energia útil calculada na Equação 3.7, através da Equação 3.8:

$\mathrm{DA}_{\mathrm{s}, \mathrm{u}, \mathrm{f}, \mathrm{p}}=\mathrm{DEUsubs}_{\mathrm{s}, \mathrm{u}, \mathrm{f}} / \eta_{\mathrm{s}, \mathrm{u}, \mathrm{p}}$

Onde:

$\mathrm{DA}_{\mathrm{s}, \mathrm{u}, \mathrm{f}, \mathrm{p}}$ é a demanda adicional pela energia final promovida, substituindo um dado o tipo de energia final no uso final considerado para o setor industrial tratado;

DEUsubs $_{\mathrm{s}, \mathrm{u}, \mathrm{f}}$ é a demanda de energia útil coberta pela energia final substituída no uso final considerado para o setor industrial tratado;

$\eta_{\mathrm{s}, \mathrm{u}, \mathrm{p}}$ é a eficiência do equipamento de uso final considerado do tipo de energia final promovida para o setor industrial tratado.

A demanda adicional calculada na Equação 3.8 está dada em unidades de energia (ex. TJ). Para expressar essa demanda em unidades físicas (ex. $\mathrm{m}^{3}$ ) basta multiplicar o valor do indicador obtido pelo fator de conversão correspondente. 
Caso mais de um tipo de energia final for substituída e/ou se mais de um uso final for considerado, o indicador de demanda adicional deve ser avaliado separadamente caso-a-caso e depois agregado. Não há prioridade na soma, se agregado primeiro em função da energia final substituída ou em função do uso final considerado. Assim, a demanda adicional pela energia final promovida no setor industrial tratado é dada pela soma das demandas adicionais calculadas caso-a-caso, como na Equação 3.9:

$$
\mathrm{DA}_{\mathrm{s}, \mathrm{p}}=\sum_{\mathrm{u}} \sum_{\mathrm{f}} \mathrm{DA}_{\mathrm{s}, \mathrm{u}, \mathrm{f}, \mathrm{p}}
$$

Onde:

$\mathrm{DA}_{\mathrm{s}, \mathrm{p}}$ é a demanda adicional pela energia final promovida para o setor industrial tratado;

$\mathrm{DA}_{\mathrm{s}, \mathrm{u}, \mathrm{f}, \mathrm{p}}$ é a demanda adicional pela energia final promovida, substituindo um dado tipo de energia final no uso final considerado para o setor industrial tratado.

\subsubsection{Mecanismo de estimação do potencial de substituição}

Com o contexto de substituição definido no início do desenvolvimento do indicador DA, o processo de estimação do potencial de substituição parte do seguinte encadeamento lógico:

a) existe uma referência de melhor técnica ou de melhor prática disponível no uso final considerado para o setor industrial tratado onde a participação da energia final substituída é conhecida, naquele uso e naquele setor;

b) para alcançar essa referência é feita a redução da participação do tipo de energia final substituída no uso final considerado para o setor industrial tratado - um caso de economia de energia via substituição, como no Programa Conserve (PICCININI, 1994).

Desse modo, a relação apontada no item b acima é estabelecida pela Equação 3.10 a seguir:

$\% \mathrm{EF}_{\mathrm{s}, \mathrm{u}, \mathrm{f}, \mathrm{benchmark}}=\left(\mathrm{EF}_{\mathrm{s}, \mathrm{u}, \mathrm{f}, \mathrm{AS}}-\mathrm{EFsubs}_{\mathrm{s}, \mathrm{u}, \mathrm{f}}\right) / \mathrm{EF}_{\mathrm{s}, \mathrm{u}, \mathrm{DS}}$

Onde:

$\% \mathrm{EF}_{\mathrm{s}, \mathrm{u}, \mathrm{f}, \text { benchmark }}$ é o valor da participação da energia final substituída no uso final considerado para o setor industrial tratado em uma referência;

$\mathrm{EF}_{\mathrm{s}, \mathrm{u}, \mathrm{f}, \mathrm{AS}}$ é a demanda do tipo de energia final substituída no uso final considerado para o setor tratado antes da substituição; 
EFsubs $_{\mathrm{s}, \mathrm{u}, \mathrm{f}}$ é a energia final substituída no uso final considerado para o setor industrial tratado; $\mathrm{EF}_{\mathrm{s}, \mathrm{u}, \mathrm{DS}}$ é a demanda de energia final no uso final considerado para o setor tratado depois da substituição.

Considerando um caso simplificado de substituição de apenas um tipo de energia final, a demanda de energia final no uso final considerado para o setor tratado depois da substituição será igual àquela antes da substituição somada à diferença entre a demanda adicional, expressa pelo indicador DA, e a energia final substituída, como na Equação 3.11:

$\mathrm{EF}_{\mathrm{s}, \mathrm{u}, \mathrm{DS}}=\mathrm{EF}_{\mathrm{s}, \mathrm{u}, \mathrm{AS}}+\mathrm{DA}_{\mathrm{s}, \mathrm{u}, \mathrm{f}, \mathrm{p}}+\mathrm{EFsubs}_{\mathrm{s}, \mathrm{u}, \mathrm{f}}$

Onde:

$\mathrm{EF}_{\mathrm{s}, \mathrm{u}, \mathrm{DS}}$ é a demanda de energia final no uso final considerado para o setor tratado depois da substituição.

$\mathrm{EF}_{\mathrm{s}, \mathrm{u}, \mathrm{AS}}$ é a demanda de energia final no uso final considerado para o setor tratado antes da substituição.

$\mathrm{DA}_{\mathrm{s}, \mathrm{u}, \mathrm{f}, \mathrm{p}}$ é a demanda adicional pela energia final promovida, substituindo um dado tipo de energia final no uso final considerado para o setor industrial tratado.

EFsubs $_{\mathrm{s}, \mathrm{u}, \mathrm{f}}$ é a energia final substituída no uso final considerado para o setor industrial tratado.

Assim, o potencial de substituição pode ser equacionado através da combinação das Equações 3.6, 3.7, 3.8, 3.10 e 3.11, resultando na Equação 3.12:

$\%_{\text {subs }_{\mathrm{s}, \mathrm{u}, \mathrm{f}, \mathrm{p}}}=\left(1-\mathrm{OEF}_{\mathrm{s}, \mathrm{u}, \mathrm{f}, \text { benchmark }} / \% \mathrm{EF}_{\mathrm{s}, \mathrm{u}, \mathrm{f}}\right) /\left(1+\% \mathrm{EF}_{\mathrm{s}, \mathrm{u}, \mathrm{f}, \mathrm{benchmark}} \cdot\left(\eta_{\mathrm{s}, \mathrm{u}, \mathrm{f}} / \eta_{\mathrm{s}, \mathrm{u}, \mathrm{p}}-1\right)\right)$

Onde:

$\%_{\text {subs } s, u, f, p}$ é o potencial de substituição do tipo de energia final substituída pelo tipo de energia final promovida no uso final considerado para o setor industrial tratado;

$\% \mathrm{EF}_{\mathrm{s}, \mathrm{u}, \mathrm{f}, \mathrm{benchmark}}$ é o valor dessa participação da energia final substituída no uso final considerado para o setor industrial tratado em uma referência;

$\% \mathrm{EF}_{\mathrm{s}, \mathrm{u}, \mathrm{f}}$ é a participação da energia final a ser substituída no uso final considerado no setor industrial tratado;

$\eta_{\mathrm{s}, \mathrm{u}, \mathrm{f}}$ é a eficiência do equipamento de uso final considerado do tipo de energia final substituída para o setor industrial tratado;

$\eta_{\mathrm{s}, \mathrm{u}, \mathrm{p}}$ é a eficiência do equipamento de uso final considerado do tipo de energia final promovida para o setor industrial tratado.

Contudo, observe-se que o denominador da Equação 3.12 funciona como um fator de correção em função da diferença na eficiência do equipamento de uso final entre a energia final substituída e a energia final promovida. Essa correção tende a ser pequena quando a diferença das eficiências é pequena, assim como quando a participação da energia final substituída na referencia é pequena também. Pode-se aproximar, nesses casos, a estimativa do potencial de substituição pela Equação 3.13:

$\%_{\text {subs }_{\mathrm{s}, \mathrm{u}, \mathrm{f}}} \approx\left(1-\mathrm{O}_{\mathrm{EF}} \mathrm{F}_{\mathrm{s}, \mathrm{u}, \mathrm{f}, \text { benchmark }} / \% \mathrm{EF}_{\mathrm{s}, \mathrm{u}, \mathrm{f}}\right)$ 
Onde:

$\%_{\text {subs }_{\mathrm{s}, \mathrm{u}, \mathrm{f}}}$ é o potencial de substituição do tipo de energia final substituída no uso final considerado para o setor industrial tratado;

$\% \mathrm{EF}_{\mathrm{s} \text {,u,f,benchmark }}$ é o valor dessa participação da energia final substituída no uso final considerado para o setor industrial tratado em uma referência;

$\% \mathrm{EF}_{\mathrm{s}, \mathrm{u}, \mathrm{f}}$ é a participação da energia final a ser substituída no uso final considerado no setor industrial tratado;

O grande desafio está no estabelecimento dessas referências para o cálculo do potencial de substituição. A seguir, nesta subseção, são apontadas duas escalas sugeridas para análise de benchmark, com as indicações de mecanismos para estabelecer as referências, que podem ser aplicadas para a técnica de análise de dados apresentada aqui.

\subsubsection{Análise de benchmark em escala de processo ou local}

A escala de processo é uma escala de análise em que se trata de detalhes dos processos produtivos dos setores industriais tratados. A escala de processo pode também ser classificada como uma escala local quando mais de um processo produtivo é analisado, como, por exemplo, uma análise que compreenda diversos processos de uma planta produtiva.

Nessas escalas a estimação do potencial de substituição pode se dar de duas formas. A primeira é uma análise comparativa com dados das melhores técnicas disponíveis ou melhores tecnologias praticáveis (BAT/BPT) como as apresentadas por Worrell et al. (2008) e pelos documentos de referência (BREF) de JRC (2018). A segunda possibilidade é utilizar a técnica de análise de dados para avaliar um caso real de substituição energética em um dado processo industrial. Como nesse caso as informações de campo são detalhadas, elas podem ser usadas diretamente para avaliar os impactos de mudanças em processos dentro de uma planta industrial.

Um exemplo da análise em escala de processo é o trabalho de Laurijssen, Faaij e Worrell (2013), intitulado "Benchmarking energy use in the paper industry: a benchmarking study on process unit level", onde é tratado o Setor de Papel. Na Erro! Fonte de referência não encontrada. está exposto o detalhamento esquemático proposto pelos autores: 
Figura 3.4 - Visão esquemática do processo produtivo da produção de papel

Stock preparation

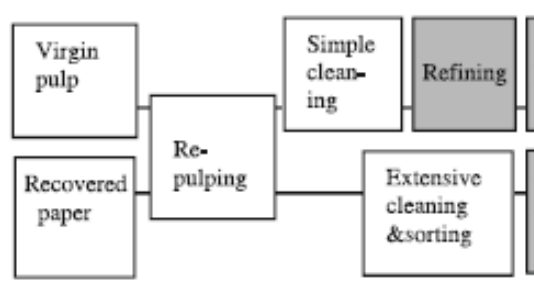

Fonte: Laurijssen, Faaij e Worrell (2013).
Finishing
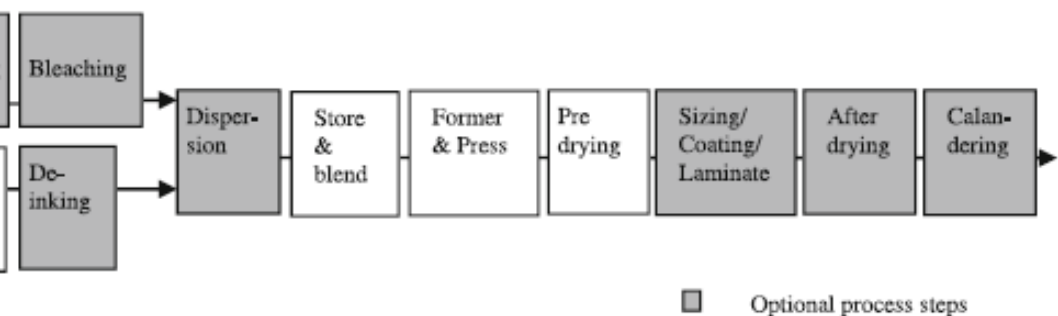

A partir desse detalhamento esquemático, os autores estudam valores de consumo especifico de energia por etapa do processo produtivo e por tipo de produto. Essas informações são a base para depois serem confrontadas com valores de referência (BAT/BPT).

Já em ElMaraghy et al. (2016), no trabalho intitulado "Energy use analysis and local benchmarking of manufacturing lines", os autores trabalham uma análise local, das linhas de produção de blocos de motores automotivos. Nessa análise, os autores fazem um levantamento da demanda energética especifica por bloco nos diferentes equipamentos de processo que operaram na linha de produção. Essas informações podem ser comparadas depois a valores de referência (BAT/BPT).

\subsubsection{Análise de benchmark em escala macro ou nacional}

A avaliação em escala macro ou nacional depende da existência de um balanço de energia final por uso final ou de um balanço de energia útil. Com base nessas informações podem ser feitas comparações com vistas a reduzir a demanda de um dado tipo de energia final ou de promover a sua demanda. Entretanto, poucos países ${ }^{36}$ publicam esse tipo de estudo e nem sempre o modo de apresentação de seus dados os torna passíveis de realização de comparações.

\footnotetext{
${ }^{36}$ Alguns desses países são: Brasil (MME/FDTE, 2005), Estados Unidos (EIA, 2013), França (BAHU, 2016), Japão (METI, 2016), Nova Zelândia (EECA, 2012) e Reino Unido (DECC, 2015).
} 
Nessa escala de análise, uma informação disponível para um conjunto significativo de países é o Balanço de Energia Final. Esses balanços não têm o nível de detalhe de informação que seria necessário para a aplicação da técnica de análise de dados, tendo em vista que é necessário ao menos saber a repartição da destinação da energia final em função dos usos finais. Duas alternativas são possíveis, ou esses balanços são usados de forma complementar a estudos que tragam informações sobre a repartição da destinação da energia final em função dos usos finais, ou então hipóteses têm de ser estabelecidas e fundamentadas para se basear apenas nos Balanços de Energia Final. Os diagramas a seguir apresentam alguns exemplos.

Figura 3.5 - Diagrama esquemático para o processo de determinação do potencial de substituição através de benchmarking usando balanços de energia final por uso final

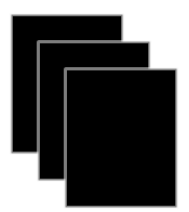

$\longrightarrow \% \mathrm{EF}_{\mathrm{s}, \mathrm{u}, \mathrm{f}, \text { benchmark }}$

Balanços de energia final por uso final de referência
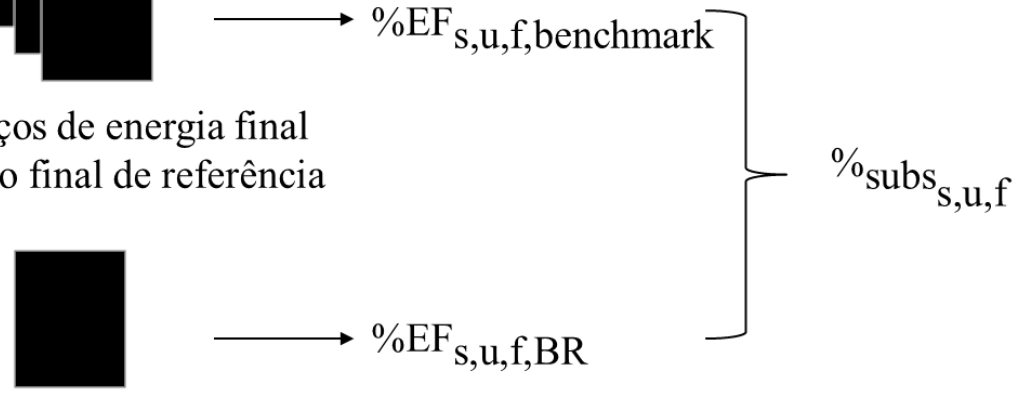

Balanço de energia final por uso final do Brasil

Fonte: Elaboração própria.

Na análise da Erro! Fonte de referência não encontrada., o potencial de substituição do tipo de energia final substituída no uso final considerado para o setor industrial tratado $\left(\%_{\text {subs }_{\text {s,u,f }}}\right)$ é obtido através da Equação 3.12 ou 3.13 usando o valor da participação da energia final substituída no uso final considerado para o setor industrial tratado de referência $\left(\% \mathrm{EF}_{\mathrm{s}, \mathrm{u}, \mathrm{f}, \text { benchmark }}\right)$, que é calculado a partir da participação da energia final substituída no uso final considerado para o setor industrial tratado nos países representados nos balanços de energia final por uso final e o valor da participação da energia final substituída no uso final considerado para o setor industrial tratado no Brasil $\left(\% \mathrm{EF}_{\mathrm{s}, \mathrm{u}, \mathrm{f}, \mathrm{BR}}\right)$, obtido do balanço de energia final por uso final do Brasil. 
Figura 3.6 - Diagrama esquemático para o processo de determinação do potencial de substituição através de benchmarking usando balanços de energia final

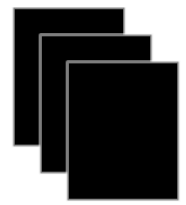

$\longrightarrow \% \mathrm{EF}_{\mathrm{s}, \mathrm{f}, \text { benchmark }}$

Balanços de energia final

de referência
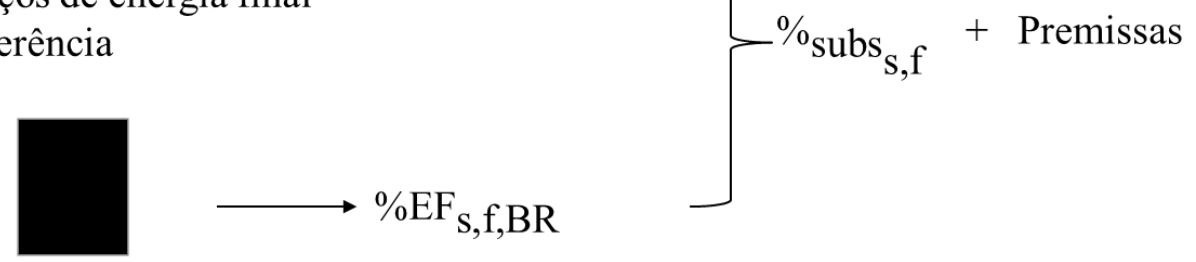

Balanço de energia final

do Brasil

Fonte: Elaboração própria.

Na análise da Erro! Fonte de referência não encontrada., o potencial de substituição do tipo de energia final substituída para o setor industrial tratado $\left(\%_{\text {subs }_{\mathrm{s}, \mathrm{f}}}\right)$ é obtido usando o valor da participação da energia final substituída para o setor industrial tratado de referência $\left(\% \mathrm{EF}_{\mathrm{s}, \mathrm{f}, \mathrm{benchmark}}\right)$, que é calculado a partir da participação da energia final substituída para o setor industrial tratado nos países representados nos balanços de energia final e o valor da participação da energia final substituída para o setor industrial tratado no Brasil $\left(\% \mathrm{EF}_{\mathrm{s}, \mathrm{f}, \mathrm{BR}}\right)$, obtido do balanço de energia do Brasil. Entretanto, para que valores possam ser aplicados à Equação 3.12 ou 3.13, visto que esses valores não estão dados por uso final, há que se adotar premissas, que devem ser estudadas caso a caso, mas podem, por exemplo, estar vinculadas a potenciais de economia do tipo de energia substituída.

Uma outra alternativa é calcular o potencial de substituição do tipo de energia final substituída pelo tipo de energia final promovida no uso final considerado para o setor industrial tratado $\left(\%_{\text {subs s}_{\mathrm{s}, \mathrm{f}} \mathrm{f}}\right)$ através de modelos energético-econômicos como o apresentado por CNI/FIEMG (2015), onde chamado de Modelo GEE-Matriz, modelo este que projeta a matriz energética industrial do gás natural com base em diferentes cenários de competitividade do gás natural, sendo considerados os elementos de elasticidade-renda e a elasticidade cruzada ${ }^{37}$.

\footnotetext{
${ }^{37}$ A elasticidade-renda da demanda mede a variação percentual na quantidade demandada de um bem dado uma variação percentual na renda do consumidor, no caso de um setor industrial o proxy da renda é o PIB setorial. A
} 


\subsubsection{Indicador de Impacto em Energia Primária (IEP)}

Antes de se iniciar a avaliação do indicador de Impacto em Energia Primária (IEP) é necessário determinar os fatores de conversão em energia primária para o tipo de energia final substituída e para o tipo de energia final promovida no uso final considerado para o setor industrial tratado, conforme abordado na Subseção 3.1.2.

O primeiro cálculo a ser feito é o da variação na demanda de energia primária através da Equação 3.14:

$\Delta \mathrm{DEP}_{\mathrm{s}}=\mathrm{DEP}_{\mathrm{s}, \mathrm{DS}}-\mathrm{DEP}_{\mathrm{s}, \mathrm{AS}}$

Onde:

$\triangle \mathrm{DEP}_{\mathrm{s}}$ é a variação na demanda de energia primária para o setor industrial tratado;

$\mathrm{DEP}_{\mathrm{S}, \mathrm{DS}}$ é a demanda de energia primária para o setor industrial tratado depois da substituição;

$\mathrm{DEP}_{\mathrm{s}, \mathrm{AS}}$ é a demanda de energia primária para o setor industrial tratado antes da substituição.

A demanda de energia primária no setor industrial tratado antes da realização das substituições é dada através da Equação 3.15:

$\operatorname{DEP}_{\mathrm{s}, \mathrm{AS}}=\sum_{\mathrm{i}}\left(\mathrm{FCEP}_{\mathrm{i}}\left(\sum_{\mathrm{u}} \mathrm{EF}_{\mathrm{s}, \mathrm{u}, \mathrm{i}, \mathrm{AS}}\right)\right)$

Onde:

$\mathrm{DEP}_{\mathrm{s}, \mathrm{AS}}$ é a demanda de energia primária para o setor industrial tratado antes da substituição;

$\mathrm{FCEP}_{\mathrm{i}}$ é o fator de conversão em energia primária para um dado tipo de energia final;

$\mathrm{EF}_{\mathrm{s}, \mathrm{u}, \mathrm{i}, \mathrm{AS}}$ é a demanda de uma dada energia final no uso final considerado para o setor tratado antes da substituição.

Já a demanda de energia primária no setor industrial tratado depois da realização das substituições é dada através da Equação 3.16:

$\mathrm{DEP}_{\mathrm{s}, \mathrm{DS}}=\sum_{\mathrm{i}}\left(\mathrm{FCEP}_{\mathrm{i}}\left(\sum_{\mathrm{u}} \mathrm{EF}_{\mathrm{s}, \mathrm{u}, \mathrm{i}, \mathrm{DS}}\right)\right)$

Onde:

$\mathrm{DEP}_{\mathrm{s}, \mathrm{DS}}$ é a demanda de energia primária para o setor industrial tratado depois da substituição;

$\mathrm{FCEP}_{\mathrm{i}}$ é o fator de conversão em energia primária para um dado tipo de energia final;

elasticidade cruzada mede a variação percentual na quantidade demandada de um bem dado uma variação percentual no preço de outro bem substituto (KRUGMAN e WELLS, 2016). 
$\mathrm{EF}_{\mathrm{s}, \mathrm{u}, \mathrm{i}, \mathrm{AS}}$ é a demanda de uma dada energia final no uso final considerado para o setor tratado depois da substituição.

Os valores de $\mathrm{EF}_{\mathrm{s}, \mathrm{u}, \mathrm{i}, \mathrm{DS}}$ para o tipo de energia final substituída e para o tipo de energia final promovida são calculados respectivamente pelas Equações 3.17 e 3.18:

$\mathrm{EF}_{\mathrm{s}, \mathrm{u}, \mathrm{f}, \mathrm{DS}}=\mathrm{EF}_{\mathrm{s}, \mathrm{u}, \mathrm{f}, \mathrm{AS}}-\mathrm{EFsubs}_{\mathrm{s}, \mathrm{u}, \mathrm{f}}$

Onde:

$\mathrm{EF}_{\mathrm{s}, \mathrm{u}, \mathrm{f}, \mathrm{DS}}$ é a demanda do tipo de energia final substituída no uso final considerado para o setor tratado depois da substituição;

$\mathrm{EF}_{\mathrm{s}, \mathrm{u}, \mathrm{f}, \mathrm{AS}}$ é a demanda do tipo de energia final substituída no uso final considerado para o setor tratado antes da substituição;

EFsubs $_{\mathrm{s}, \mathrm{u}, \mathrm{f}}$ é a energia final substituída no uso final considerado para o setor industrial tratado.

$\mathrm{EF}_{\mathrm{s}, \mathrm{u}, \mathrm{p}, \mathrm{DS}}=\mathrm{EF}_{\mathrm{s}, \mathrm{u}, \mathrm{p}, \mathrm{AS}}+\mathrm{DA}_{\mathrm{s}, \mathrm{u}, \mathrm{f}, \mathrm{p}}$

Onde:

$\mathrm{EF}_{\mathrm{s}, \mathrm{u}, \mathrm{p}, \mathrm{DS}}$ é a demanda do tipo de energia final promovida no uso final considerado para o setor tratado depois da substituição;

$\mathrm{EF}_{\mathrm{s}, \mathrm{u}, \mathrm{p}, \mathrm{AS}}$ é a demanda do tipo de energia final promovida no uso final considerado para o setor tratado antes da substituição;

$\mathrm{DA}_{\mathrm{s}, \mathrm{u}, \mathrm{f}, \mathrm{p}}$ é a demanda adicional pela energia final promovida, substituindo um dado o tipo de energia final no uso final considerado para o setor industrial tratado.

Dessa forma, combinando as Equações 3.14 a 3.18, obtém-se a Equação 3.19, uma forma simplificada para a determinação da variação na demanda de energia primária:

$$
\Delta \operatorname{DEP}_{\mathrm{s}}=\sum_{\mathrm{p}}\left(\operatorname{FCEP}_{\mathrm{p}}\left(\sum_{\mathrm{u}} \sum_{\mathrm{f}} \mathrm{DA}_{\mathrm{s}, \mathrm{u}, \mathrm{f}, \mathrm{p}}\right)\right)-\sum_{\mathrm{f}}\left(\operatorname{FCEP}_{\mathrm{f}}\left(\sum_{\mathrm{u}} \operatorname{EFsubs}_{\mathrm{s}, \mathrm{u}, \mathrm{f}}\right)\right)
$$

Onde:

$\triangle \mathrm{DEP}_{\mathrm{s}}$ é a variação na demanda de energia primária para o setor industrial tratado;

$\mathrm{FCEP}_{\mathrm{p}}$ é o fator de conversão em energia primária para o tipo de energia final promovida;

$\mathrm{DA}_{\mathrm{s}, \mathrm{u}, \mathrm{f}, \mathrm{p}}$ é a demanda adicional pela energia final promovida, substituindo um dado o tipo de energia final no uso final considerado para o setor industrial tratado;

$\mathrm{FCEP}_{\mathrm{f}}$ é o fator de conversão em energia primária para o tipo de energia final substituída;

EFsubs $_{\mathrm{s}, \mathrm{u}, \mathrm{f}}$ é a energia final substituída no uso final considerado para o setor industrial tratado.

Se mais de um tipo de energia final for substituída e/ou mais de um uso final for considerado, os valores devem ser agregados apropriadamente no cálculo da demanda de energia primária depois da realização das substituições. Tendo em vista que na conversão em energia primária há um fator característico para cada tipo de energia final, a agregação que deve ser feita inicialmente em função do uso final e depois em função do tipo de energia final, como já apresentado na Equação 3.19. 
Assim, quando for considerado o indicador de impacto em energia primária em unidades de energia (ex. TJ), o valor do indicador corresponde diretamente ao valor calculado anteriormente na Equação 3.19, como apontado na Equação 3.20.

$\mathrm{IEP}_{\mathrm{s}}[\mathrm{em}$ unidades de energia $]=\Delta \mathrm{DEP}_{\mathrm{s}}$

Onde:

$\mathrm{IEP}_{\mathrm{s}}$ é o indicador de Impacto em Energia Primária no setor industrial tratado;

$\triangle \mathrm{DEP}_{\mathrm{s}}$ é a variação na demanda de energia primária para o setor industrial tratado.

$\mathrm{O}$ indicador de impacto em energia primária (IEP) também pode ser expresso como uma variação percentual da demanda de energia primária, como na Equação 3.21:

$\mathrm{IEP}_{\mathrm{s}}[$ como \% de mudança no setor $]=\left(\Delta \mathrm{DEP}_{\mathrm{s}} / \mathrm{DEP}_{\mathrm{s}, \mathrm{AS}}\right)$

Onde:

$\mathrm{IEP}_{\mathrm{s}}$ é o indicador de Impacto em Energia Primária no setor industrial tratado;

$\triangle \mathrm{DEP}_{\mathrm{s}}$ é a variação na demanda de energia primária para o setor industrial tratado;

$\mathrm{DEP}_{\mathrm{s}, \mathrm{AS}}$ é a demanda de energia primária para o setor industrial tratado antes da substituição.

\subsubsection{Indicador de Impacto em Emissões de Carbono (IEC)}

Antes de se iniciar a avaliação do indicador de Impacto em Emissões de Carbono (IEC) é necessário determinar os fatores de emissão de $\mathrm{CO}_{2}$ para o tipo de energia final substituída e para o tipo de energia final promovida no uso final considerado para o setor industrial tratado, conforme abordado na Subseção 3.1.2.

Calcula-se então a variação nas emissões de $\mathrm{CO}_{2}$ resultante da substituição de energia final no uso final considerado do setor industrial tratado. Essa mudança é calculada em função da redução na demanda da energia final substituída e do aumento na demanda da energia final promovida, multiplicadas por fatores de emissão de $\mathrm{CO}_{2}$ específicos de cada tipo de energia final. Esse cálculo é análogo ao cálculo da variação na demanda de energia primária, sendo descrito pela Equação 3.22: 
$\Delta \mathrm{EmC}_{\mathrm{s}}=\sum_{\mathrm{p}}\left(\mathrm{FEm}_{\mathrm{p}}\left(\sum_{\mathrm{u}} \sum_{\mathrm{f}} \mathrm{DA}_{\mathrm{s}, \mathrm{u}, \mathrm{f}, \mathrm{p}}\right)\right)-\sum_{\mathrm{f}}\left(\mathrm{FEm}_{\mathrm{f}}\left(\sum_{\mathrm{u}} \operatorname{EFsubs}_{\mathrm{s}, \mathrm{u}, \mathrm{f}}\right)\right)$

Onde:

$\Delta \mathrm{EmC}_{\mathrm{s}}$ é a variação nas emissões de $\mathrm{CO}_{2}$ para o setor industrial tratado;

$\mathrm{FEm}_{\mathrm{p}}$ é o fator de emissões de $\mathrm{CO}_{2}$ para o tipo de energia final promovida;

$\mathrm{DA}_{\mathrm{s}, \mathrm{u}, \mathrm{f}, \mathrm{p}}$ é a demanda adicional pela energia final promovida, substituindo um dado o tipo de energia final no uso final considerado para o setor industrial tratado;

$\mathrm{FEm}_{\mathrm{f}}$ é o fator de emissões de $\mathrm{CO}_{2}$ para o tipo de energia final substituída;

EFsubs $_{\mathrm{s}, \mathrm{u}, \mathrm{f}}$ é a energia final substituída no uso final considerado para o setor industrial tratado.

Se mais de um tipo de energia final for substituída e/ou mais de um uso final for considerado, os valores devem ser agregados apropriadamente no cálculo da mudança nas emissões de $\mathrm{CO}_{2}$. Tendo em vista que na conversão em emissões de $\mathrm{CO}_{2}$ há um fator característico para cada tipo de energia final, a agregação que deve ser feita inicialmente em função do uso final e depois em função do tipo de energia final, como já apresentado na Equação 3.22 .

Assim, quando for considerado o indicador de Impacto em Emissões de Carbono em unidades de contabilização de emissões (ex. $\mathrm{MtCO}_{2}$ ), o valor do indicador corresponde diretamente ao valor calculado anteriormente na Equação 3.22, como apontado na Equação 3.23 .

$\mathrm{IEC}_{\mathrm{s}}[\mathrm{em}$ unidades de emissão de carbono $]=\Delta \mathrm{EmC}_{\mathrm{s}}$

Onde:

$\mathrm{IEC}_{\mathrm{s}}$ é o indicador de Impacto em Emissões de Carbono para o setor industrial tratado; $\Delta \mathrm{EmC}_{\mathrm{s}}$ é a variação nas emissões de $\mathrm{CO}_{2}$ para o setor industrial tratado.

$\mathrm{O}$ indicador de Impacto em Emissões de Carbono ( IEC $_{\mathrm{s}}$ ) também pode ser expresso como uma variação percentual em relação às emissões de $\mathrm{CO}_{2}$ do setor industrial tratado associadas ao uso de energia, como na Equação 3.24:

$\mathrm{IEC}_{\mathrm{S}}[$ como \% de mudança no setor $]=\left(\Delta \mathrm{EmC}_{\mathrm{S}} / \mathrm{EmC}_{\mathrm{s}, \mathrm{AS}}\right)$

Onde:

$\mathrm{IEC}_{\mathrm{s}}$ é o indicador de Impacto em Emissões de Carbono para o setor industrial tratado;

$\Delta \mathrm{EmC}_{\mathrm{s}}$ é a variação nas emissões de $\mathrm{CO}_{2}$ para o setor industrial tratado;

$\mathrm{EmC}_{\mathrm{s}, \mathrm{AS}}$ é a quantidade de emissões de $\mathrm{CO}_{2}$ associadas ao uso de energia no setor industrial tratado antes das substituições. 


\subsubsection{Indicador de Impacto no Custo Energético (ICE)}

Antes de se iniciar a avaliação do indicador de Impacto no Custo Energético (ICE) é necessário determinar os preços (ou tarifas) para o tipo de energia final substituída e para o tipo de energia final promovida no uso final considerado para o setor industrial tratado, através de pesquisa nos órgãos responsáveis do país considerado ou estudos de organizações internacionais como IEA (2016b, 2016c).

Calcula-se então a variação nos custos energéticos $\left(\Delta C E n_{s}\right)$ resultante da substituição de energia final no uso final considerado do setor industrial tratado. Essa mudança é calculada em função da redução na demanda da energia final substituída e do aumento na demanda da energia final promovida, multiplicadas pelo preço (ou tarifa) específicos de cada tipo de energia final. Esse cálculo é análogo ao cálculo da variação na demanda de energia primária e da variação nas emissões de $\mathrm{CO}_{2}$, sendo descrito pela Equação 3.25:

$$
\Delta \mathrm{CEn}_{\mathrm{s}}=\sum_{\mathrm{p}}\left(\mathrm{p}_{\mathrm{p}}\left(\sum_{\mathrm{u}} \sum_{\mathrm{f}} \mathrm{DA}_{\mathrm{s}, \mathrm{u}, \mathrm{f}, \mathrm{p}}\right)\right)-\sum_{\mathrm{f}}\left(\mathrm{p}_{\mathrm{f}}\left(\sum_{\mathrm{u}} \operatorname{EFsubs}_{\mathrm{s}, \mathrm{u}, \mathrm{f}}\right)\right)
$$

Onde:

$\triangle \mathrm{CEn}_{\mathrm{s}}$ é a variação nos custos energéticos para o setor industrial tratado; $\mathrm{p}_{\mathrm{p}}$ é o preço (ou tarifa) para o tipo de energia final promovida;

$\mathrm{DA}_{\mathrm{s}, \mathrm{u}, \mathrm{f}, \mathrm{p}}$ é a demanda adicional pela energia final promovida, substituindo um dado o tipo de energia final no uso final considerado para o setor industrial tratado;

$\mathrm{p}_{\mathrm{f}}$ é o preço (ou tarifa) para o tipo de energia final substituída;

EFsubs $_{\mathrm{s}, \mathrm{u}, \mathrm{f}}$ é a energia final substituída no uso final considerado para o setor industrial tratado.

Se mais de um tipo de energia final for substituída e/ou mais de um uso final for considerado, os valores devem ser agregados apropriadamente no cálculo da mudança nos custos energéticos. Tendo em vista que na conversão em custos há um preço (ou tarifa) característico para cada tipo de energia final, a agregação que deve ser feita inicialmente em função do uso final e depois em função do tipo de energia final, como já apresentado na Equação 3.25 .

Assim, quando for considerado o indicador de Impacto em Custo Energético em unidades de monetárias (ex. R\$), o valor do indicador corresponde diretamente ao valor calculado anteriormente pela Equação 3.25, como apontado na Equação 3.26. 
$\mathrm{ICE}_{\mathrm{s}}[\mathrm{em}$ unidades monetárias $]=\Delta \mathrm{CEn}_{\mathrm{s}}$

Onde:

$\mathrm{ICE}_{\mathrm{s}}$ é o indicador de Impacto em Custo Energético para o setor industrial tratado;

$\Delta \mathrm{CEn}_{\mathrm{s}}$ é a variação no custo energético para o setor industrial tratado.

$\mathrm{O}$ indicador de impacto em custo energético $\left(\mathrm{ICE}_{\mathrm{s}}\right)$ também pode ser expresso como uma variação percentual em relação ao custo energético total dos tipos de energia final substituídos $\left(\sum_{\mathrm{f}} \mathrm{CEn}_{\mathrm{s}, \mathrm{f}, \mathrm{AS}}\right)$ para o setor industrial tratado antes da substituição, como na Equação 3.27:

$\mathrm{ICE}_{\mathrm{s}}[$ como \% de mudança no setor $]=\left(\Delta \mathrm{CEn}_{\mathrm{s}} /\left(\sum_{\mathrm{f}} \mathrm{CEn}_{\mathrm{s}, \mathrm{f}, \mathrm{AS}}\right)\right)$

Onde:

$\mathrm{ICE}_{\mathrm{s}}$ é o indicador de Impacto em Custo Energético para o setor industrial tratado;

$\Delta \mathrm{CEn}_{\mathrm{s}}$ é a variação no custo energético para o setor industrial tratado;

$\mathrm{CEn}_{\mathrm{s}, \mathrm{f}, \mathrm{AS}}$ é o custo energético do tipo de energia final substituída para o setor industrial tratado.

\subsubsection{Considerações finais da formulação dos indicadores}

Considerando um caso simplificado, com a substituição de um tipo de energia final por um outro tipo de energia a ser promovida em um único uso final para um dado setor industrial, as equações apresentadas anteriormente podem ser simplificadas para representar os indicadores da forma expressa nas Equações 3.28 a 3.31:

$\mathrm{DA}_{\mathrm{s}, \mathrm{p}}=\mathrm{EF}_{\mathrm{s}, \mathrm{u}, \mathrm{f}} \cdot\left(\eta_{\mathrm{s}, \mathrm{u}, \mathrm{f}} / \eta_{\mathrm{s}, \mathrm{u}, \mathrm{p}}\right) \cdot \%_{\mathrm{subs}_{\mathrm{s}, \mathrm{u}, \mathrm{f}, \mathrm{p}}}$

Onde:

$\mathrm{DA}_{\mathrm{s}, \mathrm{p}}$ é a demanda adicional pela energia final promovida para o setor industrial tratado;

$\mathrm{EF}_{\mathrm{s}, \mathrm{u}, \mathrm{f}}$ é a demanda de energia final do tipo substituído no uso final considerado para o setor industrial tratado;

$\eta_{\mathrm{s}, \mathrm{u}, \mathrm{f}}$ é a eficiência do equipamento de uso final considerado do tipo de energia final substituída para o setor industrial tratado;

$\eta_{\mathrm{s}, \mathrm{u}, \mathrm{p}}$ é a eficiência do equipamento de uso final considerado do tipo de energia final promovida para o setor industrial tratado;

$\%_{\text {subs }_{\mathrm{s}, \mathrm{u}, \mathrm{f}, \mathrm{p}}}$ a a porcentagem do tipo de energia final substituída no uso final considerado para o setor industrial tratado. 
$\operatorname{IEP}_{\mathrm{s}}=\mathrm{EF}_{\mathrm{s}, \mathrm{u}, \mathrm{f} \cdot} \cdot\left[\left(\eta_{\mathrm{s}, \mathrm{u}, \mathrm{f}} / \eta_{\mathrm{s}, \mathrm{u}, \mathrm{p}}\right) \cdot \mathrm{FCEP}_{\mathrm{p}}-\mathrm{FCEP}_{\mathrm{f}}\right] \cdot \%_{\text {subs }} \mathrm{s,u,f,p}$

Onde:

$\mathrm{IEP}_{\mathrm{s}}$ é o indicador de Impacto em Energia Primária no setor industrial tratado;

$\mathrm{EF}_{\mathrm{s}, \mathrm{u}, \mathrm{f}}$ é a demanda de energia final do tipo substituído no uso final considerado para o setor industrial tratado;

$\eta_{\mathrm{s}, \mathrm{u}, \mathrm{f}}$ é a eficiência do equipamento de uso final considerado do tipo de energia final substituída para o setor industrial tratado;

$\eta_{\mathrm{s}, \mathrm{u}, \mathrm{p}}$ é a eficiência do equipamento de uso final considerado do tipo de energia final promovida para o setor industrial tratado;

$\mathrm{FCEP}_{\mathrm{f}}$ é o fator de conversão em energia primária para o tipo de energia final substituída;

$\mathrm{FCEP}_{\mathrm{p}}$ é o fator de conversão em energia primária para o tipo de energia final promovida;

$\%_{\text {subs }_{\text {s,u,f,p }}}$ é a porcentagem do tipo de energia final substituída no uso final considerado para o setor industrial tratado.

$\mathrm{IEC}_{\mathrm{s}}=\mathrm{EF}_{\mathrm{s}, \mathrm{u}, \mathrm{f}} \cdot\left[\left(\eta_{\mathrm{s}, \mathrm{u}, \mathrm{f}} \mathrm{\eta}_{\mathrm{s}, \mathrm{u}, \mathrm{p}}\right) \cdot \mathrm{FEm}_{\mathrm{p}}-\mathrm{FEm}_{\mathrm{f}}\right] \cdot \%_{\mathrm{subs}_{\mathrm{s}, \mathrm{u}, \mathrm{f}, \mathrm{p}}}$

Onde:

$\mathrm{IEC}_{\mathrm{s}}$ é o indicador de Impacto em Emissões de Carbono para o setor industrial tratado;

$\mathrm{EF}_{\mathrm{s}, \mathrm{u}, \mathrm{f}}$ é a demanda de energia final do tipo substituído no uso final considerado para o setor industrial tratado;

$\eta_{\mathrm{s}, \mathrm{u}, \mathrm{f}}$ é a eficiência do equipamento de uso final considerado do tipo de energia final substituída para o setor industrial tratado;

$\eta_{\mathrm{s}, \mathrm{u}, \mathrm{p}}$ é a eficiência do equipamento de uso final considerado do tipo de energia final promovida para o setor industrial tratado;

$\mathrm{FEm}_{\mathrm{f}}$ é o fator de emissões de $\mathrm{CO}_{2}$ para o tipo de energia final substituída;

$\mathrm{FEm}_{\mathrm{p}}$ é o fator de emissões de $\mathrm{CO}_{2}$ para o tipo de energia final promovida;

$\%_{\text {subs }_{\text {s,u,f,p }}}$ é a porcentagem do tipo de energia final substituída no uso final considerado para o setor industrial tratado.

$\mathrm{ICE}_{\mathrm{s}}=\mathrm{EF}_{\mathrm{s}, \mathrm{u}, \mathrm{f}} \cdot\left[\left(\eta_{\mathrm{s}, \mathrm{u}, \mathrm{f}} / \eta_{\mathrm{s}, \mathrm{u}, \mathrm{p}}\right) \cdot \mathrm{p}_{\mathrm{p}}-\mathrm{p}_{\mathrm{f}}\right] \cdot \%_{\mathrm{subs}_{\mathrm{s}, \mathrm{u}, \mathrm{f}, \mathrm{p}}}$

Onde:

$\mathrm{ICE}_{\mathrm{s}}$ é o indicador de Impacto em Custo Energético para o setor industrial tratado;

$\mathrm{EF}_{\mathrm{s}, \mathrm{u}, \mathrm{f}}$ é a demanda de energia final do tipo substituído no uso final considerado para o setor industrial tratado;

$\eta_{\mathrm{s}, \mathrm{u}, \mathrm{f}}$ é a eficiência do equipamento de uso final considerado do tipo de energia final substituída para o setor industrial tratado;

$\eta_{\mathrm{s}, \mathrm{u}, \mathrm{p}}$ é a eficiência do equipamento de uso final considerado do tipo de energia final promovida para o setor industrial tratado;

$\mathrm{p}_{\mathrm{f}}$ é o preço (ou tarifa) para o tipo de energia final substituída;

$\mathrm{p}_{\mathrm{p}}$ é o preço (ou tarifa) para o tipo de energia final promovida;

$\%_{\text {subs }_{\mathrm{s}, \mathrm{u}, \mathrm{f}, \mathrm{p}}}$ é a porcentagem do tipo de energia final substituída no uso final considerado para o setor industrial tratado.

Observe-se que os indicadores são sempre compostos por uma sequência lógica de três elementos: uma informação de demanda de energia final por uso final, um potencial de substituição e um fator de conversão. O primeiro elemento constitui um balanço de energia final por uso final, que também pode ser extraído também de um balanço de energia útil. Os fatores 
de conversão incluem, além dos fatores apresentados na subseção anterior, a relação de preços e a relação das eficiências no uso final. Finalmente, o potencial de substituição é um fator que tem de ser estimado, como apresentado na Subseção 3.2.2.

\subsection{Considerações finais do capítulo 3}

A técnica de análise de dados, apresentada nas duas seções anteriores, pode ser resumida em algumas etapas, particularmente com a ajuda da Equação 3.32, baseada nas Equações 3.28 a 3.31, que representa genericamente como os indicadores podem ser expressos num formato matricial:

$\left[\text { Indicador }_{\mathrm{s}, \mathrm{u}, \mathrm{p}}\right]_{1 \mathrm{xn}}=\left[\mathrm{EF}_{\mathrm{s}, \mathrm{u}}\right]_{1 \mathrm{xn}} *\left[\mathrm{FC}_{\mathrm{s}, \mathrm{u}, \mathrm{p}}\right]_{\mathrm{nxn}} *\left[\%_{\mathrm{subs}_{\mathrm{s}, \mathrm{u}, \mathrm{p}}}\right]_{\mathrm{nxn}}$

Onde, num cenário com ' $n$ ' tipos de energia final a serem substituídas por um dado tipo ' $p$ ' de energia final a ser promovida, considerando um dado uso final 'u' e setor industrial 's':

- o indicador [ Indicador $\left._{\mathrm{s}, \mathrm{u}, \mathrm{p}}\right]_{1 \mathrm{xm}}$ é um vetor linha que tem 'n' colunas, onde cada uma delas tem o valor do indicador relativo à promoção do tipo de energia final 'p' para cada tipo de energia final substituída;

- o vetor linha $\left[\mathrm{EF}_{\mathrm{s}, \mathrm{u}}\right]_{1 \mathrm{xn}}$ tem 'n' colunas e representa uma parte da linha do balanço de energia final por uso final, aquela que representa a distribuição do uso dos ' $n$ ' tipos de energia final substituídos no dado uso final ' $u$ ' e setor industrial ' $\mathrm{s}$ ';

- a matriz diagonal $\left[\mathrm{FC}_{\mathrm{s}, \mathrm{u}, \mathrm{p}}\right]_{\mathrm{nxn}}$ tem ' $\mathrm{n}$ ' colunas e ' $\mathrm{n}$ ' linhas e apresenta os fatores de conversão em função dos tipos de energia final a ser substituída e a ser promovida no dado uso final ' $u$ ' e setor industrial 's';

- a matriz diagonal $\left[\%_{\text {subs s,u,p }_{s, p}}\right]_{n x n}$ tem 'n' colunas e 'n' linhas e estabelece a ligação entre os diferentes tipos de energia final pelo potencial de substituição verificado entre eles.

Esse formato permite estabelecer algumas observações sobre as etapas para o cálculo dos indicadores. Primeiramente, é fundamental estabelecer inicialmente um balanço de energia 
final por uso final, particularmente no que diz respeito aos usos finais de energia e tipos de energia final que serão objetos de análise de substituição. Essa etapa permite construir os vetores linha $\left[\mathrm{EF}_{\mathrm{s}, \mathrm{u}}\right]_{1 \mathrm{xn}}$, função do número de setores industriais tratados e usos finais considerados.

Em seguida, deve ser feito o levantamento dos parâmetros necessários para a determinação dos fatores de conversão necessários para os indicadores, envolvendo então informações sobre eficiência do equipamento de uso final de energia, fatores de conversão em energia primária, fatores de emissão e preços (ou tarifas). Assim, esse levantamento permite a construção das matrizes diagonais $\left[\mathrm{FC}_{\mathrm{s}, \mathrm{u}, \mathrm{p}}\right]_{\mathrm{nxn}}$, função do número de setores industriais tratados, usos finais considerados e tipos de energia final promovidos.

Nesse ponto é possível fazer uma primeira estimativa dos indicadores, considerando o valor de $1 \%$ de substituição na diagonal das matrizes $\left[\%_{\text {subs }_{\mathrm{s}, \mathrm{u}, \mathrm{p}}}\right]_{\mathrm{nxn}}$. Pode-se então fazer comparações relativas entre os valores obtidos, contudo, não se pode tirar uma conclusão final pois essa depende da estimativa dos potenciais de substituição.

Assim, chega-se na última etapa, que envolve o processo de estimação dos potenciais de substituição, conforme apresentado na Subseção 3.2.2. Com o valor desses potenciais, o último elemento da Equação 3.32 pode ser construído, que são as matrizes diagonais $\left[\%_{\text {subs s }_{\mathrm{s}, \mathrm{u}, \mathrm{p}}}\right]_{\mathrm{nxn}}$, função do número de setores industriais tratados, usos finais considerados e tipos de energia final promovidos.

Dessa forma, seguindo essas três etapas é possível se obter os elementos necessários para a aplicação da técnica de análise de dados e determinar os valores dos indicadores para as substituições consideradas. Observe-se que o resultado dos indicadores no formado de vetor linha $\left(\left[\text { Indicador }_{\mathrm{s}, \mathrm{u}, \mathrm{p}}\right]_{1 \mathrm{xn}}\right.$ ) permite que alguns tratamentos sejam feitos nos resultados, como por exemplo, os indicadores podem ser apresentados em valores totais e parciais, mostrando a contribuição de cada substituição considerada. 


\section{APLICAÇÃO dA TÉCNICA DE ANÁliSE DE DADOS - AVALIAÇÃO DA INSERÇÃO DO GÁS NATURAL NO SETOR INDUSTRIAL BRASILEIRO}

Este capítulo trata da aplicação da técnica de análise de dados desenvolvida no capítulo anterior para avaliar a inserção do gás natural no setor industrial brasileiro, que é o objetivo principal dessa dissertação.

Inicialmente, na primeira seção, é realizada a delimitação do estudo, ou seja, são especificadas que substituições no uso final de energia serão consideradas, envolvendo as motivações e justificativas para essas escolhas. Em seguida, na segunda seção, é aplicada a técnica de análise de dados desenvolvida nesta dissertação, seguindo a divisão em três partes apontada nas considerações finais do capítulo anterior.

Na terceira seção são apresentados os resultados dos indicadores de forma desagregada e na quarta seção são apresentados os resultados consolidados e feitas as considerações finais sobre a aplicação da técnica de análise de dados desenvolvida e esses resultados obtidos.

\subsection{Definição das substituições a serem consideradas}

As substituições a serem consideradas visam promover a inserção do gás natural no setor industrial brasileiro, para tanto essas substituições têm de ser definidas em dois elementos: em que usos finais a substituição será analisada e que tipos de energia final serão substituídos. Com base nas informações presentes no Balanço de Energia Útil - BEU (MME/FDTE, 2005) - e no Balanço Energético Nacional - BEN (EPE, 2014) - pode-se apontar os principais usos finais de energia e os principais tipos de energia final observados no setor industrial brasileiro e assim, juntamente com as exposições motivadoras apresentadas na Introdução presentes no Capítulo 1, possibilitar a delimitação dos elementos a serem considerados para a presente análise. 


\subsubsection{A definição dos usos finais a serem analisados}

De acordo com MME/FDTE (2005), o uso final de energia pode ser dividido nos seguintes usos finais: força motriz, calor de processo, aquecimento direto, refrigeração, iluminação, eletroquímica e outros usos (que incluem, por exemplo, equipamentos de escritório, de telecomunicações e de controle).

O calor de processo, de acordo com MME/FDTE (2005) e Costa (2013), é o uso final de energia para produção de energia térmica em que o processo de transferência de calor entre o ponto de uso da energia final e a carga a ser aquecida é indireto, ocorrendo através de um fluido intermediário como, por exemplo, água, vapor e óleo térmico. Entre as tecnologias de aplicação desse uso final de energia estão os aquecedores, de água ou óleo térmico, e as caldeiras, de produção de água quente ou vapor.

Figura 4.1 - Distribuição da demanda da energia do setor industrial brasileiro por uso final (ano-base 2013)

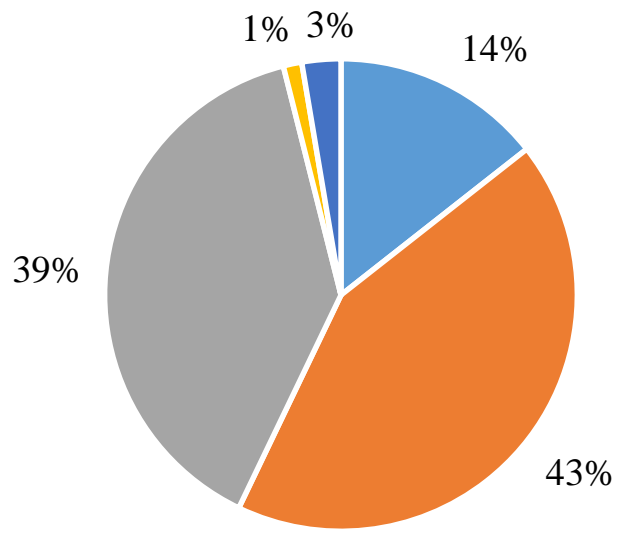

• Força-motriz

- Calor de Processo

- Aquecimento Direto

- Refrigeração

- Iluminação+Eletroquímica+Outros

Fonte: Elaboração própria, baseado em MME/FDTE (2005) e EPE (2014).

O aquecimento direto, de acordo com MME/FDTE (2005) e Costa (2013), é o uso final de energia para produção de energia térmica em que o processo de transferência de calor entre o ponto de uso da energia final e a carga a ser aquecida é direto, como no caso da radiação, indução, condução e micro-ondas, ou ainda através da convecção do ar no ambiente de aquecimento. Entre as tecnologias de aplicação desse uso final de energia estão os fornos, as estufas e secadoras. Cerca de $80 \%$ da demanda de energia final do setor industrial está concentrado nesses dois usos finais de energia, calor de processo e aquecimento direto, 
conforme Figura 4.1., doravante denominados genericamente de processos térmicos (MME/FDTE, 2005; EPE, 2014).

A força motriz, de acordo com MME/FDTE (2005), é o uso final de energia para produção de energia mecânica, seja em motores estacionários ou em motores de veículos, incluindo os motores elétricos e os motores a combustíveis. Este uso final é o segundo mais importante, respondendo por cerca de $15 \%$ da demanda de energia final do setor industrial, vide Figura 4.1. Os demais usos finais de energia têm pequena participação na demanda de energia final do setor industrial (MME/FDTE, 2005; EPE, 2014).

Essa exposição embasa a escolha dos usos finais que vão ser objeto de estudo para substituição: os processos térmicos.

\subsubsection{A definição dos tipos de energia final a serem substituídos}

De acordo com EPE (2014), os tipos de energia final empregados de forma mais significativa pelo setor industrial são a biomassa e resíduos renováveis, a eletricidade e os derivados de petróleo, respondendo por, respectivamente, cerca de 40\%, $20 \%$ e $15 \%$ da demanda de energia final, considerando o ano base 2013, conforme Figura 4.2.

Figura 4.2 - Distribuição da demanda de energia final do setor industrial brasileiro (ano-base 2013)

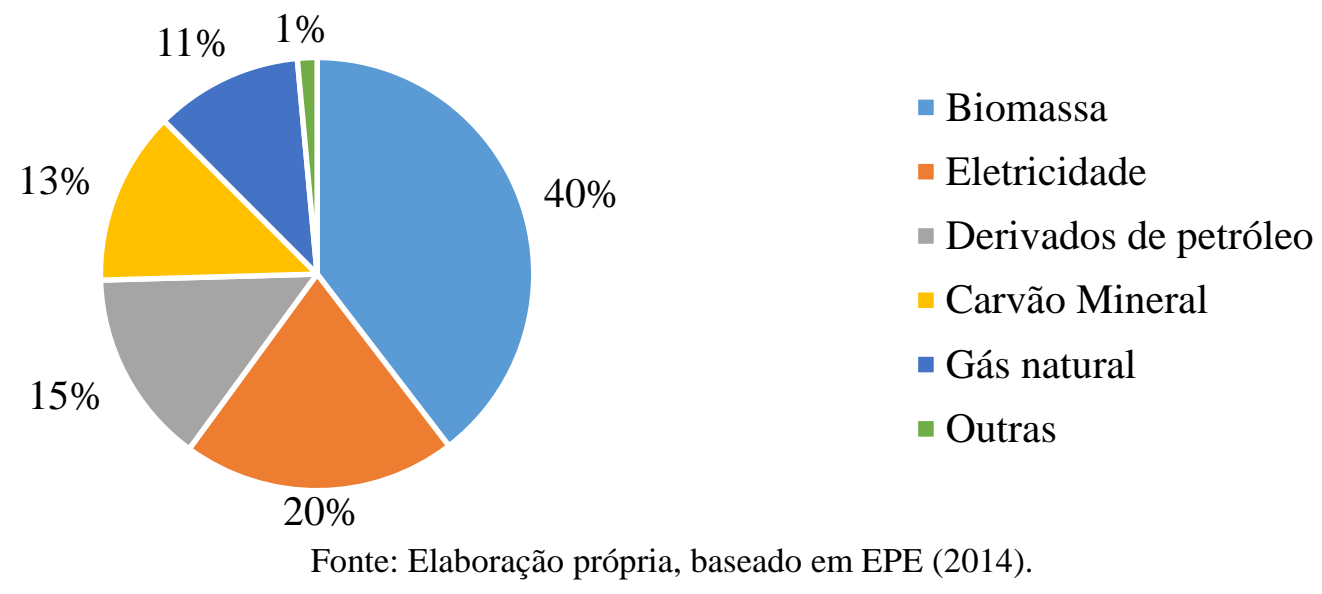

A biomassa e resíduos renováveis são um tipo de energia final que abrange uma categoria extensa de tipos de energia final, incluindo a lenha, o carvão vegetal, o licor negro e 
os produtos de cana (bagaço e palha, por exemplo). Dentre esses, o maior representante desse tipo de energia final são os produtos de cana, cuja utilização é concentrada no Setor de Açúcar, incluído no Setor de Alimentos e Bebidas. O licor negro, subproduto da produção de papel e celulose, tem aplicação concentrada no Setor de Papel e Celulose. Separados esses tipos de energia final, devido sua aplicabilidade específica nesses setores, a biomassa e resíduos renováveis passa a responder por cerca de $13 \%$ da demanda de energia final do setor industrial, enquanto os produtos de cana por cerca de $20 \%$ e o licor negro por cerca de $7 \%$ (EPE, 2014), conforme Figura 4.3.

Figura 4.3 - Distribuição da demanda de energia final (com a biomassa detalhada por tipo) do setor industrial brasileiro (ano-base 2013)

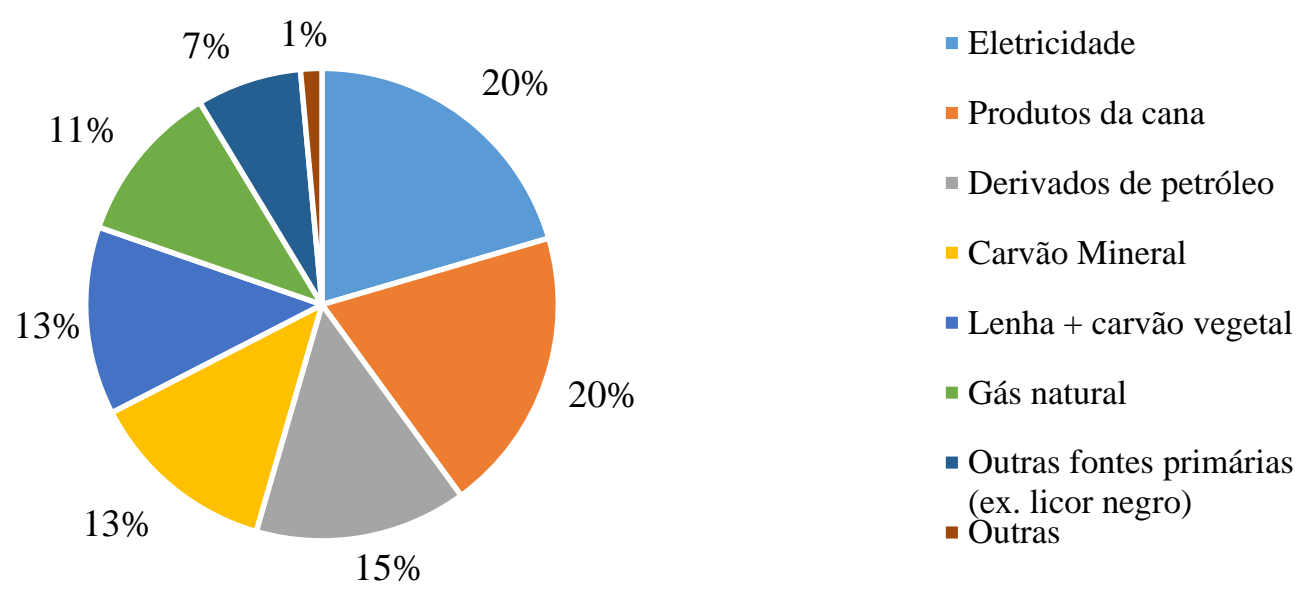

Fonte: Elaboração própria, baseado em EPE (2014).

Assim, os principais tipos de energia final consumidos de forma distribuída pelos diversos setores industriais brasileiros são a eletricidade e os derivados de petróleo. Cabe ainda uma observação sobre este último, que inclui uma gama de produtos, como o óleo combustível, o óleo diesel, o gás liquefeito de petróleo (GLP) e as "outras secundárias de petróleo", que incluem o coque de petróleo, o gás de refinaria, entre outros. Esse último tem aplicação majoritariamente concentrada em dois setores industriais, o cimenteiro e o químico, que respondem por mais de 70\% dessa demanda (EPE, 2014), conforme Figura 4.4. Os outros três primeiros têm uso mais difundido pelos setores industriais, sendo que a demanda de óleo combustível é a maior dentre eles e sua aplicação é exclusiva em usos finais térmicos, ao passo que o óleo diesel tem grande parte de sua utilização em força-motriz e o GLP tem sua aplicação dividida entre esses dois usos finais (MME/FDTE, 2005). 
Figura 4.4 - Distribuição dos tipos de derivados de petróleo demandados pelo setor industrial brasileiro (anobase 2013)

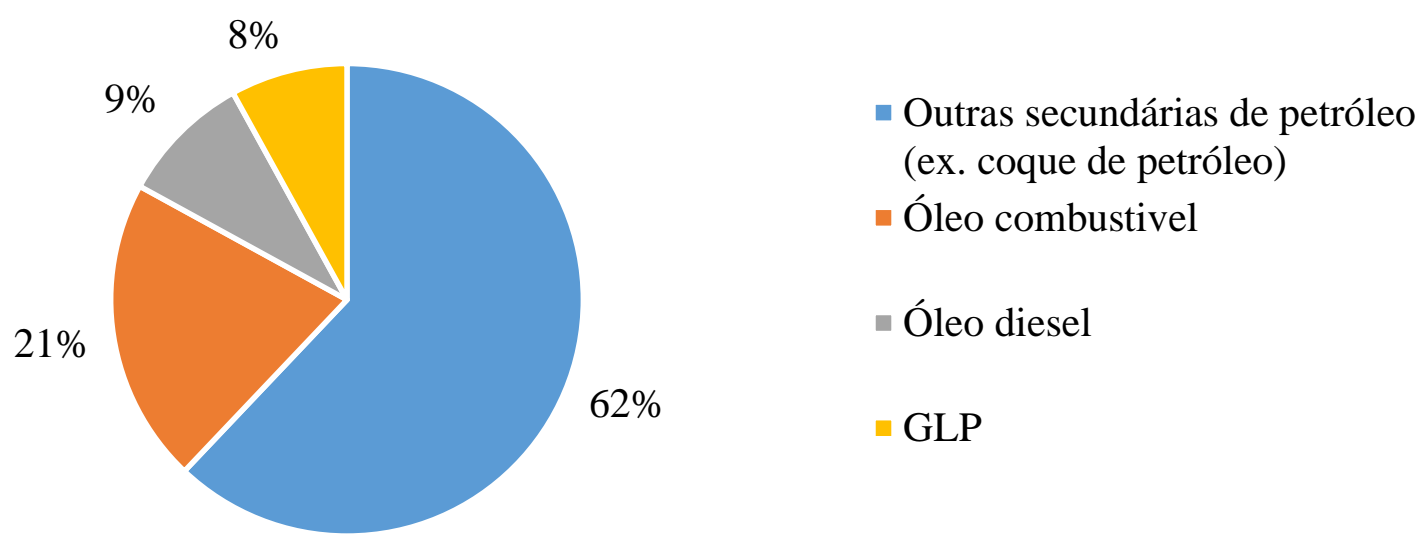

Fonte: Elaboração própria, baseado em EPE (2014).

Essa exposição, somada à apresentação feita na Introdução no Capítulo 1, sobre a eletrotermia, embasa a escolha dos tipos de energia final que serão alvos da substituição: a eletricidade e o óleo combustível.

\subsubsection{As limitações técnicas das substituições consideradas}

Considerações devem ser feitas sobre algumas limitações técnicas identificadas na substituição de eletricidade e óleo combustível por gás natural em processos térmicos. A necessidade dessa análise reside no fato de que as limitações podem impactar no potencial de substituição e, assim, na forma com que esse potencial deve ser estimado. Destaca-se que as limitações aqui identificadas cobrem apenas aspectos técnicos, não adentrando no mérito econômico ou de disponibilidade do gás natural.

Do ponto de vista do uso final de calor de processo, não existem limitações técnicas, pois os equipamentos desse uso final, como aquecedores e caldeiras, realizam a geração de calor a partir da energia final (eletricidade, óleo combustível, gás natural) para aquecer um fluido intermediário (água, vapor, óleo térmico). Assim, a despeito de cada tecnologia ter sua especificidade no que diz respeito ao projeto para utilizar os diferentes tipos de energia final, a saída desses equipamentos é a mesma, um fluido intermediário aquecido que, por sua vez, 
realiza troca de calor no equipamento dedicado do processo industrial onde está instalado (MME/FDTE, 2005; COSTA, 2013).

Já no caso do uso final de aquecimento direto, algumas limitações técnicas existem e são função de dois aspectos: o tipo de processo de transferência de calor prioritário e as condições da câmara de processo de transferência de calor (FERNANDES, 2008). O primeiro aspecto limitante é particularmente significativo quando se trata da radiação térmica, uma onda eletromagnética que possui a banda de comprimento de onda como apresentado na Figura 4.5.

Figura 4.5 - Espectro da radiação eletromagnética e os diferentes tipos de radiação

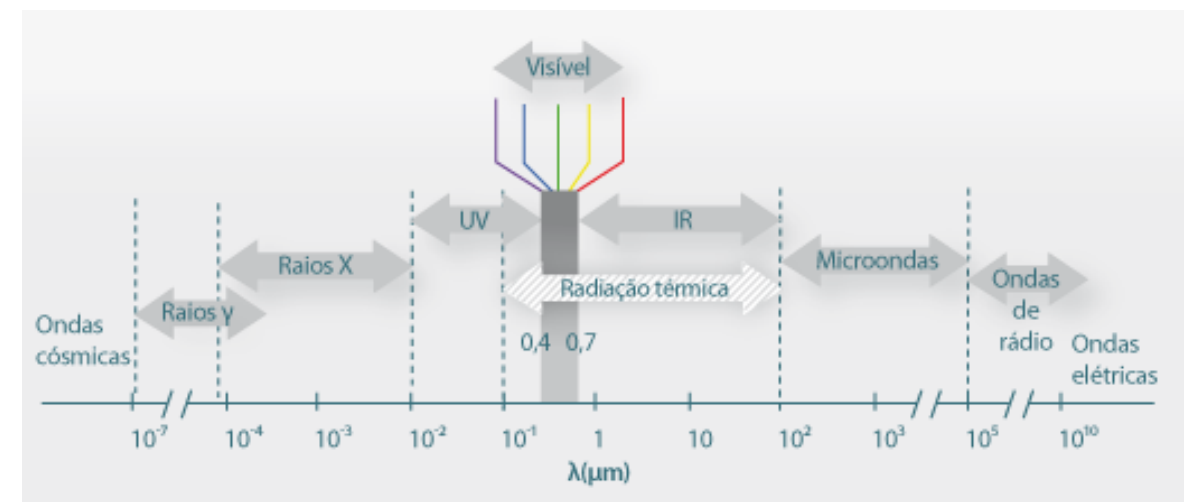

Fonte: PORTAL DE ENGENHARIA QUÍMICA (2018).

Segundo Siegel e Howell (1972), a agitação molecular e atômica associada com a energia interna de toda substância faz com que ela emita continuamente radiação eletromagnética. Em estado de equilíbrio, a energia interna é diretamente proporcional à temperatura, de modo que a quantidade de radiação emitida seja também proporcional à temperatura, como descreve a Lei de Stefan-Boltzmann (INCROPERA e DEWITT, 2008), na Equação 4.1 abaixo.

$\mathrm{E}_{\mathrm{cn}}=\sigma \cdot \mathrm{T}^{4}$

Onde $E_{\mathrm{cn}}$ é o poder emissivo total ${ }^{38}$ de um corpo negro, $\sigma$ é a constante de StefanBoltzmann $\left(\sigma=5,670 \cdot 10^{-8} \mathrm{~W} /\left(\mathrm{m}^{2} \cdot \mathrm{K}^{4}\right)\right.$ e T é a temperatura da superfície do corpo negro (em $\left.\mathrm{K}\right)$.

38 “O poder emissivo total é a quantidade de radiação emitida em todas as direções e ao longo de todos os comprimentos de onda” (INCROPERA e DEWITT, 2008). 
Outra relação importante é a que ocorre entre o comprimento de onda de máxima emissão de radiação e a temperatura, derivada da Distribuição de Planck $^{39}$, a Lei do Deslocamento de Wien estabelece essa relação, para um corpo negro ${ }^{40}$, pela Equação 4.2 abaixo.

$\lambda_{\max } \cdot \mathrm{T}=\mathrm{C}_{3}$

Onde $\lambda_{\max }$ é o comprimento de onda correspondente à máxima emissão de radiação, $\mathrm{T}$ é a temperatura da superfície do corpo negro (em K) e $\mathrm{C}_{3}$ é a terceira constante da radiação $\left(\mathrm{C}_{3}\right.$ $=2898 \mu \mathrm{m} . \mathrm{K})$.

Analisando então a queima de combustíveis como a emissão de um corpo negro, como tratado em British Gas (1992), os gases como o hidrogênio, oxigênio e nitrogênio não emitem ou absorvem radiação térmica e, desta forma, não contribuem para a transferência de calor por radiação. Já a radiação envolvendo $\mathrm{CO}_{2}$ e $\mathrm{H}_{2} \mathrm{O}$ estão na região do infravermelho, sendo importantes emissores e absorvedores de radiação térmica. Assim, desde que a chama produza concentração significante, eles desempenham uma parte importante na transferência de calor por radiação em fornos industriais. Destaca-se nesse processo a fuligem ${ }^{41}$, que emite em um espectro contínuo na banda visível e infravermelho e é extremamente importante e pode dobrar ou triplicar o calor que será radiado, em comparação aos produtos de combustão gasosos.

${ }^{39}$ A Distribuição de Plank descreve o poder emissivo de um corpo negro em função do comprimento de onda e da temperatura através da seguinte equação: $\mathrm{E}_{\mathrm{cn}}(\lambda, \mathrm{T})=\mathrm{C}_{1} /\left\{\lambda^{5} \cdot\left[\exp \left(\frac{\mathrm{C}_{2}}{\lambda . \mathrm{T}}\right)-1\right]\right\}$, onde $\mathrm{E}_{\mathrm{cn}}(\lambda, \mathrm{T})$ é o poder emissivo de um corpo negro em função do comprimento de onda e da temperatura, $\lambda$ é o comprimento de onda de emissão de radiação, $\mathrm{T}$ é a temperatura da superfície do corpo negro, $\mathrm{C}_{1}$ é a primeira constante de radiação $\left(\mathrm{C}_{1}=3,742.10^{8}\right.$ W. $\left.\mu \mathrm{m}^{4} / \mathrm{m}^{2}\right)$ e $\mathrm{C}_{2}$ é a segunda constante da radiação $\left(\mathrm{C}_{2}=1,439 \cdot 10^{4} \mu \mathrm{m} . \mathrm{K}\right)$. (INCROPERA e DEWITT, 2008).

${ }^{40} \mathrm{O}$ corpo negro é a definição de um absorvedor e emissor de radiação perfeito, servindo de comparação para as superfícies reais. Segundo Incropera e Dewitt (2008):

Um corpo negro absorve toda a radiação incidente, independentemente de seu comprimento de onda e de sua direção; para uma dada temperatura e comprimento de onda, nenhuma superfície pode emitir mais energia que um corpo negro; embora a radiação emitida por um corpo negro seja uma função do comprimento de onda e da temperatura, ela é independente da direção, isto é, o corpo negro é um emissor difuso (INCROPERA e DEWITT, 2008, p. 466).

\footnotetext{
${ }^{41}$ Segundo Britsh Gas (1992), a fuligem são partículas de carbono finamente divididas que não foram consumidas na combustão.
} 
Esta análise explica porque a queima do gás natural, majoritariamente composto por metano $\left(\mathrm{CH}_{4}\right)$, um hidrocarboneto cuja molécula contém apenas um átomo de carbono, apresenta uma radiação menor do que a queima de óleo combustível, que possuem hidrocarbonetos cujas moléculas contém um número de átomos de carbono muito maior ${ }^{42}$. Essa diferença pode limitar a substituição de óleo combustível por gás natural em casos particulares, havendo uma necessidade de avaliação caso a caso do processo produtivo.

Dentre os equipamentos de aquecimento direto elétricos ${ }^{43}$, os que usam a radiação térmica como processo de transferência de calor possuem resistências nas quais a corrente elétrica passa e a eletricidade é convertida majoritariamente em calor ${ }^{44}$, pelo chamado Efeito Joule $^{45}$. Tendo em vista a Lei de Deslocamento de Wien, equipamentos de aquecimento direto elétricos resistivos podem ter a faixa de maior emissão de radiação ajustadas em termos de comprimento de onda devido à maior facilidade no controle da temperatura do emissor que depende diretamente do quadrado da corrente, como descrito pela Lei de Joule ${ }^{45}$.

Para substituir esses equipamentos elétricos, os equivalentes a gás natural devem possuir queimadores com estruturas que permitam uma melhor distribuição da radiação térmica, assim como alcançar níveis de densidade de potência similares. Queimadores com superfícies radiantes podem trabalhar nessas situações, como apresentado por Comgas e Abrinstal (2016), atingindo níveis de densidade e distribuição de potência equiparáveis a de equipamentos elétricos como os apresentados por IBREL (2011). Esse tipo de tecnologia será comentado novamente adiante quando da discussão sobre as condições da câmara de processo.

O segundo aspecto limitante na substituição no uso final de aquecimento direto, ou seja, as condições da câmara de processo, decorre do fato que podem existir restrições do contato da

\footnotetext{
42 Segundo ANP (2018b), o óleo combustível é uma mistura de hidrocarbonetos cujas cadeias podem ter até 39 átomos de carbono.

${ }^{43}$ Existem outros tipos de equipamento de aquecimento direto elétrico com uso de micro-ondas, indução e arco elétrico (FINOCCHIO, 2014). Para essas tecnologias, uma substituição por um equipamento a gás natural deve ser estudada caso a caso.

${ }^{44}$ Parte da eletricidade também é convertida em luz (a parte da radiação térmica que está na região do visível apontada no espectro da Figura 4.1).

${ }^{45} \mathrm{O}$ fenômeno de dissipação de calor em um corpo atravessado por uma corrente elétrica é conhecido como como Efeito Joule. Potência de calor (P) dissipado quando uma corrente elétrica de intensidade (i) atravessa um fio com resistência elétrica $(\mathrm{R})$ é dado por $\mathrm{P}=\mathrm{R} . \mathrm{i}^{2}$. (PASSOS, 2009)
} 
carga a ser aquecida com os gases de combustão, por razões de possível contaminação, ataque químico, alteração de cores e/ou oxidação da carga, entre outros, o que é indesejável (COSTA, 2013). Um exemplo dessa situação são os fornos de recozimento brilhante no setor metalmecânico, onde a superfície do metal deve estar numa atmosfera controlada para evitar oxidação (COMGAS e ABRINSTAL, 2016).

Nesse aspecto, a eletricidade não sofre limitação, somente as formas de energia química que necessitem de combustão para a liberação de calor. O óleo combustível tem grandes limitações nesse aspecto, tendo em vista a presença de longas cadeias de carbono, o que aumenta a possibilidade de formação de fuligem e ao mesmo tempo demanda maior nível de excesso de $\mathrm{ar}^{46}$, conforme Considine ${ }^{47}$ (1977, apud PINHEIRO e VALLE, 1995), o que por sua vez aumenta a concentração de oxigênio nos gases de combustão, aumentando o efeito de oxidação na carga. O gás natural é visto nesse caso como um substituto direto ao óleo combustível por reduzir significativamente a produção de fuligem e necessitar um menor excesso de ar, gerando uma combustão mais limpa (PINHEIRO e VALLE, 1995).

Ainda no primeiro aspecto, a indústria de equipamentos a gás natural mantém um contínuo desenvolvimento de alternativas aos equipamentos elétricos para essas aplicações. $\mathrm{O}$ maior foco de desenvolvimento está nas estruturas que segregam os gases de combustão da carga, sendo os tubos radiantes e as superfícies radiantes (ou muflas) as tecnologias mais conhecidas. No primeiro caso, os queimadores estão instalados dentro de tubos que, por sua vez, estão instalados no interior da câmara de processo do equipamento a ser aquecido. Durante o processo, a queima ocorre dentro do tubo radiante, os gases de combustão percorrem o tubo e são liberados para o exterior do equipamento, sem contato com a carga, como ilustrado na Figura 4.6. A troca de calor ocorre por radiação, emitida pelas paredes do tubo radiante que

\footnotetext{
${ }^{46} \mathrm{O}$ excesso de ar é um parâmetro usual para avaliar o ar de combustão, definido como a porcentagem em que o fluxo de ar excede o requisito teórico de ar (RTA). Por exemplo, 100\% de excesso de ar indica uma taxa de fluxo de ar na combustão que é o dobro do RTA. O excesso de ar é indicado para garantir a combustão completa, ou seja, a conversão total do combustível nos dois produtos de combustão em estágio de oxidação mais elevado (água e dióxido de carbono). O RTA é definido como o número de volumes de ar necessário para a combustão estequiométrica por volume de combustível. A combustão estequiométrica de um combustível hidrocarboneto $\mathrm{C}_{\mathrm{x}} \mathrm{H}_{\mathrm{y}}$ com o ar (simplificadamente $20 \% \quad \mathrm{O}_{2}$ e $80 \% \quad \mathrm{~N}_{2}$ ) pode ser descrita pela seguinte equação: $\mathrm{C}_{\mathrm{x}} \mathrm{H}_{\mathrm{y}}+\left(\mathrm{x}+\frac{\mathrm{y}}{4}\right) \cdot\left[\mathrm{O}_{2}+3,76 \cdot \mathrm{N}_{2}\right] \stackrel{\text { calor inicial }}{\longrightarrow} \mathrm{x} \cdot \mathrm{CO}_{2}+\frac{\mathrm{y}}{2} \cdot \mathrm{H}_{2} \mathrm{O}+3,76 \cdot\left(\mathrm{x}+\frac{\mathrm{y}}{4}\right) \cdot \mathrm{N}_{2}$. Assim, é possível determinar que RTA é igual a 4,76.( $\mathrm{x}+\mathrm{y} / 4)$. (JONES, 1989)

${ }^{47}$ CONSIDINE, D. M. Energy technology handbook. Nova Iorque: McGraw-Hill, 1977.
} 
foram aquecidas pelos gases de combustão (COSTA, 2013; COMGAS e ABRINSTAL, 2016; ENGIE, 2016).

Figura 4.6 - Exemplos de tipos de queimadores com tubo radiante (um tubo reto e um tubo em U), à esquerda, e um exemplo de aplicação (forno contínuo), à direita
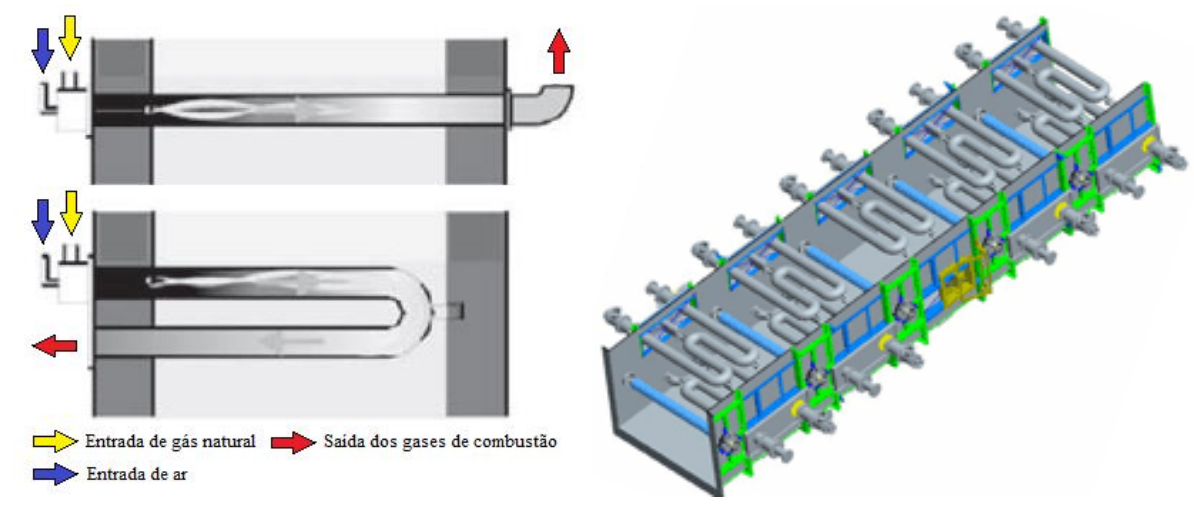

Fonte: Flamme et al. (2011) e Primetals (2018).

Figura 4.7 - Estrutura dos queimadores com superfície radiante, à esquerda, e exemplo de aplicação (queimador usado na secagem de papel), à direita
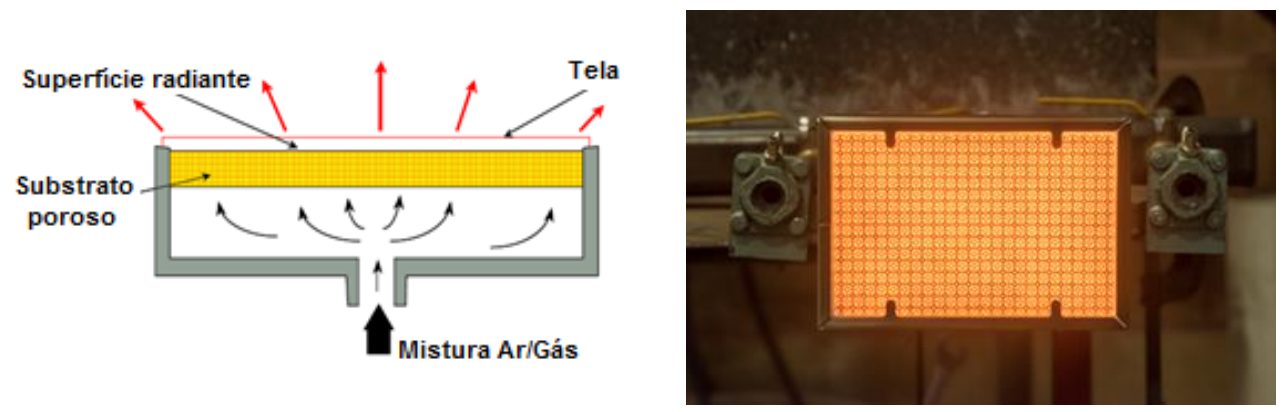

Fonte: Singh e Bennett (1999) e Selas (2018)

No segundo caso, as superfícies radiantes confinam as chamas da queima dentro de uma estrutura metálica ou cerâmica no formato de placas. Essas estruturas se aquecem e emitem calor para o interior da câmara de processo por radiação, como ilustrado na Figura 4.7. Entretanto, ao contrário aos tubos radiantes, as superfícies radiantes não são estanques e os gases de combustão atravessam a sua estrutura, ou seja, parte da troca de calor ocorre também pela convecção desses gases que chegam à carga numa temperatura inferior à da chama. Dessa forma, o uso de superfícies radiantes pode demandar um anteparo adicional (como uma placa de vidro) pode ser necessário para isolar completamente os gases de combustão da carga (COSTA, 2013; COMGAS e ABRINSTAL, 2016; ENGIE, 2016). 


\subsection{Aplicação da técnica de análise de dados para as substituições consideradas}

A aplicação da técnica de análise de dados para as substituições de eletricidade e óleo combustível em processos térmicos no setor industrial brasileiro será desenvolvida nesta seção em três etapas. Inicialmente será feita a definição, na forma de equações matriciais, dos indicadores definidos na técnica de análise de dados. A segunda etapa consiste no levantamento das informações necessárias para o cálculo dos indicadores, como o balanço de energia final por uso final, os fatores de conversão, e, por fim, a estimação do potencial de substituição. As etapas desenvolvidas nessa seção permitem o cálculo dos indicadores, cujo resultado final será apresentado na Seção 4.3.

\subsubsection{A definição dos indicadores}

Dessa forma, considerando a substituição de eletricidade (E) e óleo combustível (o) por gás natural $(\mathrm{GN})$ em processos térmicos $(\mathrm{T})$ em um setor industrial $(\mathrm{s})$, os indicadores desenvolvidos na técnica de análise de dados, segundo as Equações 3.24 a 3.27, e no formato matricial, como na Equação 3.29, podem ser escritos como as Equações 4.3 a 4.6 abaixo:

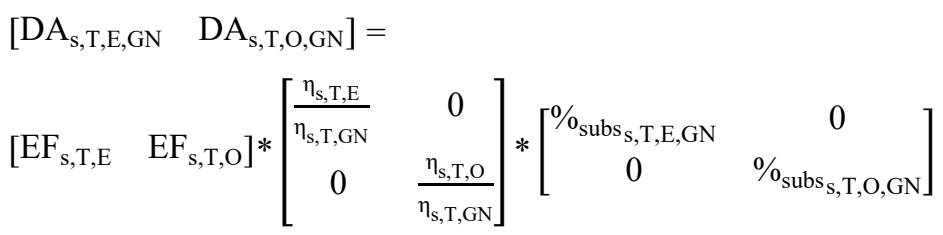

Onde $\mathrm{DA}_{\mathrm{S}, \mathrm{T}, \mathrm{E}, \mathrm{GN}}$ é a demanda adicional por gás natural pela substituição de eletricidade em processos térmicos para o setor industrial tratado, $\mathrm{DA}_{\mathrm{s}, \mathrm{T}, \mathrm{O}, \mathrm{GN}}$ é a demanda adicional por gás natural pela substituição de óleo combustível em processos térmicos para o setor industrial tratado, $\mathrm{EF}_{\mathrm{S}, \mathrm{T}, \mathrm{E}}$ é a demanda de eletricidade em processos térmicos para o setor industrial tratado, $\mathrm{EF}_{\mathrm{s}, \mathrm{T}, \mathrm{O}}$ é a demanda de óleo combustível em processos térmicos para o setor industrial tratado, $\eta_{\mathrm{s}, \mathrm{T}, \mathrm{E}}$ é a eficiência do equipamento de uso final elétrico para o setor industrial tratado, $\eta_{\mathrm{s}, T, \mathrm{E}}$ é a eficiência do equipamento de uso final a óleo combustível para o setor industrial 
tratado, $\eta_{\mathrm{s}, \mathrm{T}, \mathrm{GN}}$ é a eficiência do equipamento de uso final a gás natural para o setor industrial tratado, $\%_{\text {subs }_{\text {S,T,E,GN }}}$ é a porcentagem de eletricidade substituída por gás natural em processos

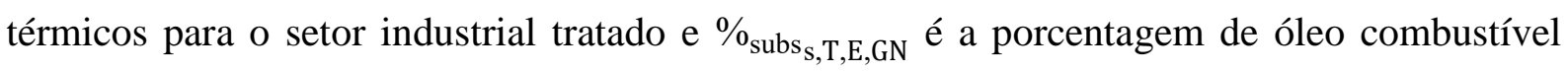
substituída por gás natural em processos térmicos para o setor industrial tratado.

$$
\begin{aligned}
& {\left[\operatorname{IEP}_{\mathrm{S}, \mathrm{T}, \mathrm{E}, \mathrm{GN}} \quad \mathrm{IEP}_{\mathrm{s}, \mathrm{T}, \mathrm{O}, \mathrm{GN}}\right]=} \\
& {\left[\begin{array}{ll}
\mathrm{EF}_{\mathrm{s}, \mathrm{T}, \mathrm{E}} & \mathrm{EF}_{\mathrm{s}, \mathrm{T}, \mathrm{O}}
\end{array}\right] *\left[\begin{array}{cc}
\left(\frac{\eta_{\mathrm{s}, \mathrm{T}, \mathrm{E}}}{\eta_{\mathrm{s}, \mathrm{T}, \mathrm{GN}}}\right) \cdot \mathrm{FCEP}_{\mathrm{GN}}-\mathrm{FCEP}_{\mathrm{E}} & 0 \\
0 & \left(\frac{\eta_{\mathrm{s}, \mathrm{T}, \mathrm{O}}}{\eta_{\mathrm{s}, \mathrm{T}, \mathrm{GN}}}\right) \cdot \mathrm{FCEP}_{\mathrm{GN}}-\mathrm{FCEP}_{\mathrm{O}}
\end{array}\right] *\left[\begin{array}{cc}
\%_{\text {subs }_{\mathrm{s}, \mathrm{T}, \mathrm{E}, \mathrm{GN}}} & 0 \\
0 & \%_{\text {subs }_{\mathrm{s}, \mathrm{T}, \mathrm{O}, \mathrm{GN}}}
\end{array}\right]}
\end{aligned}
$$

Onde $\mathrm{IEP}_{\mathrm{S}, \mathrm{T}, \mathrm{E}, \mathrm{GN}}$ é o indicador de Impacto em Energia Primária devido à substituição de eletricidade por gás natural em processos térmicos para o setor industrial tratado, $\mathrm{IEP}_{\mathrm{s}, \mathrm{T}, \mathrm{O}, \mathrm{GN}} \mathrm{O}$ indicador de Impacto em Energia Primária devido à substituição de óleo combustível por gás natural em processos térmicos para o setor industrial tratado, $\mathrm{EF}_{\mathrm{S}, \mathrm{T}, \mathrm{E}}$ é a demanda de eletricidade em processos térmicos para o setor industrial tratado, $\mathrm{EF}_{\mathrm{S}, \mathrm{T}, \mathrm{O}}$ é a demanda de óleo combustível em processos térmicos para o setor industrial tratado, $\eta_{\mathrm{s}, \mathrm{T}, \mathrm{E}}$ é a eficiência do equipamento de uso final elétrico para o setor industrial tratado, $\eta_{\mathrm{s}, \mathrm{T}, \mathrm{E}}$ é a eficiência do equipamento de uso final a óleo combustível para o setor industrial tratado, $\eta_{\mathrm{s}, \mathrm{T}, \mathrm{GN}}$ é a eficiência do equipamento de uso final a gás natural para o setor industrial tratado, $\mathrm{FCEP}_{\mathrm{E}}$ é o fator de conversão em energia primária para eletricidade, $\mathrm{FCEP}_{0}$ é o fator de conversão em energia primária para óleo combustível, $\mathrm{FCEP}_{\mathrm{GN}}$ é o fator de conversão em energia primária para gás natural, $\%_{\mathrm{subs}} \mathrm{s,T,E,GN}$ é a porcentagem de eletricidade substituída por gás natural em processos térmicos para o setor industrial tratado e \% $\%_{\text {subs }_{\text {S,TE,GN }}}$ é a porcentagem de óleo combustível substituída por gás natural em processos térmicos para o setor industrial tratado.

$$
\begin{aligned}
& {\left[\mathrm{IEC}_{\mathrm{s}, \mathrm{T}, \mathrm{E}, \mathrm{GN}} \quad \mathrm{IEC}_{\mathrm{s}, \mathrm{T}, \mathrm{O}, \mathrm{GN}}\right]=} \\
& {\left[\begin{array}{ll}
\mathrm{EF}_{\mathrm{s}, \mathrm{T}, \mathrm{E}} & \mathrm{EF}_{\mathrm{s}, \mathrm{T}, \mathrm{O}}
\end{array}\right] *\left[\begin{array}{cc}
\left(\frac{\eta_{\mathrm{s}, \mathrm{T}, \mathrm{E}}}{\eta_{\mathrm{s}, \mathrm{T}, \mathrm{GN}}}\right) \cdot \mathrm{FEm}_{\mathrm{GN}}-\mathrm{FEm}_{\mathrm{E}} & 0 \\
0 & \left(\frac{\eta_{\mathrm{s}, \mathrm{T}, \mathrm{O}}}{\eta_{\mathrm{s}, \mathrm{T}, \mathrm{GN}}}\right) \cdot \mathrm{FEm}_{\mathrm{GN}}-\mathrm{FEm}_{\mathrm{O}}
\end{array}\right] *\left[\begin{array}{cc}
\%_{\text {subs }_{\mathrm{s}, \mathrm{T}, \mathrm{E}, \mathrm{GN}}} & 0 \\
0 & \%_{\mathrm{subs}_{\mathrm{s}, \mathrm{T}, \mathrm{O}, \mathrm{GN}}}
\end{array}\right]}
\end{aligned}
$$

Onde $\mathrm{IEC}_{\mathrm{S}, \mathrm{T}, \mathrm{E}, \mathrm{GN}}$ é o indicador de Impacto em Emissões de Carbono devido à substituição de eletricidade por gás natural em processos térmicos para o setor industrial tratado, $\mathrm{IEC}_{\mathrm{s}, \mathrm{T}, \mathrm{O}, \mathrm{GN}}$ o indicador de Impacto em Emissões de Carbono devido à substituição de óleo combustível por 
gás natural em processos térmicos para o setor industrial tratado, $\mathrm{EF}_{\mathrm{s}, \mathrm{T}, \mathrm{E}}$ é a demanda de eletricidade em processos térmicos para o setor industrial tratado, $\mathrm{EF}_{\mathrm{s}, \mathrm{T}, \mathrm{O}}$ é a demanda de óleo combustível em processos térmicos para o setor industrial tratado, $\eta_{\mathrm{s}, \mathrm{T}, \mathrm{E}}$ é a eficiência do equipamento de uso final elétrico para o setor industrial tratado, $\eta_{\mathrm{s}, \mathrm{T}, \mathrm{E}}$ é a eficiência do equipamento de uso final a óleo combustível para o setor industrial tratado, $\eta_{\mathrm{s}, \mathrm{T}, \mathrm{GN}}$ é a eficiência do equipamento de uso final a gás natural para o setor industrial tratado, $\mathrm{FEm}_{\mathrm{E}}$ é o fator de emissão de $\mathrm{CO}_{2}$ para eletricidade, $\mathrm{FEm}_{\mathrm{O}}$ é o fator de emissão de $\mathrm{CO}_{2}$ para óleo combustível, $\mathrm{FEm}_{\mathrm{GN}}$ é o fator de emissão de $\mathrm{CO}_{2}$ para gás natural, $\%_{\text {subs }_{\mathrm{s}, \mathrm{T}, \mathrm{E}, \mathrm{GN}}}$ é a porcentagem de eletricidade substituída por gás natural em processos térmicos para o setor industrial tratado e $\%_{\text {subs }_{\mathrm{S}, \mathrm{T}, \mathrm{E}, \mathrm{GN}}}$ é a porcentagem de óleo combustível substituída por gás natural em processos térmicos para o setor industrial tratado.

$$
\begin{aligned}
& {\left[\mathrm{ICE}_{\mathrm{S}, \mathrm{T}, \mathrm{E}, \mathrm{GN}} \quad \mathrm{ICE}_{\mathrm{s}, \mathrm{T}, \mathrm{O}, \mathrm{GN}}\right]=} \\
& {\left[\begin{array}{ll}
\mathrm{EF}_{\mathrm{s}, \mathrm{T}, \mathrm{E}} & \mathrm{EF}_{\mathrm{s}, \mathrm{T}, \mathrm{O}}
\end{array}\right] *\left[\begin{array}{cc}
\left(\frac{\eta_{\mathrm{s}, \mathrm{T}, \mathrm{E}}}{\eta_{\mathrm{s}, \mathrm{T}, \mathrm{GN}}}\right) \cdot \mathrm{p}_{\mathrm{GN}}-\mathrm{p}_{\mathrm{E}} & 0 \\
0 & \left(\frac{\eta_{\mathrm{s}, \mathrm{T}, \mathrm{O}}}{\eta_{\mathrm{s}, \mathrm{T}, \mathrm{GN}}}\right) \cdot \mathrm{p}_{\mathrm{GN}}-\mathrm{p}_{\mathrm{O}}
\end{array}\right] *\left[\begin{array}{cc}
\%_{\text {subs }_{\mathrm{s}, \mathrm{T}, \mathrm{E}, \mathrm{GN}}} & 0 \\
0 & \%_{\text {subs }_{\mathrm{s}, \mathrm{T}, \mathrm{O}, \mathrm{GN}}}
\end{array}\right]}
\end{aligned}
$$

Onde $\mathrm{ICE}_{\mathrm{S}, \mathrm{T}, \mathrm{E}, \mathrm{GN}}$ é o indicador de Impacto em Custo Energético devido à substituição de eletricidade por gás natural em processos térmicos para o setor industrial tratado, $\mathrm{ICE}_{\mathrm{S}, \mathrm{T}, \mathrm{O}, \mathrm{GN}} \mathrm{O}$ indicador de Impacto em Custo Energético devido à substituição de óleo combustível por gás natural em processos térmicos para o setor industrial tratado, $\mathrm{EF}_{\mathrm{s}, \mathrm{T}, \mathrm{E}}$ é a demanda de eletricidade em processos térmicos para o setor industrial tratado, $\mathrm{EF}_{\mathrm{s}, \mathrm{T}, \mathrm{O}}$ é a demanda de óleo combustível em processos térmicos para o setor industrial tratado, $\eta_{\mathrm{s}, \mathrm{T}, \mathrm{E}}$ é a eficiência do equipamento de uso final elétrico para o setor industrial tratado, $\eta_{\mathrm{s}, \mathrm{T}, \mathrm{E}}$ é a eficiência do equipamento de uso final a óleo combustível para o setor industrial tratado, $\eta_{\mathrm{s}, \mathrm{T}, \mathrm{GN}}$ é a eficiência do equipamento de uso final a gás natural para o setor industrial tratado, $\mathrm{p}_{\mathrm{E}}$ é o preço (ou tarifa) para eletricidade, $\mathrm{p}_{\mathrm{O}}$ é o preço (ou tarifa) para óleo combustível, $\mathrm{p}_{\mathrm{GN}}$ é o preço (ou tarifa) para gás natural, $\%_{\text {subs }_{\mathrm{s}, \mathrm{T}, \mathrm{E}, \mathrm{GN}}}$ é a porcentagem de eletricidade substituída por gás natural em processos térmicos para o setor industrial tratado e $\%_{\text {subs }_{\text {S,T,E,GN }}}$ é a porcentagem de óleo combustível substituída por gás natural em processos térmicos para o setor industrial tratado. 


\subsubsection{O balanço de energia final por uso final}

Baseado no Balanço de Energia Útil - BEU (MME/FDTE, 2005) - e no Balanço Energético Nacional - BEN (EPE, 2014) - é possível se construir o balanço de energia final por uso final necessário para a avalição. Uma primeira observação deve ser feita e diz respeito aos setores industriais presentes em cada balanço. São tratados no BEN os seguintes setores industriais: Setor de Alimentos e Bebidas; Setor Cerâmico; Setor Cimenteiro; Setor de FerroGusa e Aço; Setor de Ferro-Ligas; Setor de Mineração e Pelotização; Setor de Não-Ferrosos e Outros da Metalurgia; Setor de Papel e Celulose; Setor Químico e Setor Têxtil. (EPE, 2014). No BEU estão presentes algumas subdivisões desses setores: o Setor de Mineração e Pelotização é dividido em dois, um para Mineração e outro para Pelotização; o Setor de NãoFerrosos e Outros da Metalurgia é dividido em dois, um para Alumínio e outro para Outros Produtos Não-Ferrosos; e o Setor de Alimentos e Bebidas é dividido em dois, um para Alimentos e Bebidas Exceto Açúcar e outro para Açúcar (MME/FDTE, 2005).

Figura 4.8 - Comparação da distribuição do percentual do consumo energético por energia final e por uso final entre o Setor de Alimentos e Bebidas Exceto Açúcar e do Setor de Açúcar

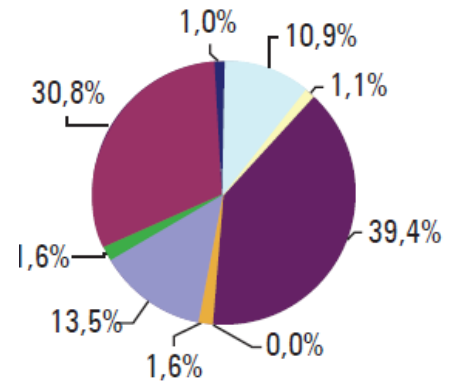

Alimentos e Bebidas excl. Açucar

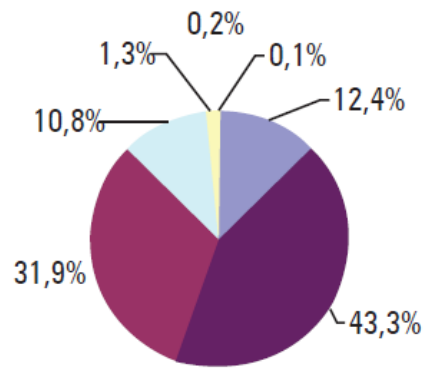

Alimentos e Bebidas excl. Açucar

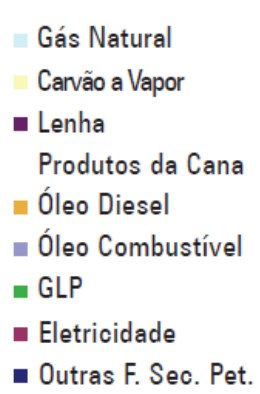

- Outras F. Sec. Pet.

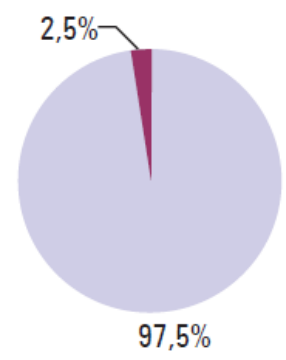

Açucar

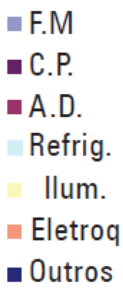

- Outros

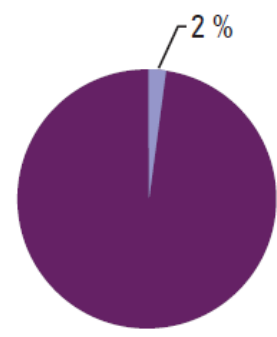

$98 \%$

Açucar

Fonte: Rocha, Bajay e Gorla (2010)

Nota: Outras F. Sec. Pet. significa Outras Fontes Secundárias de Petróleo, F.M. significa força-motriz, C.P. significa calor de processo, A.D. significa aquecimento direto, Refrig. significa refrigeração, Ilum. significa iluminação e Eletroq significa eletroquímica. 
Opta-se por manter a divisão presente no BEN, exceto no tocante do Setor de Alimentos e Bebidas, para o qual será considerado apenas o Setor de Alimentos e Bebidas Exceto Açúcar. A razão para essa escolha está na diferença significativa entre a composição da demanda de energia final e dos usos finais presentes entre o Setor de Alimentos e Bebidas Exceto Açúcar e o Setor de Açúcar, particularmente devido às características do Setor de Açúcar que possui uma grande utilização de bagaço de cana como insumo energético, como pode ser observado nas Figura Figura 4.8. Essa diferença impacta na avaliação geral do Setor de Alimentos e Bebidas o que traria problemas na comparação com outros países, visto que o Setor de Açúcar brasileiro só seria comparável ao indiano ${ }^{48}$.

Assim, tendo em vista essa organização dos setores industriais, do BEN é extraído a distribuição da demanda de energia final em função destes, ao passo que do BEU são extraídos os coeficientes de destinação, que relacionam como cada tipo de energia final é destinada em termos de usos finais para cada setor industrial tratado. O resultado do balanço está apresentado na Tabela 4.1 abaixo.

Tabela 4.1 - Balanço de energia final por uso final considerando a eletricidade e o óleo combustível em processos térmicos por setor industrial

\begin{tabular}{ccc}
\hline Setor $(\mathrm{s})$ & $\mathrm{EF}_{\mathrm{s}, \mathrm{T}, \mathrm{E}}(\mathrm{TJ})$ & $\mathrm{EF}_{\mathrm{s}, \mathrm{T}, \mathrm{O}}(\mathrm{TJ})$ \\
\hline Alimentos e Bebidas (Exceto Açúcar) & 22404 & 7998 \\
Cerâmicas & 1005 & 5235 \\
Cimento & 0 & 712 \\
Ferro-Gusa e Aço & 5193 & 1675 \\
Ferro-Ligas & 25293 & 2596 \\
Mineração e Pelotização & 2345 & 8501 \\
Não-Ferrosos e Outros Da Metalurgia & 39657 & 48074 \\
Papel e Celulose & 2136 & 12647 \\
Química & 3057 & 17755 \\
Têxtil & 1549 & 1926 \\
\hline
\end{tabular}

Fonte: Elaboração própria, baseada em (MME/FDTE, 2005; EPE, 2014).

\footnotetext{
${ }^{48}$ De acordo com FAO (2017a), em 2016, o Brasil respondeu por 36\% da área plantada e 38\% da produção em toneladas de cana de açúcar, em escala mundial. A título de comparação, nesta mesma referência, a Índia responde por $17 \%$ nos dois indicadores, e os outros 103 países representam $47 \%$ e $45 \%$ respectivamente.
} 


\subsubsection{Os fatores de conversão necessários}

O próximo passo para o cálculo dos indicadores apresentados nas Equações 4.1 a 4.4 é a determinação dos fatores de conversão necessários. O primeiro deles é a eficiência do equipamento de uso final de energia, que pode ser obtida do BEU, sendo os dados apresentados na Tabela 4.2.

O segundo é o fator de conversão em energia primária $\left(\mathrm{FCEP}_{\mathrm{f}}\right)$ para a eletricidade, o óleo combustível e o gás natural. Para os dois últimos são adotados os valores apresentados por Leslie (2014), sendo FCEPo igual a 1,19 e FCEP $_{\mathrm{GN}}$ igual a 1,09. Já para o caso da eletricidade, o FCEPE é calculado através da Equação 3.21, sendo necessário o levantamento do rendimento médio das termoelétricas com uso de combustíveis fósseis presente no mix de geração $\left(\eta_{\mathrm{GTf} \text {,médio }}\right)$ e a porcentagem de perdas na transmissão e distribuição de eletricidade $\left(\mathrm{P}_{\mathrm{T \& D}, \mathrm{E}}\right)$. Esses dois parâmetros podem ser obtidos do EPE (2014), sendo $\eta_{\mathrm{GTf} \text {,médio }}$ igual a 42,3\% e $\mathrm{P}_{\mathrm{T \& D}, \mathrm{E}}$ igual a 16,6\% (relação entre perdas e total de eletricidade gerado). Assim, o FCEP $\mathrm{E}$ é igual a 2,84 .

Tabela 4.2 - Eficiência do equipamento de uso final de energia considerando a eletricidade, o óleo combustível e o gás natural em processos térmicos por setor industrial

\begin{tabular}{cccc}
\hline Setor $(\mathrm{s})$ & $\eta_{\mathrm{s}, \mathrm{T}, \mathrm{E}}(\%)$ & $\eta_{\mathrm{s}, \mathrm{T}, \mathrm{O}}(\%)$ & $\eta_{\mathrm{s}, \mathrm{T}, \mathrm{GN}}(\%)$ \\
\hline Alimentos e Bebidas & 81 & 64 & 76 \\
Cerâmicas & 76 & 64 & 64 \\
Cimento & 75 & 59 & 59 \\
Ferro-Gusa e Aço & 77 & 64 & 64 \\
Ferro-Ligas & 77 & 64 & 64 \\
Mineração e Pelotização & 66 & 61 & 64 \\
Não-Ferrosos e Outros Da Metalurgia & 55 & 69 & 60 \\
Papel e Celulose & 97 & 83 & 88 \\
Química & 83 & 72 & 88 \\
Têxtil & 85 & 84 & 86 \\
\hline
\end{tabular}

Fonte: Elaboração própria, baseada em MME/FDTE (2005). 
O terceiro fator de conversão necessário é o fator de emissões $\left(\mathrm{FEm}_{\mathrm{f}}\right)$ para a eletricidade, o óleo combustível e o gás natural. Para os dois últimos são adotados os valores apresentados por IPCC (1997), sendo FEmo igual a 21,1 tC/TJ e FEM $\mathrm{GN}_{\mathrm{GN}}$ igual a 15,3 tC/TJ. Ainda segundo IPCC (1997), para converter as emissões de tC/TJ em $\mathrm{tCO}_{2} / \mathrm{TJ}$ é necessário multiplicar o valor por 44/12. Assim, FEmo passa a 77,4 $\mathrm{tCO}_{2} / \mathrm{TJ}$ e $\mathrm{FEM}_{\mathrm{GN}}$ a $56,1 \mathrm{tCO}_{2} / \mathrm{TJ}$. Já para o caso da eletricidade, inicialmente é necessário definir a abordagem de cálculo, se média ou marginal, conforme apresentado na Subseção 3.1.2. Tendo em vista que a eletricidade vai ser substituída marginalmente, pois os processos térmicos representam menos de $30 \%$ da demanda de eletricidade como energia final e apenas parte dessa demanda será substituída, a abordagem de cálculo adotada será a marginal. Assim, FEmE pode ser calculado a partir de uma combinação das Equações 3.22 e 3.23, resultando na Equação 4.7.

$\mathrm{FEm}_{\mathrm{E}, \text { marginal }}=\mathrm{FEm}_{\mathrm{E}, \text { médio }} / \% \mathrm{GTf}$

Onde $\mathrm{FEm}_{\mathrm{E} \text {,marginal }}$ é o fator de emissões de $\mathrm{CO}_{2}$ marginal da eletricidade, $\mathrm{FEm}_{\mathrm{E} \text {,médio }}$ é o fator de emissões de $\mathrm{CO}_{2}$ médio da eletricidade e \%GTf é a participação no mix de geração de eletricidade da geração termoelétrica com uso de combustíveis fosseis. Esse último

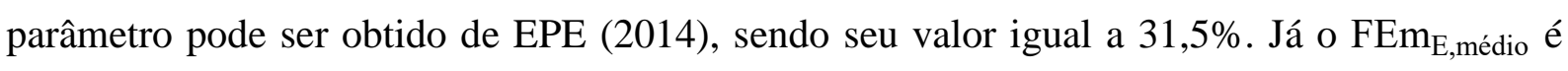
obtido através da referência de MCTIC (2017), onde este fator vale 0,096 tCO $/ \mathrm{MWh}$, ou seja,

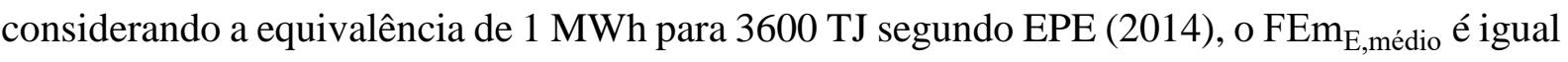

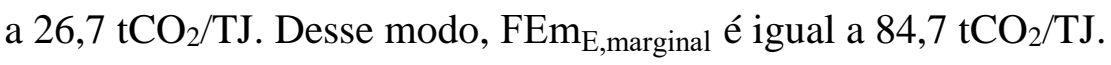

Finalmente, o último fator de conversão é o preço (ou tarifa) ( $\mathrm{p}_{\mathrm{f}}$ ) da eletricidade, do óleo combustível e do gás natural. O valor desse fator para a eletricidade ( $\mathrm{p}_{\mathrm{E}}$ ) é adotado de FIRJAN (2017), sendo igual a R \$336,08/MWh, ou seja, considerando a equivalência de $1 \mathrm{MWh}$ para

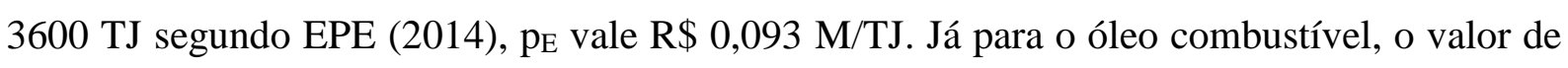
po é adotado de MME (2014), sendo igual a R \$220/bep, ou seja, considerando a equivalência de 1 bep para 5950 TJ segundo EPE (2014), o po vale R \$ 0,037 M/TJ. Finalmente, para o gás natural é adotado o valor de MME (2015), assim $\mathrm{p}_{\mathrm{GN}}$ é igual a $\mathrm{R} \$ 1,32 / \mathrm{m}^{3} \mathrm{GN}$, ou seja, considerando a equivalência de $1 \mathrm{~m}^{3} \mathrm{GN}$ para 36,84 TJ segundo BEM, o p $\mathrm{GN}$ vale $\mathrm{R}$ \$ 0,036 M/TJ.

Os fatores de conversão em energia primária, fator de emissão de CO2 e preço (ou tarifa) para a eletricidade, o óleo combustível e o gás natural em processos térmicos necessários para a avaliação dos indicadores das Equações 4.1 a 4.4 estão resumidos na Tabela 4.3 abaixo. 
Tabela 4.3 - Fator de conversão em energia primária, fator de emissão de $\mathrm{CO}_{2}$ e preço (ou tarifa) considerando a eletricidade, o óleo combustível e o gás natural em processos térmicos

\begin{tabular}{cccc}
\hline Energia final $(\mathrm{f})$ & $\mathrm{FCEP}_{\mathrm{f}}(\mathrm{TJ} / \mathrm{TJ})$ & $\mathrm{FEm}_{\mathrm{f}}\left(\mathrm{tCO}_{2} / \mathrm{TJ}\right)$ & $\mathrm{p}_{\mathrm{f}}(\mathrm{R} \$ \mathrm{M} / \mathrm{TJ})$ \\
\hline Eletricidade & 2,84 & 84,7 & 0,093 \\
Óleo combustível & 1,19 & 77,4 & 0,037 \\
Gás natural & 1,09 & 56,1 & 0,036 \\
\hline
\end{tabular}

Fonte: Elaboração própria, baseada em (IPCC, 1997; EPE, 2014; Leslie, 2014; MME, 2014, 2015; MCTIC, 2017; FIRJAN, 2017).

\subsubsection{O potencial das substituições}

Esta é a última etapa para permitir o cálculo dos indicadores e envolve a estimação do potencial das substituições consideradas na Seção 4.1. Uma primeira avaliação do potencial de substituição de óleo combustível por gás natural em processos térmicos $\left(\%_{\text {subs }_{\mathrm{s}, \mathrm{T}, \mathrm{O}, \mathrm{GN}}}\right)$ deve levar em consideração as limitações apontadas na Subseção 4.1.3. A partir de MME/FDTE (2005) e EPE (2014) é possível verificar que repartição de óleo combustível entre os dois usos finais considerados dentro dos processos térmicos é quase equânime (52\% para calor de processo e $48 \%$ para aquecimento direto). Assim, como não há limitações técnicas para a substituição em calor de processo, ao menos $52 \%$ do óleo combustível pode ser substituído. Já no caso de aquecimento direto, em alguns casos a substituição depende da escolha de equipamentos com características de transferência de calor semelhante ou de uma conversão que leve esse fator em consideração, havendo soluções para as duas situações (FERNANDES, 2008). Dessa forma, pode-se considerar que, no limite, há um potencial de substituição de $100 \%$ do óleo combustível por gás natural em processos térmicos $\left(\%_{\mathrm{subs}_{\mathrm{s}, \mathrm{T}, \mathrm{O}, \mathrm{GN}}}=100 \%\right)$.

O caso substituição da eletricidade é mais complexo, tendo em vista a variedade de tecnologias empregadas e as limitações, tanto do processo de transferência de calor como das condições da câmara de processo. Assim, opta-se por estimar o potencial de substituição de eletricidade por gás natural em processos térmicos $\left(\%_{\mathrm{subs}_{\mathrm{s}, \mathrm{T}, \mathrm{E}, \mathrm{GN}}}\right)$ através de um benchmarking de análise em escala macro, como descrito na Subseção 3.3.2. Essa estimativa será feita com 
base na Equação 3.28, que, utilizando as definições dos indicadores da Subseção 4.2.1, resulta na Equação 4.8 abaixo:

$$
\%_{\text {subs }_{\mathrm{s}, \mathrm{T}, \mathrm{E}, \mathrm{GN}}}=\left(1-\% \mathrm{EF}_{\mathrm{s}, \mathrm{T}, \mathrm{E}, \mathrm{benchmark}} / \% \mathrm{EF}_{\mathrm{s}, \mathrm{T}, \mathrm{E}}\right) /\left(1+\% \mathrm{EF}_{\mathrm{s}, \mathrm{T}, \mathrm{E}, \text { benchmark }} \cdot\left(\eta_{\mathrm{s}, \mathrm{T}, \mathrm{E}} / \eta_{\mathrm{s}, \mathrm{T}, \mathrm{GN}}-1\right)\right)
$$

Onde $\%_{\text {subs }_{\mathrm{s}, \mathrm{T}, \mathrm{E}, \mathrm{GN}}}$ é potencial de substituição de eletricidade por gás natural em processos térmicos, $\% \mathrm{EF}_{\mathrm{S}, \mathrm{T}, \mathrm{E}}$ é a participação da eletricidade nos processos térmicos do setor industrial tratado, $\% \mathrm{EF}_{\mathrm{S}, \mathrm{T}, \mathrm{E} \text {, benchmark }}$ é a participação da eletricidade nos processos térmicos do setor industrial tratado em uma referência, $\eta_{\mathrm{s}, \mathrm{T}, \mathrm{E}}$ é a eficiência de equipamentos elétricos em processos térmicos e $\eta_{\mathrm{s}, \mathrm{T}, \mathrm{GN}}$ é a eficiência de equipamentos a gás em processos térmicos.

Em Gallo et al. (2017), já foi apresentada uma primeira avalição, nesse caso com uso de uma base de dados de balanços de energia final por uso final para levantamento detalhado da participação da eletricidade nos processos térmicos do setor industrial para diferentes países, cujas referências foram:

- Estados Unidos, com o balanço de energia final por uso final da EIA (2013);

- Reino Unido, com o balanço de energia final por uso final do DECC (2015);

- Nova Zelândia, com o balanço de energia final por uso final reportado da EECA (2012);

- Europa-OCDE, com uma combinação entre o balanço de energia final da IEA (2015b) e um estudo sobre a destinação do uso da energia final nos usos finais para alguns setores industriais de FLEITER et al. (2016);

A vantagem dessa abordagem estava na coleta de dados detalhados, o que permitia uma comparação entre as participações da eletricidade nos processos térmicos do setor industrial do Brasil e dessas referências diretamente, sem necessidade de nenhuma hipótese para a comparação. Uma desvantagem está no número reduzido de referências, assim, para a estimativa que será apresentada aqui foi adotada a estratégia de construir uma base de dados a partir de balanços de energia final publicados pela IEA (2015a, 2015b).

No entanto, esses balanços não trazem informação detalhada sobre a destinação do uso final dos tipos de energia final retratados. Considerando que, pela formulação apontada na Equação 3.28, o potencial de substituição pode ser observado como um potencial de redução no uso final do tipo de energia final a ser substituída, pode-se partir da seguinte premissa: o 
potencial calculado com uso da base de dados com balanços de energia final pode ser observado como um potencial de conservação de eletricidade aplicável a todos usos finais e, no caso de processos térmicos, essa conservação se dá através da substituição por gás natural. Essa premissa se apoia na existência de importantes potenciais de conservação de eletricidade nos setores industriais brasileiros, conforme apresentado por CNI/Eletrobras (2010).

Assim, a Equação 4.8 passa a ser reescrita para aplicação com a base de dados de balanços de energia final, como a Equação 4.9 abaixo.

$\%_{\text {subs }_{\mathrm{s}, \mathrm{T}, \mathrm{E}, \mathrm{GN}}}=\left(1-\% \mathrm{EF}_{\mathrm{s}, \mathrm{E}, \text { benchmark }} / \% \mathrm{EF}_{\mathrm{s}, \mathrm{E}}\right) /\left(1+\% \mathrm{EF}_{\mathrm{s}, \mathrm{E}, \text { benchmark }} \cdot\left(\eta_{\mathrm{s}, \mathrm{T}, \mathrm{E}} / \eta_{\mathrm{s}, \mathrm{T}, \mathrm{GN}}-1\right)\right)$

Onde $\%_{\text {subs }_{\mathrm{S}, \mathrm{T}, \mathrm{E}, \mathrm{GN}}}$ é potencial de substituição de eletricidade por gás natural em processos térmicos, $\% \mathrm{EF}_{\mathrm{S}, \mathrm{E}}$ é a participação da eletricidade na demanda de energia final do setor industrial tratado, $\% \mathrm{EF}_{\mathrm{s}, \mathrm{E}, \text { benchmark }}$ a participação da eletricidade na demanda de energia final do setor industrial tratado em uma referência, $\eta_{\mathrm{s}, \mathrm{T}, \mathrm{E}}$ é a eficiência de equipamentos elétricos em processos térmicos e $\eta_{\mathrm{s}, \mathrm{T}, \mathrm{GN}}$ é a eficiência de equipamentos a gás em processos térmicos.

A base de dados é construída com balanços de energia final publicados pela IEA (2015a, 2015b). Uma primeira triagem dos países presentes foi feita em função de uma característica fundamental dos dados presentes nos balanços, a repartição por setor da demanda de eletricidade, sem a qual não é possível calcular a sua participação na demanda de energia final do setor. Essa triagem resultou numa lista de 33 países membros da OCDE e 26 países nãomembros da OCDE, além do Brasil, apresentada na Tabela A.1, no Apêndice A. Para cada país presente nessa tabela são apresentados balanços de energia final resumidos nas Tabelas A.2 e A.3.

Entretanto, são feitas mais triagens nos países a serem considerados para cada setor industrial, adotando-se critérios objetivos para que cada setor industrial tenha pelo menos 5 e no máximo 15 países de referência. O limite inferior decorre da representatividade mínima de cerca de $10 \%$ da base de dados, enquanto que o limite superior representa $25 \%$ da base de dados e permite que mais de um critério de triagem seja utilizado para setores com mais países representativos. 
O segundo critério de triagem é que a participação da eletricidade na demanda de energia final de cada setor industrial deve ser menor que a participação da eletricidade na demanda de energia final do mesmo setor industrial brasileiro. Esse é um critério fundamental, pois buscase países com menor participação da eletricidade na demanda de energia final. Entretanto, em um caso esse critério é flexibilizado (Setor de Papel e Celulose) em que é aceitável uma participação até $20 \%$ maior que a observada no respectivo setor industrial brasileiro. A adoção dessa flexibilização permite que o limite mínimo de países seja atendido por esse setor industrial.

Após essa segunda triagem, cinco setores industriais já possuem um número de países de referência na faixa de 5 a 15, são eles (entre parênteses o número de países de referência): Setor de Ferro e Aço (7), Setor de Minerais Não-Metálicos (6), Setor de Metais Não-Ferrosos (11), Setor de Mineração (12) e Setor de Papel e Celulose (5). Os outros três setores industriais possuem mais que 15 países de referência, são eles (entre parênteses o número de países de referência): Setor de Alimentos e Bebidas (32), Setor Químico (24) e Setor Têxtil (42).

Assim, uma triagem adicional pode ser feita, que consiste na verificação da participação da demanda de energia final desses setores industriais em relação à demanda de energia final do país em que ele se encontra. Assim, pode-se avaliar a importância energética desses setores industriais nos países presentes na base de dados e comparar essa importância com a do respectivo setor industrial no Brasil. Nessa triagem o critério é estabelecido caso a caso, em função do setor industrial, de modo a reduzir o número de países de referência a 15. Em resumo, os critérios foram: no caso do Setor de Alimentos e Bebidas, a participação mínima é equivalente a 1,45 vezes a participação desse setor no Brasil; no caso do Setor Químico, a participação mínima é equivalente a 1,3 vezes a participação desse setor no Brasil; no caso do Setor Têxtil, a participação mínima é equivalente a 1,55 vezes a participação desse setor no Brasil.

O resultado da triagem, com a lista de países de referência para os setores industriais e a participação da eletricidade na demanda de energia final em cada setor industrial por país, está apresentado nas Tabelas A.4 e A.5, localizadas no Apêndice A. 
A partir dos valores apresentados após a triagem é calculada então uma média e estabelecido seu intervalo de confiança ${ }^{49}$ (IC) de $95 \%$, cujos resultados por setor industrial são apresentados na Tabela 4.4. A título de comparação também foi incluído nessa Tabela $4.4^{50} \mathrm{o}$ valor da participação da eletricidade na demanda de energia final em cada setor industrial observada no Brasil, também baseada em IEA (2015a, 2015b).

Tabela 4.4 - Resultados sobre a participação da eletricidade na demanda de energia final em cada setor industrial

\begin{tabular}{lcccccccc}
\cline { 2 - 8 } & \multicolumn{7}{c}{ Setor (s) } \\
\cline { 2 - 8 } & A\&B & F\&A & MIN & MNF & MNM & P\&C & QUI & TEX \\
\hline Limite inferior do IC & $19 \%$ & $10 \%$ & $14 \%$ & $21 \%$ & $5 \%$ & $11 \%$ & $15 \%$ & $40 \%$ \\
Média & $24 \%$ & $13 \%$ & $20 \%$ & $29 \%$ & $7 \%$ & $16 \%$ & $19 \%$ & $46 \%$ \\
Limite superior do IC & $29 \%$ & $17 \%$ & $25 \%$ & $38 \%$ & $9 \%$ & $20 \%$ & $22 \%$ & $51 \%$ \\
Brasil & $34 \%$ & $18 \%$ & $32 \%$ & $45 \%$ & $11 \%$ & $16 \%$ & $29 \%$ & $59 \%$ \\
\hline
\end{tabular}

Fonte: Elaboração própria.

Nota: O intervalo pode não ser simétrico devido aos arredondamentos.

Antes de estimar o potencial de substituição é preciso fazer um ajuste no tocante à divisão em setores industriais, dado que a divisão presente nas Tabelas 4.1 e 4.2 diferem das Tabelas A.2 a A.5, pois as primeiras são baseadas em MME/FDTE (2005) e EPE (2014), enquanto as últimas são baseadas no IEA (2015a, 2015b). A equivalência setorial é apresentada a seguir na Tabela 4.5. Esse ajuste tem impactos nos dados presentes nas Tabelas 4.1 e 4.2. No caso da primeira tabela é necessário somar os valores dos setores industriais que foram agregados em uma única categoria. Já para a segunda tabela deve ser feita uma média ponderada

\footnotetext{
${ }^{49}$ Um intervalo de confiança (IC) é um modo de apresentar a estimativa de um parâmetro pelo relato de um intervalo de valores possíveis, com base em um grau de confiabilidade pré-estabelecido, chamado nível de confiança. O IC em questão é um intervalo de confiança da média de uma amostra, dado por: $\bar{x} \pm t_{\alpha / 2, n-1} \cdot\left(\frac{s}{\sqrt{n}}\right)$, onde $\bar{x}$ é a média da amostra, s é o desvio padrão da amostra, n é o número de elementos da amostra, 100.(1- $\alpha$ ) é o nível de confiança do intervalo e $t_{\alpha / 2, n-1}$ é o valor no qual a integral da função de distribuição de probabilidade $t$ de Student com n-1 graus de liberdade entre $-\mathrm{t}_{\alpha / 2, \mathrm{n}-1}$ e $\mathrm{t}_{\alpha / 2, \mathrm{n}-1}$ retorna o valor do nível de confiança (normalmente $t_{\alpha / 2, n-1}$ é obtido de valores tabelados em função do grau de liberdade (n-1) e do nível de confiança (100.(1- $\left.\alpha\right)$ ). (DEVORE, 2006)

${ }^{50}$ Para melhorar a diagramação das tabelas, a partir da Tabela 4.4 foram adotadas as seguintes siglas para os setores industriais: Setor de Alimentos e Bebidas Exceto Açúcar (A\&B), Setor de Ferro e Aço (F\&A), Setor de Mineração (MIN), Setor de Metais Não-Ferrosos (MNF), Setor de Minerais Não-Metálicos (MNM), Setor de Papel e Celulose (P\&C), Setor Químico (QUI) e Setor Têxtil (TEX).
} 
em função do consumo de cada tipo de energia final correspondente. Os valores das Tabelas 4.1 e 4.2 com os ajustes nos setores industriais se encontram nas Tabelas 4.6 e 4.7.

Tabela 4.5 - Equivalência dos setores industriais de diferentes referências bibliográficas e as siglas adotadas

\begin{tabular}{ccc}
\hline Sigla adotada & Setores segundo IEA & Setores segundo BEU / BEN \\
\hline A\&B & "Alimentos e Tabaco" & "Alimentos e Bebidas (Exceto Açúcar)" \\
F\&A & "Ferro e Aço" & "Ferro-gusa e Aço" + "Ferroligas" \\
MIN & "Mineração e Pedreiras" & "Mineração e Pelotização" \\
MNF & "Metais Não-Ferrosos" & "Não-ferrosos e Outros da Metalurgia" \\
MNM & "Minerais Não-Metálicos" & "Cimento" + "Cerâmica" \\
P\&C & "Papel, Celulose e Impressão" & "Papel e Celulose" \\
QUI & "Químico e petroquímico" & "Química" \\
TEX & "Têxtil e Couro" & "Têxtil" \\
\hline
\end{tabular}

Fonte: Elaboração própria, baseada em (MME/FDTE, 2005; EPE, 2014; IEA, 2015a, 2015b).

Tabela 4.6 - Tabela 4.1 com setores industriais ajustados

\begin{tabular}{lcccccccc}
\cline { 2 - 8 } & \multicolumn{8}{c}{ Setor (s) } \\
\cline { 2 - 9 } & A\&B & F\&A & MIN & MNF & MNM & P\&C & QUI & TEX \\
\hline $\mathrm{EF}_{\mathrm{s}, \mathrm{T}, \mathrm{E}}(\mathrm{TJ})$ & 22404 & 30486 & 2345 & 39657 & 1005 & 2136 & 3057 & 1549 \\
$\mathrm{EF}_{\mathrm{s}, \mathrm{T}, \mathrm{O}}(\mathrm{TJ})$ & 7998 & 4271 & 8501 & 48074 & 5947 & 12647 & 17755 & 1926 \\
\hline
\end{tabular}

Fonte: Elaboração própria, baseada em (MME/FDTE, 2005; EPE 2014).

Tabela 4.7 - Tabela 4.2 com setores industriais ajustados

\begin{tabular}{lcccccccc}
\cline { 2 - 8 } & \multicolumn{8}{c}{ Setor $(\mathrm{s})$} \\
\cline { 2 - 9 } & A\&B & F\&A & MIN & MNF & MNM & P\&C & QUI & TEX \\
\hline$\eta_{\mathrm{s}, \mathrm{T}, \mathrm{E}}(\%)$ & 81 & 77 & 66 & 55 & 75 & 97 & 83 & 85 \\
$\eta_{\mathrm{s}, \mathrm{T}, \mathrm{O}}(\%)$ & 64 & 64 & 61 & 69 & 64 & 83 & 72 & 84 \\
$\eta_{\mathrm{s}, \mathrm{T}, \mathrm{GN}}(\%)$ & 76 & 64 & 64 & 60 & 64 & 88 & 88 & 86 \\
\hline
\end{tabular}

Fonte: Elaboração própria, baseada em MME/FDTE (2005).

Agora, a partir dos resultados da Tabela 4.4 é possível estimar o potencial de substituição segundo a Equação 4.9, repetida abaixo, complementada dos dados da Tabela 4.7.

$\%_{\text {subs }_{\mathrm{s}, \mathrm{T}, \mathrm{E}, \mathrm{GN}}}=\left(1-\% \mathrm{EF}_{\mathrm{s}, \mathrm{E}, \text { benchmark }} / \% \mathrm{EF}_{\mathrm{s}, \mathrm{E}}\right) /\left(1+\% \mathrm{EF}_{\mathrm{s}, \mathrm{E}, \text { benchmark }} \cdot\left(\eta_{\mathrm{s}, \mathrm{T}, \mathrm{E}} / \eta_{\mathrm{s}, \mathrm{T}, \mathrm{GN}}-1\right)\right)$ 


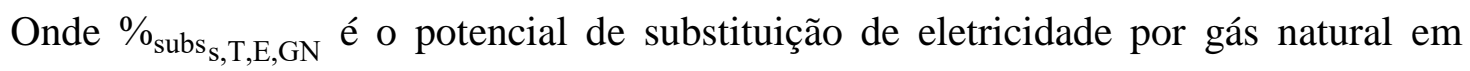
processos térmicos, $\% \mathrm{EF}_{\mathrm{s}, \mathrm{E} \text {,benchmark }}$ é a participação da eletricidade na demanda de energia final do setor industrial tratado de referência, $\% \mathrm{EF}_{\mathrm{s}, \mathrm{E}}$ é a participação da eletricidade na demanda de energia final do setor industrial tratado do Brasil (obtido da Tabela 4.4), $\eta_{\mathrm{s}, \mathrm{T}, \mathrm{E}}$ é a eficiência de equipamentos elétricos em processos térmicos (obtido da Tabela 4.7) e $\eta_{\mathrm{s}, \mathrm{T}, \mathrm{GN}}$ é a eficiência de equipamentos a gás em processos térmicos (obtido da Tabela 4.7).

O potencial de substituição de eletricidade por gás natural em processos térmicos $\left(\%_{\text {subs }_{\text {s,T,E,GN }}}\right)$ pode ser calculado em dois cenários: um cenário moderado, quando $\% \mathrm{EF}_{\mathrm{s}, \mathrm{E}, \text { benchmark }}$ é a média apresentada na Tabela 4.4; e um cenário agressivo, quando $\% \mathrm{EF}_{\mathrm{s}, \mathrm{E} \text {,benchmark }}$ é o limite inferior do IC da média apresentado na Tabela 4.4. Os resultados finais obtidos para os potenciais de substituição de eletricidade por gás natural em processos térmicos estão apresentados na Tabela 4.8 abaixo.

Tabela 4.8 - Resultado do potencial de substituição de eletricidade por gás natural em processos térmicos por setor industrial

\begin{tabular}{lccccccccc}
\cline { 2 - 8 } & \multicolumn{10}{c}{ Setor $(\mathrm{s})$} \\
\hline \% $_{\text {subs }}$ s,T,E,GN & $(\%)$ & A\&B & F\&A & MIN & MNF & MNM & P\&C & QUI & TEX \\
\hline Cenário moderado & 30 & 27 & 38 & 36 & 30 & 2 & 37 & 22 \\
Cenário agressivo & 45 & 47 & 55 & 55 & 48 & 30 & 50 & 31 \\
\hline
\end{tabular}

Fonte: Elaboração própria.

\subsection{Resultados finais dos indicadores}

Os resultados finais dos indicadores tanto para a substituição de eletricidade como de óleo combustível por gás natural em processos térmicos, calculados a partir das Equações 4.3 a 4.6 com os dados das Tabelas 4.3, 4.6, 4.7 e 4.8, são apresentados a seguir nesta seção, com uma subseção dedicada a cada indicador: Demanda Adicional (DA), Impacto em Energia Primária (IEP), Impacto em Emissões de $\mathrm{CO}_{2}$ (IEC) e Impacto em Custo Energético (ICE). 


\subsubsection{Resultados do indicador de Demanda Adicional (DA)}

Observando os resultados do indicador de Demanda Adicional através da Tabela 4.9 e das Figuras 4.9 e 4.10, os seguintes comentários podem ser feitos:

- o Setor de Metais Não-Ferrosos (MNF) é o setor com maior potencial de demanda adicional por gás natural através da substituição de óleo combustível em processos térmicos, num total de $1506 \mathrm{Mm}^{3} / \mathrm{ano}$, o que representa pouco mais da metade (51\%) do potencial total de demanda adicional por gás natural através da substituição de óleo combustível nos setores avaliados (2961 Mm³/ano);

- o Setor de Metais Não-Ferrosos (MNF) também tem destaque no potencial de demanda adicional por gás natural através da substituição de eletricidade em processos térmicos, entre 356 e $543 \mathrm{Mm}^{3} / \mathrm{ano}$, o que representa cerca de $40 \%$ do potencial total de demanda adicional por gás natural através da substituição de eletricidade nos setores avaliados (894 a 1427 Mm³/ano);

Tabela 4.9 - Resultados do indicador de Demanda Adicional (DA) para substituição de eletricidade e óleo combustível por gás natural em processos térmicos por setor industrial

\begin{tabular}{c|c|cc|c|cc}
\hline $\begin{array}{c}\text { Setor } \\
(\mathrm{s})\end{array}$ & $\begin{array}{c}\mathrm{DA}_{\mathrm{s}, \mathrm{T}, \mathrm{O}, \mathrm{GN}} \\
\left(\mathrm{Mm}^{3} / \mathrm{ano}\right)\end{array}$ & \multicolumn{2}{c|}{$\mathrm{DA}_{\mathrm{s}, \mathrm{T}, \mathrm{E}, \mathrm{GN}}\left(\mathrm{Mm}^{3} / \mathrm{ano}\right)$} & $\mathrm{DA}_{\mathrm{s}, \mathrm{T}, \mathrm{O}, \mathrm{GN}}$ & \multicolumn{2}{c}{$\mathrm{DA}_{\mathrm{s}, \mathrm{T}, \mathrm{E}, \mathrm{GN}}(\% \mathrm{OIGN})$} \\
\hline A\&B & 183 & 195 & 293 & $0,56 \%$ & $0,60 \%$ & $0,89 \%$ \\
F\&A & 116 & 269 & 468 & $0,35 \%$ & $0,82 \%$ & $1,43 \%$ \\
MIN & 221 & 25 & 36 & $0,68 \%$ & $0,08 \%$ & $0,11 \%$ \\
MNF & 1506 & 356 & 543 & $4,60 \%$ & $1,09 \%$ & $1,66 \%$ \\
MNM & 161 & 10 & 15 & $0,49 \%$ & $0,03 \%$ & $0,05 \%$ \\
P\&C & 325 & 1 & 19 & $0,99 \%$ & $0,00 \%$ & $0,06 \%$ \\
QUI & 398 & 29 & 39 & $1,22 \%$ & $0,09 \%$ & $0,12 \%$ \\
TEX & 51 & 9 & 13 & $0,16 \%$ & $0,03 \%$ & $0,04 \%$ \\
TOTAL & 2961 & 894 & 1427 & $9,05 \%$ & $2,74 \%$ & $4,76 \%$ \\
\hline
\end{tabular}

Fonte: Elaboração própria.

Nota: OIGN é a oferta interna de gás natural no Brasil, ano base 2013, obtida de MME (2015).

- outros setores com destaque no potencial de demanda adicional por gás natural através da substituição de eletricidade em processos térmicos são: o Setor de Ferro e Aço 
(F\&A), na faixa de 269 a $468 \mathrm{Mm} 3 /$ ano, o que representa cerca de $30 \%$ do potencial total de demanda adicional por gás natural através da substituição de eletricidade nos setores avaliados (894 a 1427 Mm³/ano); e o Setor de Alimentos e Bebidas (A\&B), na faixa de 195 a 293 Mm³/ano, o que representa cerca de $20 \%$ do potencial total de demanda adicional por gás natural através da substituição de eletricidade nos setores avaliados (894 a 1427 Mm³/ano);

Figura 4.9 - Indicador de Demanda Adicional (DA) para substituição de eletricidade e óleo combustível por gás natural em processos térmicos - resultados expressos em $\mathrm{Mm}^{3} / \mathrm{ano}$

2500,0

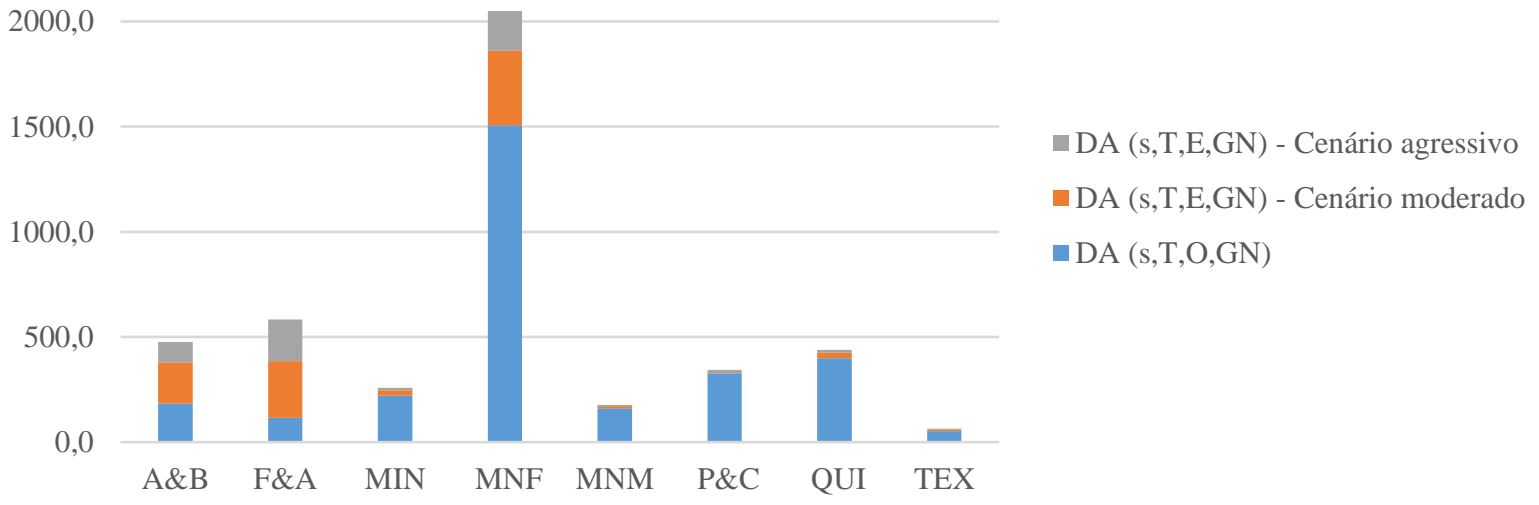

Fonte: Elaboração própria.

Nota: Os valores apresentados para o cenário agressivo são apenas o complementar em relação ao moderado.

Figura 4.10 - Indicador de Demanda Adicional (DA) para substituição de eletricidade e óleo combustível por gás natural em processos térmicos - resultados expressos em porcentagem da oferta interna de gás natural (ano-base 2013)

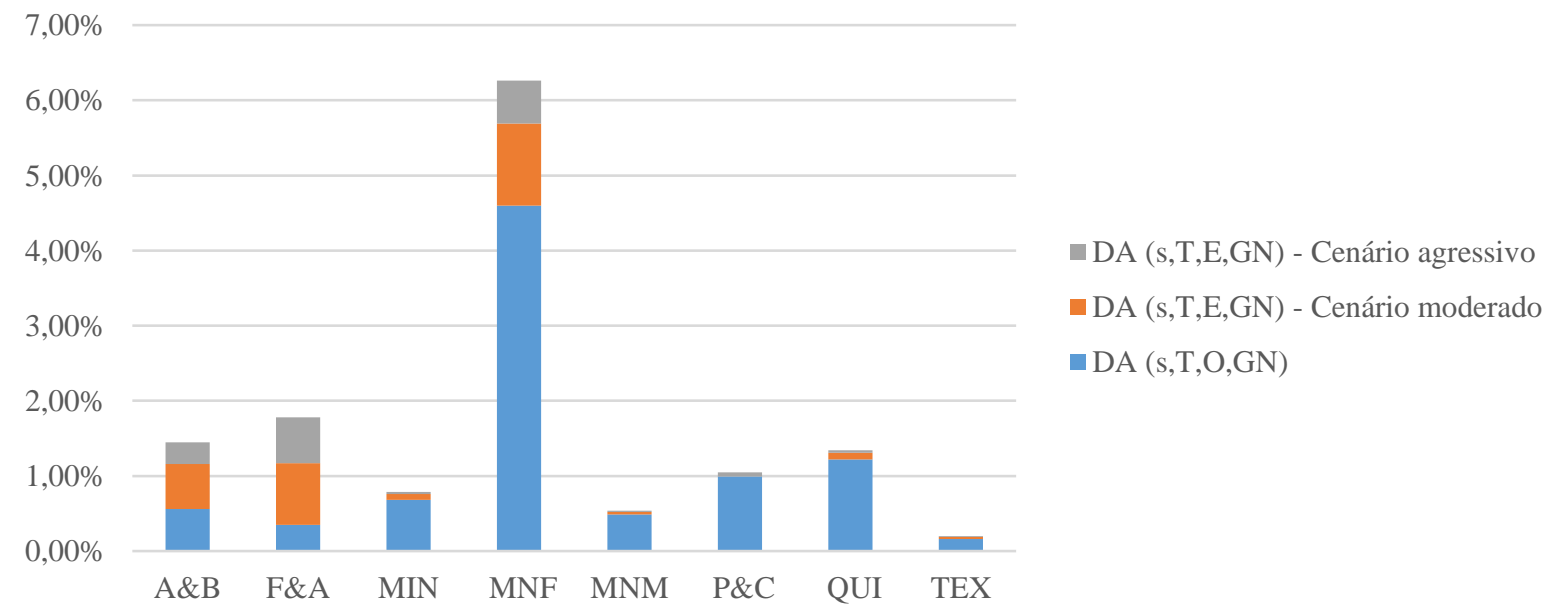

Fonte: Elaboração própria.

Nota: Os valores apresentados para o cenário agressivo são apenas o complementar em relação ao moderado. 
- considerando que a demanda de gás natural no setor industrial era de $10475 \mathrm{Mm} 3 /$ ano (no ano-base 2013), então o potencial total de demanda adicional por gás natural através da substituição de óleo combustível em processos térmicos é equivalente a $28 \%$ dessa demanda, ao passo que através da substituição de eletricidade em processos térmicos corresponde a uma faixa de 9 a $14 \%$;

- o potencial total de demanda adicional por gás natural através da substituição de óleo combustível em processos térmicos é equivalente a $9 \%$ da oferta interna de gás natural no Brasil em 2013, ao passo que através da substituição de eletricidade em processos térmicos corresponde a uma faixa de 3 a $5 \%$.

\subsubsection{Resultados do indicador de Impacto em Energia Primária (IEP)}

Observando os resultados do indicador de Impacto em Energia Primária (IEP) através da Tabela 4.10 e das Figuras 4.11 e 4.12, os seguintes comentários podem ser feitos:

- os diferentes fatores de conversão em energia primária entre eletricidade, óleo combustível e gás natural poderiam produzir um impacto linear a todos os setores industriais em função do primeiro indicador de Demanda Adicional (DA), entretanto, como foram adotadas diferentes eficiências do equipamento de uso final para cada setor industrial, os resultados não apresentam essa linearidade;

- considerando o IEP devido à substituição de óleo combustível em processos térmicos, o Setor Químico (QUI) é aquele que consegue reduzir a demanda de energia primária em maior escala absoluta (5 135 TJ/ano), seguido dos setores de Alimentos e Bebidas (A\&B) (2 169 TJ/ano) e Papel e Celulose (P\&C) (2 009 TJ/ano). Já do ponto de vista relativo, as maiores reduções setoriais de demanda de energia primária são observadas no Setor Químico (QUI) (1,11\%), Setor de Mineração (MIN) (0,55\%) e Setor de Alimentos e Bebidas (A\&B) (0,54\%).

- Um caso peculiar é do Setor de Metais Não-Ferrosos (MNF), pois o impacto foi positivo, ou seja, houve um aumento na demanda de energia primária (3 $245 \mathrm{TJ} / \mathrm{ano}$, absoluto; $0,59 \%$, relativo). Isso decorre do fato que, apesar do fator de conversão em energia 
primária ser favorável ao gás natural (1,09 contra 1,19), a eficiência do equipamento de uso final neste setor era desfavorável ao gás natural (60\% contra 69\%);

Tabela 4.10 - Resultados do indicador de Impacto em Energia Primária (IEP) para substituição de eletricidade e óleo combustível por gás natural em processos térmicos por setor industrial

\begin{tabular}{c|c|cc|c|cc}
\hline $\begin{array}{c}\text { Setor } \\
(\mathrm{s})\end{array}$ & $\begin{array}{c}\mathrm{IEP}_{\mathrm{s}, \mathrm{T}, \mathrm{O}, \mathrm{GN}} \\
(\mathrm{TJ} / \mathrm{ano})\end{array}$ & \multicolumn{2}{c|}{$\mathrm{IEP}_{\mathrm{s}, \mathrm{T}, \mathrm{E}, \mathrm{GN}}(\mathrm{TJ} / \mathrm{ano})$} & IEP $_{\mathrm{s}, \mathrm{T}, \mathrm{O}, \mathrm{GN}}$ & \multicolumn{2}{c}{$\mathrm{IEP}_{\mathrm{s}, \mathrm{T}, \mathrm{E}, \mathrm{GN}}\left(\% \mathrm{DEP}_{\mathrm{s}}\right)$} \\
\hline A\&B & -2169 & -11258 & -16887 & $-0,54 \%$ & $-2,80 \%$ & $-4,21 \%$ \\
F\&A & -427 & -12582 & -21902 & $-0,06 \%$ & $-1,68 \%$ & $-2,93 \%$ \\
MIN & -1240 & -1525 & -2207 & $-0,55 \%$ & $-0,68 \%$ & $-0,98 \%$ \\
MNF & 3245 & -26269 & -40133 & $0,59 \%$ & $-4,78 \%$ & $-7,30 \%$ \\
MNM & -595 & -471 & -754 & $-0,10 \%$ & $-0,08 \%$ & $-0,13 \%$ \\
P\&C & -2009 & -70 & -1050 & $-0,33 \%$ & $-0,01 \%$ & $-0,17 \%$ \\
QUI & -5135 & -2045 & -2763 & $-1,11 \%$ & $-0,44 \%$ & $-0,60 \%$ \\
TEX & -236 & -601 & -847 & $-0,24 \%$ & $-0,62 \%$ & $-0,88 \%$ \\
TOTAL & -8565 & -54820 & -86543 & $-0,24 \%$ & $-1,56 \%$ & $-2,46 \%$ \\
\hline
\end{tabular}

Fonte: Elaboração própria.

Nota: $\mathrm{DEP}_{\mathrm{s}}$ é a demanda de energia primária, por setor industrial, apresentada na Tabela A.6 do Apêndice A.

Figura 4.11 - Indicador de Impacto em Energia Primária (IEP) para substituição de eletricidade e óleo combustível por gás natural em processos térmicos - resultados expressos em TJ/ano

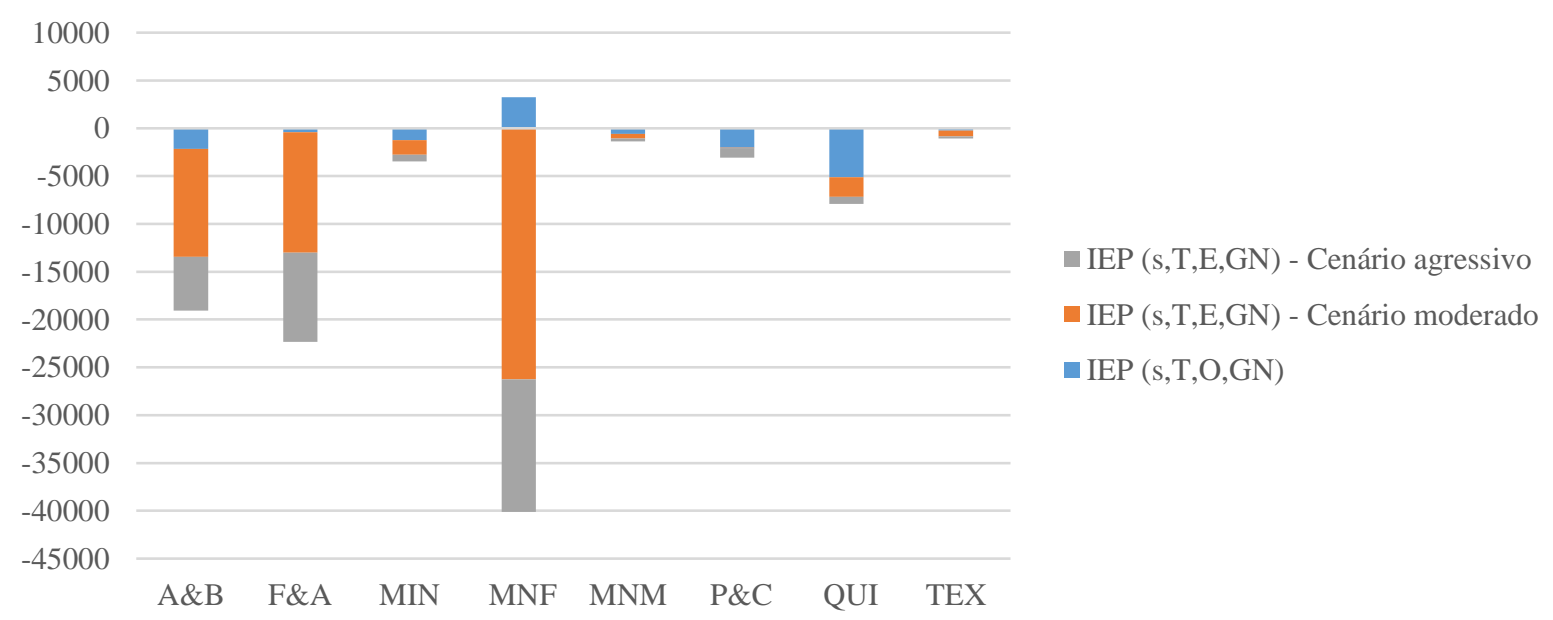

Fonte: Elaboração própria.

Nota: Os valores apresentados para o cenário agressivo são apenas o complementar em relação ao moderado.

- já quando analisado o IEP devido à substituição de eletricidade em processos térmicos, os três setores que se destacaram no indicador anterior voltam a aparecer com os três melhores indicadores. O Setor de Metais Não-Ferrosos (MNF) apresenta a maior 
redução absoluta e relativa (26 269 a 40133 TJ/ano; 4,78\% a 7,30\%), enquanto o Setor de Ferro e Aço (F\&A) apresenta a segunda maior redução absoluta (12 582 a 21902 TJ/ano) e a terceira maior relativa $(1,68 \%$ a $2,93 \%)$, trocando de posições com o Setor de Alimentos e Bebidas (A\&B) que ocupa respectivamente a terceira (11 258 a 16877 TJ/ano) e segunda $(2,80 \%$ a $4,21 \%)$ posições;

Figura 4.12 - Indicador de Impacto em Energia Primária (IEP) para substituição de eletricidade e óleo combustível por gás natural em processos térmicos - resultados expressos em porcentagem da demanda de energia primária de cada setor industrial

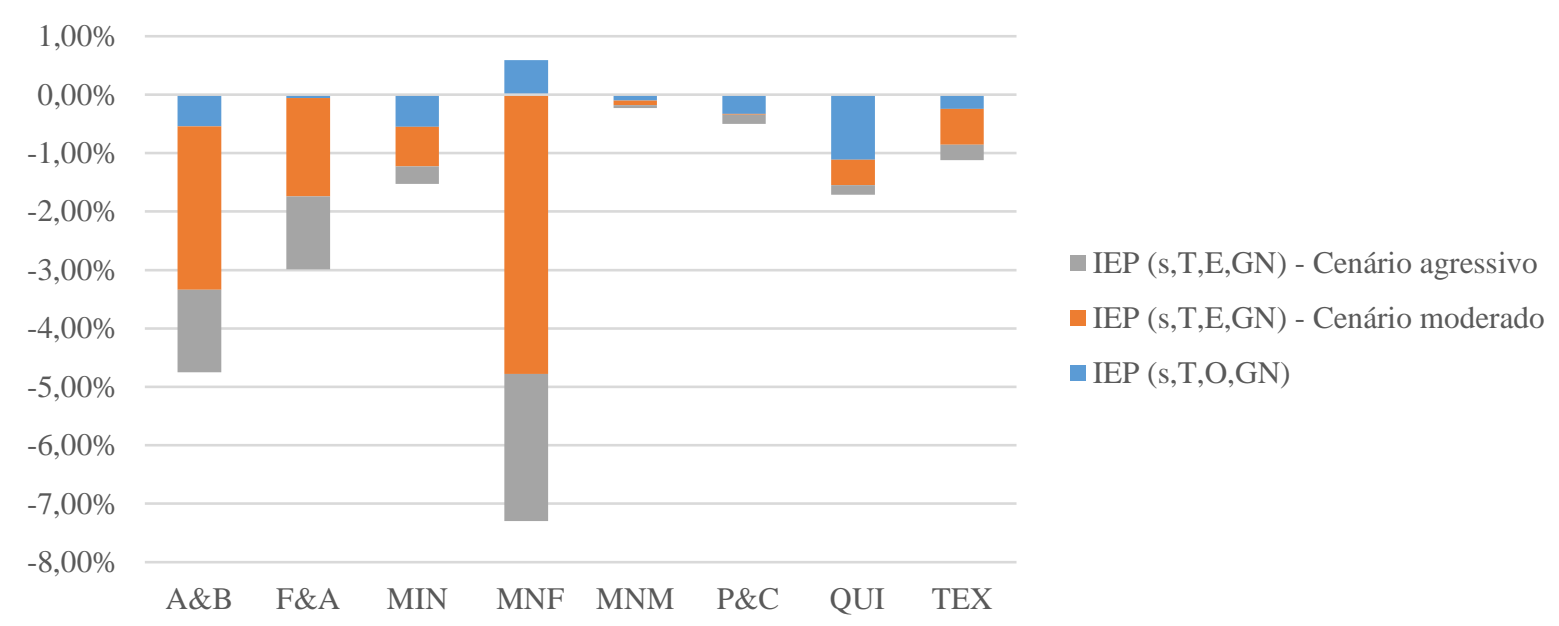

Fonte: Elaboração própria.

Nota: Os valores apresentados para o cenário agressivo são apenas o complementar em relação ao moderado.

- o impacto total em energia primária através da substituição de óleo combustível em processos térmicos é equivalente a uma redução de $0,2 \%$ da demanda de energia primária dos setores industriais considerados no Brasil em 2013, ao passo que através da substituição de eletricidade em processos térmicos corresponde a uma redução na faixa de 1,6 a $2,5 \%$.

\subsubsection{Resultados do indicador de Impacto em Emissões de Carbono (IEC)}

Observando os resultados do indicador de Impacto em Emissões de Carbono (IEC) através da Tabela 4.11 e das Figuras 4.13 e 4.14, os seguintes comentários podem ser feitos:

- os diferentes fatores de emissão de $\mathrm{CO}_{2}$ entre eletricidade, óleo combustível e gás natural poderiam produzir um impacto linear a todos os setores industriais em função 
do primeiro indicador de Demanda Adicional (DA), entretanto, assim como no indicador anterior, como foram adotadas diferentes eficiências do equipamento de uso final para cada setor industrial, os resultados não apresentam essa linearidade;

- considerando o IEC devido à substituição de óleo combustível em processos térmicos, o Setor de Metais Não-Ferrosos (MNF) é aquele que consegue reduzir as emissões de $\mathrm{CO}_{2}$ em maior escala absoluta (608 ktCO $\left.2 / \mathrm{ano}\right)$, seguido do Setor Químico (QUI) (550 $\mathrm{ktCO}_{2} / \mathrm{ano}$ ) e de Papel e Celulose (P\&C) (307 ktCO $2 / \mathrm{ano}$ ). Já do ponto de vista relativo, as maiores reduções setoriais das emissões de $\mathrm{CO}_{2}$ são observadas no Setor de Metais Não-Ferrosos (MNF) (9,99\%), Setor de Papel e Celulose (P\&C) $(7,78 \%)$ e Setor de Alimentos e Bebidas (A\&B) (5,80\%). No caso do IEC, o Setor de Metais Não-Ferrosos (MNF) teve reduções apesar da eficiência do equipamento de uso final neste setor ser desfavorável ao gás natural (60\% contra 69\%), pois o fator de emissão de $\mathrm{CO}_{2}$ é bem mais favorável $\left(56,1 \mathrm{tCO}_{2} / \mathrm{TJ}\right.$ contra $\left.77,4 \mathrm{tCO}_{2} / \mathrm{TJ}\right)$;

Tabela 4.11 - Resultados do indicador de Impacto em Emissões de Carbono (IEC) para substituição de eletricidade e óleo combustível por gás natural em processos térmicos por setor industrial

\begin{tabular}{c|c|cc|c|cc}
\hline $\begin{array}{c}\text { Setor } \\
(\mathrm{s})\end{array}$ & $\begin{array}{c}\mathrm{IEC}_{\mathrm{s}, \mathrm{T}, \mathrm{O}, \mathrm{GN}} \\
\left(\mathrm{ktCO}_{2} / \mathrm{ano}\right)\end{array}$ & $\begin{array}{c}\mathrm{IEC}_{\mathrm{s}, \mathrm{T}, \mathrm{E}, \mathrm{GN}} \\
\text { Moderado }\end{array}$ & $\begin{array}{c}\left.\mathrm{ktCO}_{2} / \mathrm{ano}\right) \\
\mathrm{IEC}_{\mathrm{s}, \mathrm{T}, \mathrm{O}, \mathrm{GN}}\end{array}$ & \multicolumn{2}{c}{$\mathrm{IEC}_{\mathrm{s}, \mathrm{T}, \mathrm{E}, \mathrm{GN}}\left(\% \mathrm{EmC}_{\mathrm{s}}\right)$} \\
$\mathrm{A} \& \mathrm{~B}$ & -241 & -166 & -249 & $-5,80 \%$ & $-4,00 \%$ & $-6,00 \%$ \\
$\mathrm{~F} \& \mathrm{~A}$ & -91 & -141 & -246 & $-1,64 \%$ & $-2,54 \%$ & $-4,43 \%$ \\
$\mathrm{MIN}$ & -201 & -24 & -34 & $-3,10 \%$ & $-0,36 \%$ & $-0,53 \%$ \\
$\mathrm{MNF}$ & -608 & -474 & -724 & $-9,99 \%$ & $-7,79 \%$ & $-11,90 \%$ \\
$\mathrm{MNM}$ & -126 & -6 & -9 & $-0,55 \%$ & $-0,02 \%$ & $-0,04 \%$ \\
P\&C & -307 & -1 & -15 & $-7,78 \%$ & $-0,02 \%$ & $-0,37 \%$ \\
QUI & -550 & -36 & -48 & $-4,05 \%$ & $-0,26 \%$ & $-0,35 \%$ \\
TEX & -43 & -10 & -14 & $-4,41 \%$ & $-1,02 \%$ & $-1,43 \%$ \\
TOTAL & -2168 & -857 & -1339 & $-3,41 \%$ & $-1,35 \%$ & $-2,10 \%$ \\
\hline
\end{tabular}

Fonte: Elaboração própria.

Nota: $\mathrm{EmC}_{\mathrm{s}}$ é a emissão de $\mathrm{CO}_{2}$ associada ao uso de energia, por setor industrial, obtida de MCTIC (2016).

- já quando analisado o IEC devido à substituição de eletricidade em processos térmicos, os três setores aparecem com os três melhores indicadores. O Setor de Metais NãoFerrosos (MNF) apresenta a maior redução absoluta e relativa (474 a 724 ktCO 2 /ano; 7,79 a 11,90\%), enquanto o Setor de Alimentos e Bebidas (A\&B) que ocupa a segunda 


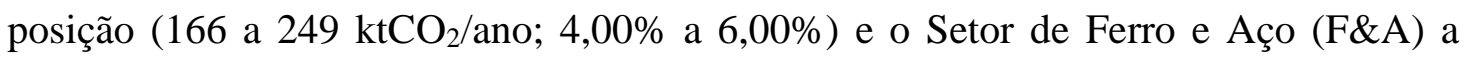
terceira posição (141 a $246 \mathrm{ktCO}_{2} / \mathrm{ano} ; 2,54 \%$ a $\left.4,43 \%\right)$;

Figura 4.13 - Indicador de Impacto em Emissões de Carbono (IEC) para substituição de eletricidade e óleo combustível por gás natural em processos térmicos - resultados expressos em $\mathrm{ktCO}_{2} /$ ano

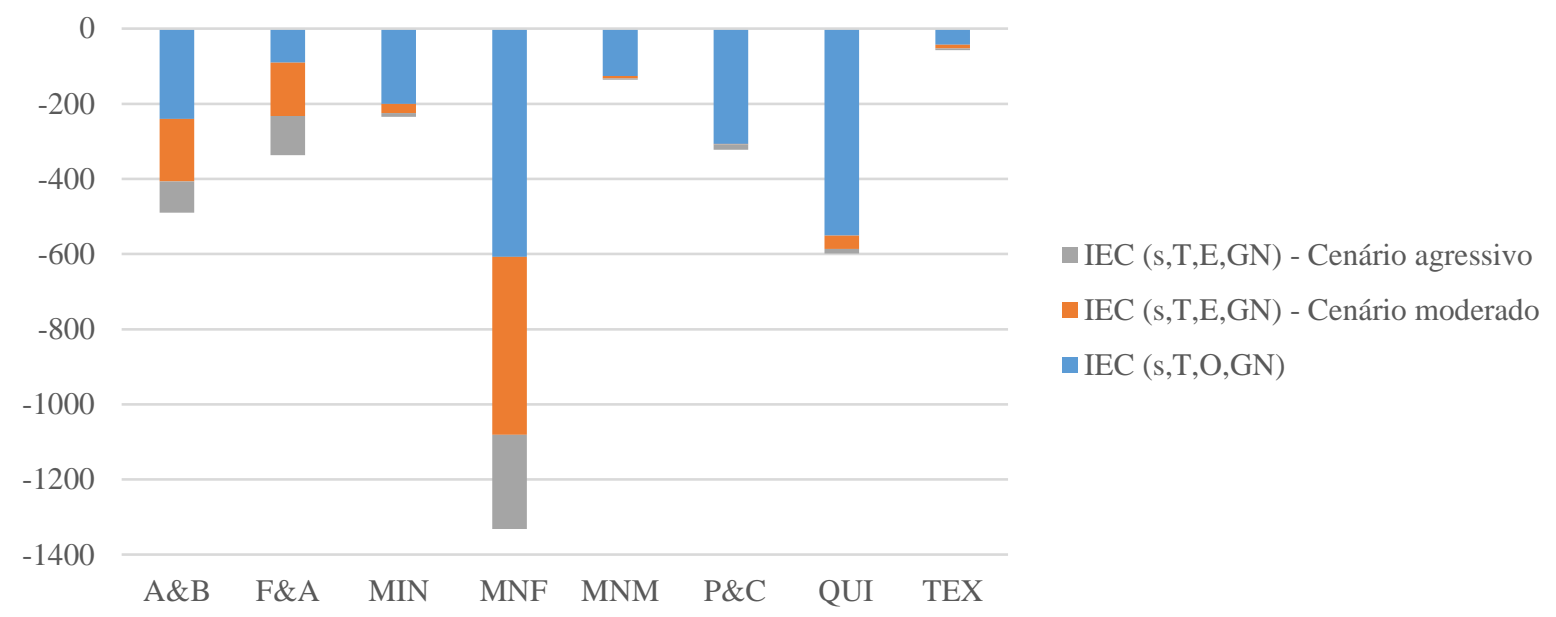

Fonte: Elaboração própria.

Nota: Os valores apresentados para o cenário agressivo são apenas o complementar em relação ao moderado.

Figura 4.14 - Indicador de Impacto em Emissões de Carbono (IEC) para substituição de eletricidade e óleo combustível por gás natural em processos térmicos - resultados expressos em porcentagem da emissão de $\mathrm{CO}_{2}$ associada ao uso de energia de cada setor industrial

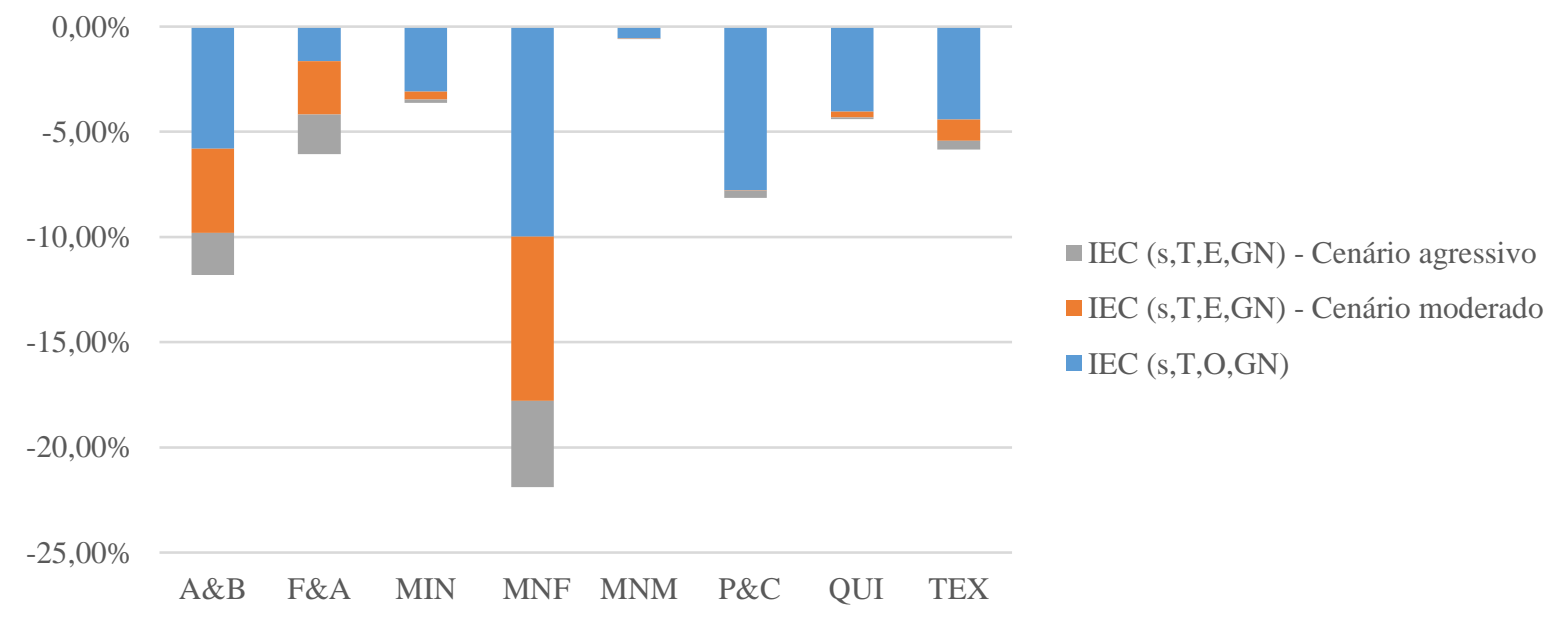

Fonte: Elaboração própria.

Nota: Os valores apresentados para o cenário agressivo são apenas o complementar em relação ao moderado.

- o impacto total em emissões de $\mathrm{CO}_{2}$ através da substituição de óleo combustível em processos térmicos é equivalente a uma redução de $3,4 \%$ das em emissões de $\mathrm{CO}_{2}$ associadas ao uso de energia dos setores industriais considerados no Brasil em 2013, ao passo que através da substituição de eletricidade em processos térmicos corresponde a uma redução na faixa de 1,4 a $2,1 \%$. 


\subsubsection{Resultados do indicador de Impacto em Custo Energético (ICE)}

Observando os resultados do indicador de Impacto em Custo Energético (IEC) através da Tabela 4.12 e das Figuras 4.15 e 4.16, os seguintes comentários podem ser feitos:

- os diferentes preços (ou tarifas) entre eletricidade, óleo combustível e gás natural poderiam produzir um impacto linear a todos os setores industriais em função do primeiro indicador de Demanda Adicional (DA), entretanto, assim como nos indicadores anteriores, como foram adotadas diferentes eficiências do equipamento de uso final para cada setor industrial, os resultados não apresentam essa linearidade;

Tabela 4.12 - Resultados do indicador de Impacto em Custo Energético (ICE) para substituição de eletricidade e óleo combustível por gás natural em processos térmicos por setor industrial

\begin{tabular}{|c|c|c|c|c|c|c|}
\hline \multirow{2}{*}{$\begin{array}{l}\text { Setor } \\
(\mathrm{s})\end{array}$} & \multirow{2}{*}{$\begin{array}{l}\mathrm{ICE}_{\mathrm{s}, \mathrm{T}, \mathrm{O}, \mathrm{GN}} \\
(\mathrm{M} \mathrm{R} \$ \text { /ano) }\end{array}$} & \multicolumn{2}{|c|}{$\mathrm{ICE}_{\mathrm{s}, \mathrm{T}, \mathrm{E}, \mathrm{GN}}(\mathrm{M} \mathrm{R} \$ / \mathrm{ano})$} & \multirow{2}{*}{$\begin{array}{l}\mathrm{ICE}_{\mathrm{s}, \mathrm{T}, \mathrm{O}, \mathrm{GN}} \\
\left(\% \mathrm{CEn}_{\mathrm{s}, \mathrm{O}, \mathrm{E}}\right)\end{array}$} & \multicolumn{2}{|c|}{$\mathrm{ICE}_{\mathrm{s}, \mathrm{T}, \mathrm{E}, \mathrm{GN}}\left(\% \mathrm{CEn}_{\mathrm{s}, \mathrm{O}, \mathrm{E}}\right)$} \\
\hline & & Moderado & Agressivo & & Moderado & Agressivo \\
\hline$\overline{A \& B}$ & -54 & -370 & -555 & $-0,63 \%$ & $-4,29 \%$ & $-6,43 \%$ \\
\hline $\mathrm{F} \& \mathrm{~A}$ & -5 & -414 & -720 & $-0,05 \%$ & $-4,31 \%$ & $-7,51 \%$ \\
\hline MIN & -23 & -50 & -73 & $-0,39 \%$ & $-0,87 \%$ & $-1,26 \%$ \\
\hline MNF & 210 & -863 & - 1319 & $1,40 \%$ & $-5,75 \%$ & $-8,79 \%$ \\
\hline MNM & -7 & -15 & -25 & $-0,06 \%$ & $-0,14 \%$ & $-0,22 \%$ \\
\hline $\mathrm{P} \& \mathrm{C}$ & -39 & -2 & -35 & $-0,53 \%$ & $-0,03 \%$ & $-0,47 \%$ \\
\hline QUI & -131 & -67 & -91 & $-1,12 \%$ & $-0,57 \%$ & $-0,78 \%$ \\
\hline TEX & -4 & -20 & -28 & $-0,14 \%$ & $-0,76 \%$ & $-1,07 \%$ \\
\hline TOTAL & -52 & -1802 & -2845 & $-0,09 \%$ & $-3,16 \%$ & $-4,99 \%$ \\
\hline
\end{tabular}

Fonte: Elaboração própria.

Nota: $\mathrm{CE}_{\mathrm{s}, \mathrm{O}, \mathrm{E}}$ é o custo energético com óleo combustível e eletricidade, por setor industrial, apresentado na Tabela A.6 do Apêndice A.

- considerando o ICE devido à substituição de óleo combustível em processos térmicos, o Setor Químico (QUI) é aquele que consegue reduzir o custo energético em maior escala absoluta (131 M R\$/ano), seguido do Setor de Alimentos e Bebidas (A\&B) (54 M R\$/ano) e do Setor de Papel e Celulose (P\&C) (39 M R \$/ano). Esses setores, nessa mesma ordem, apresentam também as maiores reduções de custo energético do ponto 
de vista relativo, sendo 1,12\% no Setor Químico (QUI), 0,63\% no Setor de Alimentos e Bebidas (A\&B) e 0,53\% no Setor de Papel e Celulose (P\&C). Um caso peculiar é do Setor de Metais Não-Ferrosos (MNF), pois o impacto foi positivo, ou seja, houve um aumento no custo energético (210 M R \$/ano, absoluto; 1,40\%, relativo). Isso decorre do fato que o diferencial de preço (ou tarifa) entre o óleo combustível e o gás natural é muito pequeno $(0,037 \mathrm{M} \mathrm{R} \$ / \mathrm{TJ}$ contra $0,036 \mathrm{M} \mathrm{R} \$ / \mathrm{TJ})$ face à diferença de eficiência do equipamento de uso final neste setor $(60 \%$ contra $69 \%)$;

Figura 4.15 - Indicador de Impacto em Custo Energético (ICE) para substituição de eletricidade e óleo combustível por gás natural em processos térmicos - resultados expressos em M R \$ano

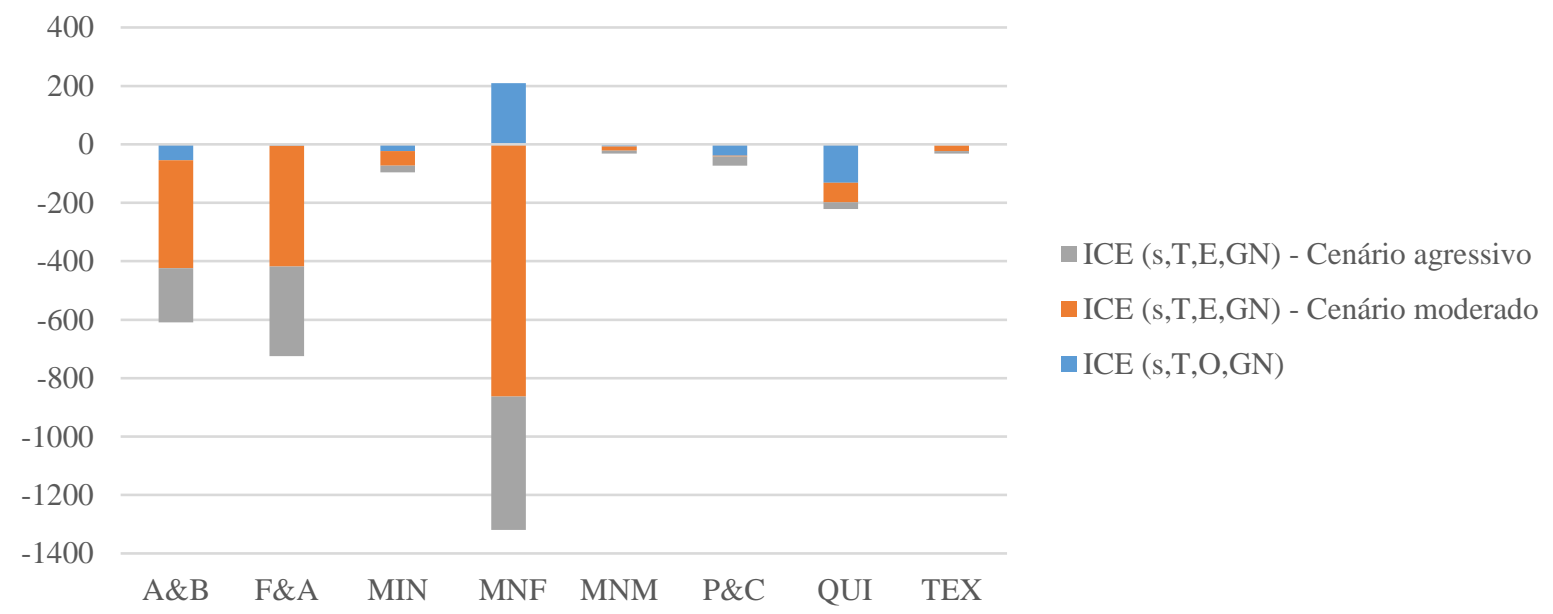

Fonte: Elaboração própria.

Nota: Os valores apresentados para o cenário agressivo são apenas o complementar em relação ao moderado.

Figura 4.16 - Indicador de Impacto em Custo Energético (ICE) para substituição de eletricidade e óleo combustível por gás natural em processos térmicos - resultados expressos em porcentagem do custo energético de eletricidade e óleo combustível de cada setor industrial

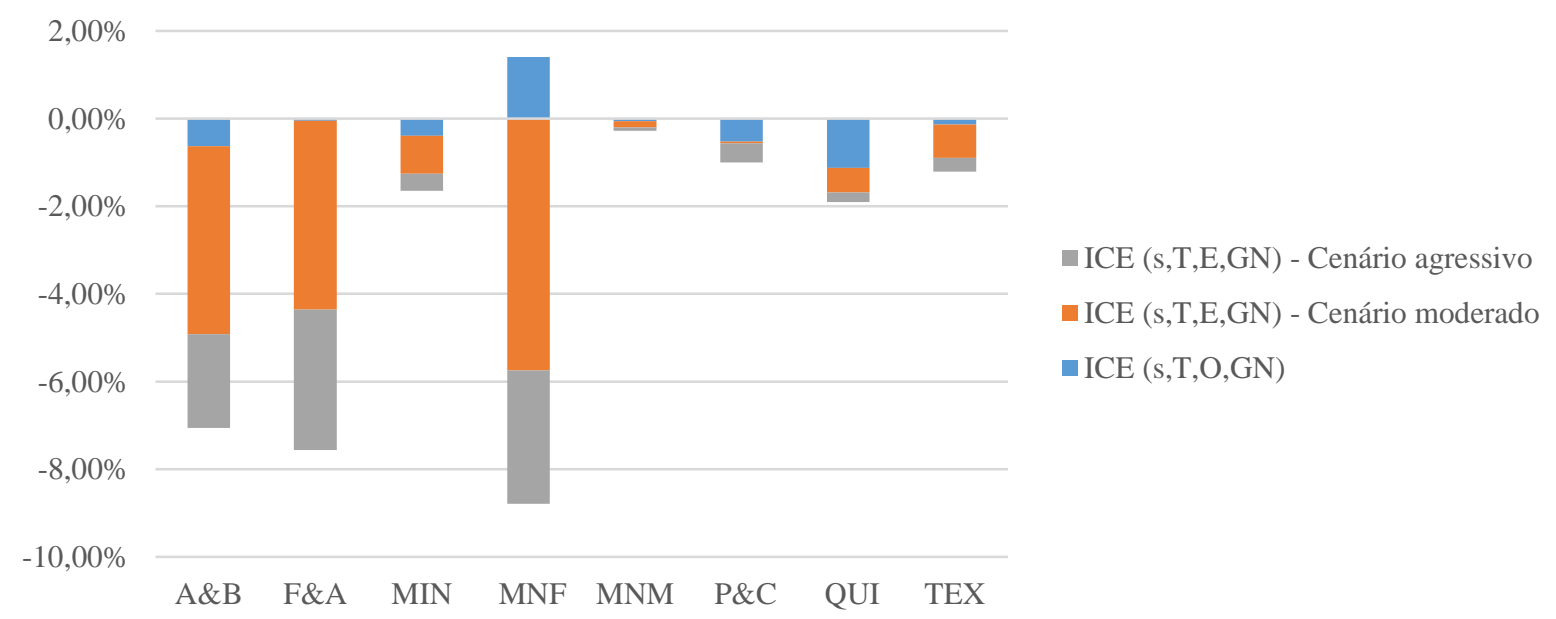

Fonte: Elaboração própria.

Nota: Os valores apresentados para o cenário agressivo são apenas o complementar em relação ao moderado. 
- já quando analisado o IEC devido à substituição de eletricidade em processos térmicos, os três setores que se destacaram no indicador anterior voltam a aparecer com os três melhores indicadores. O Setor de Metais Não-Ferrosos (MNF) apresenta a maior redução absoluta e relativa (863 a 1319 M R\$/ano; 5,75 a 8,79\%), enquanto o Setor de Ferro e Aço (F\&A) ocupa a segunda posição (414 a 720 M R\$/ano; 4,31\% a 7,51\%) e o Setor de Alimentos e Bebidas (A\&B) a terceira posição (370 a 555 M R\$/ano; 4,29 a $6,43 \%)$

- o impacto total em custo energético através da substituição de óleo combustível em processos térmicos é equivalente a uma redução de $0,1 \%$ dos custos energéticos associados a eletricidade e óleo combustível dos setores industriais considerados no Brasil em 2013, ao passo que através da substituição de eletricidade em processos térmicos corresponde a uma redução na faixa de 3,2 a 5\%.

\subsection{Considerações finais do capítulo 4}

Os resultados apresentados até agora estavam desagregados em função do tipo de energia final substituída, agora serão apresentados os resultados consolidados, para os cenários moderado e agressivo.

Os resultados consolidados do indicador de Demanda Adicional (DA) estão na Tabela 4.13 e nas Figuras 4.17 e 4.18, seguido dos indicadores de Impacto em Energia Primária (IEP), em Emissões de Carbono (IEC) e em Custo Energético (ICE), nas Tabelas 4.14 e 4.15 e nas Figuras 4.19 a 4.24 .

Os resultados consolidados do indicador de Demanda Adicional (DA) mostram um destaque de maior demanda adicional de gás natural para o Setor de Metais Não-Ferrosos (MNF), tanto no cenário moderado quanto no agressivo. Outros setores que se destacam são o Setor Químico (QUI) e Setor de Ferro e Aço (F\&A), para o cenário moderado, e Setor de Ferro e Aço (F\&A) e Setor de Alimentos e Bebidas (A\&B), para o cenário agressivo. 
Tabela 4.13 - Resultados consolidados do indicador de Demanda Adicional para substituição de eletricidade e óleo combustível por gás natural em processos térmicos por setor industrial - Cenários moderado e agressivo

\begin{tabular}{|c|c|c|c|c|}
\hline \multirow{2}{*}{$\begin{array}{c}\text { Setor } \\
\text { (s) }\end{array}$} & \multicolumn{2}{|c|}{$\mathrm{DA}_{\mathrm{s}, \mathrm{T}, \mathrm{GN}}-$ Cenário moderado } & \multicolumn{2}{|c|}{$\mathrm{DA}_{\mathrm{s}, \mathrm{T}, \mathrm{GN}}-$ Cenário agressivo } \\
\hline & (Mm³/ano) & $(\% \mathrm{OIGN})$ & $\left(\mathrm{Mm}^{3} / \mathrm{ano}\right)$ & $(\% \mathrm{OIGN})$ \\
\hline $\mathrm{A} \& \mathrm{~B}$ & 378 & $1,16 \%$ & 476 & $1,45 \%$ \\
\hline $\mathrm{F} \& \mathrm{~A}$ & 385 & $1,17 \%$ & 584 & $1,78 \%$ \\
\hline MIN & 246 & $0,76 \%$ & 257 & $0,79 \%$ \\
\hline MNF & 1862 & $5,69 \%$ & 2049 & $6,26 \%$ \\
\hline MNM & 171 & $0,52 \%$ & 176 & $0,54 \%$ \\
\hline $\mathrm{P} \& \mathrm{C}$ & 326 & $0,99 \%$ & 344 & $1,05 \%$ \\
\hline QUI & 427 & $1,31 \%$ & 437 & $1,34 \%$ \\
\hline TEX & 60 & $0,19 \%$ & 64 & $0,20 \%$ \\
\hline TOTAL & 3855 & $11,79 \%$ & 4388 & $13,81 \%$ \\
\hline
\end{tabular}

Fonte: Elaboração própria.

Figura 4.17 - Indicador de Demanda Adicional (DA) para substituição de eletricidade e óleo combustível por gás natural em processos térmicos - resultados consolidados expressos em $\mathrm{Mm}^{3} / \mathrm{ano}$

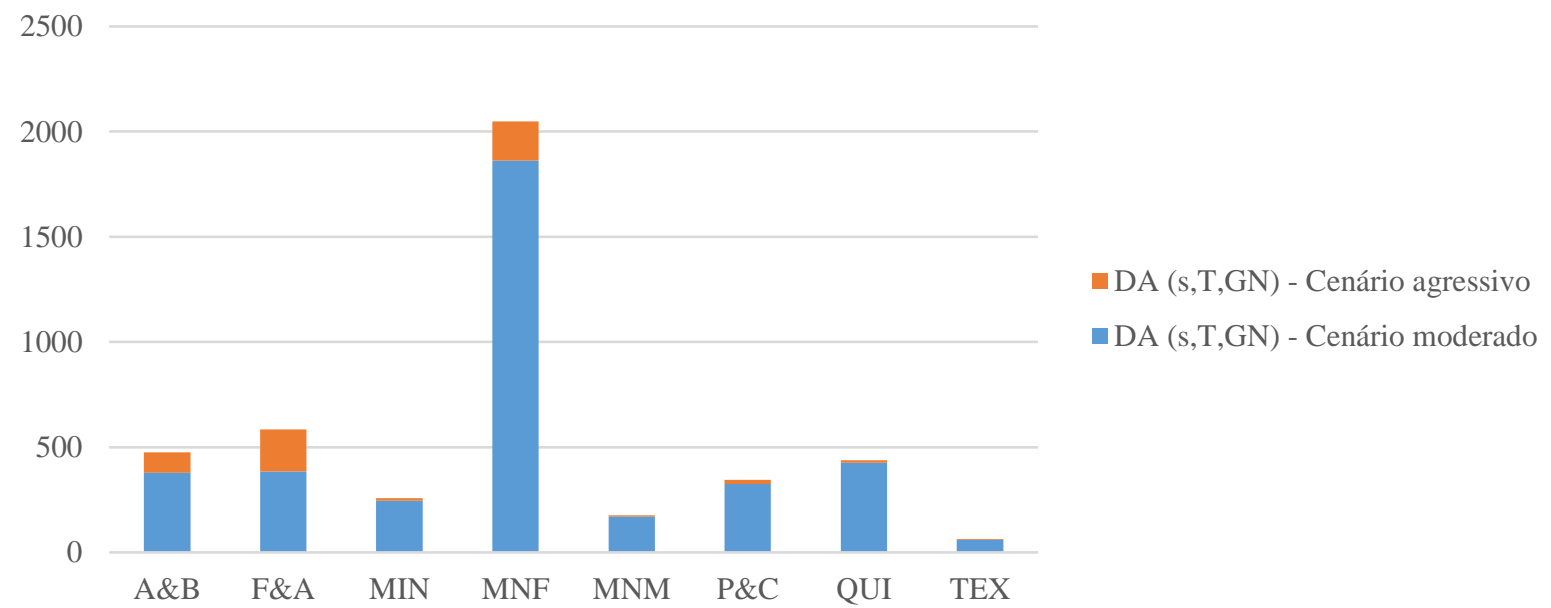

Fonte: Elaboração própria.

Nota: Os valores apresentados para o cenário agressivo são apenas o complementar em relação ao moderado. 
Figura 4.18 - Indicador de Demanda Adicional (DA) para substituição de eletricidade e óleo combustível por gás natural em processos térmicos - resultados consolidados expressos em porcentagem da oferta interna de gás natural (ano-base 2013)

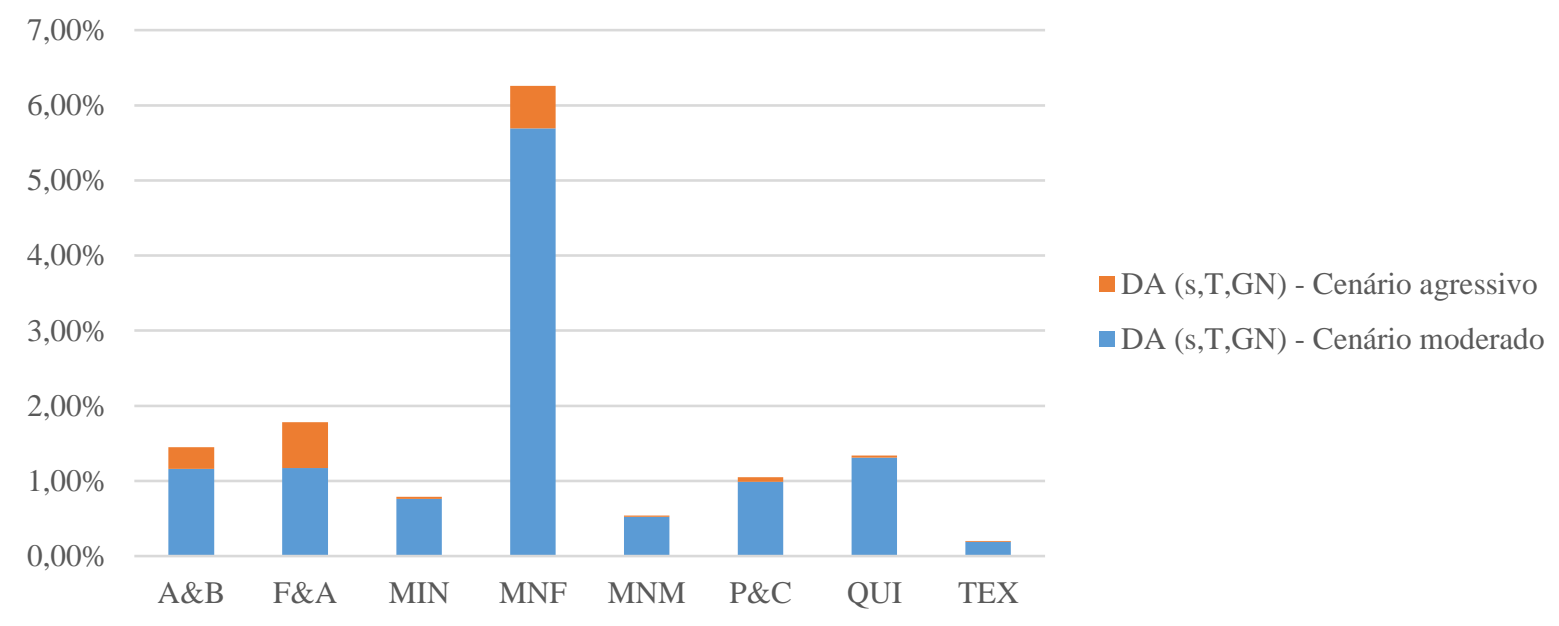

Fonte: Elaboração própria.

Nota: Os valores apresentados para o cenário agressivo são apenas o complementar em relação ao moderado.

Os resultados consolidados do indicador de Impacto em Energia Primária (IEP) mostram um destaque de maior redução na demanda de energia primária em valores absolutos para o Setor de Metais Não-Ferrosos (MNF), Setor de Ferro e Aço (F\&A) e Setor de Alimentos e Bebidas (A\&B), tanto no cenário moderado quanto no agressivo.

Tabela 4.14 - Resultados consolidados dos indicadores de impacto para substituição de eletricidade e óleo combustível por gás natural em processos térmicos por setor industrial - Cenário moderado

\begin{tabular}{c|cc|cc|cc}
\hline Setor & \multicolumn{2}{|c|}{$\mathrm{IEP}_{\mathrm{s}, \mathrm{T}, \mathrm{GN}}$} & \multicolumn{2}{c|}{$\mathrm{IEC}_{\mathrm{s}, \mathrm{T}, \mathrm{GN}}$} & \multicolumn{2}{c}{$\mathrm{ICE}_{\mathrm{s}, \mathrm{T}, \mathrm{GN}}$} \\
$(\mathrm{s})$ & $(\mathrm{TJ} / \mathrm{ano})$ & $\left(\% \mathrm{DEP}_{\mathrm{s}}\right)$ & $\left(\mathrm{ktCO}_{2} / \mathrm{ano}\right)$ & $\left(\% \mathrm{EmC}_{\mathrm{s}}\right)$ & $(\mathrm{M} \mathrm{R} \$ / \mathrm{ano})$ & $\left(\% \mathrm{CEn}_{\mathrm{s}, \mathrm{O}, \mathrm{E}}\right)$ \\
\hline $\mathrm{A} \& \mathrm{~B}$ & -13427 & $-3,34 \%$ & -407 & $-9,80 \%$ & -424 & $-4,92 \%$ \\
F\&A & -13009 & $-1,74 \%$ & -232 & $-4,18 \%$ & -419 & $-4,36 \%$ \\
$\mathrm{MIN}$ & -2765 & $-1,23 \%$ & -225 & $-3,46 \%$ & -73 & $-1,26 \%$ \\
MNF & -23024 & $-4,19 \%$ & -1082 & $-17,78 \%$ & -653 & $-4,35 \%$ \\
MNM & -1066 & $-0,18 \%$ & -132 & $-0,57 \%$ & -22 & $-0,20 \%$ \\
P\&C & -2079 & $-0,34 \%$ & -308 & $-7,80 \%$ & -41 & $-0,56 \%$ \\
QUI & -7180 & $-1,55 \%$ & -586 & $-4,31 \%$ & -198 & $-1,69 \%$ \\
TEX & -837 & $-0,86 \%$ & -53 & $-5,43 \%$ & -24 & $-0,90 \%$ \\
TOTAL & -63385 & $-1,80 \%$ & -3025 & $-4,75 \%$ & -1854 & $-3,25 \%$ \\
\hline
\end{tabular}

Fonte: Elaboração própria. 
Os resultados consolidados do indicador de Impacto em Emissões de Carbono (IEC) mostram, por sua vez, um destaque de maior redução nas emissões de $\mathrm{CO}_{2}$ em valores absolutos para o Setor de Metais Não-Ferrosos (MNF), Setor Químico (QUI) e Setor de Alimentos e Bebidas (A\&B), tanto no cenário moderado quanto no agressivo.

Por fim, os resultados consolidados do indicador de Impacto em Custo Energético (ICE) mostram um destaque de maior redução no custo energético em valores absolutos para o Setor de Metais Não-Ferrosos (MNF), Setor de Ferro e Aço (F\&A) e Setor de Alimentos e Bebidas (A\&B), tanto no cenário moderado quanto no agressivo.

Tabela 4.15 - Resultados consolidados dos indicadores para substituição de eletricidade e óleo combustível por gás natural em processos térmicos por setor industrial - Cenário agressivo

\begin{tabular}{c|cc|cc|cc}
\hline $\begin{array}{c}\text { Setor } \\
(\mathrm{s})\end{array}$ & \multicolumn{2}{|c|}{$\mathrm{IEP}_{\mathrm{s}, \mathrm{T}, \mathrm{GN}}$} & \multicolumn{2}{c|}{$\mathrm{IEC}_{\mathrm{s}, \mathrm{T}, \mathrm{GN}}$} & \multicolumn{2}{c}{$\mathrm{ICE}_{\mathrm{s}, \mathrm{T}, \mathrm{GN}}$} \\
\hline $\mathrm{A} \& \mathrm{~B} / \mathrm{ano})$ & $\left(\% \mathrm{DEP}_{\mathrm{s}}\right)$ & $\left(\mathrm{ktCO}_{2} / \mathrm{ano}\right)$ & $\left(\% \mathrm{EmC}_{\mathrm{s}}\right)$ & $(\mathrm{M} \mathrm{R} \$ \mathrm{ano})$ & $\left(\% \mathrm{CEn}_{\mathrm{s}, \mathrm{O}, \mathrm{E}}\right)$ \\
F\&A & -22329 & $-2,99 \%$ & -337 & $-6,07 \%$ & -725 & $-7,56 \%$ \\
$\mathrm{MIN}$ & -3447 & $-1,53 \%$ & -235 & $-3,63 \%$ & -96 & $-1,65 \%$ \\
$\mathrm{MNF}$ & -36888 & $-6,71 \%$ & -1332 & $-21,89 \%$ & -1109 & $-7,39 \%$ \\
$\mathrm{MNM}$ & -1349 & $-0,23 \%$ & -135 & $-0,59 \%$ & -32 & $-0,28 \%$ \\
P\&C & -3059 & $-0,50 \%$ & -322 & $-8,15 \%$ & -74 & $-1,00 \%$ \\
QUI & -7898 & $-1,71 \%$ & -598 & $-4,40 \%$ & -222 & $-1,90 \%$ \\
TEX & -1083 & $-1,12 \%$ & -57 & $-5,84 \%$ & -32 & $-1,21 \%$ \\
TOTAL & -95108 & $-2,7 \%$ & -3507 & $-5,51 \%$ & -2897 & $-5,08 \%$ \\
\hline
\end{tabular}

Fonte: Elaboração própria.

Uma eventual classificação dos resultados da maior redução, seja em demanda de energia primária, em emissões de $\mathrm{CO}_{2}$ ou em custo energético, não é a mesma quando observase os resultados em valores absolutos e quando utilizados os resultados relativos, expressos em porcentagem de cada base de cálculo, respectivamente a demanda de energia primária, as emissões de $\mathrm{CO}_{2}$ associada ao uso de energia e o custo energético com óleo combustível e eletricidade. Isso fica evidente comparando as Figuas 4.19 e 4.20, no caso do indicador de Impacto em Energia Primária (IEP), as Figuas 4.21 e 4.22, no caso do indicador de Impacto em Emissões de Carbono (IEC), as Figuas 4.23 e 4.24, no caso do indicador de Impacto em Custo Energético (ICE). 
A razão para essas diferenças está exatamente na base de cálculo do valor do indicador em termos relativos que é diferente para cada setor industrial tratado. Esse efeito não é observado no caso do primeiro indicador, o indicador de Demanda Adicional (DA), pois a base de cálculo é a mesma, a oferta interna de gás natural (OIGN), que é única para o Brasil.

Figura 4.19 - Indicador de Impacto em Energia Primária (IEP) para substituição de eletricidade e óleo combustível por gás natural em processos térmicos - resultados consolidados expressos em TJ/ano

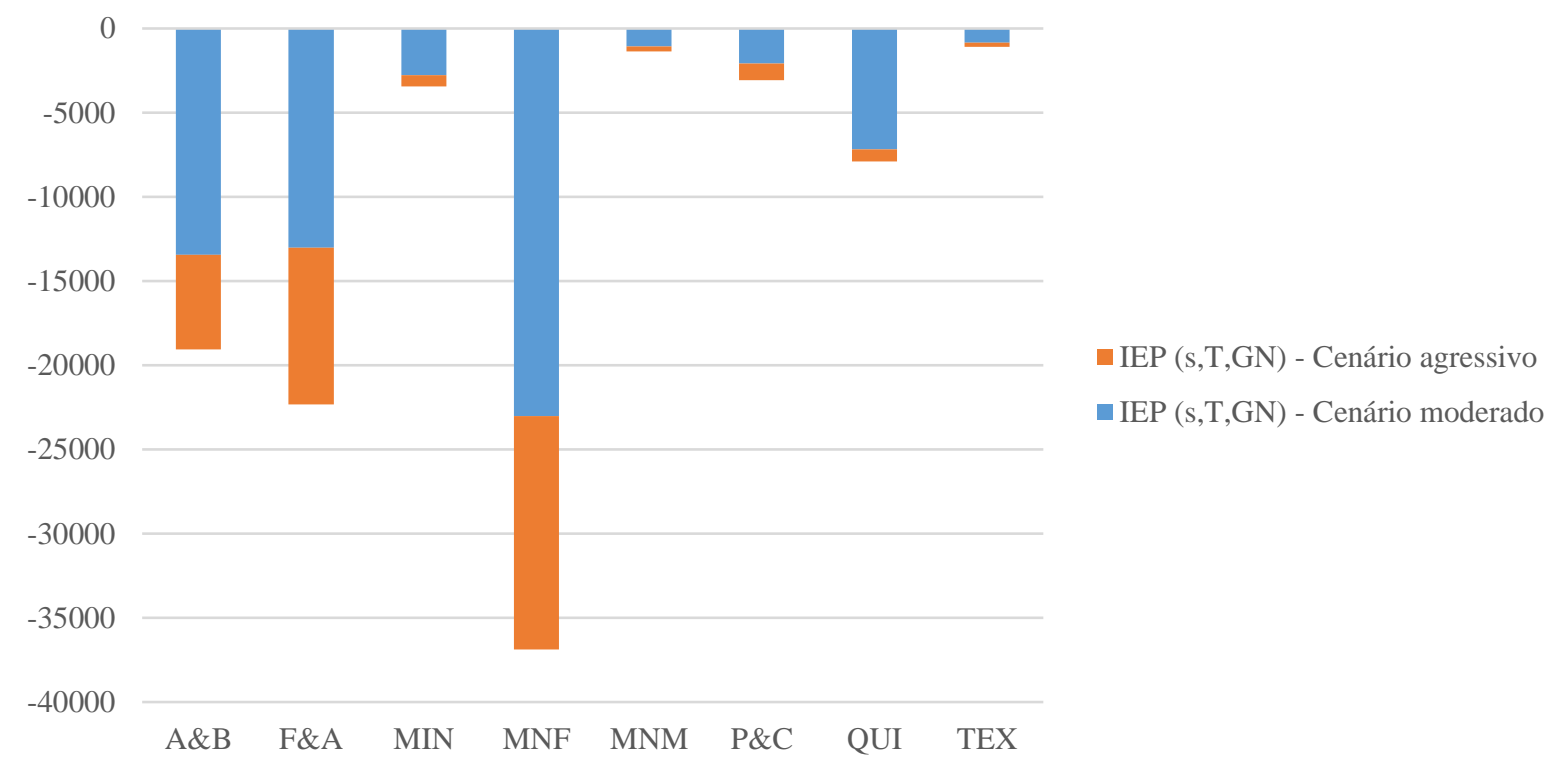

Fonte: Elaboração própria.

Nota: Os valores apresentados para o cenário agressivo são apenas o complementar em relação ao moderado.

Figura 4.20 - Indicador de Impacto em Energia Primária (IEP) para substituição de eletricidade e óleo combustível por gás natural em processos térmicos - resultados consolidados expressos em porcentagem da demanda de energia primária de cada setor industrial

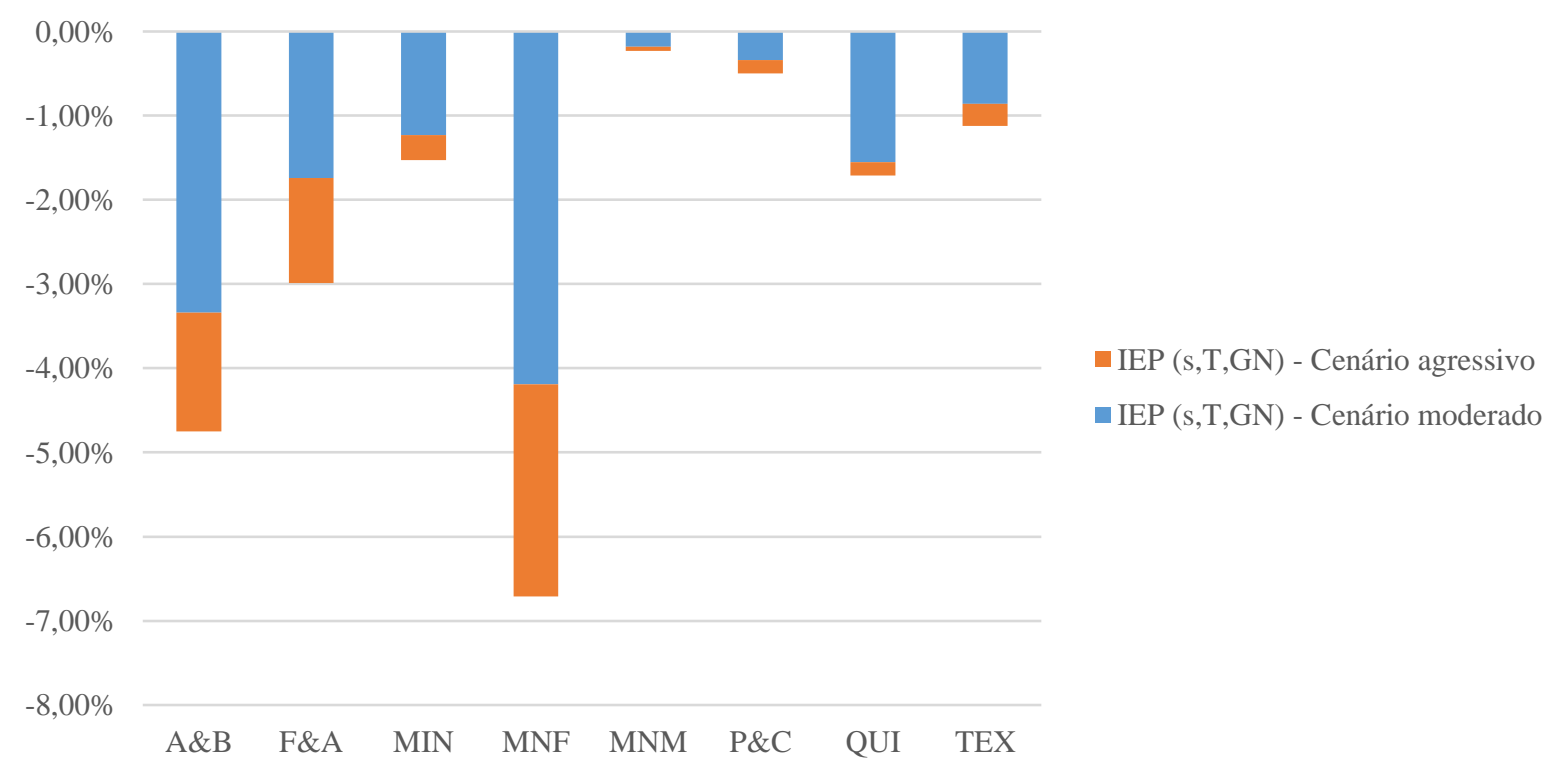

Fonte: Elaboração própria.

Nota: Os valores apresentados para o cenário agressivo são apenas o complementar em relação ao moderado. 
Figura 4.21 - Indicador de Impacto em Emissões de Carbono (IEC) para substituição de eletricidade e óleo combustível por gás natural em processos térmicos - resultados consolidados expressos em $\mathrm{ktCO}_{2} / \mathrm{ano}$

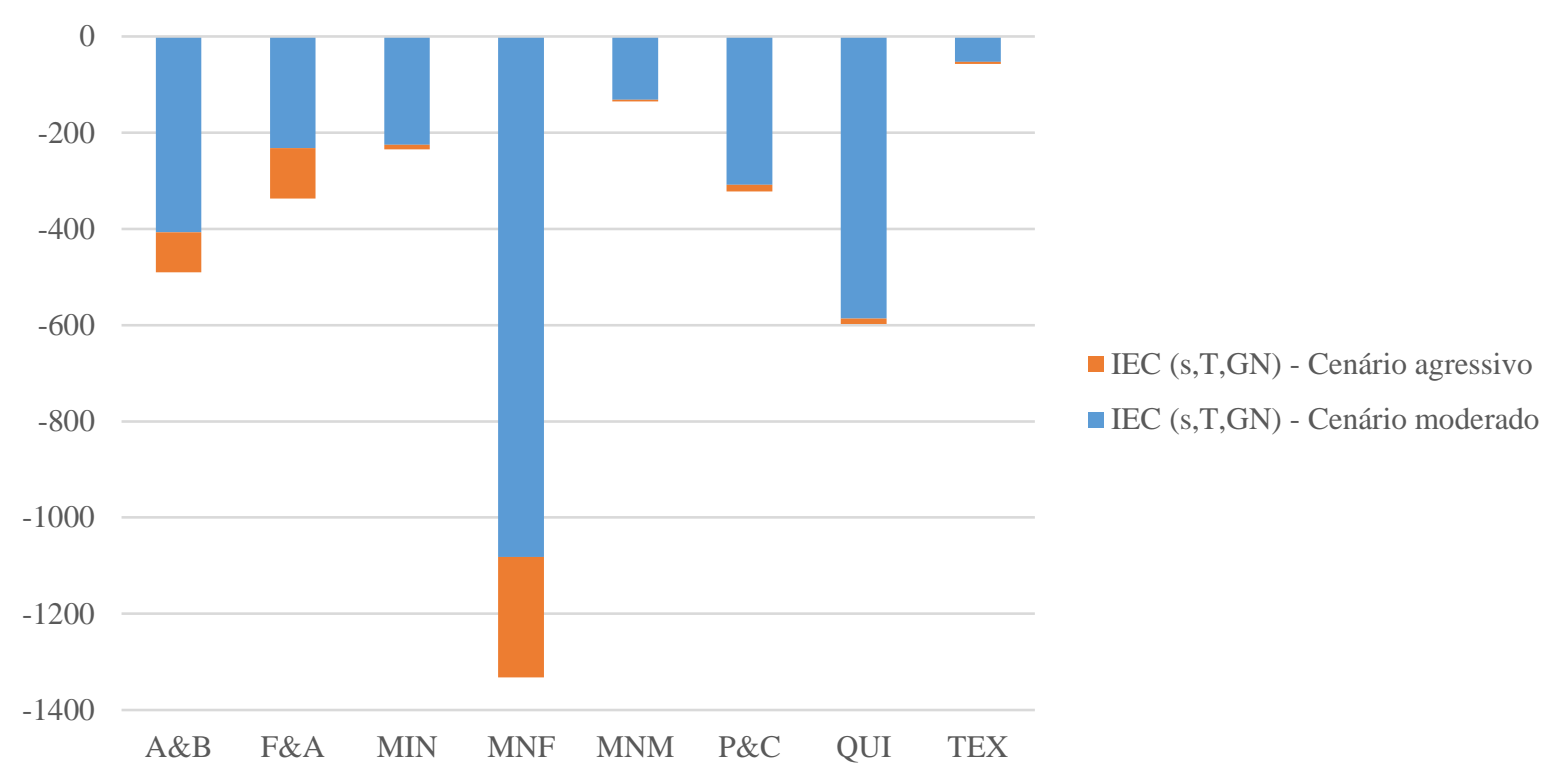

Fonte: Elaboração própria.

Nota: Os valores apresentados para o cenário agressivo são apenas o complementar em relação ao moderado.

Figura 4.22 - Indicador de Impacto em Emissões de Carbono (IEC) para substituição de eletricidade e óleo combustível por gás natural em processos térmicos - resultados consolidados expressos em porcentagem da emissão de $\mathrm{CO}_{2}$ associada ao uso de energia de cada setor industrial

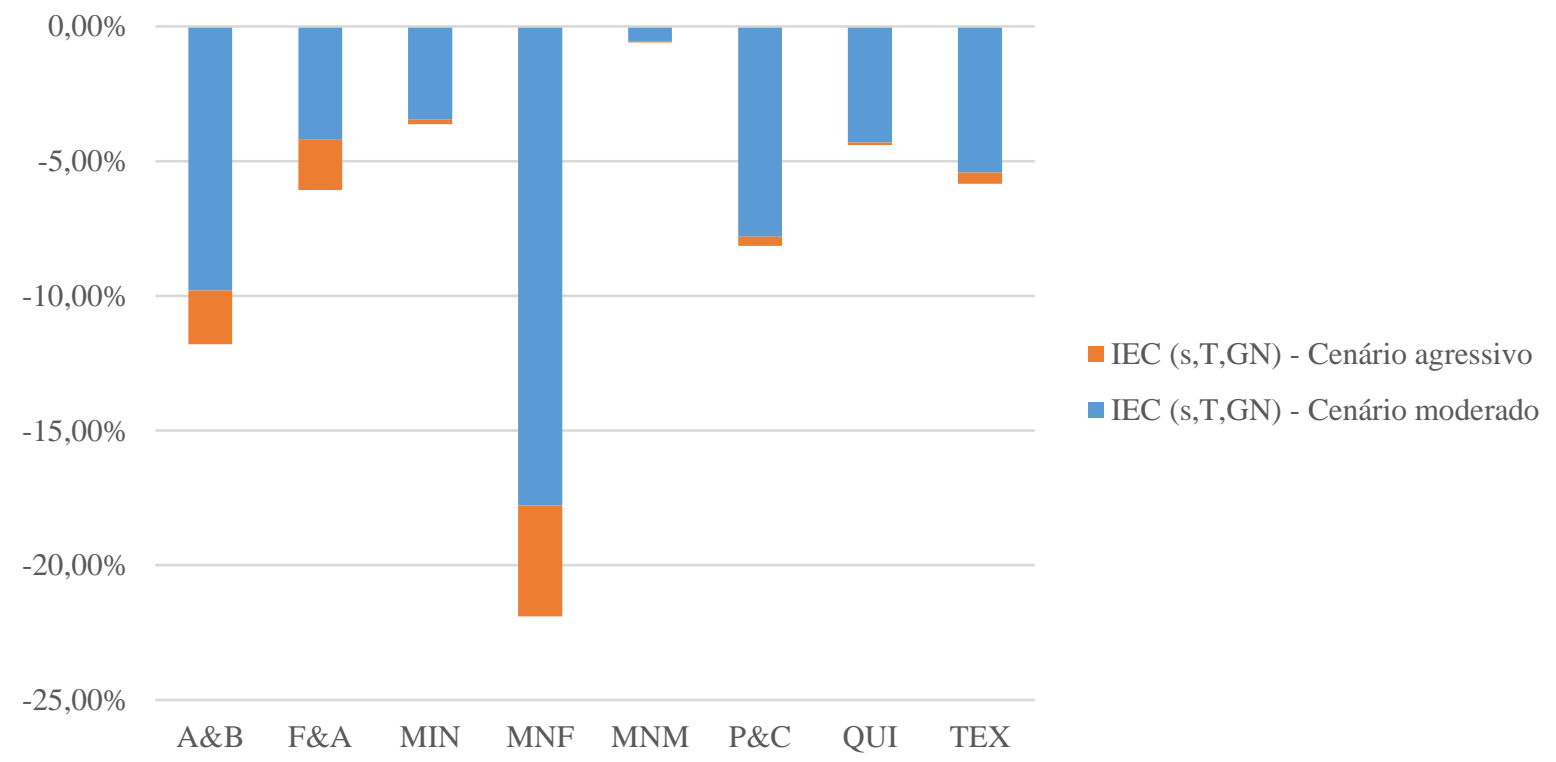

Fonte: Elaboração própria.

Nota: Os valores apresentados para o cenário agressivo são apenas o complementar em relação ao moderado. 
Figura 4.23 - Indicador de Impacto em Custo Energético (ICE) para substituição de eletricidade e óleo combustível por gás natural em processos térmicos - resultados consolidados expressos em M R \$/ano

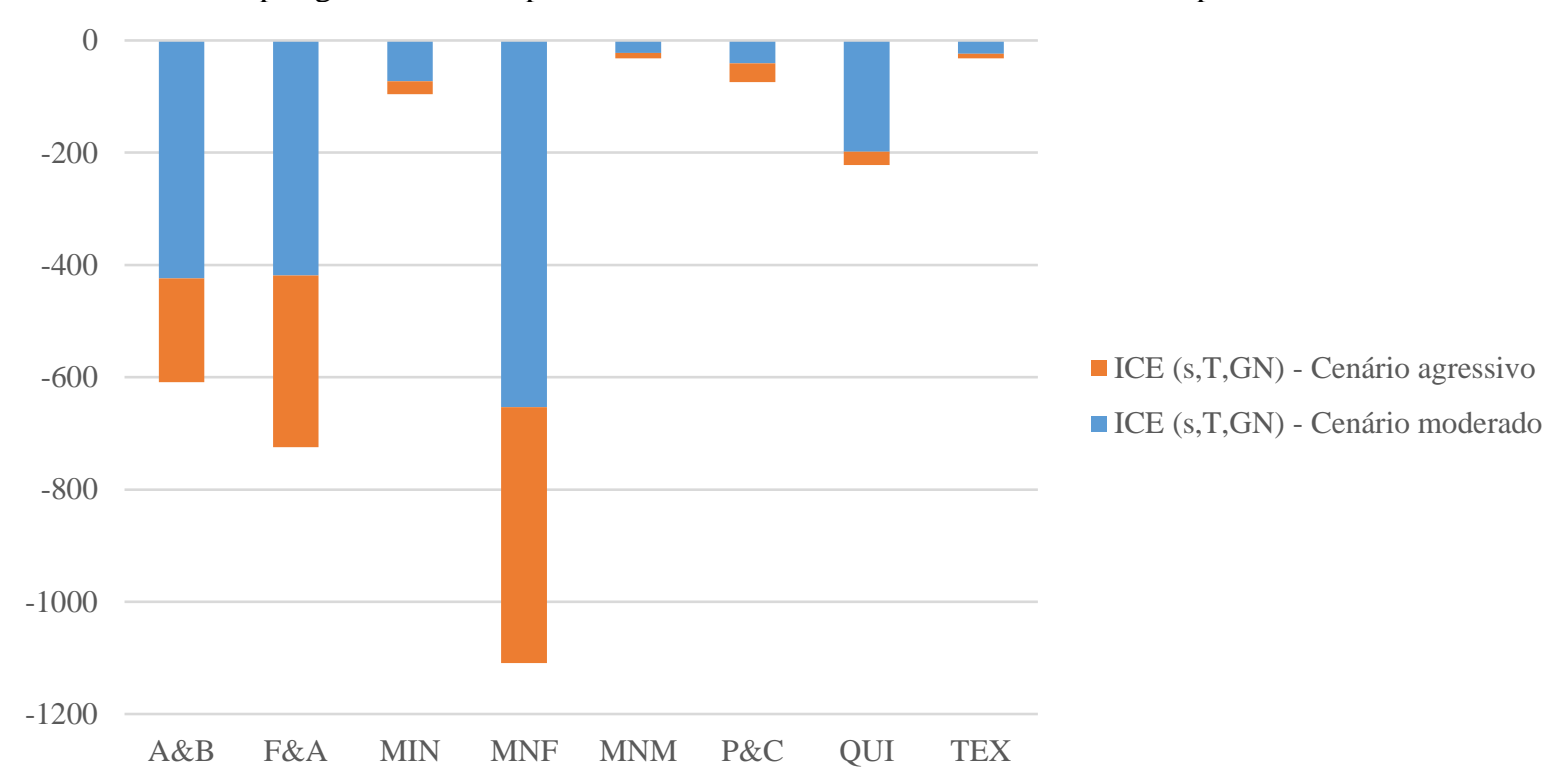

Fonte: Elaboração própria.

Nota: Os valores apresentados para o cenário agressivo são apenas o complementar em relação ao moderado.

Figura 4.24 - Indicador de Impacto em Custo Energético (ICE) para substituição de eletricidade e óleo combustível por gás natural em processos térmicos - resultados consolidados expressos em porcentagem do custo energético de eletricidade e óleo combustível de cada setor industrial

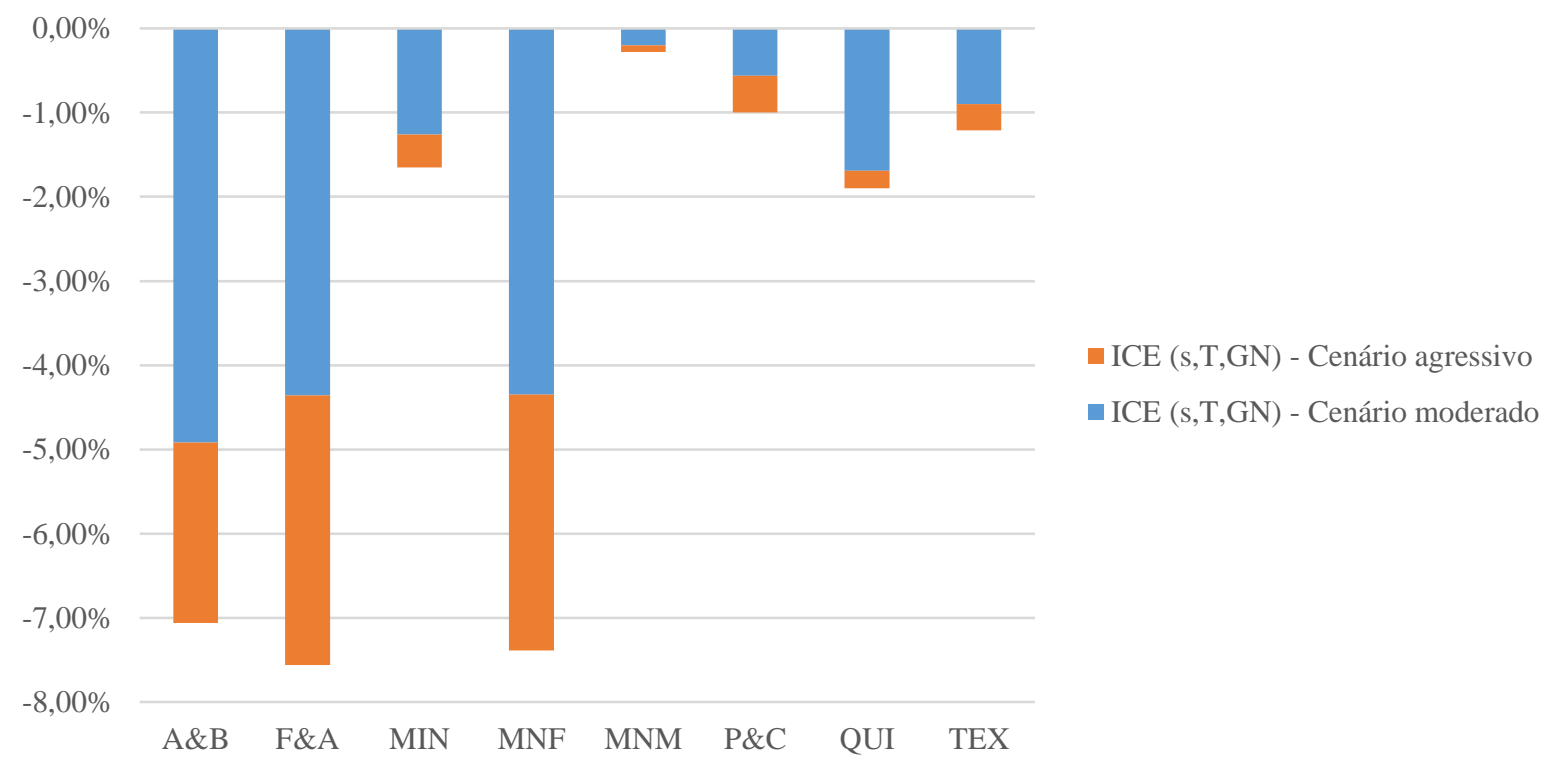

Fonte: Elaboração própria.

Nota: Os valores apresentados para o cenário agressivo são apenas o complementar em relação ao moderado.

Após a apresentação dos resultados consolidados, os seguintes comentários podem ser tecidos a respeito deles:

- o Setor de Metais Não-Ferrosos (MNF) se destacou ao apresentar a maior demanda adicional de gás natural e as maiores reduções de demanda de energia primária, de 
emissões de $\mathrm{CO}_{2}$ e de custo energético, exceto em um caso de análise (Impacto em Custo Energético (ICE) expressos em porcentagem do custo energético de eletricidade e óleo combustível de cada setor industrial) onde ficou muito próximo do outro setor que apresentou a maior redução (Setor de Ferro e Aço (F\&A));

- o Setor de Ferro e Aço (F\&A) e Setor de Alimentos e Bebidas (A\&B) também se destacaram, apresentando significativas demandas adicionais de gás natural e reduções de demanda de energia primária, de emissões de $\mathrm{CO}_{2}$ e de custo energético em quase todas as análises;

- observando os potenciais de substituição de eletricidade por gás natural estimados, na Tabela 4.8, observa-se que o valor fica, na média, entre $30 \%$ e $45 \%$. Considerando que, segundo IEA (2015a), os setores industriais em análise eram responsáveis por $34 \%$ da demanda de eletricidade no Brasil, esse potencial de substituição iria produzir uma redução na demanda de eletricidade do país entre $10 \%$ e $15 \%$. Essa faixa de valor pode ser considerada marginal, tendo em vista que a geração térmica com uso de gás natural, óleo diesel e óleo combustível, para o ano-base 2013, foi de 16\%, segundo EPE (2014). Dessa forma, a adoção dos fatores de conversão em energia primária e fator de emissão de $\mathrm{CO}_{2}$ pelo cálculo marginal mostrou-se uma decisão acertada;

- um outro comentário ainda pode ser a respeito dos potenciais de substituição de eletricidade por gás natural estimados, na Tabela 4.8. Como o valor médio fica entre $30 \%$ e $45 \%$ e que os usos finais térmicos representam cerca de $30 \%$ da demanda de eletricidade da indústria (MME/FDTE, 2005; EPE, 2014), o potencial de substituição iria representar a conservação de eletricidade numa faixa de $9 \%$ a 12\%, comparável aos níveis de conservação de energia elétrica apresentado por CNI/Eletrobras (2010). Dessa forma, também se reafirma a decisão acertada na adoção da premissa de cálculo dos potenciais de substituição a partir dos balanços de energia final. 


\section{CONCLUSÕES}

A compreensão de que o paradigma atual do uso da energia no setor industrial brasileiro é fruto da conjuntura histórica do setor energético no país permite explicar características particulares observadas no setor industrial brasileiro. A eletricidade, a biomassa e os derivados de petróleo foram historicamente as principais fontes de energia final para a indústria e, devido aos Choques do Petróleo, políticas energéticas direcionaram a eletricidade como substituta dos derivados de petróleo na indústria de modo a minimizar os impactos dessa crise. Essa contextualização histórica explica a origem da utilização intensiva de eletricidade em processos térmicos, a eletrotermia, algo que perdura até hoje, ainda que tenha sido observada a disponibilização, a partir de meados dos anos 1980 e principalmente a partir dos anos 2000, de outra fonte de energia final ao setor industrial, que é o gás natural. Hoje, o cenário nacional de produção de gás natural é promissor, no contexto da rápida e crescente produção do Pré-Sal, o que sinaliza para uma grande oportunidade em se explorar esse recurso natural para usos energéticos com maior valor agregado, como por exemplo como energia final para a indústria.

É neste contexto que foi desenvolvida esta dissertação que, do ponto de vista de metodologia científica, é uma pesquisa descritiva que busca caracterizar a inserção do gás natural no setor industrial brasileiro e estabelecer relações entre variáveis (como o potencial de inserção do gás natural e seus impactos energético, econômico e ambiental), delineada de forma documental e bibliográfica, com levantamento tanto estudos prévios e informações da literatura (fontes secundárias) como levantamentos de contabilidade oferta e demanda de energia final, os balanços de energia (fontes primárias), tendo natureza quantitativa, pois objetiva quantificar o potencial de inserção e também os impactos dessa inserção. A técnica de análise de dados aplicada nesta dissertação é quantitativa e foi construída como parte integrante desta dissertação, com objetivo de permitir a análise do fenômeno de interesse.

Quando realizada a apresentação dos estudos prévios de avaliação do uso da energia no setor industrial brasileiro, duas abordagens foram identificadas e tratadas, a que estuda o assunto sob o aspecto da eficiência energética e a que o estuda sob o aspecto da promoção dos gases combustíveis. A temática da primeira abordagem não foi objeto de estudo nesta dissertação, mas guarda relação direta ao objeto principal, pois o uso racional da energia é, sem 
dúvida, um dos principais pilares sobre os quais estão as iniciativas destinadas a promover o consumo sustentável de recursos naturais e combater as mudanças climáticas. Uma das estratégias possíveis é adequar a qualidade da fonte de energia final em uso com sua destinação. Dado que a eletricidade é a forma de energia com mais alto grau de qualidade, destiná-la para outros fins e utilizar o gás natural em usos finais térmicos, de qualidade mais baixa em termos relativos, é uma forma de melhorar a alocação dos recursos energéticos e, de certa forma, promover o aumento de eficiência do sistema energético como um todo.

Assim, dentro da primeira abordagem, a referência mais significativa é o estudo desenvolvido pela parceria CNI/Eletrobras. Esse estudo é uma significativa referência para estudos de economia de energia na indústria brasileira, contendo uma grande quantidade de informações de dados secundários validados com dados primários. Da segunda abordagem, dois são os estudos mais expressivos. O primeiro, de Montes (2000), é significativo por ser um dos primeiros estudos a trabalhar com a possibilidade de aumento da penetração do gás natural no setor industrial brasileiro, no contexto da entrada em operação do Gasbol. O segundo, de Strapasson (2004), é um estudo de substituição no uso final de energia visando a economia de energia primária através da inserção de energia química, o gás natural é um exemplo. Este último foi a principal referência e fonte de inspiração para o desenvolvimento dos estudos dessa dissertação.

Na sequência da apresentação dos estudos prévios, é desenvolvida a técnica de análise de dados que foi aplicada nesta dissertação. A técnica desenvolvida constitui-se na avaliação de quatro indicadores: Demanda Adicional (DA), que retrata a substituição na forma da demanda adicional de gás natural que seria promovida; Impacto em Energia Primária (IEP); Impacto em Emissões de Carbono (IEC), do ponto de vista de emissões de $\mathrm{CO}_{2}$; e Impacto em Custo Energético (ICE). Particularmente o IEP e o IEC envolveram a discussão sobre fatores, de conversão em energia primária e de emissões de $\mathrm{CO}_{2}$, assuntos recorrentes no cenário energético mundial devido à relação com o uso sustentável de energia e seus impactos nas mudanças climáticas.

O processo de formulação dos indicadores mostrou que são três as etapas fundamentais para a aplicação da técnica de análise de dados desenvolvida. Primeiramente, é preciso estabelecer um balanço de energia final por uso final, particularmente no que diz respeito aos usos finais de energia e tipos de energia final que serão objetos de análise de substituição. Em 
segundo lugar, deve ser feito o levantamento dos parâmetros necessários para a determinação dos fatores de conversão necessários para os indicadores (dados sobre eficiência do equipamento de uso final de energia, fatores de conversão em energia primária, fatores de emissão e preços ou tarifas). A terceira e última etapa é o diagnóstico do potencial de substituição, podendo este ser avaliado em escala de processo produtivo ou em escala nacional. Para o segundo caso, duas soluções de avaliação por comparação (chamada de benchmarking) foram descritas.

Após a apresentação da técnica de análise de dados, foi feita a sua aplicação ao caso de interesse, a inserção do gás natural no setor industrial brasileiro através da substituição da eletricidade e do óleo combustível em processos térmicos. Foram avaliados os setores de Alimentos e Bebidas Exceto Açúcar, Ferro e Aço, Mineração, Metais Não-Ferrosos, Minerais Não-Metálicos, Papel e Celulose, Químico e Têxtil. O potencial de substituição de óleo combustível foi assumido em 100\% a partir da análise das limitações técnicas das substituições consideradas. No caso da substituição de eletricidade, os potenciais foram calculados através de comparação com outros países através de uma base de dados desenvolvida a partir dos Balanços de Energia publicados pela IEA. Dos resultados obtidos, os principais pontos foram:

- o Setor de Metais Não-Ferrosos (MNF) se destacou ao apresentar a maior demanda adicional de gás natural e as maiores reduções de demanda de energia primária, de emissões de $\mathrm{CO}_{2}$ e de custo energético, exceto em um caso de análise (Impacto em Custo Energético (ICE) expressos em porcentagem do custo energético de eletricidade e óleo combustível de cada setor industrial) onde ficou muito próximo do outro setor que apresentou a maior redução (Setor de Ferro e Aço (F\&A));

- o Setor de Ferro e Aço (F\&A) e Setor de Alimentos e Bebidas (A\&B) também se destacaram, apresentando significativas demandas adicionais de gás natural e reduções de demanda de energia primária, de emissões de $\mathrm{CO}_{2}$ e de custo energético em quase todas as análises;

- considerando que a demanda de gás natural no setor industrial era de $10475 \mathrm{Mm}^{3} / \mathrm{ano}$ (no ano-base 2013), então o potencial total de demanda adicional por gás natural através da substituição de óleo combustível em processos térmicos é equivalente a $28 \%$ dessa demanda, ao passo que o potencial total de demanda adicional por gás natural através 
da substituição de eletricidade em processos térmicos corresponde a uma faixa de 9 a $14 \%$;

- o potencial total de demanda adicional por gás natural através da substituição de óleo combustível em processos térmicos é equivalente a $9 \%$ da oferta interna de gás natural no Brasil em 2013, ao passo que o potencial total de demanda adicional por gás natural através da substituição de eletricidade em processos térmicos corresponde a uma faixa de 3 a $5 \%$;

- o impacto total em energia primária através da substituição de óleo combustível em processos térmicos é equivalente a uma redução de $0,2 \%$ da demanda de energia primária dos setores industriais considerados no Brasil em 2013, ao passo que o impacto total em energia primária através da substituição de eletricidade em processos térmicos corresponde a uma redução na faixa de 1,6 a 2,5\%.

- o impacto total em emissões de $\mathrm{CO}_{2}$ através da substituição de óleo combustível em processos térmicos é equivalente a uma redução de $3,4 \%$ das em emissões de $\mathrm{CO}_{2}$ associadas ao uso de energia dos setores industriais considerados no Brasil em 2013, ao passo que o impacto total em emissões de $\mathrm{CO}_{2}$ através da substituição de eletricidade em processos térmicos corresponde a uma redução na faixa de 1,4 a 2,1\%.

- o impacto total em custo energético através da substituição de óleo combustível em processos térmicos é equivalente a uma redução de $0,1 \%$ dos custos energéticos associados a eletricidade e óleo combustível dos setores industriais considerados no Brasil em 2013, ao passo que o impacto total em custo energético através da substituição de eletricidade em processos térmicos corresponde a uma redução na faixa de 3,2 a 5\%.

Algumas conclusões finais ainda podem ser retiradas ao observar os resultados da aplicação da metodologia:

- Os potenciais de substituição de eletricidade por gás natural estimados ficam, na média, entre $30 \%$ e $45 \%$. Considerando que os setores industriais em análise eram responsáveis por $34 \%$ da demanda de eletricidade no Brasil, esse potencial de substituição iria produzir uma redução na demanda de eletricidade do país entre $10 \%$ e $15 \%$. Essa faixa de valor pode ser considerada marginal, tendo em vista que a geração térmica com uso de gás natural, óleo diesel e óleo combustível, para o ano-base 2013, foi de 16\%, segundo EPE (2014). Dessa forma, a adoção dos fatores de conversão em energia 
primária e fator de emissão de $\mathrm{CO}_{2}$ pelo cálculo marginal mostrou-se uma decisão acertada;

- Os potenciais de substituição de eletricidade por gás natural estimados, na Tabela 4.8. Como o valor médio fica entre $30 \%$ e $45 \%$ e que os usos finais térmicos representam cerca de $30 \%$ da demanda de eletricidade da indústria, o potencial de substituição iria representar a conservação de eletricidade numa faixa de $9 \%$ a 12\%, comparável aos níveis de conservação de energia elétrica apresentado por CNI/Eletrobras (2010). Dessa forma, também se reafirma a decisão acertada na adoção da premissa de cálculo dos potenciais de substituição a partir dos balanços de energia final;

- A demanda adicional por gás natural resultante da substituição de óleo combustível e eletricidade em processos térmicos nos setores considerados representaria um aumento entre 37 a $42 \%$ na demanda de gás natural no setor industrial, equivalente a $12 \%$ a $14 \%$ da oferta interna de gás natural no Brasil em 2013, ou ainda 35\% a 40\% da capacidade máxima do Gasbol;

- O impacto total em energia primária resultante dessa substituição de óleo combustível e eletricidade por gás natural em processos térmicos representaria uma redução de $2 \%$ a 3\% da demanda de energia primária dos setores industriais considerados no Brasil em 2013, ou ainda uma redução de $1 \%$ a 2\% da demanda de energia primária de todo setor industrial brasileiro no mesmo ano;

- O impacto em emissões de $\mathrm{CO}_{2}$ resultante dessa substituição de óleo combustível e eletricidade por gás natural em processos térmicos representaria uma redução de $5 \%$ a $6 \%$ das emissões de $\mathrm{CO}_{2}$ associadas ao uso de energia dos setores industriais considerados no Brasil em 2013, ou ainda uma redução de 4\% a 5\% das emissões de $\mathrm{CO}_{2}$ associadas ao uso de energia de todo setor industrial brasileiro no mesmo ano;

- O impacto total em custo energético resultante dessa substituição de óleo combustível e eletricidade por gás natural em processos térmicos representaria uma redução de $3 \%$ a 5\% dos custos energéticos associados a eletricidade e óleo combustível dos setores industriais considerados no Brasil em 2013, ou ainda 2\% a 4\% dos custos energéticos associados a eletricidade e óleo combustível de todo setor industrial brasileiro no mesmo ano. 
Assim, a principal conclusão obtida através dos resultados do trabalho desenvolvido é que existe uma oportunidade de inserção do gás natural no setor industrial brasileiro resultante da substituição de óleo combustível e eletricidade por gás natural em processos térmicos. De forma geral, seus impactos são positivos, reduzindo a demanda de energia primária, as emissões de $\mathrm{CO}_{2}$ e o custo energético. Retomando a introdução desta dissertação, a proposição da substituição de óleo combustível e a eletricidade por gás natural remete ao Programa Conserve criado na esteira dos Choques do Petróleo, que acabou por representar um programa de substituição energética. Essa observação faz emergir mais fortemente a importância de se fomentar a eficiência energética, para todos os usos finais e tipos de energia final em uso, de modo a se obter um maior impacto em termos de conservação de energia e mitigação de emissões, dois elementos importantes no debate atual sobre combate a mudanças climáticas.

Uma outra conclusão obtida através do trabalho desenvolvido é que a técnica de análise de dados desenvolvida possui uma grande flexibilidade, permitindo sua aplicação em diversas situações. Uma primeira aplicação seria direcionada à avaliação de processos produtivos, avaliando um caso real de substituição entre combustíveis em um dado processo industrial. Uma segunda aplicação seria direcionada à escala macro, ou nacional, que pode fazer uso de diferentes tipos de balanços de energia final. Uma terceira aplicação envolve a avaliação de estudos já realizados para permitir uma comparação dos resultados.

Empreendedores do setor industrial podem usar a primeira aplicação para analisar possibilidades de substituição entre combustíveis, assim como representantes comerciais de empresas do setor de energia podem usá-la para demonstrar os resultados possíveis da substituição entre combustíveis para seus clientes. A segunda aplicação pode auxiliar o poder público, estimando alguns efeitos de uma dada política pública de promoção de um tipo de combustível. Já a terceira aplicação permite que pesquisadores façam uma coleta ampla de diferentes estudos de substituição entre combustíveis e possam compará-los.

Esses casos de aplicação apresentados acima são sugestões de trabalhos futuros que podem ser desenvolvidos com a utilização da técnica de análise de dados desenvolvida e apresentada nesta dissertação. 


\section{REFERÊNCIAS BIBLIOGRÁFICAS}

ADAPT CONSULTING. Conversion Factors for Electricity in Energy Policy: A review of regulatory application of conversion factors for electricity and an assessment of their impact on EU energy and climate goals. Oslo: ADAPT Consulting, 2013.

AGÊNCIA NACIONAL DO PETRÓLEO, GÁS NATURAL E BIOCOMBUSTÍVEIS. Glossário. Disponível em: <http://www.anp.gov.br/ wwwanp/glossario〉. Acesso em: 14 jan. 2018a.

Petróleo e Derivados. Disponível em: <http://www.anp.gov.br/wwwanp/precos-edefesa/2-uncategorised/709-petroleo-e-derivados> Acesso em: 14 jan. 2018 b.

ALMEIDA, E. et al. Atratividade do Upstream Brasileiro para Além do Pré-Sal. Rio de Janeiro: IBP/UFRJ - Instituto Brasileiro de Petróleo, Gás e Biocombustíveis / Universidade Federal do Rio de Janeiro, 2017a. Texto para Discussão. Ciclo de Debates sobre Petróleo e Economia.

Gás do Pré-Sal: Oportunidades, Desafios e Perspectivas. Rio de Janeiro: IBP/UFRJ - Instituto Brasileiro de Petróleo, Gás e Biocombustíveis / Universidade Federal do Rio de Janeiro, 2017b. Texto para Discussão. Ciclo de Debates sobre Petróleo e Economia.

AMERICAN PUBLIC GAS ASSOCIATION. Primary Energy Efficiency. Disponível em: < http://www.apga.org/apgamainsite/aboutus/facts/primary-energy> Acesso em: 14 jan. 2018.

ASSAF NETO, A. Os métodos quantitativos de análise de investimentos. Caderno de Estudos, n. 6, p. 01-16, 1992.

BAHU, M. Les consommations d'énergie dans l'industrie en 2014. Insee Résultats $n^{\circ} 84$. Paris: Insee, 2016.

BAJAY, S. V. e SANT'ANA, P. H. M. Experiências internacionais em eficiência energética para a indústria. In: $\mathrm{CNI} /$ Eletrobras. Oportunidades de eficiência energética para a indústria. Brasília: CNI/Eletrobras, 2010a.

. Novas Tecnologias para Processos Industriais: Eficiência Energética na indústria. In: CNI/Eletrobras. Oportunidades de eficiência energética para a indústria. Brasília: CNI/Eletrobras, 2010b.

- Relatório Setorial: Setor de cal e gesso. In: CNI/Eletrobras. Oportunidades de eficiência energética para a indústria. Brasília: CNI/Eletrobras, 2010c.

Relatório Setorial: Setor têxtil. In: CNI/Eletrobras. Oportunidades de eficiência energética para a indústria. Brasília: CNI/Eletrobras, 2010d. 
BAJAY, S. V., BEISSMANN, A. e GORLA, F. D. Relatório Setorial: Setor químico. In: $\mathrm{CNI} /$ Eletrobras. Oportunidades de eficiência energética para a indústria. Brasília: CNI/Eletrobras, 2010.

BAJAY, S. V., GORLA, F. D. e BORDONI, O. F. J. G. Os segmentos industriais energointensivos de maiores potenciais técnicos de conservação de energia no Brasil. Revista Brasileira de Energia, v. 15, p. 89-107, 2009.

BERNI, M. D., BAJAY, S. V. e GORLA, F. D. Relatório Setorial: Setor cerâmico. In: $\mathrm{CNI} /$ Eletrobras. Oportunidades de eficiência energética para a indústria. Brasília: CNI/Eletrobras, 2010a.

Relatório Setorial: Setor papel e celulose. In: CNI/Eletrobras. Oportunidades de eficiência energética para a indústria. Brasília: CNI/Eletrobras, $2010 \mathrm{~b}$.

BONOMI, A. et al. Estimate of the Specific Energy Consumption in Basic Industrial Processes with Respect to the First and Second Thermodynamic Principles. Bruxelas: Comissão Europeia, DG Pesquisa Ciência e Educação, 1980. Relatório Final. EUR 6752 EN.

BRITISH GAS. Combustion Engineering and Gas Utilisation: British Gas School of Fuel Management. Editor: CORNFORTH, J. R. 3. ed. Londres: E\&FN SPON, 1992.

CARMO, T. O. e SANTOS, G. F. Demanda por Gás Natural na Indústria Brasileira sob a Ótica da Substituição Energética na Indústria. Revista Brasileira de Energia, v. 20, n. 2, p. 49-61, 2014.

COMGAS e ABRINSTAL. Usos Inovadores do Gás Natural (GN) - Promoção da Eficiência Energética em Arranjos Produtivos Locais (APLs). São Paulo: COMGAS e ABRINSTAL, 2016.

CONFEDERAÇÃO NACIONAL DA INDÚSTRIA. Oportunidades de negócios para a indústria em projetos de eficiência energética com MDL programático. In: $\mathrm{CNI} /$ Eletrobras. Oportunidades de eficiência energética para a indústria. Brasília: CNI/Eletrobras, 2010.

CONFEDERAÇÃO NACIONAL DA INDÚSTRIA/ELETROBRAS. Oportunidades de eficiência energética para a indústria. Brasília: CNI/Eletrobras, 2010.

CONFEDERAÇÃO NACIONAL DA INDÚSTRIA/FEDERAÇÃO DAS INDÚSTRIAS DO ESTADO DE MINAS GERAIS. Exploração e Produção de Gás Natural em Minas Gerais: Estimativa dos Benefícios Econômicos e Sociais. Belo Horizonte: CNI/FIEMG, 2015.

COSTA, F. C. Gases combustíveis como alternativas à eletrotermia em aquecimento direto e calor de processo no setor industrial brasileiro. 2013. 211. Tese (Doutorado - Programa de Pós-Graduação em Energia) - Universidade de São Paulo, São Paulo; 2013.

CURSINO DOS SANTOS, A. H. Eficiência energética e a contribuição dos gases combustíveis: análise de caso das políticas de avaliação de edificações. 2011. 175f. Dissertação (Mestrado - Programa de Pós-Graduação em Energia) - Universidade de São Paulo, São Paulo; 2011. 
DE LORENZO, H. C. Eletrificação e crescimento industrial no estado de São Paulo: 18801940. Perspectivas: Revista de Ciências Sociais, 1994.

DE MOURA CUNHA, G. H. et al. A Industrialização Brasileira entre 1900 e 1930 em uma perspectiva histórica. Hegemonia - Revista Eletrônica de Relações Internacionais do Centro Universitário Unieuro. Brasília, n. 21, p. 82-106, 2017.

DE SOUZA, A., GUERRA, J. C. C. e KRUGER, E. L. Os programas brasileiros em eficiência energética como agentes de reposicionamento do setor elétrico. Revista Tecnologia e Sociedade, v. 7, n. 12, 2011.

DE STERCKE, S. Dynamics of Energy Systems: a Useful Perspective. Laxenburg: International Institute for Applied Systems Analysis (IIASA), 2014. IIASA Interim Report $\mathrm{N}^{\mathbf{0}}$ IR-14-013.

DEPARTMENT OF ENERGY AND CLIMATE CHANGE. Chapter 4: Industrial energy consumption in the UK between 1970 and 2014. In: . Energy Consumption in the UK. London: DECC, 2015.

DEVORE, J. L. Capítulo 7. Intervalos estatísticos baseados em uma única amostra. In:

Probabilidade e estatística: para engenharia e ciências. São Paulo: Cengage Learning, 2006.

DORILEO, I. L., BAJAY, S. V. e GORLA, F. D. Relatório Setorial: Setor cimenteiro. In: $\mathrm{CNI} /$ Eletrobras. Oportunidades de eficiência energética para a indústria. Brasília: CNI/Eletrobras, 2010a.

Relatório Setorial: Setor extrativo mineral. In: CNI/Eletrobras. Oportunidades de eficiência energética para a indústria. Brasília: CNI/Eletrobras, $2010 \mathrm{~b}$.

DUFLOU, J. R. et al. Towards energy and resource efficient manufacturing: A processes and systems approach. CIRP Annals-Manufacturing Technology, v. 61, n. 2, p. 587-609, 2012.

ELMARAGHY, H. A. et al. Energy use analysis and local benchmarking of manufacturing lines. Journal of Cleaner Production, 2016.

EMPRESA DE PESQUISA ENERGÉTICA. Balanço Energético Nacional 2014: Ano base 2013. Rio de Janeiro: EPE, 2014.

14 jan. 2018.

Balanço Energético Nacional. Disponível em: <https://ben.epe.gov.br/>. Acesso em:

ENERGY EFFICIENCY AND CONSERVATION AUTHORITY. Energy End Use Database. Wellington: EECA, 2012.

ENERGY INFORMATION ADMINISTRATION. Manufacturing Energy Consumption Survey (MECS). Washington: EIA, 2013.

ENGIE. Combustion and Thermal Process in Industrial Sectors. Saint Denis - La Plaine: ENGIE Lab - CRIGEN, 2016. 
ESSER, A. e SENSFUSS, F. Evaluation of Primary Energy Factor Calculation Options for Electricity. Karlsruhe: Fraunhofer-Institut für System und Innovationsforschung (ISI), 2016. Review of the default primary energy factor (PEF) reflecting the estimated average EU generation efficiency referred to in Annex IV of Directive 2012/27/EU and possible extension of the approach to other energy carriers. Final Report.

FEDERAÇÃO DAS INDÚSTRIAS DO ESTADO DO RIO DE JANEIRO. Quanto custa a energia elétrica para a pequena e média indústria no Brasil? Rio de Janeiro: FIRJAN, 2017.

FERNANDES, F. et al. Mudança Tecnológica de Equipamentos Elétricos para Gás Natural: Um Estudo de Caso. In: Anais do $4^{\circ}$ Congresso Brasileiro de P\&D em Petróleo e Gás. 2007.

FERNANDES, F. GRIMONI, J. A. B. e FAGÁ, M. T. W. Impactos no Fator de Potência e Harmônicas na Substituição da Eletrotermia por Gás Natural. In: Anais do $4^{\circ}$ Congresso Brasileiro de P\&D em Petróleo e Gás. 2007.

FERNANDES, F. Metodologia para escolha de segmentos industriais para substituição da eletrotermia por gás. In: Anais do $3^{\circ}$ Congresso Brasileiro de P\&D em Petróleo e Gás. 2004.

Substituição da Eletrotermia por Gases Combustíveis no Setor Industrial. 2008. 208f. Tese (Doutorado - Programa de Pós-Graduação em Energia) - Universidade de São Paulo, São Paulo; 2008.

FINOCCHIO, M. A. F. Eletrotermia. Cornélio Procópio: Laboratório de Iluminação Segurança e Eficiência Energética (LABSIEE), Universidade Tecnológica Federal do Paraná (UTFPR), 2014. Disponível em: <http://paginapessoal.utfpr.edu.br/mafinocchio/labsilaboratorio-de-seguranca-e-iluminacao/fontes-de-energias-alternativas $>$. Acesso em: 14 jan. 2018.

FLAMME, M. et al. Radiant Tube Burners. Chapter 24. In: BAUKAL JR, C.E (Org). Industrial Combustion Testing. Boca Raton: CRC Press, 2011.

FLEITER, T. et al. Mapping and analyses for the current and future (2020 - 2030) heating/cooling fuel development (fossil/renewables). Bruxelas: Comissão Europeia, DG Energia, 2016.

FOOD AND AGRICULTURE ORGANIZATION. FAOSTAT: emissions - land use. Disponível em: <http://faostat3.fao.org/faostat-gateway/go/to/download/G2/*/E >. Acesso em: 20 nov. 2017.

G1. Petrobras estima 3,3 bilhões de barris de petróleo em área de Libra. 2017. Disponível em : <https://g1.globo.com/economia/noticia/petrobras-estima-33-bilhoes-de-barris-depetroleo-em-area-de-libra.ghtml> Acesso em: 14 jan. 2018.

GALLO, A. B. et al. Promoting energy efficiency by increasing natural gas use: An opportunity assessment in the Brazilian industrial sector through benchmark analysis In: Proceedings of International Gas Union Research Conference IGRC 2017. Rio de Janeiro: IBP, 2017. 
GORLA, F. D. Potencial técnico de conservação de energia na indústria brasileira. 2009. Dissertação (Mestrado - Programa de Pós-Graduação em Planejamento de Sistemas Energéticos) - Universidade Estadual de Campinas (UNICAMP), Campinas, 2009.

GUARDIA, E. et al. Histórico de Programas. In: CNI/Eletrobras. Oportunidades de eficiência energética para a indústria. Brasília: CNI/Eletrobras, 2010.

HARVEY, L. D. D. A guide to global warming potentials (GWPs). Energy Policy, v. 21, n. 1, p. 24-34, 1993.

HOUAISS. Grande Dicionário Houaiss. Disponível em: <https://houaiss.uol.com.br/>. Acesso em: 14 jan. 2018.

IBREL. Sistemas de Aquecimento Industrial. São Paulo: IBREL, 2011. Catálogo.

INCROPERA, P. F. e DEWITT, D. Capítulo 12. Radiação: Processos e Propriedades. In: Fundamentos de Transferência de Calor e de Massa. 6. ed. Rio de Janeiro: Editora LTC, 2008.

INTERGOVERNMENTAL PANEL ON CLIMATE CHANGE. Climate Change 2007: Working Group I: The Physical Science Basis. TS.2.5 Net Global Radiative Forcing, Global Warming Potentials and Patterns of Forcing. Disponível em: <http://www.ipcc.ch/publications_and_data/ar4/wg1/en/tssts-2-5.html>. Acesso em: 14 jan. 2018.

Molule 1: Energy. In: Revised 1996 IPCC Guidelines for National Greenhouse Gas Inventories. Paris: IPCC/OECD/IEA; 1997.

INTERNATIONAL ENERGY AGENCY. CO2 Emissions from Fuel Combustion: Highlights. 2014 Edition. Paris: OECD/IEA Publishing, 2014.

Conceptual framework for evaluating multiple benefits from energy efficiency. Paris: OECD/IEA Publishing, 2016a. $2015 \mathrm{a}$.

Energy Balances of Non-OECD Countries 2015. Paris: OECD/IEA Publishing,

Energy Balances of OECD Countries 2015. Paris: OECD/IEA Publishing, 2015b.

Energy Efficiency in Emerging Economies (E4) Training Weeks. Paris: OECD/IEA Publishing, 2015c.

Energy Prices and Taxes. Quarterly Statistics. First Quarter of 2016. Paris: OECD/IEA Publishing, 2016b.

Key World Energy Statistics. Paris: OECD/IEA Publishing, 2016c.

. Tracking Industrial Energy Efficiency and CO2 emissions. Paris: OECD/IEA Publishing, 2007. 
INTERNATIONAL ENERGY AGENCY. World Energy Outlook 2012. Paris: OECD/IEA Publishing, 2012.

IOST, C. S. Análise do pré-sal brasileiro quanto ao retorno energético sobre o investimento e as emissões de gases de efeito estufa. 2015. 156f. Dissertação (Mestrado - Programa de PósGraduação em Energia) -Universidade de São Paulo, São Paulo, 2015.

JOINT RESEARCH CENTRE - EUROPEAN COMMISSION. Reference documents under the IPPC Directive and the IED. Disponível em: < http://eippcb.jrc.ec.europa.eu/reference/>. Acesso em: 14 jan. 2018.

JONES, H.R.N. The Application of Combustion Principles to Domestic Gas Burner Design. Londres: Taylor \& Francis associada a British Gas, 1989.

KRUGMAN, P. e WELLS, R. Capítulo 6. Elasticidade. In: Introdução à economia. Elsevier Brasil, 2016.

LAMARÃO, S. T. N. A energia elétrica e o parque industrial carioca (1880-1920). 1997. Tese (Doutorado em História) Universidade Federal Fluminense - UFF, Niterói, 1997.

LAMMEL, G. e GRABL, H. Greenhouse Effect of NOx. Environmental Science and Pollution Research, v. 2, n. 1, p. 40-45, 1995.

LANDI, M. Energia elétrica e políticas públicas: A experiência do setor elétrico brasileiro no período de 1934 a 2005. 2006. 219f. Tese (Doutorado - Programa de Pós-Graduação em Energia) - Universidade de São Paulo, São Paulo; 2006.

LAURIJSSEN, J., FAAIJ, A. e WORRELL, E. Benchmarking energy use in the paper industry: a benchmarking study on process unit level. Energy efficiency, v. 6, n. 1, p. 49-63, 2013.

LEITE, A. A. F., BAJAY, S. V. e GORLA, F. D. Relatório Setorial: Setor de ferro-ligas. In: $\mathrm{CNI} /$ Eletrobras. Oportunidades de eficiência energética para a indústria. Brasília: CNI/Eletrobras, 2010a.

Relatório Setorial: Setores não energo-intensivos. In: CNI/Eletrobras. Oportunidades de eficiência energética para a indústria. Brasília: CNI/Eletrobras, $2010 \mathrm{~b}$.

Relatório Setorial: Setor vidreiro. In: CNI/Eletrobras. Oportunidades de eficiência energética para a indústria. Brasília: CNI/Eletrobras, 2010c.

LESLIE, N. Full-Fuel-Cycle Energy and Emission Factors for Building Energy Consumption - 2013 Update. Des Plaines: GTI, Gas Technology Institute, 2014.

LOURENÇO, G. M. O gás natural boliviano e o Brasil. Análise Conjuntural, v. 28, n. 05-06, 2006.

LUCCHESI, C. F. Petróleo. Estudos avançados, v. 12, n. 33, p. 17-40, 1998.

LYRA, F. Capacitação da engenharia nacional na área de projetos. Revista do Serviço Público, v. 43, p. 67-70, 1987. 
MARQUES, M. C. S. et al. Conservação de energia: eficiência energética de equipamentos e instalações. Itajubá: FUPAI, 2006.

MARSON, M. D. A industrialização brasileira antes de 1930: uma contribuição sobre a evolução da indústria de máquinas e equipamentos no estado de São Paulo, 19001920. Estudos Econômicos (São Paulo), v. 45, n. 4, p. 753-785, 2015.

MINISTÉRIO DE CIÊNCIA, TECNOLOGIA, INOVAÇÕES E COMUNICAÇÕES. Estimativas Anuais de Emissões de Gases de Efeito Estufa no Brasil. 3. ed. Brasília: MCTI, 2016.

Fator médio - Inventários corporativos. Brasília: MCTIC, 2017. Disponível em: <http://www.mctic.gov.br/mctic/opencms/ciencia/SEPED/clima/textogeral/emissao_corporati vos.html>. Acesso em: 14 jan. 2018.

MINISTÉRIO DE MINAS E ENERGIA. Análise Retrospectiva. In: Plano Nacional de Energia 2030. Brasília: MME, colaboração EPE, 2007.

Boletim Anual de Exploração e Produção de Petróleo e Gás Natural - 2016. 4. ed. Brasília: MME, 2017.

Boletim Mensal de Acompanhamento da Indústria de Gás Natural. 94. ed. Brasília: MME, 2015.

Gás natural terá novas diretrizes com medidas do “Gás para Crescer”. 2016. Disponível em: < http://www.mme.gov.br/web/guest/pagina-inicial/outras-noticas//asset_publisher/32hLrOzMKwWb/content/gas-natural-tera-novas-diretrizes-com-medidasdo-gas-para-crescer->. Acesso em: 14 jan. 2018.

Relatório do Mercado de Derivados de Petróleo. 97. ed. Brasília: MME, 2014.

MINISTÉRIO DE MINAS E ENERGIA/FUNDAÇÃO DE DESENVOLVIMENTO TECNOLÓGICO DA ENGENHARIA. Balanço de Energia Útil 2005. Brasília: MME, 2005.

MINISTRY OF ECONOMY, TRADE AND INDUSTRY. Minister's Secretariat, Research and Statistics Department. Yearbook of the Current Survey of Energy Consumption in Manufacturing, 2014. Tokyo: METI, 2016.

MONTES, P. M. F. e SCHAEFFER, R. O potencial do consumo de gás natural pelo setor industrial no Brasil. Revista Brasileira de Energia, v. 8, p. 79-109, 2000.

MONTES, P. M. F. O Potencial de Consumo de Gás Natural pelo Setor Industrial no Brasil. 2000. 366f. Dissertação (Mestrado - Programa de Pós-Graduação em Planejamento Energético) COPPE - Universidade Federal do Rio de Janeiro, Rio de Janeiro, 2000.

NESS, B et al. Categorising tools for sustainability assessment. Ecological economics, v. 60, n. 3, p. 498-508, 2007. 
NOGUEIRA, L. A. H. et al. Bioetanol de cana-de-açúcar no Brasil. In: Bioetanol de cana-de-açúcar: energia para o desenvolvimento sustentável. Rio de Janeiro: BNDES CGEE (Centro de Gestão e Estudos Estratégicos), 2008.

PASSOS, J. C. Os experimentos de Joule e a primeira lei da termodinâmica. Revista Brasileira de Ensino de Física, v. 31, n. 3, p. 3603-1-8, 2009.

PATTERSON, Murray G. What is energy efficiency? Concepts, indicators and methodological issues. Energy Policy, v. 24, n. 5, p. 377-390, 1996.

PERLOTTI, E. A., MOUTINHO DOS SANTOS, E. e COSTA, H. K. M. Concentração espacial da indústria de São Paulo: evidências sobre o papel da disponibilidade de gás natural. Estudos Avançados, v. 30, n. 87, p. 143-164, 2016.

PETRO \& QUÍMICA. Gas natural já supre indústrias nacionais. Edição 234. 2002. Disponível em: <http://petroquimica.com.br/edicoes/ed_234/ed_234b.html>. Acesso em: 20 nov. 2017.

PICCININI, M. S. Conservação de energia na indústria: as políticas adotadas na época da crise energética. Revista do BNDES, Rio de Janeiro, v. 1, n. 2, 1994.

PINHEIRO, P. C. C. e VALLE, R. M. Controle de Combustão: Otimização do Excesso de ar. In: Anais do II Congresso de Equipamentos e Automação da Industria Química e Petroquímica, São Paulo: ABIQUIM, Associação Brasileira da Industria Química e de Produtos Derivados, p. 157-162, 1995.

PONTE, V. M. R. et al. Análise das metodologias e técnicas de pesquisas adotadas nos estudos brasileiros sobre balanced scorecard: um estudo dos artigos publicados no período de 1999 a 2006. In: Congresso ANPCONT. 2007.

PORTAL DE ENGENHARIA QUÍMICA. Transferência de Calor. Disponível em: $<$ http://labvirtual.eq.uc.pt/siteJoomla/index.php?option=com_content\&task=view\&id=248\&It emid=> Acesso em: 14 jan. 2018.

PRÉ-SAL PETRÓLEO S.A. O Pré-Sal em números. A evolução da produção de petróleo dos principais campos do Pré-Sal. 2017. Disponível em: < http://www.presalpetroleo.gov.br/ppsa/o-pre-sal-em-numeros/evolucao-da-producao-depetroleo-dos-principais-campos-do-pre-sal> Acesso em: 14 jan. 2018.

PRICE, L. e MCKANE, A. Policies and Measures to realize Industrial Energy Efficiency and mitigate Climate Change. Viena: UN Energy (UNIDO, LBNL, IAEA), 2009.

PRIMETALS. Primetals Technologies Japan Ltd. Furnace Section. Disponível em: <http://www.primetals.co.jp/products/pro3_4_2.html> Acesso em : 14 jan. 2018.

PROSKURYAKOVA, L. e KOVALEV, A. Measuring energy efficiency: Is energy intensity a good evidence base? Applied Energy, v. 138, p. 450-459, 2015.

REVISTA BRASIL ENERGIA. O Estrategista do Pré-Sal. Rio de Janeiro: Editora Brasil Energia, n. 343, junho 2009. 
ROCHA, C. R., BAJAY, S. V. e GORLA, F. D. Relatório Setorial: Setor de alimentos e bebidas. In: $\mathrm{CNI} /$ Eletrobras. Oportunidades de eficiência energética para a indústria. Brasília: CNI/Eletrobras, 2010.

SANTANA, P.H.M.; BAJAY, S.V. New approaches for improving energy efficiency in the Brazilian industry. Energy Reports, v. 2, p. 62-66, 2016.

SAUER, I. Plano de Massificação do Uso de Gás Natural. In: I Fórum de Distribuidoras de Gás Natural - Gás Natural uma Nova Fronteira. 2003. Disponível em: <https://professorildosauer.files.wordpress.com/2010/02/2003-aprmassifusogasnat.pdf>. Acesso em: 14 jan. 2018.

SELAS. Red-Ray High Intensity Infrared Emitter Exclusively Designed for Paper Drying. [Streetsboro: Selas]. Disponível em: https://www.selas.com/product/industrialburners/infrared-burners/red-ray-high-intensity-infrared-emitter-for-paper-drying/> Acesso em : 14 jan. 2018.

SENADO FEDERAL. Lei que destina recursos a programa de eficiência energética é sancionada. 2016. Disponível em : <https://www12.senado.leg.br/noticias/materias/2016/05/ 04/lei-que-destina-recursos-a-programa-de-eficiencia-energetica-e-sancionada>. Acesso em : 14 jan. 2018.

SHEN, B et al. Techno-economic evaluation of strategies for addressing energy and environmental challenges of industrial boilers in China. Energy, v. 118, p. 526-533, 2017.

SIEGEL, R.; HOWELL, J. R. Thermal radiation heat transfer. Tokyo: McGraw Hill Kogakusha, 1972

SIMÕES, A. F. e BAJAY, S. V. Relatório Setorial: Setor de fundição. In: CNI/Eletrobras. Oportunidades de eficiência energética para a indústria. Brasília: CNI/Eletrobras, 2010a.

Relatório Setorial: Setor de metais não-ferrosos. In: CNI/Eletrobras. Oportunidades de eficiência energética para a indústria. Brasília: CNI/Eletrobras, $2010 b$.

SINGH, S.N. e BENNETT, R. General Infrared Process Heating Application Tool. Topical Report. Chicago: GRI (Gas Research Institute), 1999.

SOUZA, H. M., et al. Reflexões sobre os Principais Programas em Eficiência Energética Existentes no Brasil. Revista Brasileira de Energia, v. 15, p. 7-26, 2009.

STANEK, W. et al. Chapter 2. Resources. Production. Depletion. In: STANEK, Wojciech et al. Resources. Production. Depletion. In: Thermodynamics for Sustainable Management of Natural Resources. Springer International Publishing, 2017. p. 7-36.

STRAPASSON, A. B. A energia térmica e o paradoxo da eficiência energética - desafios para um novo modelo de planejamento energético. 2004. 133f. Dissertação (Mestrado Programa de Pós-Graduação em Energia) - Universidade de São Paulo, São Paulo, 2004. 
STRAPASSON, A. B. e FAGA, M. T. W. Energy efficiency and heat generation. An integrated analysis of the Brazilian energy mix. International Energy Journal, v. 8, n. 3, p. 171-179, 2007.

Impacto da qualidade exergética da energia final no consumo de energia primária: caso gás natural. Petro \& Química, v. 1, p. 88-91, 2004a.

Usos Finais Térmicos da Energia: Elementos para um Novo Modelo de Eficiência Energética. In: Anais do IV Congresso Brasileiro de Planejamento Energético. Itajubá: SBPE - Sociedade Brasileira de Planejamento Energético, 2004b.

SUZIGAN, W. et al. Industrialização brasileira em perspectiva histórica. História Econômica \& História de Empresas, v. 3, n. 2, p. 7-25, 2000.

UNITED NATIONS INDUSTRIAL DEVELOPMENT ORGANIZATION. Global Industrial Energy Efficiency Benchmarking. An Energy Policy Tool. Working paper. Viena: UNIDO, 2010 .

VICECONTI, Paulo Eduardo V. O processo de industrialização brasileira. Revista de Administração de Empresas, v. 17, n. 6, p. 33-43, 1977.

WALL, G e GONG, M. On exergy and sustainable development - Part 1: Conditions and concepts. Exergy, An International Journal, v. 1, n. 3, p. 128-145, 2001.

WALL, G. Exergy - a Useful Concept within Resource Accounting. Chalmers tekniska högskola, Göteborgs universitet. 1977.

Exergy Conversion in the Japanese Society. Energy. v. 15, n. 5, p. 435-444, 1990.

WORLD RESOURCES INSTITUTE. Climate analysis indicators tool (CAIT) 2.0: WRI's climate data explorer. Disponível em: <http://cait.wri.org>. Acesso em: 20 nov. 2017.

WORRELL, E. et al. World best practice energy intensity values for selected industrial sectors. Berkeley: Lawrence Berkeley National Laboratory (LBNL), 2008. 


\section{APÊNDICE A - Tabelas da Base de dados de balanços de energia final}

A construção de uma base de dados de balanços de energia final com um dado conjunto de países foi necessária para a determinação do potencial de substituição de eletricidade por gás natural em processos térmicos na aplicação da técnica de análise de dados no Capítulo 4 desta dissertação. A base de dados foi construída com balanços de energia final publicados pela IEA (2015a, 2015b). Três critérios de triagem foram adotados: a presença da repartição por setor industrial da demanda de eletricidade; a participação da eletricidade na demanda de energia final de cada setor industrial deve ser menor que essa do respectivo setor industrial brasileiro $\left(\% \mathrm{EF}_{\mathrm{S}, \mathrm{E}}<\% \mathrm{EF}_{\mathrm{S}, \mathrm{E}, \mathrm{BR}}\right)$; a participação da demanda de energia final de um dado setor industrial em relação à demanda de energia final total do setor industrial do país em que ele se encontra (\% $\mathrm{EF}_{\mathrm{s}} / \% \mathrm{EF}_{\text {INDÚSTRIA }}$ em relação à mesma participação do respectivo setor industrial no Brasil deve ser maior que um dado valor, estabelecido setor a setor, nos casos aplicáveis. Mais detalhes sobre a construção da base de dados estão apresentados no Capítulo 4.

A primeira triagem resultou numa lista de 33 países membros da OCDE e 26 países nãomembros da OCDE, além do Brasil, apresentada na Tabela A.1. Para esses países são apresentados balanços de energia final resumidos nas Tabelas A.2 e A.3, apresentando a demanda de derivados de petróleo, de gás natural, de eletricidade e de energia final total. Também já são apresentados nessas tabelas os valores dos parâmetros para o segundo e o terceiro critério de triagem, ou seja, a participação da eletricidade na demanda de energia final por setor industrial $\left(\% \mathrm{EF}_{\mathrm{s}, \mathrm{E}}\right)$ e participação da demanda de energia final de cada setor industrial em relação à demanda de energia final total do setor industrial do país (\% $\left.\mathrm{EF}_{\mathrm{s}} / \% \mathrm{EF}_{\text {INDÚsTRIA }}\right)$. Os valores do setor industrial brasileiro para esses parâmetros estão apresentados na Tabela A.6. O resultado final da triagem é apresentado nas Tabelas A.4 e A.5.

Por fim na Tabela A.6 também são apresentados, por setor industrial para o Brasil, a demanda de energia primária e o custo energético com óleo combustível e eletricidade. $\mathrm{O}$ primeiro é calculado usando os fatores de conversão em energia primária da Tabela 4.3, sendo que, para os tipos de energia primária não presentes na tabela foi adotado o menor valor. Já o segundo foi calculado usando os valores de demanda de eletricidade e por óleo combustível presentes na Tabela A.6 e os preços (ou tarifas) apresentados na Tabela 4.3. 
Tabela A.1 - Lista de países da base de dados de balanços de energia final

\begin{tabular}{cccc}
\hline \multicolumn{2}{c}{ Países Membros OCDE } & Países Não-membros OCDE \\
\hline Alemanha & Hungria & África do Sul & Marrocos \\
Austrália & Irlanda & Albânia & Moldávia \\
Áustria & Islândia & Argélia & Romênia \\
Bélgica & Itália & Azerbaijão & Rússia \\
Canadá & Japão & Bielorrússia & Sérvia \\
Chile & Luxemburgo & Bósnia Herzegovina & Tailândia \\
Coréia do Sul & México & Bulgária & Taiwan \\
Dinamarca & Noruega & Cazaquistão & Tunísia \\
Eslováquia & Nova Zelândia & China & Ucrânia \\
Eslovênia & Polônia & Colômbia & \\
Espanha & Portugal & Croácia & \\
Estados Unidos & Reino Unido & Filipinas & \\
Estônia & República Tcheca & Geórgia & \\
Finlândia & Suécia & Índia & \\
França & Suíça & Letônia & \\
Grécia & Turquia & Lituânia & \\
Holanda & & Macedônia & \\
\hline
\end{tabular}

Fonte: Elaboração própria, baseada em IEA (2015a, 2015b) 
Tabela A.2 - Balanço de energia final e parâmetros de triagem baseado em IEA (2015b)

(continua)

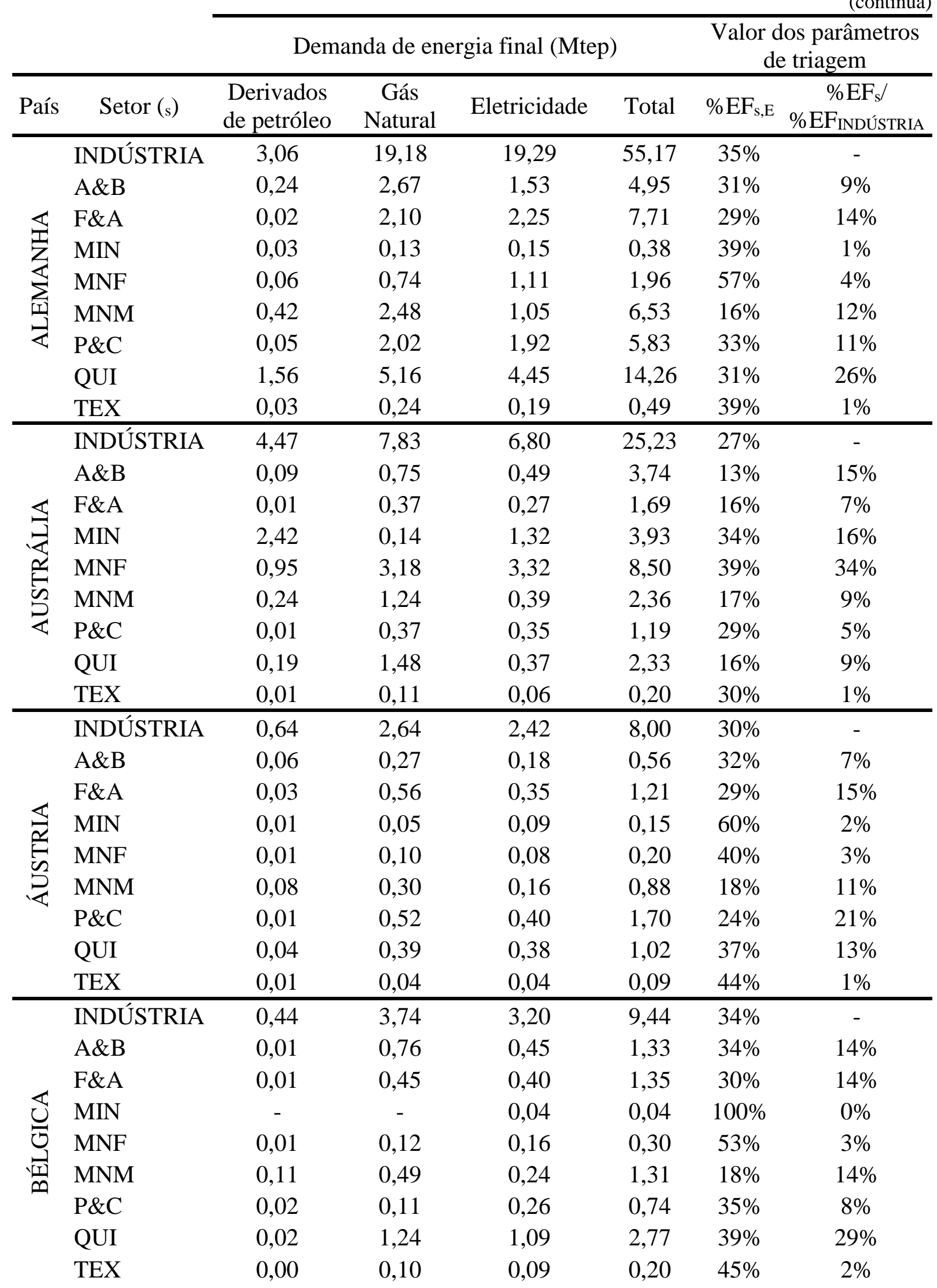


Tabela A.2 - Balanço de energia final e parâmetros de triagem baseado em IEA (2015b)

(continução)

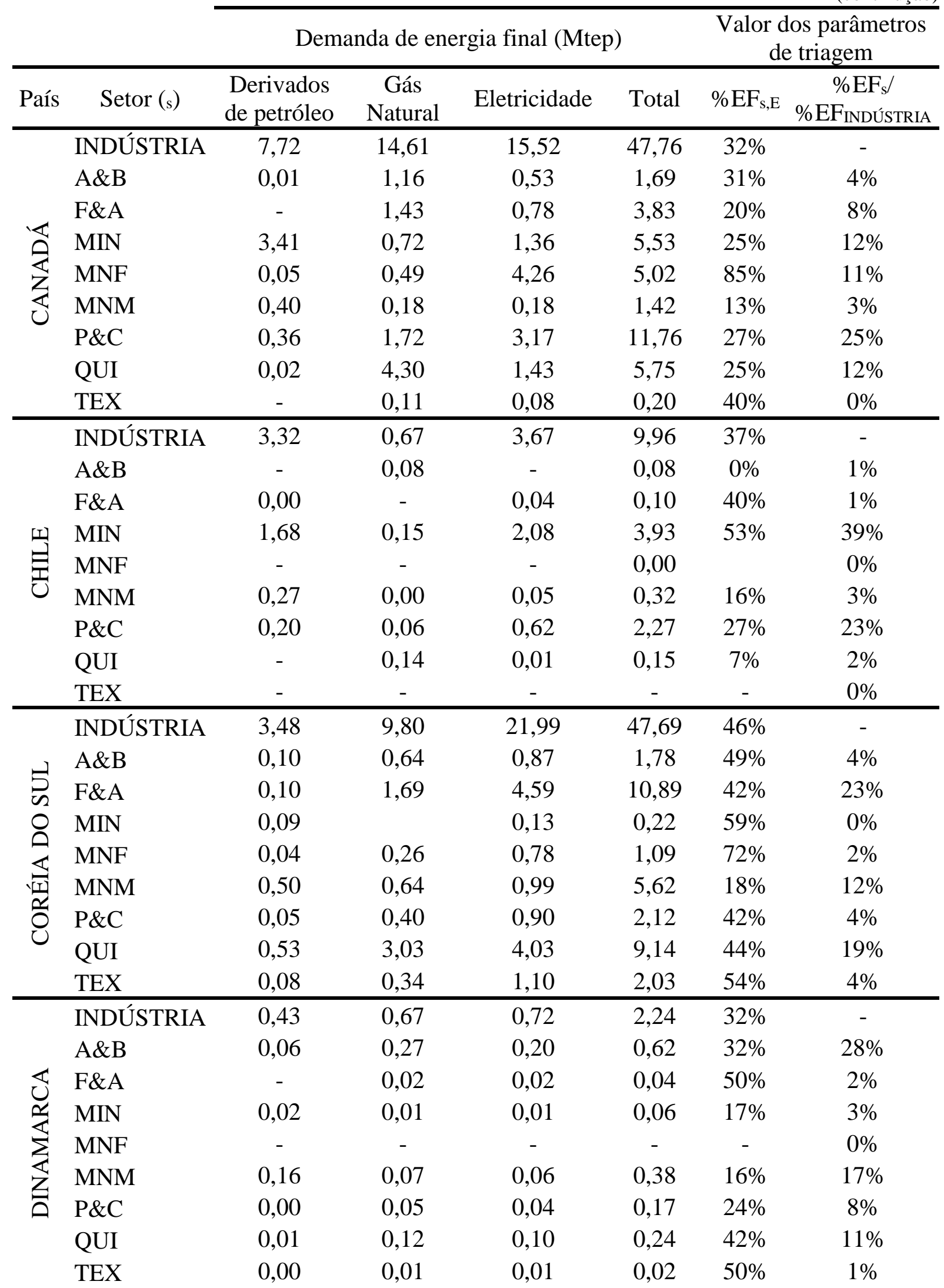


Tabela A.2 - Balanço de energia final e parâmetros de triagem baseado em IEA (2015b)

(continução)

\begin{tabular}{|c|c|c|c|c|c|c|c|}
\hline \multirow[b]{2}{*}{ País } & \multirow[b]{2}{*}{ Setor $(\mathrm{s})$} & \multicolumn{4}{|c|}{ Demanda de energia final (Mtep) } & \multicolumn{2}{|c|}{$\begin{array}{c}\text { Valor dos parâmetros } \\
\text { de triagem }\end{array}$} \\
\hline & & $\begin{array}{l}\text { Derivados } \\
\text { de petróleo }\end{array}$ & $\begin{array}{c}\text { Gás } \\
\text { Natural }\end{array}$ & Eletricidade & Total & $\% \mathrm{EF}_{\mathrm{s}, \mathrm{E}}$ & $\begin{array}{c}\% \mathrm{EF}_{\mathrm{s}} / \\
\% \mathrm{EF}_{\text {INDÚSTRIA }}\end{array}$ \\
\hline \multirow{9}{*}{ 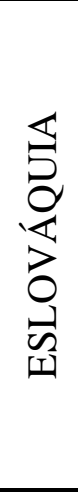 } & INDÚSTRIA & 0,07 & 0,84 & 1,01 & 3,20 & $32 \%$ & - \\
\hline & $\mathrm{A} \& \mathrm{~B}$ & - & 0,08 & 0,04 & 0,14 & $29 \%$ & $4 \%$ \\
\hline & F\&A & - & 0,21 & 0,21 & 1,14 & $18 \%$ & $36 \%$ \\
\hline & MIN & 0,00 & 0,00 & 0,00 & 0,01 & $0 \%$ & $0 \%$ \\
\hline & MNF & - & 0,03 & 0,21 & 0,24 & $88 \%$ & $8 \%$ \\
\hline & MNM & 0,04 & 0,13 & 0,06 & 0,39 & $15 \%$ & $12 \%$ \\
\hline & $\mathrm{P} \& \mathrm{C}$ & - & 0,06 & 0,10 & 0,43 & $23 \%$ & $13 \%$ \\
\hline & QUI & 0,01 & 0,10 & 0,12 & 0,30 & $40 \%$ & $9 \%$ \\
\hline & TEX & - & 0,02 & 0,01 & 0,03 & $33 \%$ & $1 \%$ \\
\hline \multirow{9}{*}{ 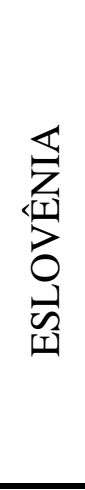 } & INDÚSTRIA & 0,12 & 0,39 & 0,51 & 1,20 & $43 \%$ & - \\
\hline & $\mathrm{A} \& \mathrm{~B}$ & 0,01 & 0,02 & 0,02 & 0,06 & $33 \%$ & $5 \%$ \\
\hline & $\mathrm{F} \& A$ & 0,00 & 0,07 & 0,07 & 0,15 & $47 \%$ & $13 \%$ \\
\hline & MIN & 0,00 & 0,00 & 0,01 & 0,02 & $50 \%$ & $2 \%$ \\
\hline & $\mathrm{MNF}$ & 0,01 & 0,03 & 0,11 & 0,15 & $73 \%$ & $13 \%$ \\
\hline & MNM & 0,04 & 0,06 & 0,03 & 0,18 & $17 \%$ & $15 \%$ \\
\hline & $\mathrm{P} \& \mathrm{C}$ & 0,00 & 0,08 & 0,05 & 0,16 & $31 \%$ & $13 \%$ \\
\hline & QUI & 0,01 & 0,05 & 0,05 & 0,15 & $33 \%$ & $13 \%$ \\
\hline & TEX & 0,00 & 0,01 & 0,01 & 0,03 & $33 \%$ & $3 \%$ \\
\hline \multirow{9}{*}{ 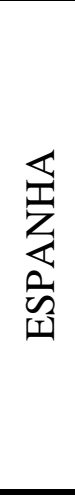 } & INDÚSTRIA & 2,66 & 9,03 & 6,02 & 20,12 & $30 \%$ & - \\
\hline & $\mathrm{A} \& \mathrm{~B}$ & 0,31 & 0,79 & 0,79 & 2,17 & $36 \%$ & $11 \%$ \\
\hline & $\mathrm{F} \& \mathrm{~A}$ & 0,08 & 0,48 & 1,10 & 2,35 & $47 \%$ & $12 \%$ \\
\hline & MIN & 0,16 & 0,15 & 0,11 & 0,42 & $26 \%$ & $2 \%$ \\
\hline & MNF & 0,06 & 0,12 & 0,88 & 1,09 & $81 \%$ & $5 \%$ \\
\hline & MNM & 1,25 & 1,41 & 0,54 & 3,38 & $16 \%$ & $17 \%$ \\
\hline & $\mathrm{P} \& \mathrm{C}$ & 0,09 & 0,93 & 0,43 & 2,05 & $21 \%$ & $10 \%$ \\
\hline & QUI & 0,15 & 2,98 & 0,70 & 4,01 & $17 \%$ & $20 \%$ \\
\hline & TEX & 0,02 & 0,16 & 0,17 & 0,35 & $49 \%$ & $2 \%$ \\
\hline \multirow{9}{*}{ 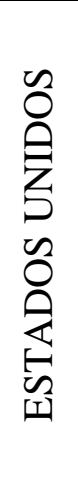 } & INDÚSTRIA & 21,61 & 107,36 & 72,80 & 261,05 & $28 \%$ & - \\
\hline & $\mathrm{A} \& \mathrm{~B}$ & 0,36 & 15,99 & 6,39 & 27,76 & $23 \%$ & $11 \%$ \\
\hline & $\mathrm{F} \& \mathrm{~A}$ & 0,35 & 8,70 & 4,03 & 17,07 & $24 \%$ & $7 \%$ \\
\hline & MIN & 3,08 & 1,92 & 2,74 & 7,84 & $35 \%$ & $3 \%$ \\
\hline & MNF & 0,03 & 3,70 & 5,90 & 9,72 & $61 \%$ & $4 \%$ \\
\hline & MNM & 1,76 & 7,32 & 2,65 & 17,77 & $15 \%$ & $7 \%$ \\
\hline & $\mathrm{P} \& \mathrm{C}$ & 0,65 & 8,27 & 5,10 & 40,76 & $13 \%$ & $16 \%$ \\
\hline & QUI & 2,50 & 30,16 & 9,60 & 49,35 & $19 \%$ & $19 \%$ \\
\hline & TEX & 0,08 & 1,00 & 1,44 & 2,72 & $53 \%$ & $1 \%$ \\
\hline
\end{tabular}


Tabela A.2 - Balanço de energia final e parâmetros de triagem baseado em IEA (2015b)

(continução)

\begin{tabular}{|c|c|c|c|c|c|c|c|}
\hline \multirow[b]{2}{*}{ País } & \multirow[b]{2}{*}{ Setor $(\mathrm{s})$} & \multicolumn{4}{|c|}{ Demanda de energia final (Mtep) } & \multicolumn{2}{|c|}{$\begin{array}{c}\text { Valor dos parâmetros } \\
\text { de triagem }\end{array}$} \\
\hline & & $\begin{array}{l}\text { Derivados } \\
\text { de petróleo }\end{array}$ & $\begin{array}{l}\text { Gás } \\
\text { Natural }\end{array}$ & Eletricidade & Total & $\% \mathrm{EF}_{\mathrm{s}, \mathrm{E}}$ & $\begin{array}{c}\% \mathrm{EF}_{\mathrm{s}} / \\
\% \mathrm{EF}_{\text {INDÚSTRIA }}\end{array}$ \\
\hline \multirow{9}{*}{ 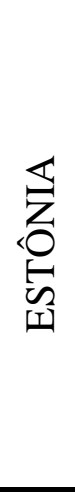 } & INDÚSTRIA & 0,07 & 0,15 & 0,19 & 0,64 & $30 \%$ & - \\
\hline & $\mathrm{A} \& \mathrm{~B}$ & 0,01 & 0,03 & 0,02 & 0,06 & $33 \%$ & $9 \%$ \\
\hline & F\&A & - & 0,00 & 0,00 & 0,00 & - & $0 \%$ \\
\hline & MIN & 0,01 & 0,01 & 0,00 & 0,01 & $0 \%$ & $2 \%$ \\
\hline & MNF & - & 0,00 & 0,00 & 0,00 & - & $0 \%$ \\
\hline & MNM & 0,00 & 0,02 & 0,02 & 0,17 & $12 \%$ & $27 \%$ \\
\hline & $\mathrm{P} \& \mathrm{C}$ & - & 0,03 & 0,03 & 0,06 & $50 \%$ & $9 \%$ \\
\hline & QUI & 0,00 & 0,04 & 0,02 & 0,07 & $29 \%$ & $11 \%$ \\
\hline & TEX & 0,00 & 0,00 & 0,01 & 0,01 & $100 \%$ & $2 \%$ \\
\hline \multirow{9}{*}{ 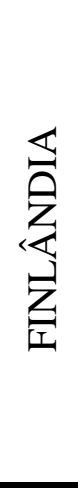 } & INDÚSTRIA & 1,17 & 0,61 & 3,33 & 10,40 & $32 \%$ & - \\
\hline & $\mathrm{A} \& \mathrm{~B}$ & 0,04 & 0,02 & 0,12 & 0,35 & $34 \%$ & $3 \%$ \\
\hline & $\mathrm{F} \& A$ & 0,12 & 0,05 & 0,33 & 0,76 & $43 \%$ & $7 \%$ \\
\hline & MIN & 0,04 & - & 0,11 & 0,16 & $69 \%$ & $2 \%$ \\
\hline & $\mathrm{MNF}$ & 0,03 & 0,00 & 0,18 & 0,30 & $60 \%$ & $3 \%$ \\
\hline & MNM & 0,09 & 0,03 & 0,06 & 0,27 & $22 \%$ & $3 \%$ \\
\hline & $\mathrm{P} \& \mathrm{C}$ & 0,10 & 0,47 & 1,62 & 5,89 & $28 \%$ & $57 \%$ \\
\hline & QUI & 0,26 & 0,01 & 0,41 & 1,03 & $40 \%$ & $10 \%$ \\
\hline & TEX & 0,01 & 0,00 & 0,02 & 0,03 & $67 \%$ & $0 \%$ \\
\hline \multirow{9}{*}{ 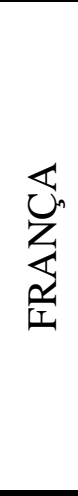 } & INDÚSTRIA & 2,64 & 11,77 & 9,58 & 28,00 & $34 \%$ & - \\
\hline & $\mathrm{A} \& \mathrm{~B}$ & 0,28 & 2,53 & 1,79 & 4,93 & $36 \%$ & $18 \%$ \\
\hline & $\mathrm{F} \& \mathrm{~A}$ & 0,02 & 0,87 & 1,06 & 3,52 & $30 \%$ & $13 \%$ \\
\hline & MIN & 0,09 & 0,03 & 0,14 & 0,27 & $52 \%$ & $1 \%$ \\
\hline & MNF & 0,02 & 0,39 & 0,72 & 1,14 & $63 \%$ & $4 \%$ \\
\hline & MNM & 0,78 & 2,24 & 0,70 & 4,17 & $17 \%$ & $15 \%$ \\
\hline & $\mathrm{P} \& \mathrm{C}$ & 0,06 & 1,21 & 0,85 & 2,74 & $31 \%$ & $10 \%$ \\
\hline & QUI & 0,48 & 2,35 & 1,76 & 5,18 & $34 \%$ & $19 \%$ \\
\hline & TEX & 0,02 & 0,15 & 0,13 & 0,31 & $42 \%$ & $1 \%$ \\
\hline \multirow{9}{*}{ 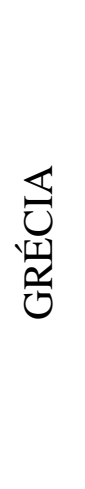 } & INDÚSTRIA & 0,98 & 0,54 & 0,98 & 2,84 & $35 \%$ & - \\
\hline & $\mathrm{A} \& \mathrm{~B}$ & 0,14 & 0,06 & 0,18 & 0,47 & $38 \%$ & $17 \%$ \\
\hline & F\&A & 0,03 & 0,04 & 0,07 & 0,14 & $50 \%$ & $5 \%$ \\
\hline & MIN & 0,07 & - & 0,00 & 0,07 & $0 \%$ & $2 \%$ \\
\hline & $\mathrm{MNF}$ & 0,01 & 0,32 & 0,41 & 0,88 & $47 \%$ & $31 \%$ \\
\hline & MNM & 0,53 & 0,02 & 0,09 & 0,73 & $12 \%$ & $26 \%$ \\
\hline & $\mathrm{P} \& \mathrm{C}$ & 0,03 & 0,02 & 0,05 & 0,10 & $50 \%$ & $4 \%$ \\
\hline & QUI & 0,03 & 0,03 & 0,05 & 0,11 & $45 \%$ & $4 \%$ \\
\hline & TEX & 0,01 & 0,01 & 0,03 & 0,04 & $75 \%$ & $1 \%$ \\
\hline
\end{tabular}


Tabela A.2 - Balanço de energia final e parâmetros de triagem baseado em IEA (2015b)

(continução)

\begin{tabular}{|c|c|c|c|c|c|c|c|}
\hline \multirow[b]{2}{*}{ País } & \multirow[b]{2}{*}{ Setor $(\mathrm{s})$} & \multicolumn{4}{|c|}{ Demanda de energia final (Mtep) } & \multicolumn{2}{|c|}{$\begin{array}{c}\text { Valor dos parâmetros } \\
\text { de triagem }\end{array}$} \\
\hline & & $\begin{array}{l}\text { Derivados } \\
\text { de petróleo }\end{array}$ & $\begin{array}{l}\text { Gás } \\
\text { Natural }\end{array}$ & Eletricidade & Total & $\% \mathrm{EF}_{\mathrm{s}, \mathrm{E}}$ & $\begin{array}{c}\% \mathrm{EF}_{\mathrm{s}} / \\
\% \mathrm{EF}_{\text {INDÚSTRIA }}\end{array}$ \\
\hline \multirow{9}{*}{ 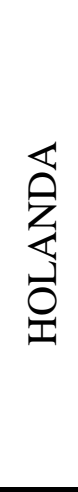 } & INDÚSTRIA & 0,43 & 4,97 & 3,00 & 12,30 & $24 \%$ & - \\
\hline & $\mathrm{A} \& \mathrm{~B}$ & 0,00 & 1,22 & 0,55 & 1,90 & $29 \%$ & $15 \%$ \\
\hline & F\&A & 0,00 & 0,27 & 0,23 & 1,06 & $22 \%$ & $9 \%$ \\
\hline & MIN & 0,01 & 0,08 & 0,02 & 0,11 & $18 \%$ & $1 \%$ \\
\hline & MNF & - & 0,06 & 0,24 & 0,31 & $77 \%$ & $3 \%$ \\
\hline & MNM & 0,01 & 0,40 & 0,11 & 0,55 & $20 \%$ & $4 \%$ \\
\hline & $\mathrm{P} \& \mathrm{C}$ & - & 0,33 & 0,22 & 0,69 & $32 \%$ & $6 \%$ \\
\hline & QUI & 0,06 & 1,94 & 1,07 & 6,02 & $18 \%$ & $49 \%$ \\
\hline & TEX & - & 0,07 & 0,03 & 0,10 & $30 \%$ & $1 \%$ \\
\hline \multirow{9}{*}{ 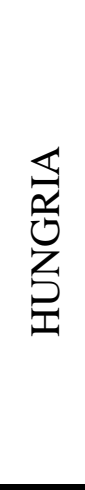 } & INDÚSTRIA & 0,26 & 1,27 & 1,27 & 3,38 & $38 \%$ & - \\
\hline & $\mathrm{A} \& \mathrm{~B}$ & 0,01 & 0,26 & 0,19 & 0,51 & $37 \%$ & $15 \%$ \\
\hline & $\mathrm{F} \& A$ & 0,00 & 0,06 & 0,05 & 0,26 & $19 \%$ & $8 \%$ \\
\hline & MIN & 0,01 & 0,01 & 0,01 & 0,03 & $33 \%$ & $1 \%$ \\
\hline & $\mathrm{MNF}$ & - & 0,07 & 0,04 & 0,15 & $27 \%$ & $4 \%$ \\
\hline & MNM & 0,08 & 0,17 & 0,09 & 0,38 & $24 \%$ & $11 \%$ \\
\hline & $\mathrm{P} \& \mathrm{C}$ & 0,00 & 0,08 & 0,07 & 0,18 & $39 \%$ & $5 \%$ \\
\hline & QUI & 0,03 & 0,24 & 0,26 & 0,75 & $35 \%$ & $22 \%$ \\
\hline & TEX & 0,00 & 0,02 & 0,02 & 0,04 & $50 \%$ & $1 \%$ \\
\hline \multirow{9}{*}{ 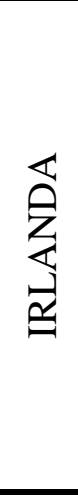 } & INDÚSTRIA & 0,49 & 0,62 & 0,80 & 2,18 & $37 \%$ & - \\
\hline & $\mathrm{A} \& \mathrm{~B}$ & 0,12 & 0,09 & 0,17 & 0,43 & $40 \%$ & $20 \%$ \\
\hline & $\mathrm{F} \& \mathrm{~A}$ & 0,00 & - & - & 0,00 & - & $0 \%$ \\
\hline & MIN & 0,04 & 0,01 & 0,06 & 0,11 & $55 \%$ & $5 \%$ \\
\hline & MNF & 0,10 & 0,32 & 0,06 & 0,48 & $13 \%$ & $22 \%$ \\
\hline & MNM & 0,11 & 0,01 & 0,05 & 0,30 & $17 \%$ & $14 \%$ \\
\hline & $\mathrm{P} \& \mathrm{C}$ & 0,00 & 0,00 & 0,02 & 0,02 & $100 \%$ & $1 \%$ \\
\hline & QUI & 0,03 & 0,06 & 0,15 & 0,23 & $65 \%$ & $11 \%$ \\
\hline & TEX & 0,01 & 0,00 & 0,01 & 0,02 & $50 \%$ & $1 \%$ \\
\hline \multirow{9}{*}{ 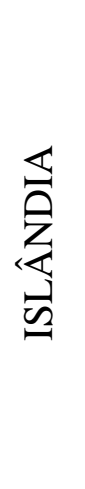 } & INDÚSTRIA & 0,04 & - & 1,26 & 1,41 & $89 \%$ & - \\
\hline & $\mathrm{A} \& \mathrm{~B}$ & 0,00 & - & 0,05 & 0,05 & $100 \%$ & $4 \%$ \\
\hline & $\mathrm{F} \& \mathrm{~A}$ & 0,01 & - & 0,09 & 0,20 & $45 \%$ & $14 \%$ \\
\hline & MIN & - & - & 0,00 & 0,00 & - & $0 \%$ \\
\hline & MNF & 0,00 & - & 1,11 & 1,11 & $100 \%$ & $79 \%$ \\
\hline & MNM & 0,00 & - & 0,00 & 0,00 & - & $0 \%$ \\
\hline & $\mathrm{P} \& \mathrm{C}$ & - & - & 0,00 & 0,00 & - & $0 \%$ \\
\hline & QUI & - & - & 0,00 & 0,00 & - & $0 \%$ \\
\hline & TEX & - & - & 0,00 & 0,00 & - & $0 \%$ \\
\hline
\end{tabular}


Tabela A.2 - Balanço de energia final e parâmetros de triagem baseado em IEA (2015b)

(continução)

\begin{tabular}{|c|c|c|c|c|c|c|c|}
\hline \multirow[b]{2}{*}{ País } & \multirow[b]{2}{*}{ Setor $(\mathrm{s})$} & \multicolumn{4}{|c|}{ Demanda de energia final (Mtep) } & \multicolumn{2}{|c|}{$\begin{array}{c}\text { Valor dos parâmetros } \\
\text { de triagem }\end{array}$} \\
\hline & & $\begin{array}{l}\text { Derivados } \\
\text { de petróleo }\end{array}$ & $\begin{array}{c}\text { Gás } \\
\text { Natural }\end{array}$ & Eletricidade & Total & $\% \mathrm{EF}_{\mathrm{s}, \mathrm{E}}$ & $\begin{array}{c}\% \mathrm{EF}_{\mathrm{s}} / \\
\% \mathrm{EF}_{\text {INDÚSTRIA }}\end{array}$ \\
\hline \multirow{9}{*}{ 空 } & INDÚSTRIA & 2,74 & 8,73 & 9,89 & 26,14 & $38 \%$ & - \\
\hline & $\mathrm{A} \& \mathrm{~B}$ & 0,16 & 1,17 & 1,03 & 2,66 & $39 \%$ & $10 \%$ \\
\hline & F\&A & 0,07 & 1,21 & 1,57 & 4,36 & $36 \%$ & $17 \%$ \\
\hline & MIN & 0,02 & 0,03 & 0,06 & 0,12 & $50 \%$ & $0 \%$ \\
\hline & MNF & 0,03 & 0,40 & 0,21 & 0,64 & $33 \%$ & $2 \%$ \\
\hline & MNM & 1,52 & 2,00 & 0,81 & 4,98 & $16 \%$ & $19 \%$ \\
\hline & $\mathrm{P} \& \mathrm{C}$ & 0,06 & 0,61 & 0,78 & 2,02 & $39 \%$ & $8 \%$ \\
\hline & QUI & 0,47 & 1,05 & 1,28 & 4,12 & $31 \%$ & $16 \%$ \\
\hline & TEX & 0,08 & 0,59 & 0,46 & 1,17 & $39 \%$ & $4 \%$ \\
\hline \multirow{9}{*}{ 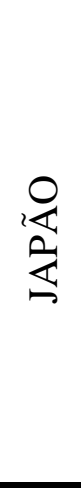 } & INDÚSTRIA & 22,97 & 7,54 & 23,33 & 82,01 & $28 \%$ & - \\
\hline & $\mathrm{A} \& \mathrm{~B}$ & 1,50 & 1,25 & 1,50 & 4,25 & $35 \%$ & $5 \%$ \\
\hline & $\mathrm{F} \& \mathrm{~A}$ & 1,38 & 2,15 & 5,75 & 19,23 & $30 \%$ & $23 \%$ \\
\hline & MIN & 0,12 & 0,11 & 0,08 & 0,32 & $25 \%$ & $0 \%$ \\
\hline & $\mathrm{MNF}$ & 0,21 & 0,06 & 1,30 & 1,82 & $71 \%$ & $2 \%$ \\
\hline & MNM & 1,48 & 0,43 & 1,87 & 7,84 & $24 \%$ & $10 \%$ \\
\hline & $\mathrm{P} \& \mathrm{C}$ & 0,61 & 0,40 & 2,52 & 7,58 & $33 \%$ & $9 \%$ \\
\hline & QUI & 9,41 & 1,08 & 4,18 & 17,78 & $24 \%$ & $22 \%$ \\
\hline & TEX & - & - & - & - & - & $0 \%$ \\
\hline \multirow{9}{*}{ 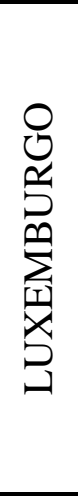 } & INDÚSTRIA & 0,01 & 0,23 & 0,22 & 0,54 & $41 \%$ & - \\
\hline & $\mathrm{A} \& \mathrm{~B}$ & 0,00 & 0,01 & 0,01 & 0,03 & $33 \%$ & $6 \%$ \\
\hline & $\mathrm{F} \& \mathrm{~A}$ & 0,00 & 0,13 & 0,10 & 0,24 & $42 \%$ & $44 \%$ \\
\hline & MIN & - & 0,00 & 0,00 & 0,00 & - & $0 \%$ \\
\hline & $\mathrm{MNF}$ & - & - & - & - & - & $0 \%$ \\
\hline & MNM & - & 0,03 & 0,02 & 0,11 & $18 \%$ & $20 \%$ \\
\hline & $\mathrm{P} \& \mathrm{C}$ & - & 0,01 & 0,01 & 0,01 & $100 \%$ & $2 \%$ \\
\hline & QUI & 0,00 & 0,02 & 0,03 & 0,05 & $60 \%$ & $9 \%$ \\
\hline & TEX & - & 0,01 & 0,01 & 0,02 & $50 \%$ & $4 \%$ \\
\hline \multirow{9}{*}{ 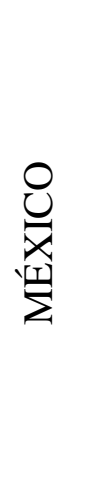 } & INDÚSTRIA & 5,77 & 10,60 & 11,82 & 34,72 & $34 \%$ & - \\
\hline & $\mathrm{A} \& \mathrm{~B}$ & 0,29 & 0,35 & 0,17 & 2,19 & $8 \%$ & $6 \%$ \\
\hline & $\mathrm{F} \& \mathrm{~A}$ & 0,15 & 2,48 & 0,52 & 4,73 & $11 \%$ & $14 \%$ \\
\hline & MIN & 0,38 & 0,20 & 0,87 & 1,44 & $60 \%$ & $4 \%$ \\
\hline & MNF & - & - & 0,07 & 0,07 & $100 \%$ & $0 \%$ \\
\hline & MNM & 2,40 & 1,14 & 0,96 & 4,65 & $21 \%$ & $13 \%$ \\
\hline & $\mathrm{P} \& \mathrm{C}$ & 0,16 & 0,70 & 0,25 & 1,11 & $23 \%$ & $3 \%$ \\
\hline & QUI & 0,32 & 1,76 & 0,53 & 2,62 & $20 \%$ & $8 \%$ \\
\hline & TEX & - & - & 0,01 & 0,01 & $100 \%$ & $0 \%$ \\
\hline
\end{tabular}


Tabela A.2 - Balanço de energia final e parâmetros de triagem baseado em IEA (2015b)

(continução)

\begin{tabular}{|c|c|c|c|c|c|c|c|}
\hline \multirow[b]{2}{*}{ País } & \multirow[b]{2}{*}{ Setor $(\mathrm{s})$} & \multicolumn{4}{|c|}{ Demanda de energia final (Mtep) } & \multicolumn{2}{|c|}{$\begin{array}{c}\text { Valor dos parâmetros } \\
\text { de triagem }\end{array}$} \\
\hline & & $\begin{array}{l}\text { Derivados } \\
\text { de petróleo }\end{array}$ & $\begin{array}{c}\text { Gás } \\
\text { Natural }\end{array}$ & Eletricidade & Total & $\% \mathrm{EF}_{\mathrm{s}, \mathrm{E}}$ & $\begin{array}{c}\% \mathrm{EF}_{\mathrm{s}} / \\
\% \mathrm{EF}_{\text {INDÚSTRIA }}\end{array}$ \\
\hline \multirow{9}{*}{ 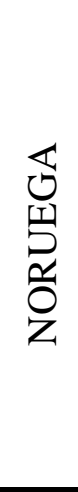 } & INDÚSTRIA & 0,83 & 0,29 & 3,74 & 5,80 & $64 \%$ & - \\
\hline & $\mathrm{A} \& \mathrm{~B}$ & 0,08 & 0,06 & 0,22 & 0,38 & $58 \%$ & $7 \%$ \\
\hline & F\&A & 0,02 & 0,00 & 0,43 & 0,68 & $63 \%$ & $12 \%$ \\
\hline & MIN & 0,07 & 0,00 & 0,05 & 0,13 & $38 \%$ & $2 \%$ \\
\hline & MNF & 0,02 & 0,04 & 1,65 & 1,71 & $96 \%$ & $29 \%$ \\
\hline & MNM & 0,08 & 0,05 & 0,08 & 0,34 & $24 \%$ & $6 \%$ \\
\hline & $\mathrm{P} \& \mathrm{C}$ & 0,02 & 0,01 & 0,31 & 0,51 & $61 \%$ & $9 \%$ \\
\hline & QUI & 0,33 & 0,11 & 0,62 & 1,36 & $46 \%$ & $23 \%$ \\
\hline & TEX & 0,00 & 0,00 & 0,01 & 0,01 & $100 \%$ & $0 \%$ \\
\hline \multirow{9}{*}{ 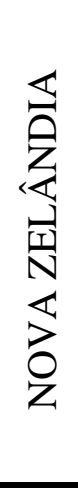 } & INDÚSTRIA & 0,42 & 0,99 & 1,16 & 4,09 & $28 \%$ & - \\
\hline & $\mathrm{A} \& \mathrm{~B}$ & - & 0,22 & 0,19 & 0,70 & $27 \%$ & $17 \%$ \\
\hline & $\mathrm{F} \& A$ & - & 0,06 & 0,09 & 0,19 & $47 \%$ & $5 \%$ \\
\hline & MIN & 0,09 & 0,00 & 0,03 & 0,12 & $25 \%$ & $3 \%$ \\
\hline & $\mathrm{MNF}$ & - & 0,01 & 0,46 & 0,46 & $100 \%$ & $11 \%$ \\
\hline & MNM & - & 0,02 & 0,03 & 0,15 & $20 \%$ & $4 \%$ \\
\hline & $\mathrm{P} \& \mathrm{C}$ & - & 0,07 & 0,08 & 0,33 & $24 \%$ & $8 \%$ \\
\hline & QUI & - & 0,53 & 0,04 & 0,56 & $7 \%$ & $14 \%$ \\
\hline & TEX & - & 0,01 & 0,01 & 0,02 & $50 \%$ & $0 \%$ \\
\hline \multirow{9}{*}{ 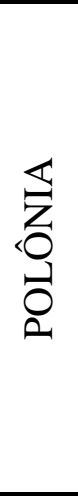 } & INDÚSTRIA & 0,96 & 3,23 & 4,11 & 14,38 & $29 \%$ & - \\
\hline & $\mathrm{A} \& \mathrm{~B}$ & 0,09 & 0,58 & 0,48 & 1,84 & $26 \%$ & $13 \%$ \\
\hline & $\mathrm{F} \& \mathrm{~A}$ & 0,00 & 0,39 & 0,52 & 1,71 & $30 \%$ & $12 \%$ \\
\hline & MIN & 0,06 & 0,04 & 0,21 & 0,38 & $55 \%$ & $3 \%$ \\
\hline & $\mathrm{MNF}$ & 0,01 & 0,16 & 0,17 & 0,41 & $41 \%$ & $3 \%$ \\
\hline & MNM & 0,08 & 0,98 & 0,38 & 2,55 & $15 \%$ & $18 \%$ \\
\hline & $\mathrm{P} \& \mathrm{C}$ & 0,04 & 0,15 & 0,37 & 1,57 & $24 \%$ & $11 \%$ \\
\hline & QUI & 0,54 & 0,35 & 0,76 & 2,97 & $26 \%$ & $21 \%$ \\
\hline & TEX & 0,01 & 0,04 & 0,05 & 0,12 & $42 \%$ & $1 \%$ \\
\hline \multirow{9}{*}{ 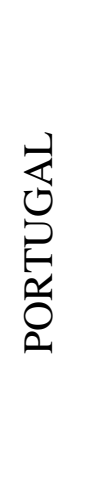 } & INDÚSTRIA & 0,65 & 1,08 & 1,38 & 4,59 & $30 \%$ & - \\
\hline & $\mathrm{A} \& \mathrm{~B}$ & 0,09 & 0,13 & 0,15 & 0,42 & $36 \%$ & $9 \%$ \\
\hline & $\mathrm{F} \& \mathrm{~A}$ & 0,00 & 0,05 & 0,12 & 0,18 & $67 \%$ & $4 \%$ \\
\hline & MIN & 0,03 & 0,01 & 0,05 & 0,11 & $45 \%$ & $2 \%$ \\
\hline & MNF & 0,00 & 0,01 & 0,01 & 0,02 & $50 \%$ & $0 \%$ \\
\hline & MNM & 0,36 & 0,42 & 0,15 & 1,08 & $14 \%$ & $24 \%$ \\
\hline & $\mathrm{P} \& \mathrm{C}$ & 0,03 & 0,09 & 0,26 & 1,41 & $18 \%$ & $31 \%$ \\
\hline & QUI & 0,01 & 0,16 & 0,20 & 0,49 & $41 \%$ & $11 \%$ \\
\hline & TEX & 0,01 & 0,13 & 0,11 & 0,29 & $38 \%$ & $6 \%$ \\
\hline
\end{tabular}


Tabela A.2 - Balanço de energia final e parâmetros de triagem baseado em IEA (2015b)

(continução)

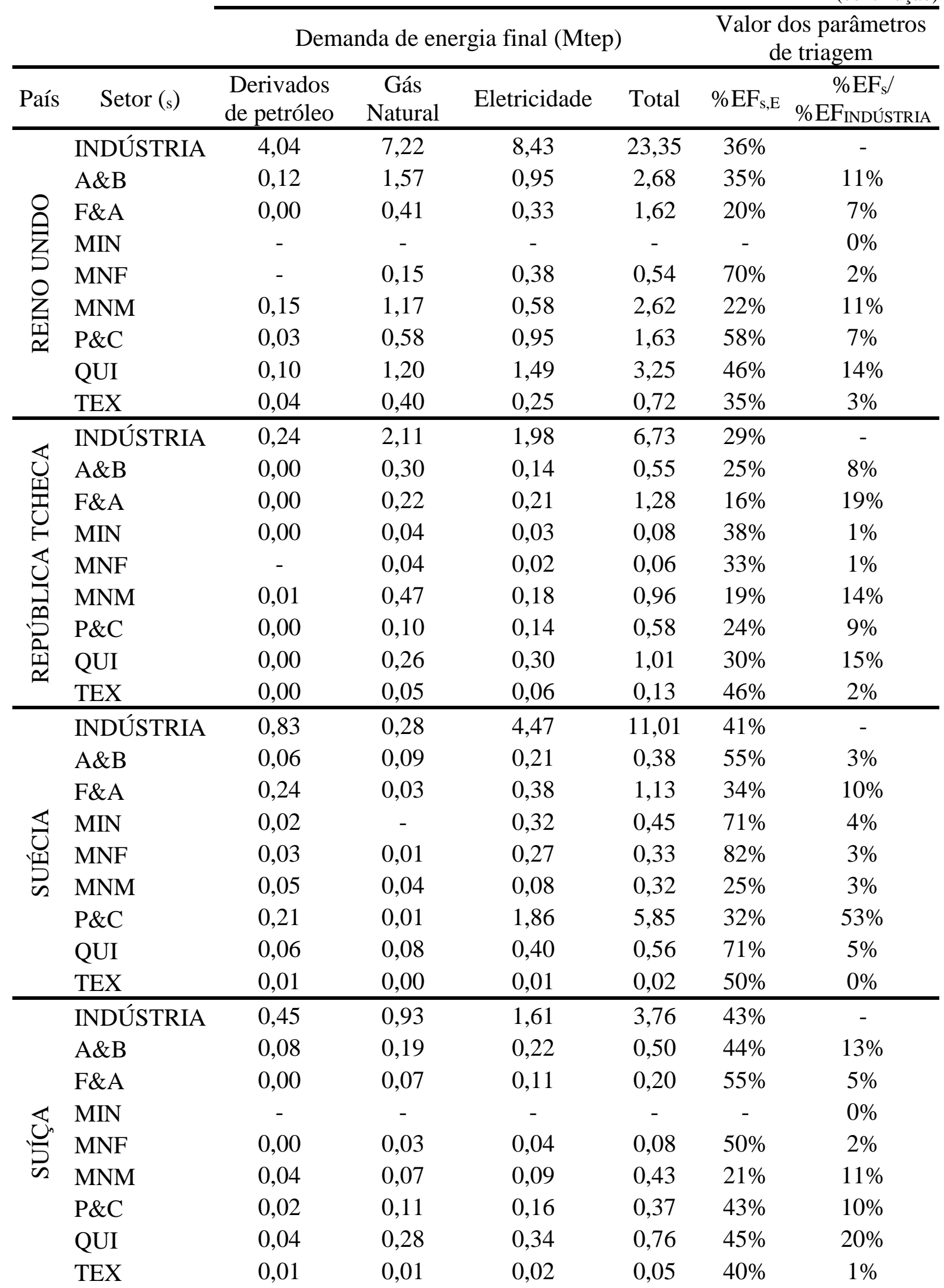


Tabela A.2 - Balanço de energia final e parâmetros de triagem baseado em IEA (2015b)

(conclusão)

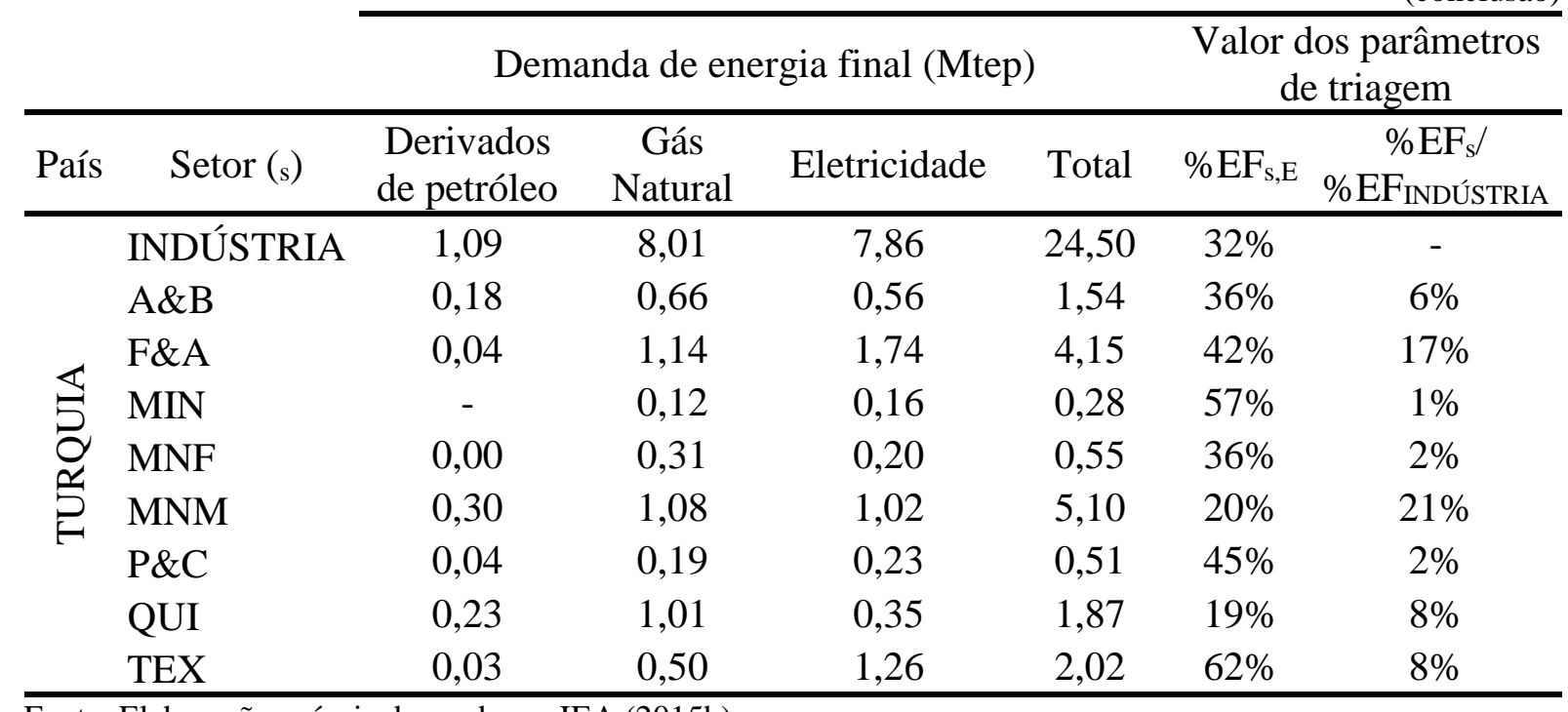

Fonte: Elaboração própria, baseada em IEA (2015b).

Tabela A.3 - Balanço de energia final e parâmetros de triagem baseado em IEA (2015a)

(continua)

Demanda de energia final (ktep) $\quad$ Valor dos parâmetros

\begin{tabular}{|c|c|c|c|c|c|c|c|}
\hline País & Setor $(\mathrm{s})$ & $\begin{array}{l}\text { Derivados } \\
\text { de petróleo }\end{array}$ & $\begin{array}{c}\text { Gás } \\
\text { Natural }\end{array}$ & Eletricidade & Total & $\% \mathrm{EF}_{\mathrm{s}, \mathrm{E}}$ & $\begin{array}{c}\% \mathrm{EF}_{\mathrm{s}} / \\
\% \mathrm{EF}_{\text {INDÚSTRIA }}\end{array}$ \\
\hline \multirow{9}{*}{ 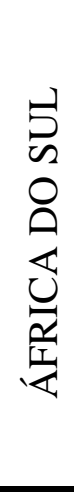 } & INDÚSTRIA & 2006 & 1698 & 10019 & 26444 & $38 \%$ & - \\
\hline & $\mathrm{A} \& \mathrm{~B}$ & - & 65 & 62 & 149 & $42 \%$ & $1 \%$ \\
\hline & $\mathrm{F} \& \mathrm{~A}$ & - & 236 & 325 & 4518 & $7 \%$ & $17 \%$ \\
\hline & MIN & 1181 & - & 2650 & 4119 & $64 \%$ & $16 \%$ \\
\hline & $\mathrm{MNF}$ & - & 14 & 1478 & 2289 & $65 \%$ & $9 \%$ \\
\hline & MNM & - & 314 & 223 & 1835 & $12 \%$ & $7 \%$ \\
\hline & $\mathrm{P} \& \mathrm{C}$ & - & 21 & 139 & 211 & $66 \%$ & $1 \%$ \\
\hline & QUI & - & 933 & 979 & 2868 & $34 \%$ & $11 \%$ \\
\hline & TEX & - & - & 11 & 11 & $100 \%$ & $0 \%$ \\
\hline \multirow{9}{*}{ 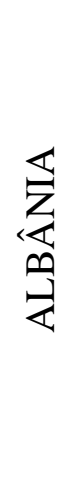 } & INDÚSTRIA & 83 & 6 & 119 & 281 & $42 \%$ & - \\
\hline & $\mathrm{A} \& \mathrm{~B}$ & - & - & - & - & - & - \\
\hline & $\mathrm{F} \& \mathrm{~A}$ & 7 & - & 15 & 22 & $68 \%$ & $8 \%$ \\
\hline & MIN & - & - & - & - & - & - \\
\hline & $\mathrm{MNF}$ & - & - & - & - & - & - \\
\hline & MNM & 27 & - & 6 & 95 & $6 \%$ & $34 \%$ \\
\hline & $\mathrm{P} \& \mathrm{C}$ & - & - & - & - & - & - \\
\hline & QUI & 9 & - & 10 & 18 & $56 \%$ & $6 \%$ \\
\hline & TEX & - & - & - & - & - & - \\
\hline
\end{tabular}


Tabela A.3 - Balanço de energia final e parâmetros de triagem baseado em IEA (2015a)

(continução)

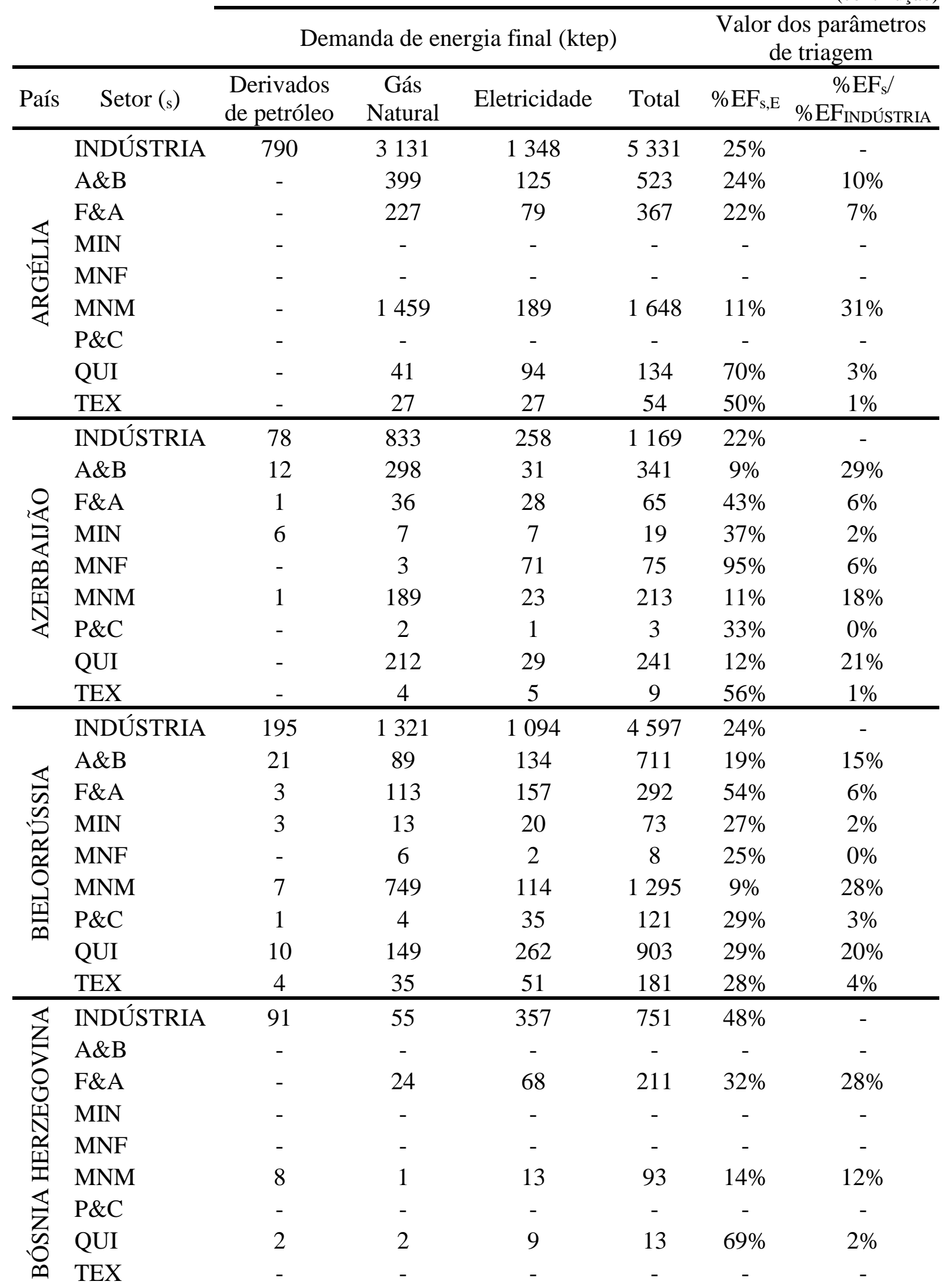


Tabela A.3 - Balanço de energia final e parâmetros de triagem baseado em IEA (2015a)

(continução)

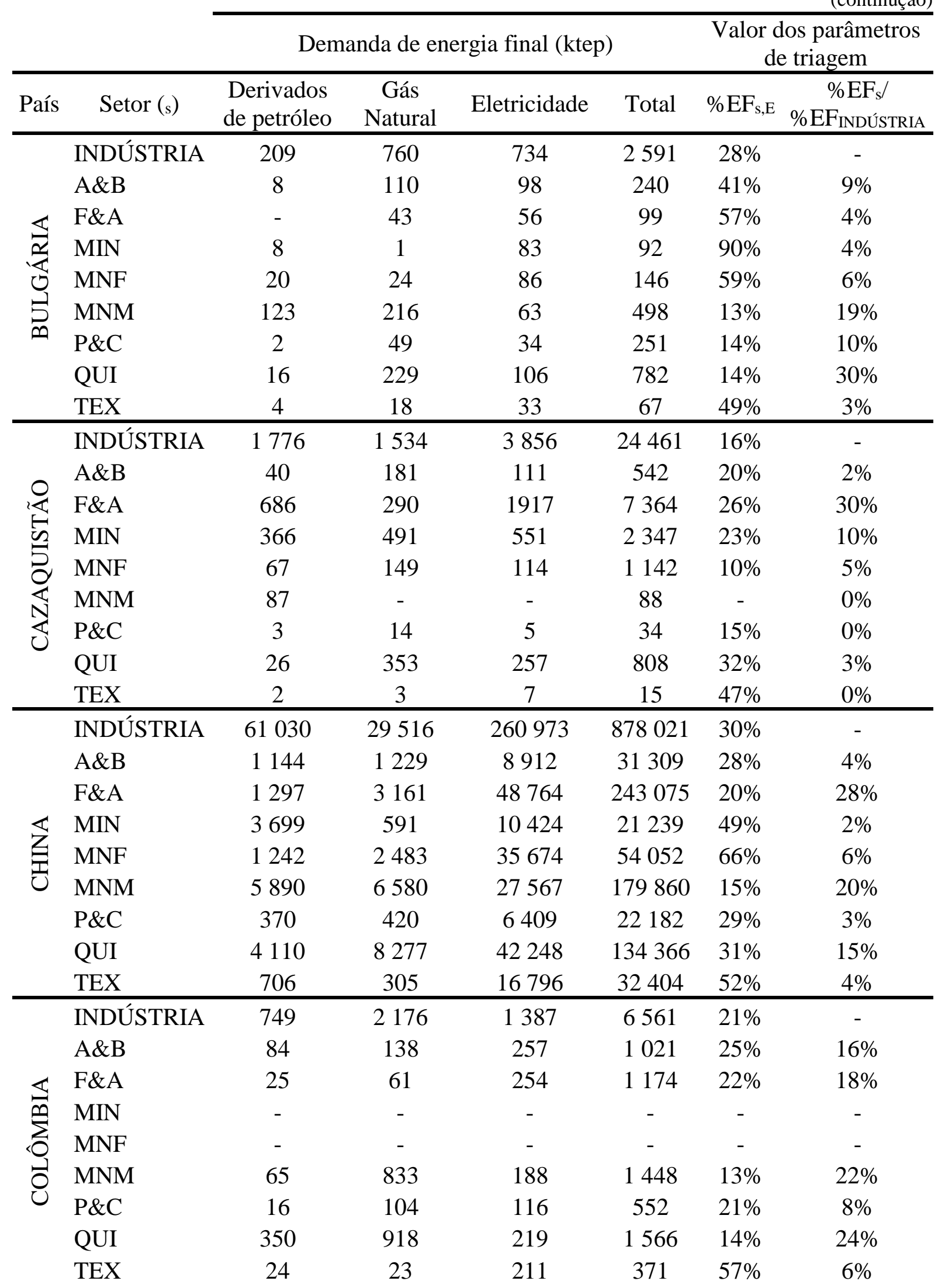


Tabela A.3 - Balanço de energia final e parâmetros de triagem baseado em IEA (2015a)

(continução)

\begin{tabular}{|c|c|c|c|c|c|c|c|}
\hline \multirow[b]{2}{*}{ País } & \multirow[b]{2}{*}{ Setor $(\mathrm{s})$} & \multicolumn{4}{|c|}{ Demanda de energia final (ktep) } & \multicolumn{2}{|c|}{$\begin{array}{c}\text { Valor dos parâmetros } \\
\text { de triagem }\end{array}$} \\
\hline & & $\begin{array}{l}\text { Derivados } \\
\text { de petróleo }\end{array}$ & $\begin{array}{c}\text { Gás } \\
\text { Natural }\end{array}$ & Eletricidade & Total & $\% \mathrm{EF}_{\mathrm{s}, \mathrm{E}}$ & $\begin{array}{c}\% \text { EF }_{s} / \\
\% \text { EF INDÚSTRIA }^{2}\end{array}$ \\
\hline \multirow{9}{*}{ 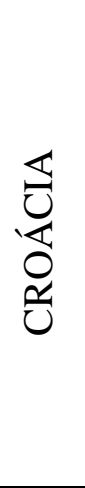 } & INDÚSTRIA & 282 & 351 & 271 & 1119 & $24 \%$ & - \\
\hline & $\mathrm{A} \& \mathrm{~B}$ & 20 & 101 & 58 & 219 & $26 \%$ & $20 \%$ \\
\hline & F\&A & 3 & 5 & 14 & 25 & $56 \%$ & $2 \%$ \\
\hline & MIN & 13 & 5 & 4 & 21 & $19 \%$ & $2 \%$ \\
\hline & $\mathrm{MNF}$ & 7 & 1 & 7 & 15 & $47 \%$ & $1 \%$ \\
\hline & MNM & 120 & 68 & 46 & 338 & $14 \%$ & $30 \%$ \\
\hline & $\mathrm{P} \& \mathrm{C}$ & 3 & 30 & 22 & 57 & $39 \%$ & $5 \%$ \\
\hline & QUI & 3 & 101 & 23 & 137 & $17 \%$ & $12 \%$ \\
\hline & TEX & 2 & 11 & 13 & 28 & $46 \%$ & $3 \%$ \\
\hline \multirow{9}{*}{$\begin{array}{l}\text { 足 } \\
\text { 竞 } \\
\text { 是 }\end{array}$} & INDÚSTRIA & 1281 & 63 & 1778 & 6893 & $26 \%$ & - \\
\hline & $\mathrm{A} \& \mathrm{~B}$ & 322 & - & 325 & 2329 & $14 \%$ & $34 \%$ \\
\hline & $\mathrm{F} \& \mathrm{~A}$ & 92 & - & 362 & 674 & $54 \%$ & $10 \%$ \\
\hline & MIN & 282 & - & 55 & 342 & $16 \%$ & $5 \%$ \\
\hline & $\mathrm{MNF}$ & - & - & - & - & - & - \\
\hline & MNM & 176 & - & 135 & 1979 & $7 \%$ & $29 \%$ \\
\hline & $\mathrm{P} \& \mathrm{C}$ & 10 & - & 100 & 177 & $56 \%$ & $3 \%$ \\
\hline & QUI & 114 & - & 108 & 226 & $48 \%$ & $3 \%$ \\
\hline & TEX & 10 & - & 138 & 254 & $54 \%$ & $4 \%$ \\
\hline \multirow{9}{*}{ 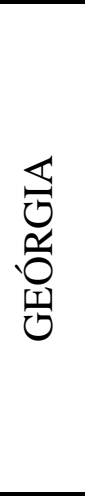 } & INDÚSTRIA & 6 & 307 & 247 & 642 & $38 \%$ & - \\
\hline & $\mathrm{A} \& \mathrm{~B}$ & - & - & - & - & - & - \\
\hline & $\mathrm{F} \& A$ & - & 61 & 124 & 185 & $67 \%$ & $29 \%$ \\
\hline & MIN & - & - & - & - & - & - \\
\hline & $\mathrm{MNF}$ & - & - & - & - & - & - \\
\hline & MNM & - & 32 & 28 & 139 & $20 \%$ & $22 \%$ \\
\hline & $\mathrm{P} \& \mathrm{C}$ & - & - & - & - & - & - \\
\hline & QUI & - & 186 & 62 & 248 & $25 \%$ & $39 \%$ \\
\hline & TEX & - & - & - & - & - & - \\
\hline \multirow{9}{*}{$\underset{\underline{Z}}{\mathbb{Z}}$} & INDÚSTRIA & 18527 & 7126 & 32188 & 179090 & $18 \%$ & - \\
\hline & $\mathrm{A} \& \mathrm{~B}$ & 5 & - & 1500 & 1505 & $100 \%$ & $1 \%$ \\
\hline & $\mathrm{F} \& \mathrm{~A}$ & 593 & - & 5677 & 47222 & $12 \%$ & $26 \%$ \\
\hline & MIN & 1032 & - & 3 & 1035 & $0 \%$ & $1 \%$ \\
\hline & MNF & 100 & - & 1049 & 1510 & $69 \%$ & $1 \%$ \\
\hline & MNM & 9294 & - & 1691 & 29302 & $6 \%$ & $16 \%$ \\
\hline & $\mathrm{P} \& \mathrm{C}$ & - & - & 601 & 1828 & $33 \%$ & $1 \%$ \\
\hline & QUI & 4137 & - & 3132 & 8731 & $36 \%$ & $5 \%$ \\
\hline & TEX & 397 & - & 2648 & 3389 & $78 \%$ & $2 \%$ \\
\hline
\end{tabular}


Tabela A.3 - Balanço de energia final e parâmetros de triagem baseado em IEA (2015a)

(continução)

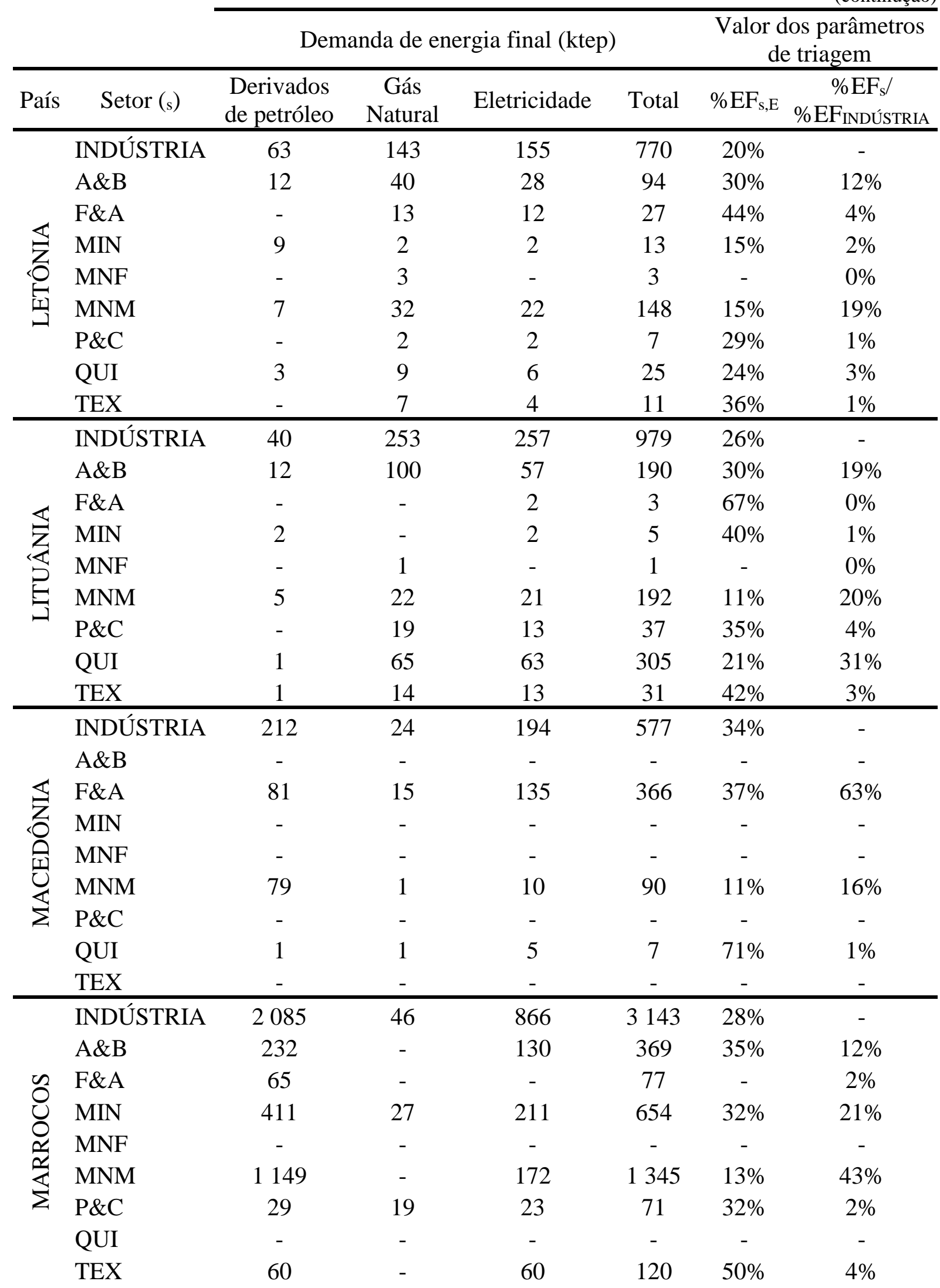


Tabela A.3 - Balanço de energia final e parâmetros de triagem baseado em IEA (2015a)

(continução)

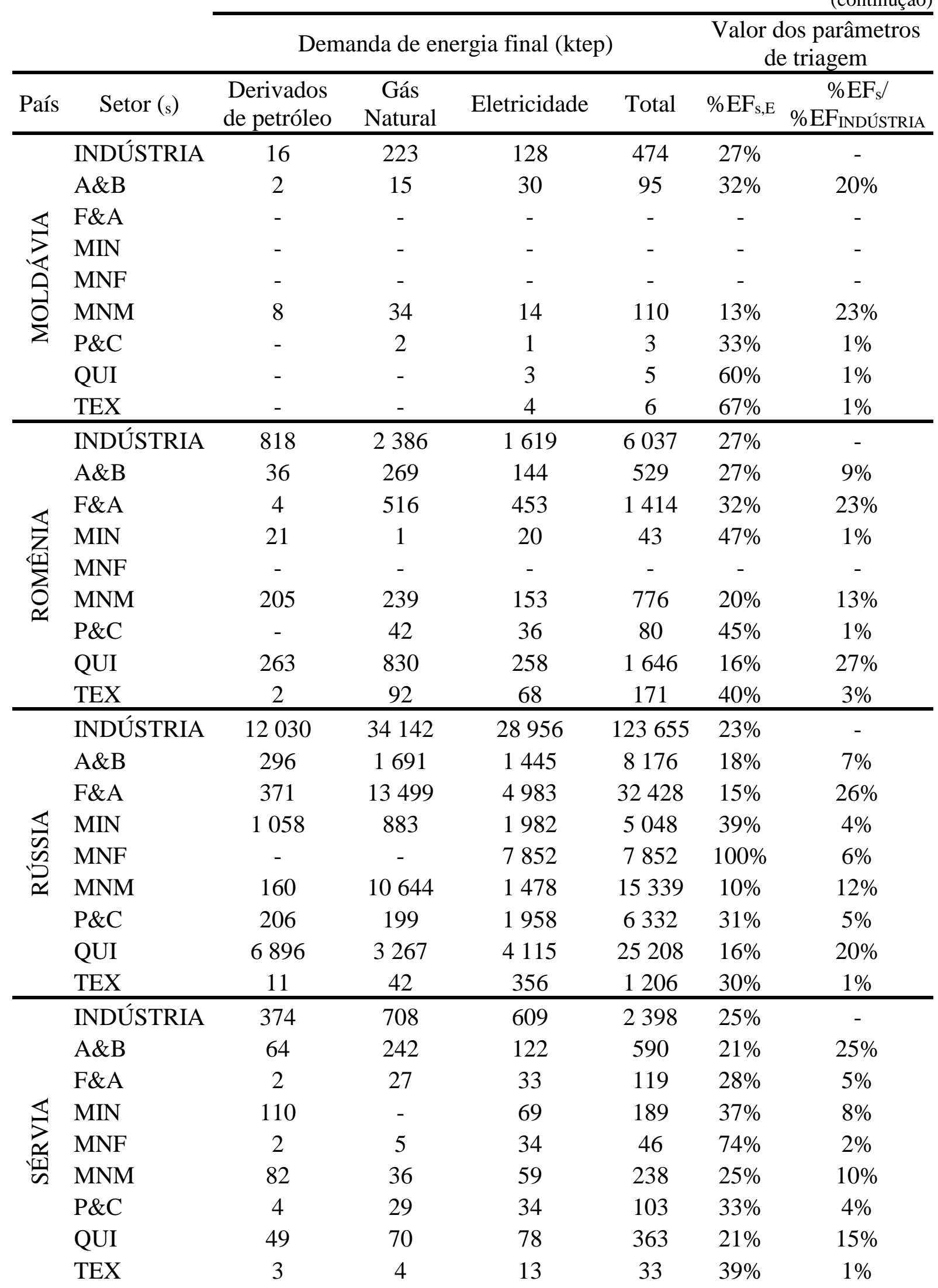


Tabela A.3 - Balanço de energia final e parâmetros de triagem baseado em IEA (2015a)

(conclusão)

\begin{tabular}{|c|c|c|c|c|c|c|c|}
\hline \multirow[b]{2}{*}{ País } & \multirow[b]{2}{*}{ Setor $(\mathrm{s})$} & \multicolumn{4}{|c|}{ Demanda de energia final (ktep) } & \multicolumn{2}{|c|}{$\begin{array}{c}\text { Valor dos parâmetros } \\
\text { de triagem }\end{array}$} \\
\hline & & $\begin{array}{l}\text { Derivados } \\
\text { de petróleo }\end{array}$ & $\begin{array}{l}\text { Gás } \\
\text { Natural }\end{array}$ & Eletricidade & Total & $\% \mathrm{EF}_{\mathrm{s}, \mathrm{E}}$ & $\begin{array}{c}\% \mathrm{EF}_{\mathrm{s}} / \\
\% \mathrm{EF}_{\text {INDÚSTRIA }}\end{array}$ \\
\hline \multirow{9}{*}{ 忞 } & INDÚSTRIA & 5081 & 2408 & 5900 & 29896 & $20 \%$ & - \\
\hline & $\mathrm{A} \& \mathrm{~B}$ & 1192 & 98 & 1181 & 7318 & $16 \%$ & $24 \%$ \\
\hline & F\&A & 426 & 256 & 600 & 1297 & $46 \%$ & $4 \%$ \\
\hline & MIN & 20 & - & - & 20 & - & $0 \%$ \\
\hline & MNF & - & - & - & 77 & - & $0 \%$ \\
\hline & MNM & 336 & 677 & 604 & 8978 & $7 \%$ & $30 \%$ \\
\hline & $\mathrm{P} \& \mathrm{C}$ & 177 & 665 & 214 & 1138 & $19 \%$ & $4 \%$ \\
\hline & QUI & 507 & 553 & 940 & 2009 & $47 \%$ & $7 \%$ \\
\hline & TEX & 156 & 25 & 600 & 791 & $76 \%$ & $3 \%$ \\
\hline \multirow{9}{*}{ 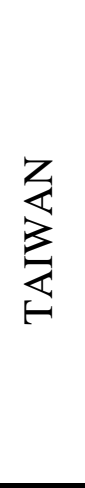 } & INDÚSTRIA & 2397 & 1393 & 11356 & 23116 & $49 \%$ & - \\
\hline & $\mathrm{A} \& \mathrm{~B}$ & 213 & 7 & 327 & 559 & $58 \%$ & $2 \%$ \\
\hline & $\mathrm{F} \& \mathrm{~A}$ & 256 & 257 & 1293 & 3576 & $36 \%$ & $15 \%$ \\
\hline & MIN & 34 & - & 39 & 73 & $53 \%$ & $0 \%$ \\
\hline & $\mathrm{MNF}$ & 50 & 31 & 99 & 179 & $55 \%$ & $1 \%$ \\
\hline & MNM & 268 & 180 & 494 & 2555 & $19 \%$ & $11 \%$ \\
\hline & $\mathrm{P} \& \mathrm{C}$ & 62 & 14 & 341 & 938 & $36 \%$ & $4 \%$ \\
\hline & QUI & 873 & 316 & 3271 & 8427 & $39 \%$ & $36 \%$ \\
\hline & TEX & 335 & 32 & 498 & 912 & $55 \%$ & $4 \%$ \\
\hline \multirow{9}{*}{ 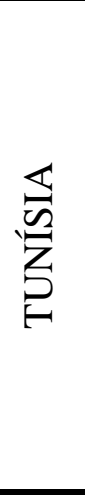 } & INDÚSTRIA & 736 & 891 & 456 & 2090 & $22 \%$ & - \\
\hline & $\mathrm{A} \& \mathrm{~B}$ & - & 70 & 58 & 128 & $45 \%$ & $6 \%$ \\
\hline & $\mathrm{F} \& \mathrm{~A}$ & - & 5 & 24 & 30 & $80 \%$ & $1 \%$ \\
\hline & MIN & - & 9 & 28 & 37 & $76 \%$ & $2 \%$ \\
\hline & $\mathrm{MNF}$ & - & - & - & - & - & - \\
\hline & MNM & 421 & 557 & 139 & 1124 & $12 \%$ & $54 \%$ \\
\hline & $\mathrm{P} \& \mathrm{C}$ & - & 45 & 16 & 61 & $26 \%$ & $3 \%$ \\
\hline & QUI & - & 109 & 60 & 169 & $36 \%$ & $8 \%$ \\
\hline & TEX & - & 53 & 45 & 98 & $46 \%$ & $5 \%$ \\
\hline \multirow{9}{*}{ 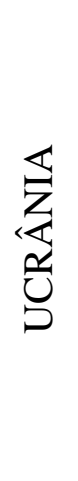 } & INDÚSTRIA & 1028 & 4360 & 5038 & 21860 & $23 \%$ & - \\
\hline & $\mathrm{A} \& \mathrm{~B}$ & 141 & 259 & 383 & 1658 & $23 \%$ & $8 \%$ \\
\hline & $\mathrm{F} \& \mathrm{~A}$ & 130 & 2451 & 1822 & 12080 & $15 \%$ & $55 \%$ \\
\hline & MIN & 326 & 332 & 902 & 1664 & $54 \%$ & $8 \%$ \\
\hline & $\mathrm{MNF}$ & 6 & 201 & 155 & 688 & $23 \%$ & $3 \%$ \\
\hline & MNM & 62 & 484 & 232 & 1545 & $15 \%$ & $7 \%$ \\
\hline & $\mathrm{P} \& \mathrm{C}$ & 9 & 24 & 93 & 280 & $33 \%$ & $1 \%$ \\
\hline & QUI & 24 & 291 & 376 & 1788 & $21 \%$ & $8 \%$ \\
\hline & TEX & 3 & 6 & 29 & 62 & $47 \%$ & $0 \%$ \\
\hline
\end{tabular}

Fonte: Elaboração própria, baseada em IEA (2015a). 
Tabela A.4 - Lista de países membros da OCDE referência para os setores industriais e a participação da eletricidade na demanda de energia final em cada setor industrial

\begin{tabular}{lcccccccc} 
& \multicolumn{7}{c}{ Setores industriais } \\
\hline Países & A\&B & F\&A & MIN & MNF & MNM & P\&C & QUI & TEX \\
\hline Alemanha & $13 \%$ & $16 \%$ & - & $39 \%$ & - & - & - & - \\
Áustria & - & - & - & $40 \%$ & - & - & - & - \\
Bélgica & $34 \%$ & - & - & - & - & - & - & - \\
Canadá & - & - & $25 \%$ & - & - & - & - & - \\
Coréia do Sul & - & - & - & - & - & - & - & $54 \%$ \\
Dinamarca & $32 \%$ & - & $17 \%$ & - & - & - & - & - \\
Espanha & - & - & $26 \%$ & - & - & - & $17 \%$ & - \\
Estados Unidos & - & - & - & - & - & $13 \%$ & $19 \%$ & - \\
Holanda & $29 \%$ & - & $18 \%$ & - & - & - & $18 \%$ & - \\
Hungria & - & - & - & $27 \%$ & - & - & - & - \\
Irlanda & - & - & - & $13 \%$ & - & - & - & - \\
Itália & - & - & - & $33 \%$ & - & - & - & $39 \%$ \\
Japão & - & - & $25 \%$ & - & - & - & $24 \%$ & - \\
Luxemburgo & - & - & - & - & - & - & - & $50 \%$ \\
México & - & $11 \%$ & - & - & - & - & - & - \\
Nova Zelândia & $27 \%$ & - & $25 \%$ & - & - & - & $7 \%$ & - \\
Polônia & $26 \%$ & - & - & $41 \%$ & - & - & $26 \%$ & - \\
Portugal & - & - & - & & - & $18 \%$ & - & $38 \%$ \\
Reino Unido & - & - & - & & - & - & - & $35 \%$ \\
República Tcheca & - & $16 \%$ & - & $33 \%$ & - & - & - & - \\
Turquia & - & - & - & $36 \%$ & - & - & - & - \\
\hline Fonte: Elary & & & & & & & & \\
\hline
\end{tabular}

Fonte: Elaboração própria.

Nota: Os países que constam na Tabela A.1 e que não estão representados nessa tabela (Austrália; Chile; Eslováquia; Eslovênia; Estônia; Finlândia; França; Grécia; Islândia; Noruega; Suécia; Suíça) foram eliminados por nenhum de seus setores industriais atenderem os critérios de triagem adotados. 
Tabela A.5 - Lista de países não-membros da OCDE referência para os setores industriais e a participação da eletricidade na demanda de energia final em cada setor industrial

Setores industriais

\begin{tabular}{|c|c|c|c|c|c|c|c|c|}
\hline Países & $A \& B$ & F\&A & MIN & MNF & MNM & $\mathrm{P} \& \mathrm{C}$ & QUI & TEX \\
\hline África do Sul & - & $7 \%$ & - & - & - & - & - & - \\
\hline Albânia & $9 \%$ & - & - & - & - & - & $12 \%$ & - \\
\hline Azerbaijão & $19 \%$ & - & $27 \%$ & $25 \%$ & $9 \%$ & - & $29 \%$ & $28 \%$ \\
\hline Bósnia Herzegovina & - & - & - & - & - & $14 \%$ & $14 \%$ & $49 \%$ \\
\hline Bulgária & - & - & $23 \%$ & $10 \%$ & - & $15 \%$ & - & - \\
\hline Cazaquistão & - & - & - & - & - & - & - & $52 \%$ \\
\hline China & $25 \%$ & - & - & - & - & - & $14 \%$ & $57 \%$ \\
\hline Colômbia & $26 \%$ & - & $19 \%$ & - & - & - & - & - \\
\hline Croácia & $14 \%$ & - & $16 \%$ & - & $7 \%$ & - & - & $54 \%$ \\
\hline Filipinas & - & - & - & - & - & - & $25 \%$ & - \\
\hline Geórgia & - & $12 \%$ & $0 \%$ & - & $6 \%$ & - & - & - \\
\hline Índia & - & - & $15 \%$ & - & - & - & - & - \\
\hline Letônia & $30 \%$ & - & - & - & - & - & $21 \%$ & $42 \%$ \\
\hline Macedônia & - & - & - & - & - & - & - & $50 \%$ \\
\hline Marrocos & $32 \%$ & - & - & - & - & - & - & - \\
\hline Moldávia & - & - & - & - & - & - & $16 \%$ & $40 \%$ \\
\hline Romênia & - & $15 \%$ & - & - & $10 \%$ & - & $16 \%$ & - \\
\hline Rússia & $21 \%$ & - & - & - & - & - & $21 \%$ & - \\
\hline Sérvia & $16 \%$ & - & - & - & $7 \%$ & $19 \%$ & - & - \\
\hline Tailândia & - & - & - & - & - & - & - & $55 \%$ \\
\hline Taiwan & - & - & - & - & - & - & - & $46 \%$ \\
\hline Tunísia & - & $15 \%$ & - & $23 \%$ & - & - & - & - \\
\hline Ucrânia & - & $7 \%$ & - & - & - & - & - & - \\
\hline
\end{tabular}

Fonte: Elaboração própria.

Nota: Os países que constam na Tabela A.1 e que não estão representados nessa tabela (Argélia, Bielorrússia e Lituânia) foram eliminados por nenhum de seus setores industriais atenderem os critérios de triagem adotados. 
Tabela A.6 - Balanço de energia final, parâmetros de triagem, demanda de energia primária e custo energético por setor industrial para o Brasil

\begin{tabular}{ccccccccc}
\hline \multicolumn{10}{c}{ Setores industriais } \\
\cline { 1 - 5 } Indústria & A\&B & F\&A & MIN & MNF & MNM & P\&C & QUI & TEX \\
\hline \multicolumn{7}{c}{ Demanda de energia final (Mtep) } \\
12,73 & 0,73 & 0,34 & 1,14 & 1,86 & 4,38 & 0,50 & 2,61 & 0,08 \\
2,68 & 0,20 & 0,10 & 0,20 & 1,15 & 0,14 & 0,30 & 0,42 & 0,05 \\
9,22 & 0,65 & 0,99 & 0,60 & 0,89 & 1,31 & 0,77 & 1,93 & 0,30 \\
18,07 & 1,92 & 2,32 & 1,02 & 3,11 & 1,08 & 1,69 & 1,96 & 0,64 \\
65,25 & 3,30 & 12,62 & 3,19 & 6,89 & 10,29 & 10,52 & 6,72 & 1,09 \\
\hline
\end{tabular}

Valor dos parâmetros de triagem

\begin{tabular}{lccccccccc}
\hline$\% \mathrm{EF}_{\mathrm{s}, \mathrm{E}}$ & $28 \%$ & $58 \%$ & $18 \%$ & $32 \%$ & $45 \%$ & $11 \%$ & $16 \%$ & $29 \%$ & $59 \%$ \\
$\% \mathrm{EF}_{\mathrm{s}} / \% \mathrm{EF}_{\text {Indústria }}$ & - & $5 \%$ & $19 \%$ & $5 \%$ & $11 \%$ & $16 \%$ & $16 \%$ & $10 \%$ & $2 \%$ \\
\hline
\end{tabular}

Demanda de energia primária (Mtep)

\begin{tabular}{llllllllll}
\hline $\mathrm{DEP}_{\mathrm{s}}$ & 104 & 7 & 18 & 5 & 13 & 14 & 14 & 11 & 2 \\
\hline
\end{tabular}

Custo energético com óleo combustível e eletricidade (1000 M R\$)

\begin{tabular}{llllllllll}
\hline $\mathrm{CEn}_{\mathrm{s}, \mathrm{O}, \mathrm{E}}$ & 74,5 & 7,8 & 9,2 & 4,3 & 13,9 & 4,4 & 7,1 & 7,3 & 2,6 \\
\hline
\end{tabular}

Fonte: Elaboração própria. 